\title{
Oclusopatias na dentição decídua: acúmulo de riscos do nascimento à primeira infância
}

Karen Glazer de Anselmo Peres

Tese de Doutorado apresentada ao Departamento de Epidemiologia da Faculdade de Saúde Pública da Universidade de São Paulo para obtenção do grau de Doutor.

Orientadora

Professora Associada Maria do Rosário Dias de Oliveira Latorre

São Paulo

2002 
Autorizo, exclusivamente para fins acadêmicos e científicos, a reprodução total ou parcial desta tese, por meio de processos fotocopiadores. Assinatura:

Data:

$$
+296312002 \mathrm{dec}
$$


Ao Marco, vinte anos e inúmeras caminhadas juntos.

O meu amor é eterno.

Aos meus adorados filhos, Rodrigo e Rafael, que talvez já compreendam o significado de tudo isso.

Aos meus pais, Marcos e Janeth, pelo sacrifício dos primeiros anos da minha educação.

O esforço valeu a pena. 


\section{Agradecimentos}

\section{À Professora Associada MARIA DO ROSÁRIO DIAS DE OLIVEIRA} LATORRE. Orientadora deste trabalho e uma parceria que se iniciou desde os tempos do mestrado, sempre me proporcionando novos conhecimentos e desafios. Obrigada pela cumplicidade, apoio e confiança revelados em todos estes anos.

Ao Professor Titular CÉSAR GOMES VICTORA, da Universidade Federal de Pelotas. Agradeço pela confiança depositada nesta proposta de pesquisa, por integrar a saúde bucal num dos mais importantes estudos já realizados no Brasil.

A todos os professores e funcionários do Centro de Pesquisas Epidemiológicas da Universidade Federal de Pelotas. Especial referência à CARMEM e WILLIAN pela ajuda na localização das familias e auxilio na informática.

Aos parceiros de trabalho de campo MARCO AURÉLIO, KELLY, e RAQUEL. Obrigada pela parceria afinada que proporcionou $\mathrm{o}$ bom desempenho das atividades de campo.

Ao estimado Professor AUBREY SHEIHAM. O responsável pelos ótimos momentos intelectuais que passei no período de bolsa-sanduíche no Department of Epidemiology and Public Health, University College London, em Londres. Obrigada por compartilhar, a toda hora, a sua sabedoria, por 
estimular o debate, discutir as diferenças e as desigualdades, sempre com delicadeza e muito respeito. Obrigada pela amizade também.

Ao professor MARCO AURÉLIO PERES. Pelas incansáveis leituras deste trabalho. Por saber, sempre que necessário, prevalecer o nosso relacionamento profissional.

Aos queridos companheiros de trabalho na Inglaterra, PAULO GOES, FÁTIMA, SABITA, RATI, GOPAL, PEERSAK, ANNE, IAN, NOUR, HYNNEK, DANIELA e MARCOS PATUSSI. Pessoas das mais diferentes origens que amenizaram as minhas dificuldades de adaptação com a língua estrangeira e com os diferentes costumes. Que compartilharam conhecimentos e dúvidas. Obrigada pela demonstração de carinho e companheirismo.

Aos amigos JEFFERSON TRAEBERT e JOSIMARI TELINO de LACERDA. Por assumirem meus compromissos de trabalho durante a minha permanência em Londres. Obrigada pelo apoio nos momentos de conflitos e pelas calorosas discussões durante as nossas viagens.

Ao CONSELHO NACIONAL de DESENVOLVIMENTO CIENTÍFICO e TECNOLÓGICO, CNPq. Pelo apoio financeiro através de bolsa de estudos no Brasil e na Inglaterra. Sem estas, minha dedicação e o fruto deste trabalho não seriam possiveis.

ÀS CRIANÇAS DE PELOTAS. Agradeço pela disponibilidade, pelo carinho, sem exceção, que recebi durante minha estada em Pelotas. Obrigada a todos os familiares destas crianças que, mais uma vez, contribuíram para a realização de um trabalho científico. 


\section{Resumo}

Título: Oclusopatias na dentição decidua. Acúmulos de risco do nascimento à primeira infância.

Unitermos: Epidemiologia, má oclusão, oclusopatias, dentição decídua, fatores de risco biológicos, fatores de risco comportamentais.

Este estudo teve como objetivo, conhecer os fatores de risco acumulados do nascimento à infância para as oclusopatias na dentição decidua. Foi realizado um estudo transversal sobre oclusopatias, aninhado ao estudo de coorte de nascidos vivos em Pelotas, 1993, numa amostra de 400 crianças aos 6 anos de idade. Foram utilizados os critérios de Foster e Hamilton para a classificação das oclusopatias e todas as informações socioeconômicas, perinatais e da vida das crianças foram obtidas através de segmentos da coorte realizados ao nascimento, no primeiro, terceiro, sexto e décimo segundo mês de vida e aos 5 anos de idade. Foram realizadas análises univariadas através do Qui-quadrado e análise de regressão logística múltipla não condicional a partir do modelo hierárquico proposto. A prevalência de mordida anterior foi de $46,3 \% \quad\left(I C_{95 \%}[41,2 \% ; 51,4 \%]\right)$, de mordida cruzada posterior $18,2 \% \quad\left(\mathrm{IC}_{95 \%}\right.$ $[14,2 \% ; 22,2 \%]$ ) e a prevalência de oclusopatia de caninos do tipo 2 ou 3 foi igual a $15,2 \%$ (IC $95 \%[11,5 \% ; 18,9 \%])$. Os fatores de risco para a presença de mordida aberta anterior foram a idade da mãe entre 30 e 39 anos $(\mathrm{OR}=2,4[1,1 ; 5,5])$, O tempo de amamentação natural entre 4 e 8,9 meses $(O R=3,0[1,7 ; 5,9]), 1$ e 3,9 meses $(O R=3,1[1,7 ; 5,6])$ e menor do que 1 mês $(\mathrm{OR}=2,4[1,1 ; 4,9])$, a intenção da mãe em oferecer bico à criança desde o nascimento $(O R=3,0[1,2 ; 7,9])$, a ocorrência de cárie dentária $(O R=2,0[1,2 ; 3,4])$, o uso de bico entre 12 meses e 5 anos de idade $(O R=10,6[5,8 ; 19,1])$ e a sucção digital $(O R=3,1[1,3 ; 7,2])$. Para a presença de mordida cruzada foram fatores de risco o trabalho materno ao nascimento no limite da significância estatística $(\mathrm{OR}=1,7[1,0 ; 3,0])$, o tempo de amamentação natural entre 4 e 8,9 meses $(O R=3,0[1,2 ; 7,5])$ e 1 e 3,9 meses $(O R=3,1[1,3 ; 7,3])$ e a presença de oclusopatias de caninos (OR=3,8[1,9;7,4]). Os fatores de risco para a presença de oclusopatias de caninos foram a presença de dentes cariados ou perdidos por cárie $(O R=2,1[1,1 ; 4,2])$ e a presença de mordida cruzada posterior $(O R=3,0[1,6 ; 5,8])$. As oclusopatias foram associadas a situações de risco acumulados durante a vida da criança e comuns a outros problemas de saúde, o que reforça a teoria de riscos comuns. Políticas intersetoriais destinadas a toda população e com o enfoque na redução das exposições comuns nocivas à saúde, parecem ser estratégias mais adequadas para a promoção de saúde bucal em geral, inclusive as oclusopatias na dentição decídua. 


\section{Summary}

Title: Malocclusion in primary dentition. The very early life risk from birth to first childhood.

Keywords: Epidemiology, malocclusion, primary dentition, risk factors, biologic factors, behaviour

The purpose of this study was to assess very early life risk factors to primary dentition malocclusion. A cross-sectional study nested in birth cohort started in 1993, in Pelotas, Brazil, was carried out. It was obtained a sample of 400 children aged 6 . The Foster and Hamilton criteria were chosen to identify the variety of occlusal patterns. Data concerning social conditions, perinatal and childhood health and behaviour were obtained at birth, from 1, 3, 6 and 12 months and in the fifth year of children's life. Unconditional univariate and multiple logistic regression analysis were performed following the previous theoretical model. The prevalence of anterior open bite was $46,3 \%\left(\mathrm{Cl}_{95 \%}[41,2 \% ; 51,4 \%]\right)$, posterior crossbite $18,2 \%\left(\mathrm{Cl}_{95 \%}[14,2 \% ; 22,2 \%]\right)$ class 2 and 3 canines relationship was 15,2\%(Cl $\left.\mathrm{Cl}_{95 \%}[11,5 \% ; 18,9 \%]\right)$. The risk factors to anterior open bite developing were maternal age between 30-39 years old $(O R=2,4[1,1 ; 5,5])$, length of breastfeeding between $4-8,9$ months $(\mathrm{OR}=3,0[1,7 ; 5,9])$, breastfeeding duration between 1-3,9 months $(O R=3,1[1,7 ; 5,6])$ and less than one month of breastfeeding (OR=2,4[1,1;4,9]), mother's intention to give dummy to the child at birth $(\mathrm{OR}=3,0[1,2 ; 7,9])$, occurrence of dental caries $(\mathrm{OR}=2,0[1,2 ; 3,4])$, dummy sucking between 12 months and in the fifth year of children's life $(O R=10,6[5,8 ; 19,1])$, and digit sucking (OR=3,1[1,3;7,2]). Maternal work showed a border association with posterior cross bite $(O R=1,7[1,0 ; 3,0])$ while breastfeeding duration between 4-8,9 months (OR=3,0[1,2;7,5]), breastfeeding duration between $1-3,9$ months (OR=3,1[1,3;7,3]) and malocclusion canines relationship $(O R=3,8[1,9 ; 7,4])$ were significantly associated. To malocclusion canines relationship developing, decay and missing teeth $(O R=2,1[1,1 ; 4,2])$ and posterior cross bite $(O R=3,0[1,6 ; 5,8])$ were considered risk factors. Malocclusion in primary dentition was associated to early life and common risk factors to other childhood diseases. These findings reinforce the common risk approach suggesting intersectoral strategies to prevent malocclusion in primary dentition. 


\section{Índice}

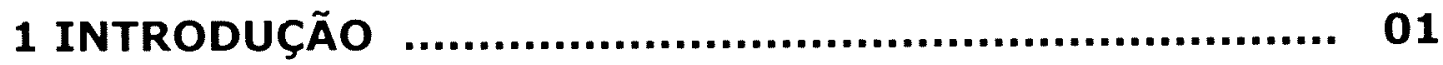

2 REVISÃO DA LITERATURA..................................... 05

2.1 Oclusopatias: Conceitos ................................. 06

2.2 As oclusopatias como problema de saúde pública $\ldots . . . . . .11$

2.3 Classificação das oclusopatias ............................. 15

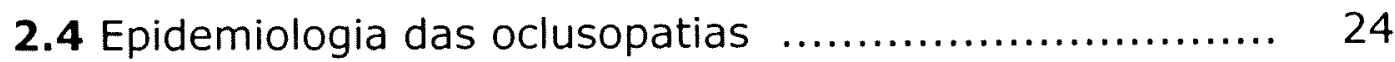

2.4.1 Quadro internacional ............................ 24

2.4.2 Quadro nacional .................................. 30

2.4.3 Tendência secular das oclusopatias ................. 35

2.5 Determinantes das oclusopatias na dentição decídua $\quad$.... 35

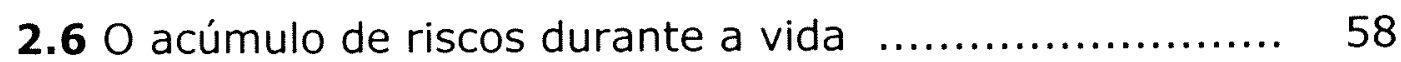

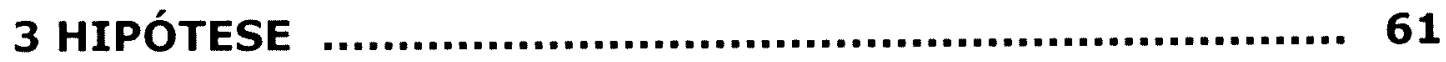

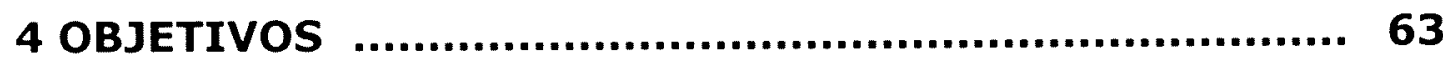

5 PROCEDIMENTOS METODOLÓGICOS ........................ 65

5.1 Local do estudo: o município de Pelotas ................... 66

5.2 A coorte de 1993 ............................................ 67

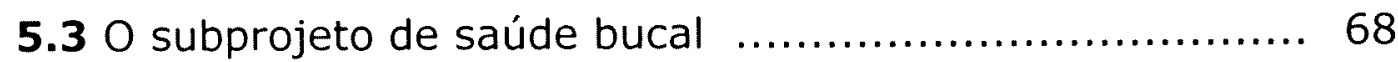

5.3.1 Delineamento do estudo de saúde bucal- ESB .... 69

5.3.2 População de estudo .................................. 69

5.3.2.1 A amostra .................................. 69

5.3.2.2 Cálculo da sub-amostra para o ESB ....... 70

5.3.3 Análise das perdas .................................. 73

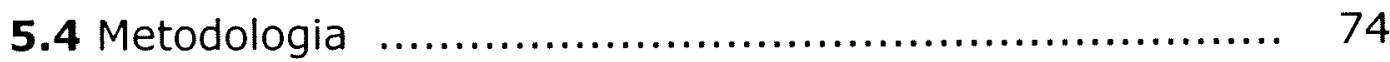

5.4.1 Coleta de dados não clínicos ....................... 75

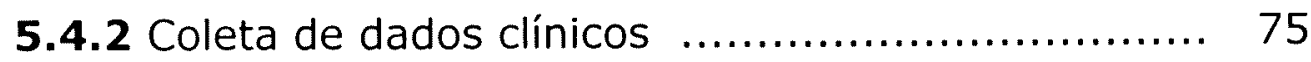

5.4.2.1 Critério de diagnóstico das oclusopatias $\quad 77$

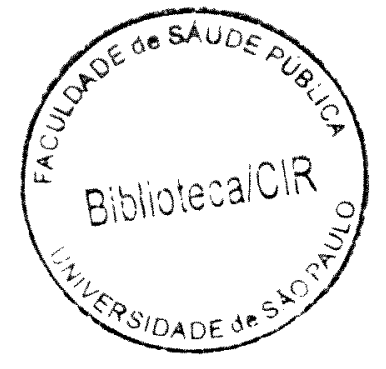


5.4.3 Estudo Piloto .................................... 77

5.4.4 Exame odontológico propriamente dito $\ldots . . . \ldots \ldots \ldots . . .77$

5.4.5 Variáveis em estudo ................................. 78

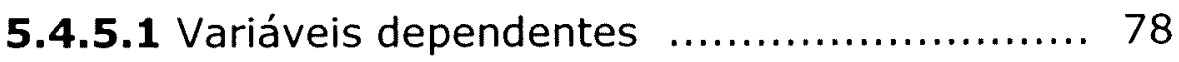

5.4.5.2 Variáveis independentes $\ldots \ldots \ldots \ldots \ldots \ldots \ldots \ldots . \ldots \ldots$

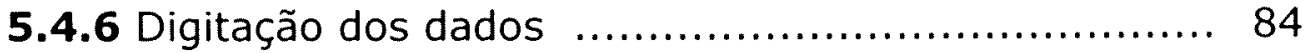

5.4.7 Análise dos dados .................................... 84

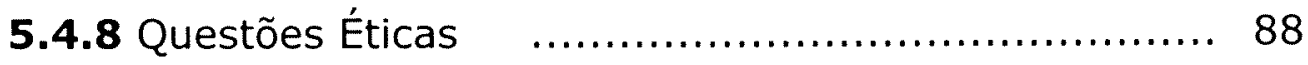

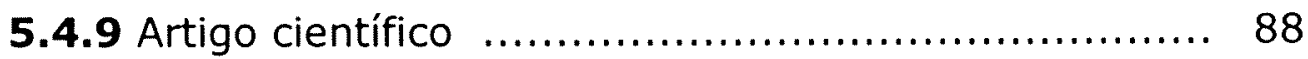

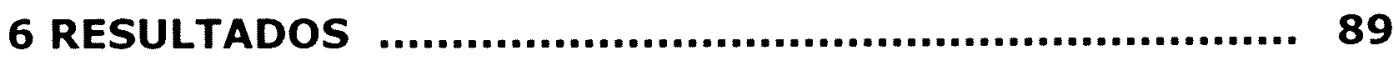

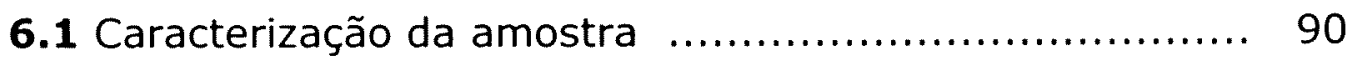

6.2 Associação entre os desfechos ............................. 101

6.3 Fatores de risco para mordida aberta anterior ............ 102

6.4 Análise múltipla para mordida aberta anterior ............. 111

6.5 Fatores de risco para mordida cruzada posterior ......... 121

6.6 Análise múltipla para mordida cruzada posterior ......... 130

6.7 Fatores de risco para oclusopatias de caninos ............. 133

6.8 Análise múltipla para oclusopatias de caninos ............. 142

7 DISCUSSÃo ....................................................... 145

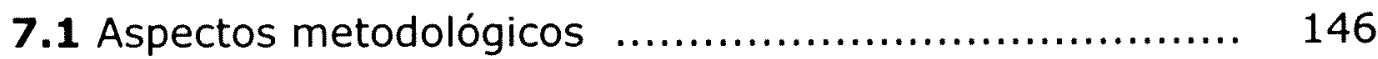

7.2 A prevalência das oclusopatias ............................ 150

7.3 Condições socioeconômicas e as oclusopatias ............... 153

7.4 As caracteristicas maternas e as oclusopatias ............ 156

7.5 Os fatores biológicos das crianças e as oclusopatias ...... 162

7.6 As características das crianças e as oclusopatias .......... 164

8 CONCLUSÕES...................................................... 180

9 REFERÊNCIAS BIBLIOGRÁFICAS ........................... 184

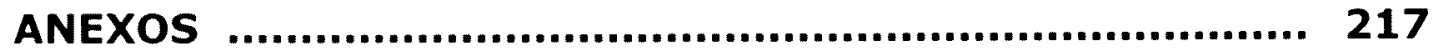




\section{Lista de tabelas}

Tabela 1: Cálculo do fator de ponderação.

Tabela 2: Teste de associação entre a amostra estudada e as perdas do estudo.

Tabela 3: Distribuição das amostra (número, \% e porcentagem ponderada), segundo classe social, renda familiar e estado marital da mãe ao nascimento da criança. Pelotas, 1999.

Tabela 4: Distribuição das amostra (número, \% e porcentagem ponderada), segundo escolaridade do pai e da mãe ao nascimento da criança. Pelotas, 1999.

Tabela 5: Distribuição das amostra (número, \% e porcentagem ponderada), segundo trabalho materno durante a vida da criança. Pelotas, 1999.

Tabela 6: Distribuição das amostra (número, \% e porcentagem ponderada), segundo comportamento e características maternas ao nascimento da criança. Pelotas, 1999.

Tabela 7: Distribuição das amostra (número, \% e porcentagem ponderada), segundo características biológicas da criança. Pelotas, 1999.

Tabela 8: Distribuição das amostra (número, \% e porcentagem ponderada), segundo uso de bico e mamadeira. Pelotas, 1999.

Tabela 9: Distribuição das amostra (número, \% e porcentagem ponderada), segundo cuidados durante a vida. Pelotas, 1999.

Tabela 10: Distribuição das amostra (número, \% e porcentagem ponderada), segundo problemas relacionados a cavidade bucal. Pelotas, 1999.

Tabela 11: Distribuição das amostra (número, \% e porcentagem ponderada), segundo hábitos e problemas de saúde. Pelotas, 1999. 
Tabela 12: Distribuição das amostra (número, \% e porcentagem ponderada), segundo presença de mordida aberta anterior, mordida cruzada posterior e classificação da relação de caninos. Pelotas, 1999.

Tabela 13: Distribuição da amostra, segundo oclusopatias estudadas (porcentagem ponderada). Pelotas, 1999.

Tabela 14: Distribuição da amostra, segundo presença de mordida aberta anterior (porcentagem ponderada) e fatores de risco socioeconômicos ao nascimento da criança. Pelotas, 1999.

Tabela 15: Distribuição da amostra, segundo presença de mordida aberta anterior (porcentagem ponderada) e medidas antropométricas da mãe. Pelotas, 1999.

Tabela 16: Distribuição da amostra, segundo presença de mordida aberta anterior (porcentagem ponderada) e fatores de risco relacionados ao trabalho materno durante a vida da criança. Pelotas, 1999.

Tabela 17: Distribuição da amostra, segundo presença de mordida aberta anterior (porcentagem ponderada) e fatores de risco relacionados ao comportamento e características maternas. Pelotas, 1999.

Tabela 18: Distribuição da amostra, segundo presença de mordida aberta anterior (porcentagem ponderada) e fatores de risco biológicos da criança. Pelotas, 1999.

Tabela 19: Distribuição da amostra, segundo presença de mordida aberta anterior (porcentagem ponderada) e fatores de risco relacionados ao uso de bico. Pelotas, 1999.

Tabela 20: Distribuição da amostra, segundo presença de mordida aberta anterior (porcentagem ponderada) e fatores de risco relacionados aos cuidados da criança. Pelotas, 1999.

Tabela 21: Distribuição da amostra, segundo presença de mordida aberta anterior (porcentagem ponderada) e problemas de saúde da 
criança. Pelotas, 1999.

109

Tabela 22: Distribuição da amostra, segundo presença de mordida aberta anterior (porcentagem ponderada) e fatores de risco relacionados ao comportamento da criança. Pelotas, 1999.

Tabela 23: Associação entre presença de mordida aberta anterior e medidas antropométricas da mãe. Modelo de regressão múltipla. Pelotas, 1999.

Tabela 24: Associação entre presença de mordida aberta anterior e fatores de risco relacionados ao trabalho e características da mãe. Modelo de regressão múltipla. Pelotas, 1999.

Tabela 25: Associação entre presença de mordida aberta anterior e fatores de risco biológicos da criança. Modelo de regressão múltipla. Pelotas, 1999.

Tabela 26: Associação entre presença de mordida aberta anterior e fatores de risco relacionados ao cuidado e hábitos da criança. Modelo de regressão múltipla. Pelotas, 1999.

Tabela 27: Mordida aberta anterior e fatores de risco. Resultados da análise de regressão múltipla hierarquizada. Pelotas, 1999.

Tabela 28: Distribuição da amostra, segundo presença de mordida cruzada posterior (porcentagem ponderada) e fatores de risco socioeconômicos ao nascimento da criança. Pelotas, 1999.

Tabela 29: Distribuição da amostra, segundo presença de mordida cruzada posterior (porcentagem ponderada) e medidas antropométricas da mãe. Pelotas, 1999.

Tabela 30: Distribuição da amostra, segundo presença de mordida cruzada posterior (porcentagem ponderada) e fatores de risco relacionados ao trabalho materno durante a vida da criança. Pelotas, 1999.

Tabela 31: Distribuição da amostra, segundo presença de mordida cruzada posterior (porcentagem ponderada) e fatores de risco relacionados ao comportamento e características maternas. Pelotas, 1999. 
Tabela 32: Distribuição da amostra, segundo presença de mordida cruzada posterior (porcentagem ponderada) e fatores de risco biológicos da criança. Pelotas, 1999.

Tabela 33: Distribuição da amostra, segundo presença de mordida cruzada posterior (porcentagem ponderada) e fatores de risco relacionados ao uso de bico. Pelotas, 1999.

Tabela 34: Distribuição da amostra, segundo presença de mordida cruzada posterior (porcentagem ponderada) e fatores de risco relacionados aos cuidados da criança. Pelotas, 1999.

Tabela 35: Distribuição da amostra, segundo presença de mordida cruzada posterior (porcentagem ponderada) e problemas de saúde da criança. Pelotas, 1999.

Tabela 36: Distribuição da amostra, segundo presença de mordida cruzada posterior (porcentagem ponderada) e fatores de risco relacionados ao comportamento da criança. Pelotas, 1999.

Tabela 37: Mordida cruzada posterior e fatores de risco. Resultados da análise de regressão múltipla. Pelotas, 1999

Tabela 38: Distribuição da amostra, segundo presença de oclusopatias de caninos (porcentagem ponderada) e fatores de risco socioeconômicos ao nascimento da criança. Pelotas, 1999.

Tabela 39: Distribuição da amostra, segundo presença de oclusopatias de caninos (porcentagem ponderada) e medidas antropométricas da mãe. Pelotas, 1999.

Tabela 40: Distribuição da amostra, segundo presença de oclusopatias de caninos (porcentagem ponderada) e fatores de risco relacionados ao trabalho materno. Pelotas, 1999.

Tabela 41: Distribuição da amostra, segundo presença de oclusopatias de caninos (porcentagem ponderada) e fatores de risco relacionados ao comportamento materno. Pelotas, 1999

Tabela 42: Distribuição da amostra, segundo presença de 
oclusopatias de caninos (porcentagem ponderada) e fatores de risco biológicos da criança. Pelotas, 1999.

Tabela 43: Distribuição da amostra, segundo presença de oclusopatias de caninos (porcentagem ponderada) e fatores de risco relacionados ao uso de bico. Pelotas, 1999.

Tabela 44: Distribuição da amostra, segundo presença de oclusopatias de caninos (porcentagem ponderada) e fatores de risco relacionados aos cuidados da criança. Pelotas, 1999.

Tabela 45: Distribuição da amostra, segundo presença de oclusopatias de caninos (porcentagem ponderada) e fatores de risco relacionados aos problemas de saúde da criança. Pelotas, 1999. .... 140

Tabela 46: Distribuição da amostra, segundo presença de oclusopatias de caninos (porcentagem ponderada) e fatores de risco relacionados ao comportamento da criança. Pelotas, 1999.

Tabela 47: Associação entre oclusopatias de caninos e fatores de risco. Resultados da análise de regressão múltipla. Pelotas, 1999. 


\section{Lista de Quadros}

Quadro 1: Estudos de prevalência de oclusopatias internacionais ...... 25

Quadro 2: Estudos de prevalência de oclusopatias nacionais ............ 31

Quadro 3: Estudos de associação entre oclusopatias e hábitos bucais 49

Quadro 4: Parâmetros utilizados para o cálculo da amostra ............ 71

Quadro 5: Resumo da análise hierárquica para os três desfechos estudados. Fatores de risco para as oclusopatias ......................... 144

\section{Lista de Figuras}

Figura 1: Localização de Pelotas 66

Figura 2: Modelo Teórico 86 


\section{Introdução}


Desde 1977, a Organização Mundial da Saúde (OMS) vem estabelecendo metas, através de documentos sobre políticas de saúde, com objetivo de proporcionar aos cidadãos de todo o mundo condições de saúde para uma vida social e econômica produtiva. Apesar de ganhos expressivos notados, desde então, como a redução da mortalidade infantil e o aumento na expectativa de vida na maioria dos países, há uma notável tendência de aumento da diferença no acesso a bens e serviços entre ricos e pobres, seja entre os paises, seja dentro de um mesmo pais. Este fenômeno implica em disparidades na prevalência de doenças e agravos à saúde, como por exemplo, o câncer, as doenças do coração (WILKINSON 1999) e a cárie dentária (DEAN 1994; O'BRIEN 1994; CHEN 1995; LALLO et al. 1999; MOYSES 2000; ANTUNES et al. 2002), entre os diferentes grupos sociais.

Conseqüentemente ao quadro descrito, tem se observado uma preocupação crescente em abordar a Saúde Pública como uma área complexa, na qual as condições sociais, como a pobreza e a ausência de perspectiva para o futuro, são determinantes chave para a compreensão do processo saúde - doença. Em outras palavras, a qualidade de vida e não apenas a sobrevivência tem se tornado a essência do objeto da Saúde Pública (NIJHUIS e VAN DER MAESEN 1994; PINE 1997).

O mesmo fenômeno acontece na área de Saúde Bucal. No Brasil, notáveis transformações ocorreram nos últimos 40 anos, como destacado por CAPISTRANO FILHO (1994): 
“...há poucos anos atrás a Odontologia era uma das práticas de saúde mais elitizadas no País. Sua inserção no setor público se limitava a precários serviços escolares e abomináveis rotinas de extração dos dentes apodrecidos da população mais pobre. As lutas pela democracia e pela extensão da cidadania e a construção do Sistema Único de Saúde previsto na constituição Federal de 1988 impulsionaram mudanças nessas práticas e nas concepções sobre o que deve fazer a Odontologia brasileira..."

A citação acima reflete a compreensão da Saúde Bucal, extensamente discutida nas últimas décadas e que aborda duas importantes vertentes: a atenção e a assistência a saúde bucal. A assistência odontológica refere-se ao conjunto de procedimentos clínico-cirúrgicos voltados aos indivíduos, doentes ou não, enquanto que a atenção a saúde bucal é um conjunto de ações que busca atingir grupos populacionais através de procedimentos que incluem a assistência odontológica individual e, também, medidas amplas que extrapolam o setor saúde, como a melhoria das condições sociais relacionadas a moradia, saneamento básico, renda, lazer, entre outros (NARVAI 1994).

Segundo NARVAI (1994):

“... a atenção a saúde bucal implica em atuar concomitantemente sobre todos os determinantes do processo saúde-doença bucal, exigindo uma abrangência que transcende não apenas o âmbito da Odontologia mas do próprio setor saúde, o que exige uma articulação e coordenação de ações desenvolvidas no conjunto da sociedade...." 
Coerente com o enfoque proposto o presente estudo abordou um dos principais problemas de Saúde Pública na área de Saúde Bucal, as oclusopatias. 
2 Revisão da Literatura 


\subsection{Oclusopatias: conceito}

A oclusão fundamenta grande parte dos estudos em Saúde Bucal, pois o objetivo comum das áreas da Odontologia é a obtenção de uma oclusão funcional estável. Para melhor compreender as oclusopatias, torna-se importante estabelecer o conceito prévio de oclusão.

ANGLE (1899) definiu oclusão, como as relações normais entre os planos inclinados oclusais dos dentes, quando os maxilares estão cerrados. A natureza empírica e estática do conceito de oclusão normal proposta por Angle em 1899 foi evidenciada por CASE (1905) que afirmou que:

“...quando os maxilares realizam movimento de mastigação e fechamento, não é correto dizer que os dentes se encontram em oclusão, salvo se fecharem em oclusão absoluta..."

Normal é uma palavra útil, porque as pequenas variações do padrão anatômico são a regra e não a exceção; e isso porque o que querem chamar de oclusão normal, na realidade é uma oclusão anatômica ideal. PROFFIT e FIELDS (1995) afirmaram que a definição de ANGLE (1899) de oclusão normal deve ser considerada como oclusão ideal, especialmente quando os critérios aplicados são rígidos. Na verdade, são raros os dentes perfeitamente interrelacionados e posicionados sobre uma linha de oclusão impecavelmente regular.

Estudos antropológicos sobre o complexo craniofacial possibilitaram a ampliação no conceito de oclusão, através da observação das variações raciais 
das chamadas oclusões normais (LISCHER 1912; SIMON 1926; HELMANN 1929).

Novas técnicas, com o advento da cefalometria (BROADBENT 1931) e os estudos sobre a articulação temporomandibular (ATM) (CLINCH 1934) trouxeram um conceito fisiológico mais amplo e mais dinâmico para a oclusão.

Observando modelos seriados de crianças do nascimento até os 3 anos de idade, SILLMAN (1940) afirmou que a criança adquire um "senso oclusal" quando inicia-se a erupção dos primeiros molares por volta dos 12 meses de idade, como resultado da formação dos reflexos que regulam os movimentos mandibulares depois que os dentes antagonistas se tocam. Este senso oclusal se define ao erupcionarem os segundos molares decíduos, por volta dos 24 meses de idade.

BAUME (1950) verificou, através de moldagens seriadas, as medidas de comprimento e largura do arco decíduo e a distância entre os segundos molares decíduos, concluindo que a partir dos 2 anos e meio até o início da erupção dos dentes permanentes, não se observa nenhuma modificação nos arcos dentários. Após a formação completa destes arcos, estes só seriam alterados quando sujeitos a influência de fatores externos, ambientais. Os arcos deciduos podem ser encontrados com espaçamento entre os incisivos (tipo I) ou sem espaçamento (tipo II). Além disso o autor verificou a presença de espaçamentos entre o canino inferior e o primeiro molar inferior e outro entre incisivo lateral superior e canino superior, designados como espaços primatas. 
COHEN (1961) descreveu a oclusão normal na dentição decidua, caracterizando-a por uma ligeira sobremordida horizontal e vertical, uma boa relação molar, podendo haver ou não espaços entre os caninos e os primeiros molares ou entre os incisivos. Além disso os dentes decíduos se apresentam verticalizados em sua base óssea, de modo que suas faces oclusais e bordas incisais se tocam num plano.

BESHNILIAN (1971) destacou que todas as funções oclusais são aprendidas em estágios, à medida que o sistema nervoso central e a musculatura bucofacial amadurecem, o que ocorre concomitantemente com o desenvolvimento da dentição. A função mastigatória é influenciada pelas relações entre os dentes e os movimentos se modificam através das alterações da oclusão provocadas por alterações na posição dental de diferentes origens, como, por exemplo, pelas perdas dentárias e pelas interferências de materiais restauradores.

STEIGMAN e WEIBERG (1985) sugeriram que um dos aspectos característicos da oclusão normal é a continuidade do arco, caracterizada pelo contato proximal entre os dentes em cada arco dentário. Porém, os autores demonstraram, em um estudo com 1269 indivíduos jovens, que 48,6\% deles apresentavam no mínimo um espaço interdentário na dentição permanente.

Além das características já mencionadas sobre a dentição decídua, VAN DER LINDEN (1986) enfatizou, confirmando os achados de BAUME (1950), que no periodo de 2,5 a 5 anos de idade poucas alterações ocorrem na dentição 
decídua, tanto com relação ao posicionamento dentário, quanto às relações sagital e transversa entre os arcos superior e inferior.

Durante muito tempo, ocorreram divergências entre os pesquisadores sobre a definição dos problemas oclusais. Estas divergências referiam-se ao limite considerado aceitável com relação ao desvio do padrão de oclusão perfeita.

A situação de oclusão não "normal", é conhecida como má-oclusão, cujo conceito definido por MOYERS (1959) refere-se a “.... desvios de crescimento e desenvolvimento do complexo buco-facial e desvios de posições dentais que podem originar as deformidades dento-faciais..." Porém, o que se observa, é que a expressão má-oclusão tem sido relacionada, principalmente, a um mau posicionamento dental (VIEGAS 1965).

A expressão má-oclusão é um termo impreciso, segundo SUMMERS (1971), pois há uma grande variação na sua definição. Epidemiologicamente, o autor sugeriu a utilização da expressão desordens oclusais pois, desta forma, permite a abordagem das variações existentes neste campo, desde uma boa oclusão até a presença dos mais diferentes problemas oclusais.

SIMÕES (1978) definiu os problemas de oclusão como:

"... problemas de crescimento e desenvolvimento, que afetam os músculos e os ossos maxilares no periodo da infância e da adolescência e que podem produzir alterações estéticas nos dentes ou na face e alterações funcionais envolvendo a mastigação, a fonação e a oclusão dos dentes....". 
O termo crescimento e desenvolvimento apesar de intimamente relacionados, apresentam diferentes significados. Crescimento refere-se, neste caso, ao acréscimo de tamanho e número, ou ambos, enquanto que desenvolvimento implica num acréscimo de complexidade. Em outras palavras, crescimento é um fenômeno anatômico, enquanto que desenvolvimento é fisiológico. Neste sentido o autor adota o uso do termo oclusopatia como forma de demonstrar a dimensão dos problemas oclusais.

PROFFIT (1986) afirmou que, diferente das outras patologias médicas e de outros problemas dentais, as más-oclusões resultam de variações no desenvolvimento normal no qual não há causa especifica e, portanto, o termo mais apropriado seria denominá-las de variações oclusais.

Tendo em vista o exposto e apoiado na extensa discussão conceitual realizada por FRAZÃO (1999) que aborda a amplitude da expressão "oclusopatia", no que diz respeito a origem do processo dos problemas oclusais, pareceu mais apropriado adotar este termo para definir os problemas abordados nesta pesquisa. 


\subsection{As oclusopatias como problema de saúde pública}

Saúde Pública tem sido definida como "...a ciência e a arte de prevenir doenças, prolongar a vida e promover saúde através de esforços organizados da sociedade..." (ACHESON 1988). Este conceito, adaptado para a Saúde Bucal, é definido como “....a ciência e a arte de prevenir doenças e problemas bucais, promover a saúde bucal e melhorar a qualidade de vida através de esforços organizados da sociedade...." (DOWNER et al. 1994).

Na busca por alcançar estes objetivos, a Saúde Pública e a Odontologia em Saúde Coletiva dedicam-se não somente a conhecer os problemas bucais isoladamente, mas, também, investigam sobre grande parte da saúde geral dos indivíduos, envolvendo conhecimentos relacionados a sociologia, psicologia, epidemiologia, estatística, a área de políticas, planejamento e administração de sistemas e serviços de saúde.

As doenças bucais infantis são de grande prevalência em todo o mundo, porém nas últimas décadas têm se observado uma evidente mudança no perfil de morbidade das doenças bucais das populações, na maioria dos paises. Medidas preventivas em Odontologia, políticas de Saúde Pública e mudanças sociais (NADANOVSKY e SHEIHAM 1995) fizeram com que o principal problema de saúde bucal na infância, até então a cárie dentária, sofresse significativa redução em sua gravidade e prevalência nos paises desenvolvidos desde a década de 70 , variando entre $20 \%$ e $70 \%$, em média, a prevalência deste problema. O mesmo ocorreu no Brasil, ainda que tardiamente, com 53\% 
de queda na prevalência da cárie aos 12 anos de idade em um período de 10 anos, entre 1986 e 1996 (SOUZA 1996).

Desta forma, outros problemas bucais passaram a ganhar importância para a Saúde Pública, aumentando-se o interesse e o desenvolvimento de pesquisas relacionadas a etiologia, métodos de prevenção e tratamento de diferentes patologias e problemas bucais.

Segundo consultores da Organização Mundial da Saúde (OMS) a escala de prioridades quanto aos problemas bucais apresenta as oclusopatias na terceira posição, sendo superada apenas pela cárie dentária e pelos problemas periodontais (WHO 1989).

As oclusopatias são consideradas um problema de Saúde Pública pois apresentam alta prevalência, possibilidade de prevenção e tratamento, além de provocarem impacto social por interferirem na qualidade de vida dos indivíduos. A desarmonia dento-facial pode influenciar negativamente a vida das pessoas no que se refere aos fatores psicossociais. Um aspecto dental desagradável pode discriminar os individuos acometidos por estes problemas, tanto no interrelacionamento pessoal como no ambiente de trabalho. Além disso, estes problemas podem comprometer a função oral (DRACKER 1960).

Estudos mostraram que famílias com baixo poder aquisitivo desejam realizar tratamento ortodôntico, provavelmente porque estes problemas têm impacto social (PROFFIT et al. 1998).

O motivo principal para a demanda por tratamento ortodôntico tem sido a melhora na aparência dento-facial, mais do que a necessidade de correção 
funcional dos dentes (SHAW 1981; TULLOCH et al. 1984; KEROSUO et al. 1995). Estes achados sugerem que a procura por tratamento ortodôntico com finalidade estética pode não ser mera vaidade e, sim, uma resposta à avaliação social (KEROSUO et al. 1995).

Há mais de 40 anos o comitê da British Dental Association (1954), citado por PINE (1997), definiu os objetivos do tratamento ortodôntico como sendo o produto da melhora funcional dos dentes através da correção de irregularidades existentes, a criação de maior resistência a outros problemas bucais como a cárie dentária e doenças periodontais e também a melhora na aparência dos indivíduos que, na vida adulta, contribuiria para a sua saúde física e mental.

Determinados problemas oclusais podem predispor, principalmente as crianças, a outros problemas bucais como, por exemplo, o trauma dentário. Sabe-se que um aumento do overjet incisal, grande sobressaliência dos incisivos superiores (DEARING 1984; ANDREASEN e ANDREASEN 1991; NGUYEN et al. 1999) e uma inadequada cobertura labial (O'MULLANE 1973; ANDREASEN e ANDREASEN 1991) podem ser fatores predisponentes para o trauma dentário. Através de uma revisão sistemática e meta- análise, realizada em 1999, cujo objetivo foi abordar a relação entre tamanho do overjet incisal e traumatismo dentário, NGUYEN et al. (1999) concluiram que crianças com overjet incisal maior que $3 \mathrm{~mm}$ têm aproximadamente duas vezes mais chance de sofrer injúrias traumáticas nos dentes anteriores do que as crianças com overjet igual ou menor do que $3 \mathrm{~mm}$. 
Seguindo esta tendência, um número maior de estudos a respeito das oclusopatias passou a ser realizado, com o objetivo principal de conhecer os tipos mais prevalentes destas condições nas populações estudadas e, um número menor de estudos, de determinar os fatores etiológicos relacionados as necessidades de tratamento destes problemas.

Mais recentemente, tem se observado a incorporação de medidas subjetivas para avaliar o impacto dos problemas oclusais na vidas das pessoas, ou seja, a necessidade percebida pelos individuos (KEROSUO et al. 1995). Este novo enfoque vai ao encontro do exposto por CHAVES (1986), que referese à busca de um critério relacionado a necessidade de tratamento sob o ponto de vista do ajustamento do indivíduo na sociedade, ou seja, a identificação do handicap na vida social.

Apesar de não serem conclusivos, estudos têm demonstrado que as oclusopatias manifestam-se em maior número e com maior gravidade na dentição permanente, quando comparado com a dentição decídua (SATURNO 1980; TSCHILL et al. 1997; PALMER 1998; FRAZÃO 1999). Este fato torna importante estudos sobre o desenvolvimento e a etiologia das oclusopatias na dentição decídua, como forma de prevenir ou pelo menos amenizar estes problemas na dentição permanente. 


\subsection{Classificação das oclusopatias}

O limite entre uma oclusão normal e a presença de problemas oclusais, não é fácil de ser identificado. Apesar da existência de muitos índices que procuram registrar os problemas oclusais, torna-se importante a distinção entre aqueles que classificam os tipos de oclusopatias do ponto vista clínico, os que registram a prevalência destes problemas através de estudos epidemiológicos e ainda aqueles que categorizam os problemas oclusais segundo a urgência e a necessidade de tratamento ortodôntico sendo que, alguns deles, abordam mais de um objetivo. Mais recentemente, pesquisadores têm constatado a existência de um significativo distanciamento entre as necessidades ortodônticas estabelecidas através de critérios clinicos, epidemiológicos, ou ambos, conhecidos como critérios normativos, daquelas necessidades realmente percebidas pelos indivíduos e, portanto, definidas através de critérios subjetivos. Neste sentido, tem sido observada a tendência de se estudar o impacto dos problemas oclusais através de indicadores baseados na autopercepção dos indivíduos. (SHAW et al. 1975; PERES et al. 2002).

Do ponto de vista da Saúde Pública, o conhecimento dos problemas oclusais têm como objetivos identificar os indivíduos de acordo com o grau de prioridade das suas necessidades e proporcionar o planejamento e a obtenção de recursos para o tratamento ortodôntico. Para isto são necessários métodos claros de mensuração e classificação dos problemas que permitam sua aplicação em nível epidemiológico e de fácil reconhecimento pelos pesquisadores e examinadores (FOSTER e MENEZES 1976; RUSSEL $s d$ 
citado por CHAVES 1986). Além disso, um bom indice requer uma boa validade e aplicabilidade clínica, deve ser objetivo e produzir informações quantitativas que possam ser analisadas, deve ser de fácil e rápido aprendizado sem treinamento especializado, ser passivel de aplicação em diferentes populações e, finalmente, ser aceitável tanto para os profissionais como para o público em geral (DEPARTMENT OF HEALTH AND SOCIAL SECURITY 1987, citado por RICHMOND 1997).

Um dos mais antigos sistemas de classificação dos problemas oclusais foi criado por Edward H. Angle (ANGLE 1899). Ele é conhecido e utilizado até os tempos atuais, por ser considerado de fácil execução. A classificação de Angle utiliza como referência sinais clínicos na dentição permanente, baseandose fundamentalmente na inter-relação entre os molares permanentes superiores e inferiores. A tese de Angle é que os primeiros molares permanentes exercem o papel de dentes-chave para o estudo das relações ântero-posteriores dos maxilares. O autor classifica a oclusão em: oclusão normal (relação ânteroposterior normal entre a maxila e a mandíbula), relação classe I (relação ânteroposterior normal entre maxila e mandibula, porém com a presença de problemas oclusais na região anterior dos maxilares), relação classe II (mandíbula posicionada posteriormente a maxila - retrognatismo) e relação classe III (mandibula anteriormente posicionada a maxila - prognatismo).

No campo da epidemiologia algumas tentativas de registro dos problemas oclusais são conhecidas há alguns anos. 
ELSASSER (1951) propôs o índice Dento-Facial (DFI) que mede diferentes pontos do perfil facial e indica o grau do problema oclusal. Foi um dos primeiros índices propostos que permitiu tratamento estatístico e que, certamente, contribuiu para o surgimento dos índices mais atuais.

Um sistema de coleta de informações contendo 10 itens a respeito de problemas ortodônticos foi proposto por GRAINGER (1967), citado por FOSTER e MENEZES (1976) e compõem o Índice de Prioridade de Tratamento Ortodôntico (TPI). O autor considera alterações oclusais prejudiciais (handicapping occlusal anomaly) aquelas onde existe estética inaceitável, significativa redução na atividade mastigatória, condição traumática que predispõe a lesões de cárie dentária ou problemas periodontais, problemas de fonação e perda de estabilidade oclusal. Estas situações, aliadas ao julgamento do clínico, definem a necessidade de tratamento ortodôntico dos indivíduos. O TPI é considerado eminentemente descritivo, não havendo separação entre os casos que necessitam de tratamento do ponto de vista da Saúde Pública, daqueles que representam apenas pequenos desvios de oclusão do ponto de vista clínico.

Um índice cuja finalidade foi a de permitir a separação objetiva em grandes grupos de crianças com problemas oclusais significativos para a Saúde Pública, foi o criado por DRACKER (1960) e conhecido como Handicapping Labio-Lingual Deviations (HLD). Este índice considera nove condições clínicas diferenciadas pela sua magnitude e gravidade, atribuindo pesos específicos para cada situação. A somatória final igual ou superior a 13 define a condição 
de handicap físico. O autor analisou as condições de deslocamentos dentais, apinhamentos, overjet (sobressaliência), overbite (sobremordida), mordida aberta anterior, mordida cruzada anterior, erupção ectópica, dentes supranumerários e hipodontia. Este método não inclui a avaliação da relação ântero- posterior ou lateral dos dentes posteriores.

Em 1962, a OMS (WHO 1962) estabeleceu como anomalias dentofaciais prejudiciais como qualquer problema que cause algum tipo de desfiguração ou impeça alguma função do aparelho estomatognático. Para tanto, propôs um método de classificação dos problemas oclusais que sugeria a avaliação da presença de determinadas anomalias como fendas labiais, fendas palatais, ou ambas, relação do molares permanentes, sobremordida, mordida aberta, apinhamentos e espaçamentos dentários, entre outros. Na prática, a utilização deste método de classificação, não mostrou adequada reprodutibilidade dos exames ortodônticos entre os examinadores, o que fez com que a OMS propusesse, mais tarde, uma redução nestes critérios (WHO 1971). Esta decisão sofreu críticas, baseadas no fato de que a classificação anterior, mais completa, mesmo com baixo padrão de reprodutibilidade proporcionava uma "coleta preliminar" de dados sobre prevalência de oclusopatias que, em muitos casos, principalmente nos paises em desenvolvimento, trataria da oportunidade única para se obter este tipo de informação (BAUME 1974).

BJORK e HELM (1964) sistematizaram uma série de informações clínicas que compõem um quadro passivel de comparação entre indivíduos, 
onde são avaliadas situações como: anomalias na dentição relacionadas a problemas de erupção dentária, alinhamento dos dentes, entre outros. Além disso, desvios de oclusão também foram considerados, principalmente com relação ao posicionamento inter-arcos superior e inferior e as condições de espaçamento nos arcos diagnosticado pela presença de apinhamento dentário ou presença de espaços interdentais. Os autores afirmaram que uma das vantagens deste sistema de classificação é que os problemas oclusais podem ser descritos a partir de qualquer combinação definida pelos sinais avaliados nos três grupos de registro descritos anteriormente, não sendo atribuídos escores para as caracteristicas oclusais encontradas. Além dos critérios clínicos, os autores adicionaram um critério subjetivo para avaliar a necessidade de tratamento ortodôntico.

Um estudo com 100 crianças entre 2 anos e meio e 3 anos de idade foi realizado por FOSTER e HAMILTON (1969) na Inglaterra e estabeleceu critérios para uma classificação especifica para oclusopatias na dentição decídua. As seguintes medidas foram consideradas: espaçamento entre os dentes, apinhamento dentário, oclusão dos molares, relação de caninos, overjet, mordida cruzada anterior, overbite, mordida aberta anterior, mordida cruzada posterior.

SUMMERS (1971) classificou a dentição decídua, mista e permanente quanto a ausência e a magnitude das necessidades de tratamento ortodôntico, através da avaliação de nove características especificas: mau posicionamento dentário, apinhamentos, overjet, relação ântero- posterior de molares, overbite, 
mordida aberta anterior, mordida cruzada anterior e posterior e hipodontia. A proposta do autor foi determinar prioridades de tratamento ortodôntico através de medidas clínicas para populações cujo acesso a este tipo de tratamento fosse limitado. Para isto, estabeleceu um sistema complexo de pesos diferenciados para todos os parâmetros envolvidos. Desta forma, os indivíduos foram alocados de acordo com diferentes sindromes de oclusopatias, definidas através do principal desvio da condição de oclusão considerada normal.

Com o objetivo de conhecer a prevalência de oclusopatias e contribuir para avaliar a necessidade de tratamento ortodôntico, BEZROUKOV et al. (1979) propuseram um método de avaliação que considerara o número de dentes permanentes perdidos, a presença de dentes supranumerários, a máformação dos incisivos, a erupção ectópica de dentes e a presença de apinhamento ou espaçamento dentário como forma de classificar as oclusopatias. A partir destes indicadores, a necessidade de tratamento ortodôntico foi classificada em desnecessária, duvidosa, necessária e urgente, considerando-se, também, a influência dos problemas oclusais detectados no desenvolvimento de outros problemas como a cárie dentária, os problemas periodontais, entre outros.

Em 1987, a OMS (WHO 1987) adotou um novo critério de classificação das oclusopatias que é utilizado até os dias de hoje, tanto para a dentição decidua quanto para a dentição permanente. Este sistema de classificação contém três categorias, a saber: $0=$ nenhuma anomalia oclusal; $1=$ anomalia leve como ligeiros apinhamentos ou espaçamentos dentários; leves rotações 
dentárias; $2=$ anomalia moderada/severa: presença de um ou mais problemas oclusais sérios como overjet maxilar de $9 \mathrm{~mm}$ ou mais, mordida cruzada anterior, mordida aberta, desvio de linha média maior do que $4 \mathrm{~mm}$ ou apinhamentos/espaçamentos maiores do que $4 \mathrm{~mm}$.

BURDI e MOYERS (1988) sugeriram a observação da presença de dentes anteriores espaçados, presença de espaços primatas (espaços encontrados entre canino e primeiro molar inferiores e canino e incisivo lateral superiores), sobressaliência e sobremordida pouco profundas, plano terminal dos molares reto, relação de caninos e molares tipo classe 1 , inclinação quase vertical dos dentes anteriores e arco dentário na forma ovóide.

BROOK e SHAW (1989) propuseram um índice para avaliar a necessidade de tratamento ortodôntico, o índice de Necessidade de Tratamento Ortodôntico (IOTN), que considera dois componentes distintos para a classificação dos indivíduos: a indicação clínica para tratamento através de um gradiente de problemas funcionais e o prejuizo estético e seu impacto, medidos através de uma escala construída com fotografias mostrando diferentes niveis de aparência dental e, conseqüentemente, definindo o grau de interferência psicológica e social dos problemas oclusais.

Em 1997, a OMS (WHO 1997) passou a adotar o Índice de Estética Dental (Dental Aesthetic Index - DAl) como referência para a realização de levantamentos epidemiológicos de oclusopatias. Este índice é recomendado para utilização em crianças a partir de 12 anos de idade e sem a presença de dentes deciduos. Ele avalia condições tais como perda de dentes incisivos, 
caninos ou pré-molares, apinhamento ou espaçamento dentário no segmento incisal, diastema, irregularidades na maxila e mandíbula no segmento anterior, overjet maxilar ou mandibular, mordida aberta e relação ântero-posterior de molar.

Como foi observado na literatura, diversos índices para se avaliar os problemas oclusais foram propostos ao longo do tempo, considerando uma série de características oclusais. Na maioria dos indivíduos, os desvios encontrados de uma oclusão considerada ideal não necessariamente significam um problema oclusal e, sim, apenas uma variação da situação ideal. A maioria das classificações existentes sobre a oclusão são úteis para a descrição clínica da oclusão, porém são consideradas medidas grosseiras quando relacionadas a muitas das caracteristicas que compõem a oclusão dentária (FOSTER e MENEZES 1976). Por outro lado, a oclusão e o posicionamento dos dentes são o resultado final observado de todos os fatores etiológicos relacionados às oclusopatias e a maioria dos indices existentes atualmente, utilizam estas medidas como base de conhecimento das oclusopatias em estudos epidemiológicos; diferente de estudos passados que utilizavam apenas um tipo de classificação como, por exemplo, a classificação de Angle (WALTHER 1960; AST et al. 1962).

Com relação a dentição decídua, poucas classificações foram propostas. A análise das relações terminais entre os molares decíduos superiores e inferiores, bem como a relação entre os caninos deciduos superiores têm sido pesquisadas. Entre os molares, a terminação em plano reto e entre os caninos 
a relação do tipo classe 1, segundo critérios de FOSTER e HAMILTON (1969), têm sido as mais prevalentes em crianças de 3 a 6 anos (INFANTE 1975; WOON 1988; FARSI e SALAMA 1996; OTUYEMI et al. 1997).

Alguns tipos de oclusopatias são mais considerados na dentição decídua como, por exemplo, a relação ântero- posterior entre os molares do tipo classe 2 ou 3 entre as faces distais dos segundos molares, cujos critérios são adaptados da classificação de Angle. Além deste tipo de oclusopatia, também são consideradas, na dentição decídua, as mordidas cruzadas posteriores e anteriores, a mordida aberta anterior, a relação do tipo classe 2 ou 3 das faces de caninos superiores e inferiores, overjet, overbite, entre outros. Estas características da dentição decídua estão representadas na classificação de FOSTER e HAMILTON (1969) e na classificação proposta pela OMS (WHO 1987) também utilizada para a dentição decídua.

Pesquisadores sugerem que estes tipos de problemas oclusais na dentição decídua podem contribuir para a continuidade do problema na dentição permanente ou potencializar possiveis problemas oclusais de origem genética devendo, portanto, serem investigados (BOGUE 1908, CHIAVARO 1915). 


\subsection{Epidemiologia das oclusopatias}

\subsubsection{Quadro internacional}

Estudos sobre a distribuição e a freqüência dos problemas oclusais têm sido desenvolvidos, principalmente, no Norte da Europa e nos Estados Unidos (SHAW 1997), porém comparações entre eles nem sempre são possíveis de serem realizadas devido à variação entre os critérios adotados, os níveis de gravidade abordados, os tamanhos e as idades que compõem as amostras, dentre outras diferenças metodológicas.

De maneira geral, pesquisadores afirmaram que as oclusopatias são problemas que afetam grande parte da população (NEWMAN 1956, SHAW 1993). Com relação aos problemas oclusais na dentição decídua, o número de estudos é reduzido, ficando as informações a respeito da primeira dentição mais escassos quando comparados à dentição permanente (INFANTE 1975).

O Quadro 1 apresenta um resumo dos principais estudos epidemiológicos internacionais acerca das oclusopatias na dentição decídua. 
Quadro 1: Estudos internacionais sobre prevalência de oclusopatias na dentição decídua, segundo autor (es), ano de publicação, local, tamanho da amostra e idade.

\begin{tabular}{|c|c|c|c|c|c|c|}
\hline Autores & Publicacão & Local & Amostra & Idade (anos) & Oclusopatia & Prevalência (\%) \\
\hline Newman e Newmark & 1956 & Bélgica & 3355 & 6 a 14 & Algum tipo & 52,0 \\
\hline Infante & 1975 & EUA & 735 & 2,5 a 6 & M. cruzada & $\begin{array}{l}7,1 \text { (brancos), 2,1(negros), } 5,3 \\
\text { (indios) }\end{array}$ \\
\hline Kisling e Krebs & 1976 & Copenhagen & 1624 & $2,5-3$ & $\begin{array}{l}\text { M. aberta } \\
\text { M. cruzada }\end{array}$ & $\begin{array}{l}57,5 \text { (fem), 84,0 (masc) } \\
15,9 \text { (fem), 12,3 (masc) }\end{array}$ \\
\hline De Vis et al. & 1984 & Bélgica & 510 & 3 a 6 & $\begin{array}{l}\text { M. aberta } \\
\text { M. cruzada }\end{array}$ & $\begin{array}{l}20,0 \\
8,9\end{array}$ \\
\hline Ghezzi et al. & 1986 & $\begin{array}{l}\text { Genova- } \\
\text { Cervante }\end{array}$ & 604 & $x^{2}$ & $\begin{array}{l}\text { Algum tipo } \\
\text { M. aberta } \\
\text { M. cruzada }\end{array}$ & $\begin{array}{l}36,8 \\
21,6 \\
13,5\end{array}$ \\
\hline Woon & 1988 & Malásia & 426 & 3 a 6 & $\begin{array}{l}\text { Rotação } \\
\text { Apinhamento } \\
\text { Relação molar } \\
\text { Relação canino } \\
\text { Overjet } \\
\text { Overbite } \\
\text { M. aberta } \\
\text { M. cruzada } \\
\text { Espaçamento }\end{array}$ & $\begin{array}{l}1,8-19,5 \\
1,8-13,5 \\
1,6-19,1 \\
9,3-25,6 \\
36,7-60,5 \\
4,7-7,7 \\
0,9-5,4 \\
1,8-2,9 \\
8,4-39,4\end{array}$ \\
\hline Jones et al. & 1993 & Richmond & 493 & 3 a 4 & $\begin{array}{l}\text { M. cruzada } \\
\text { M. aberta }\end{array}$ & $\begin{array}{l}7,0 \\
8,0\end{array}$ \\
\hline Paunio et al. & 1993 & $\begin{array}{l}\text { Turku, } \\
\text { Finlândia }\end{array}$ & 938 & 3 a 4 & $\begin{array}{l}\text { M. aberta } \\
\text { M cruzada }\end{array}$ & $\begin{array}{l}27,2 \\
8,3\end{array}$ \\
\hline Kharbanda et al. & 1994 & Nova-Deli & 1608 & 5 a 7 & $\begin{array}{l}\text { Apinhamento } \\
\text { Atrição }\end{array}$ & $\begin{array}{l}32,2 \\
14,1\end{array}$ \\
\hline Kabue et al. & 1995 & Nairobi, Kenia & 221 & 3 a 6 & $\begin{array}{l}\text { Overjet } \\
\text { M. aberta } \\
\text { M. profunda } \\
\text { M. cruzada }\end{array}$ & $\begin{array}{l}13,0 \\
5,0 \\
13,0 \\
5,0\end{array}$ \\
\hline
\end{tabular}


Continuação:

\begin{tabular}{|c|c|c|c|c|c|c|}
\hline Autores & Publicação & Local & Amostra & Idade (anos) & Oclusopatia & Prevalência(\%) \\
\hline Stecksen-Blicks e Holm & 1995 & Suécia & ignorada & 4 & $\begin{array}{l}\text { M. cruzada } \\
\text { M. aberta }\end{array}$ & $\begin{array}{l}18,0(1971), 16,0(1992) \\
35,0(1971), 41,0(1992)\end{array}$ \\
\hline Trottman e Eslbach & 1996 & EUA & 238 & 3 a 5 & $\begin{array}{l}\text { M. aberta } \\
\text { M. cruzada }\end{array}$ & $\begin{array}{l}7,1 \text { (brancos); } 12,2 \text { (negros) } \\
6,1 \text { (brancos); } 8,6 \text { (negros) }\end{array}$ \\
\hline Farsi e Salama & 1996 & Arábia Saudita & 520 & 3 a 5 & $\begin{array}{l}\text { Overjet } \\
\text { M. aberta } \\
\text { Classe } 2 \text { canino }\end{array}$ & $\begin{array}{l}2,5(\geq 6 \mathrm{~mm}) \\
9,2 \\
10,9\end{array}$ \\
\hline Johannsdottir et al. & 1997 & Islândia & 396 & 6 & $\begin{array}{l}\text { Classe 2- molar } \\
\text { Classe 3-molar }\end{array}$ & $\begin{array}{l}27,0 \text { (masculino) } 31,0 \text { (feminino) } \\
6,0 \text { (masculino) e } 5,0 \text { (feminino) }\end{array}$ \\
\hline Otuyemi et al. & 1997 & Nigéria & 525 & 3 a 4 & $\begin{array}{l}\text { Classe 3-canino } \\
\text { Classe 2-canino } \\
\text { M. cruzada } \\
\text { M. aberta }\end{array}$ & $\begin{array}{l}3,0 \\
14,7 \\
4,8 \\
5,3\end{array}$ \\
\hline Carvalho et al. & 1998 & Bélgica & 750 & 3 a 5 & $\begin{array}{l}\text { M. cruzada } \\
\text { M. aberta }\end{array}$ & $\begin{array}{l}10,1 \\
32,0\end{array}$ \\
\hline Navarrete e Espinoza & 1998 & Santiago, Chile & 211 & 2 a 4 & $\begin{array}{l}\text { M. cruzada } \\
\text { M. aberta } \\
\text { Sobremordida }\end{array}$ & $\begin{array}{l}10,3 \\
5,0 \\
8,4\end{array}$ \\
\hline Agurto et al. & 1999 & Santiago, Chile & 1110 & 3 a 6 & $\begin{array}{l}\text { Classe } 2 \text { molar } \\
\text { M. cruzada } \\
\text { M aberta }\end{array}$ & $\begin{array}{l}38,0 \\
28,0 \\
16,0\end{array}$ \\
\hline Alamoudi & 1999 & Jeddah, Arábia & 502 & 4 a 6 & Apinhamento & 14,7 \\
\hline Baez et al. & 1999 & Maracaibo, Venezuela & 579 & 3 a 6 & $\begin{array}{l}\text { Desvio médio } \\
\text { Classe } 2 \text { canino } \\
\text { Classe } 3 \text { canino } \\
\text { M. cruzada } \\
\text { Algum tipo }\end{array}$ & $\begin{array}{l}51,7 \\
21,8 \\
51,2 \\
17,0 \\
57,7\end{array}$ \\
\hline Karjalainen et al. & 1999 & Turku, Finlândia & 148 & 3 & $\begin{array}{l}\text { M. aberta } \\
\text { M. cruzada }\end{array}$ & $\begin{array}{l}18,0 \\
13,0\end{array}$ \\
\hline Thilander et al. & 2001 & Bogotá, Colômbia & 4724 & 5 a 17 & Algum tipo & $\begin{array}{l}20,0 \\
50,0\end{array}$ \\
\hline
\end{tabular}


INFANTE (1975) verificou, 735 crianças entre 2,5 e 6 anos de idade de diferentes origens étnicas, a prevalência dos tipos de relação molar e canino decíduos classes 1, 2 e 3, segundo a classificação de FOSTER e HAMILTON (1969) e a presença de mordida cruzada anterior e posterior. Crianças brancas apresentaram uma prevalência maior de classe $2(19,1 \%)$ e de mordida cruzada posterior $(7,1 \%)$ quando comparada com as crianças negras $(4,3 \%$ e $2,1 \%$, respectivamente) e índias Apache (2,7\% e 5,3\%, respectivamente). Por outro lado, as crianças negras apresentaram maior prevalência de classe $3(7,1 \%)$ do que as crianças brancas $(1,0 \%)$. Um maior número de crianças com mordida cruzada anterior foi observado entre as crianças índias Apache $(24,0 \%)$.

Crianças entre 3 e 6 anos de idade de diferentes origens étnicas vivendo na Malásia foram examinadas quanto ao tipo de oclusão. As crianças de origem chinesa e malaia apresentaram mais espaçamento entre os dentes inferiores do que entre os superiores $(29,5 \%, 26,6 \%$, respectivamente) ocorrendo o contrário nas crianças de origem indiana $(13,16 \%)$. Analisando a relação entre os caninos decíduos, as três diferentes origens étnicas apresentaram padrões similares; entretanto as crianças indianas apresentaram menos classe 1 (62\%), mais classe 2 (38\%) e nenhuma classe 3 na amostra estudada (WOON 1988).

Padrões similares foram observados em crianças de 3 a 5 anos de idade na Arábia Saudita, onde $10,9 \%$ das crianças apresentaram uma relação canina do tipo classe 2 e apenas $3,3 \%$ do tipo classe 3 . Prevalência menor quando comparada a outros estudos foi observada com relação a presença de mordida aberta anterior. Do total da amostra, apenas $9,2 \%$ das crianças apresentavam 
esta condição, observando-se um significativo aumento na prevalência de mordida aberta quando comparados os 3 anos $(8,2 \%)$ com os 5 anos de idade $(11,1 \%)$. Os autores afirmaram que as crianças da Arábia Saudita têm menos problemas oclusais na primeira dentição do que as de outros países; provavelmente porque muitos destes problemas são causados por hábitos culturais não existentes naquele pais (FARSI e SALAMA 1996).

OTUYEMI et al. (1997), analisando a dentição decídua em crianças de 3 e 4 anos de idade na Nigéria, encontraram $14,7 \%$ das crianças apresentando relação classe 2 de canino e apenas $3 \%$ com relação canina classe 3. Quanto a presença de mordida aberta anterior, $5,3 \%$ da população estudada apresentava esta condição. A presença de mordida cruzada posterior uni ou bilateral foi encontrada em $4,8 \%$ das crianças.

A prevalência de oclusopatias encontrada numa amostra de crianças de 6 anos de idade em Reykjavik, Islândia e analisada segundo a classificação de BJORK e HELM (1964) foi igual a $27 \%$ para a relação classe 2 de molares nos meninos e $31 \%$ nas meninas e para a classe 3 , igual a $6 \%$ nos meninos e $5 \%$ nas meninas. Presença de mordida cruzada posterior foi encontrada em $13 \%$ do total das crianças (JOHANNSDOTTIR et al. 1997).

Estudando as oclusopatias em crianças de 3 a 5 de idade na Bélgica, e utilizando o mesmo critério do estudo anterior (BJORK e HELM 1964), CARVALHO et al. (1998) encontraram $10,1 \%$ das crianças com mordida cruzada posterior e $32,0 \%$ delas apresentando mordida aberta anterior. A prevalência de mordida aberta anterior diminuiu conforme a idade aumentou e 
esta oclusopatia foi encontrada associada a mordida cruzada posterior em $40 \%$ das crianças que apresentavam este quadro.

Do total de crianças entre 3,5 e 5,5 anos de idade examinadas na província de İstria, Itália, 40,83\% apresentaram algum tipo de problema oclusal. As oclusopatias mais comumente encontradas foram no sentido sagital- vertical $(18 \%)$ como a presença de sobressaliência (overjet), seguida dos problemas verticais $(9,33 \%)$ como mordida aberta anterior e mordida profunda e apenas $2,89 \%$ das crianças apresentando oclusopatias no sentido transversal. (LEGOVIC et al. 1998).

Estudo transversal sobre oclusopatias na dentição decídua foi realizado em 211 crianças de 2 a 4 anos de idade matriculadas em creches em Santiago, Chile, observando-se que os principais problemas oclusais foram a presença de mordida aberta anterior $(10,3 \%)$, mordida cruzada posterior $(5 \%)$ e as sobremordidas $(8,4 \%)$ (NAVARRETE e ESPINOZA 1998).

AGURTO et al. (1999) observaram em 1100 pré-escolares entre 3 e 6 anos de idade em Santiago, Chile, a presença de relação classe 2 de molares (38\%), mordida cruzada posterior (28\%) e mordida aberta anterior (16\%).

Pré-escolares entre 3 e 6,9 anos de idade, alunos de instituições públicas e privadas de Maracaibo, Venezuela, foram examinadas quanto a presença de oclusopatias, constatando-se que $57,7 \%$ delas apresentavam algum tipo deste problema. Do total da amostra, a metade apresentou relação bilateral tipo $1 \mathrm{e}$ $21,8 \%$ apresentaram relação molar classe 1 e 2 unilateral e classe 2 e 3 unilateral de caninos (BAEZ et al. 1999). 


\subsubsection{Quadro nacional}

Existe um reduzido número de estudos nacionais sobre a prevalência de oclusopatias na dentição decídua quando comparado à literatura internacional. O Quadro 2 apresenta um resumo das pesquisas nacionais. 
Quadro 2: Estudos nacionais sobre prevalência de oclusopatias, segundo autor (es), ano de publicação, local, tamanho da amostra e idade.

\begin{tabular}{|c|c|c|c|c|c|c|}
\hline Autores & Publicação & Local & Amostra & Idade (anos) & Oclusopatia & Prevalência(\%) \\
\hline Silva e Araújo & 1983 & $\begin{array}{l}\text { llha do } \\
\text { Governador, RJ }\end{array}$ & 600 & 5 a 7 & $\begin{array}{l}\text { Algum tipo } \\
\text { M. cruzada post. } \\
\text { m. cruzada anter. }\end{array}$ & $\begin{array}{l}69,2 \\
9,5 \\
9,7\end{array}$ \\
\hline Mathias & 1984 & São Paulo, SP & 300 & 3 a 6 & $\begin{array}{l}\text { Algum tipo } \\
\text { M. aberta } \\
\text { M. cruzada }\end{array}$ & $\begin{array}{l}79,3 \\
20,3 \\
16,3\end{array}$ \\
\hline Maia & 1987 & Natal, RN & 351 & 3 a 6 & Algum tipo & 57,3 \\
\hline Valente e Mussolino & 1989 & $\begin{array}{l}\text { Ribeirão Preto, } \\
\text { SP }\end{array}$ & 120 & 2 a 6 & $\begin{array}{l}\text { Sobressaliência } \\
\text { Sobremordida } \\
\text { M. aberta }\end{array}$ & $\begin{array}{l}76,7 \text { ( } 2 \text { a } 4 \text { anos }), 41,7 \\
(4 \text { a } 6 \text { anos }) \\
29,9 \text { ( } 2 \text { a } 4 \text { anos }), 11,7 \\
(4 \text { a } 6 \text { anos }) \\
23,3\end{array}$ \\
\hline Moura et al. & 1994 & Teresina, $\mathrm{PI}$ & 144 & 3 a 6 & $\begin{array}{l}\text { Plano reto molar } \\
\text { Classe } 2 \text { molar }\end{array}$ & $\begin{array}{l}81,9 \\
4,9\end{array}$ \\
\hline $\begin{array}{l}\text { Secretaria da Saúde e do } \\
\text { Desenvolvimento Social, SC }\end{array}$ & 1995 & Florianópoliss, SC & 3441 & 6 a 12 & $\begin{array}{l}\text { Leve } \\
\text { Moderada/Severa }\end{array}$ & $\begin{array}{l}40,7 \\
12,1\end{array}$ \\
\hline Peres et al. & 1996 & Chapecó, SC & 420 & 6 & $\begin{array}{l}\text { Leve } \\
\text { Moderada/Severa }\end{array}$ & $\begin{array}{l}10,9 \\
22,6\end{array}$ \\
\hline $\begin{array}{l}\text { Universidade de São Paulo - } \\
\text { FSP, SES-SP }\end{array}$ & 1997 & São Paulo, SP & 490 & 5 & $\begin{array}{l}\text { Leve } \\
\text { Moderada/Severa }\end{array}$ & $\begin{array}{l}22,9 \\
26,1\end{array}$ \\
\hline Tomita & 1997 & Bauru, SP & 2139 & 3 a 5 & $\begin{array}{l}\text { Algum tipo } \\
\text { Apinhamento inf. } \\
\text { M. aberta } \\
\text { M. cruzada unil. }\end{array}$ & $\begin{array}{l}60,1 \text { ( } 3 \text { anos), } 54,9 \text { (4 } \\
\text { anos), 50,1 (5 anos) } \\
2,2 \\
29,2 \\
9,1\end{array}$ \\
\hline Stiz & 2001 & Camboriú, SC & 1847 & 5 a 12 & $\begin{array}{l}\text { Leve } \\
\text { Moderada/Severa }\end{array}$ & $\begin{array}{l}10,3 \\
23,0\end{array}$ \\
\hline Bortoluzzi & 2001 & Joaçaba, SC & 226 & 6 & $\begin{array}{l}\text { M. aberta } \\
\text { M. cruzada } \\
\text { Classe } 2 \text { e } 3 \text { caninos } \\
\text { Classe } 2 \text { e } 3 \text { molar }\end{array}$ & $\begin{array}{l}30,5 \\
23,5 \\
44,7 \\
44,7\end{array}$ \\
\hline
\end{tabular}


SILVA e ARAÚJO (1983) verificaram, numa população de 600 crianças entre 5 e 7 anos de idade da llha do Governador, Rio de Janeiro, a presença de $69,2 \%$ de algum tipo de oclusopatia entre elas. Segundo a classificação de Angle, a classe I foi a situação mais prevalente, seguida da classe II e da classe III. Do total da população estudada, 19,17\% apresentaram mordida cruzada posterior, predominando a mordida cruzada unilateral $(9,7 \%)$.

A prevalência de oclusopatias, em 300 escolares entre 3 e 6 anos de idade, foi pesquisada em escolas do municipio de São Paulo. $O$ autor verificou que $20,3 \%$ das crianças apresentavam mordida aberta anterior, segundo critério de GRABER (1961) e 16,3\% apresentavam mordida cruzada. (MATHIAS 1984).

MAIA (1987) analisou a oclusão de escolares entre 3 e 6 anos de idade em Natal, Rio Grande do Norte, verificando que $57,3 \%$ apresentavam algum tipo de desarmonia oclusal. A relação classe 2 de molar foi menos freqüente, conforme aumentava a idade.

Em Ribeirão Preto, São Paulo, 120 crianças entre 2 e 6 anos de idade foram analisadas segundo a oclusão, utilizando critérios de GRABER (1958), FOSTER e HAMILTON (1969) e NANDA et al. (1973). Foram encontrados overjet entre 2 e $4 \mathrm{~mm}$ em $61,66 \%$ das crianças de 2 a 4 anos de idade, contra $35 \%$ nas crianças de 4 a 6 anos de idade. Estes números passaram para $15 \%$ e $6,66 \%$, respectivamente, quando considerado um overjet maior do que $4 \mathrm{~mm}$. A presença de mordida aberta anterior foi igual a $23,32 \%$ do total das crianças examinadas considerando-se os mais diferentes graus desta oclusopatia, diminuindo conforme a idade (VALENTE e MUSSOLINO 1989). 
TOMITA (1997) analisou 2139 crianças de 3 a 5 anos de idade em Bauru, São Paulo, quanto a prevalência de problemas oclusais e fatores associados. Do total de crianças examinadas $51,3 \%$ das crianças do sexo masculino apresentaram algum tipo de oclusopatia, contra $56,9 \%$ no sexo feminino. Apenas $2,16 \%$ das crianças apresentaram apinhamento na região anterior inferior, $29,22 \%$ do total das crianças examinadas tinham mordida aberta anterior e 9,07\% apresentavam mordida cruzada unilateral.

No município de São Paulo foi realizado um levantamento epidemiológico sobre os principais problemas bucais, utilizando os critérios da OMS (WHO 1987), constatando-se com relação as oclusopatias na dentição decídua, $22,9 \%$ das crianças com oclusopatias leves e $26,1 \%$ com oclusopatias moderadas ou severas (UNIVERSIDADE DE SÃO PAULO E SECRETARIA DO ESTADO DA SAÚDE 1997).

Utilizando os mesmos critérios do estudo anterior, STIZ (2001) encontrou $10,3 \%$ de crianças de 5 anos de idade com oclusopatias leves e $23 \%$ com oclusopatias moderadas ou severas num estudo transversal realizado em Camboriú, SC.

As diferenças metodológicas existentes nos estudos apresentados, impossibilitam uma adequada comparação geral entre eles. Porém, é possível agrupar alguns estudos segundo a mesma metodologia utilizada.

CARVALHO et al. (1998) e THILANDER et al. (2001) apontaram a presença de mordida cruzada unilateral como um dos principais problemas oclusais encontrados na dentição decídua, utilizando os mesmos critérios de 
identificação das oclusopatias. A mordida aberta anterior foi o problema oclusal mais prevalente encontrado por CARVALHO et al. (1998), enquanto que para THILANDER et al. (2001) isto não ocorreu, talvez por ter pesquisado uma faixa etária maior.

Utilizando os mesmos critérios, diferentes pesquisas apontaram para uma prevalência predominante de relação classe 1 de molar e de canino na dentição decídua, com alguma variação no segundo posto entre classe 2 e 3 (INFANTE 1975, WOON 1988, VALENTE e MUSSOLINO 1989, FARSI e SALAMA 1996, OTUYEMI et al. 1997, TOMITA 1997). Estes estudos também indicaram um decréscimo na prevalência de classe 2 de molar deciduo, de presença e tamanho de overjet, overbite e mordida aberta anterior, conforme aumenta a idade (VALENTE e MUSSOLINO 1989, FARSI e SALAMA 1996).

Analisando os problemas oclusais na mesma idade e utilizando os mesmos critérios, dois estudos nacionais, um em São Paulo (UNIVERSIDADE DE SAO PAULO E SECRETARIA DO ESTADO DA SAÚDE 1997) e outro em Balneário Camboriú (STIZ 2001) apresentaram resultados semelhantes quanto a prevalência de oclusopatias moderadas ou severas, porém diferiram com relação a prevalência de oclusopatias leves sendo que, em Balneário Camboriú (SC) a proporção de crianças de 5 anos de idade com este quadro somou menos da metade das crianças que apresentavam esta situação no município de São Paulo. 


\subsubsection{Tendência secular das oclusopatias}

Apesar das diferenças entre as prevalências encontradas nos diversos estudos apresentados, há evidência de que um aumento em ambas, prevalência e gravidade das oclusopatias, desde os tempos medievais até os dias de hoje, tem ocorrido (SMYTH 1934; HELM 1979; WEILAND et al. 1997). Estudos sugerem um aumento no número de crianças com mau posicionamento dos dentes nos últimos 150 anos, principalmente em civilizações que alcançaram rápido avanço tecnológico. Antes disso, num período anterior de aproximadamente 6000 anos, estas alterações nas arcadas dentárias manifestavam-se modestamente.

Antropólogos e outros estudiosos têm, repetidamente, documentado um aumento de oclusopatias em populações rurais cuja dieta natural foi substituída por uma dieta mais mole, de fácil mastigação, típica das populações urbanas (NISWANDER 1967; LOMBARDI e BAILIT 1972 citado por CORRUCCINI e POTER 1986).

Tendência secular, como são conhecidas estas mudanças ocorridas no mundo ocidental, é um fenômeno que tem sido documentado na literatura, relacionado a diferentes fenômenos como o peso, a altura e o início da puberdade dos indivíduos, entre outros fatores (FRANÇA-JUNIOR 1998). Esta tendência também foi verificada no aumento das dimensões do esqueleto crânio-facial entre diferentes gerações; porém permanecendo semelhante a relação ântero-posterior entre os dentes ao longo do tempo (BRIN et al. 1998). 
Pesquisadores sugerem que as alterações ocorridas no esqueleto podem ter sido compensadas por movimentos dentais e que os problemas oclusais observados em maior grau nas novas gerações são atribuídos, provavelmente, aos fatores ambientais como o padrão atual da dieta ocidental, perda precoce de dentes decíduos, distúrbios endócrinos, lesões pré-natais, problemas respiratórios, hábitos bucais e trauma (CORRUCCINI 1984, CORRUCCINI et al. 1990, LAOR et al. 1993).

HELM (1979) comparou as características oclusais de amostras de duas populações dinamarquesas distintas que diferiam, fundamentalmente, por seus estilos de vida e de uma população aborigenes, todas com a dentição permanente completa. O autor constatou, através da classificação proposta por BJORK e HELM (1964), que as má-formações dentais e a hipodontia poderiam ser atribuídas à genética devido a similaridade encontrada entre as populações dinamarquesas, uma oriunda dos séculos XII a XVI e outra contemporânea, enquanto que a maioria das anomalias de oclusão como overjet, relação classe II de molar, mordida profunda, mordida cruzada e apinhamento dental seriam consideradas problemas da sociedade moderna, devido a diferença significativa encontrada entre as populações estudadas.

A variação oclusal e a ocorrência de má-oclusão na população da Finlândia foi analisada através de uma amostra de maxilas e mandíbulas derivadas de populações do século XV e XVI. A comparação dos problemas oclusais encontrados nesta amostra com as características oclusais da população da Finlândia dos tempos atuais mostrou uma prevalência menor na 
amostra contemporânea, para todos os problemas oclusais encontrados, quando comparada com as do séculos XV e XVI. Classe II de Angle, mordida profunda, apinhamento dentário e mordida cruzada foram características significativamente menos presentes nas populações mais antigas. $\mathrm{O}$ autor sugeriu que a transição do tipo de dieta mais consistente para dietas de mastigação fácil é a causa mais provável do aumento na variação oclusal entre estas gerações (VARRELA 1990).

Um significativo aumento na prevalência de oclusopatias foi observado na dentição de homens austríacos contemporâneos, quando comparados com a dentição de esqueletos do século XIX provenientes de homens da mesma faixa etária e da mesma região, reforçando a tendência secular das alterações oclusais ocorridas nos últimos cem anos (WEILAND et al. 1997).

A existência de tendência secular na distribuição dos padrões oclusais foi estudada numa comunidade judaica Ashkenazi, em duas gerações diferentes de crianças. Modelos de estudo realizados de arcadas dentárias de 102 crianças entre 5 e 13 anos de idade e nascidas entre 1969 e 1970 foram comparadas com resultados de exames clinicos de 703 crianças entre 6 e 13 anos de idade, da mesma comunidade, entre 1992 e 1993, quanto a condição oclusal. Nenhuma diferença existiu entre os dois grupos quanto a relação ântero-posterior de molares e de caninos, porém uma significativa diminuição na prevalência de oclusão considerada normal foi observada, acompanhada de uma aumento de má-oclusão do tipo I segundo classificação de Angle (BRIN et al. 1998). 


\subsection{Determinantes das oclusopatias na dentição decídua}

Os vários tipos de oclusopatias encontrados na literatura estão relacionados aos fatores dento-alveolares gerais e locais, fatores esqueléticos e fatores neuro-musculares, quando não da interação entre ambos (SHAW 1993).

Os fatores dento-alveolares gerais caracterizam-se pelo tamanho dos dentes e a existência de espaço suficiente para acomodá-los, que, quando desproporcionais, provocam o mais comum dos problemas de oclusão que é a impacção dentária. Os fatores locais são atribuídos às variações no número de dentes, na forma e no seu modo de erupção (SHAW 1993).

O padrão esquelético, isto é, o tamanho dos maxilares, a relação entre o maxilar superior e o inferior e sua relação com a base do crânio, determina a localização pré-eruptiva da dentição e, após a erupção, a localização das raízes dos dentes. Conseqüentemente, as variações esqueléticas são as primeiras causas das oclusopatias entre os arcos. Se a variação esquelética excede a capacidade da compensação dento-alveolar para obter uma oclusão normal, as oclusopatias podem se estabelecer (SHAW 1993).

O esqueleto e os dentes são circundados pela musculatura oro-facial e variações neste complexo podem contribuir para a ocorrência de oclusopatias. Por exemplo, os tecidos moles que molduram a cavidade bucal, como as bochechas, os lábios e a língua podem influenciar a disposição das coroas dentárias. Estas alterações estão relacionadas, principalmente, 'as forças de pequena magnitude conhecidas como força em repouso; sendo constantes permanecem em contato com os dentes podendo provocar alterações na 
posição dentária. Por outro lado, parece que forças de grande intensidade, porém de curta duração, não alteram a posição dos dentes (SHAW 1993).

Além disso, variações no "caminho" de fechamento da mandíbula provocado por alterações locais, alteração na função respiratória e no movimento de deglutição, dentre outros fatores relacionados à função orofacial, podem levar a distorções na oclusão (SHAW 1993).

\section{Os aspectos genéticos e as oclusopatias}

Pesquisas sobre a etiologia dos problemas oclusais têm abordado, principalmente, a influência dos fatores genéticos e dos fatores ambientais como agentes causadores das oclusopatias .

VAN DER LINDEN (1966) afirmou que:

.... i interação entre os fatores genéticos e os fatores ambientais inicia-se na concepção e continua até o final da vida. Durante a vida fetal, a inter-relação entre os componentes genéticos e os fatores ambientais é limitada. Por outro lado, todos os componentes periféricos aos genes, como por exemplo o protoplasma do óvulo, podem ser considerados meio ambiente. Até a vida adulta, a interação entre os fatores genéticos e os fatores ambientais guia $e$ controla o processo de crescimento e desenvolvimento e determina as características morfológicas e a fisiológicas dos indivíduos. Porém, existe adequada evidência de que os fatores genéticos são os responsáveis pelo controle por muitas das condições desenvolvidas.... 
CORRUCCINI e POTTER (1980), questionando a inexistência de variabilidade genética entre gêmeos, compararam a oclusão dentária entre gêmeos mono e dizigotos. Os autores estimaram a variabilidade oclusal atribuída a causas genéticas/hereditárias, encontrando heterogeneidade em 20 de 40 características oclusais estudadas, evidenciando que uma série de fatores comportamentais ocultos podem estar influenciando esta variação oclusal.

Comparando 10 diferentes características oclusais em 358 pares de gêmeos mono e dizigotos, CORRUCCINI et al. (1990) verificaram uma variabilidade genética não significativa com relação a características oclusais como overbite, overjet, relação molar, mordida cruzada e mau posicionamento dentário em dentes anteriores. A hereditariedade estimada para os fatores genéticos foi baixa, enfatizando a importância da influência de fatores comportamentais na variação oclusal.

Por muitos anos, predominou o conceito de que os componentes genéticos/hereditários foram os responsáveis, em primeira instância, pelos problemas oclusais existentes nas populações. Os ortodontistas geralmente assumem que os problemas oclusais ocorrem devido a fatores genéticos, na sua maioria, baseados em estudos realizados com gêmeos mono e dizigotos. Estes estudos, apesar de apresentarem grandes diferenças quanto a metodologia, avaliam a variação oclusal e a presença de oclusopatias, comparando-as com a variação de fatores genéticos e não genéticos a que esta população esteve exposta, concluindo que gêmeos monozigotos apresentam 
maior similaridade quanto ao tamanho do arco dentário a forma de oclusão do que entre os dizigotos (DETLEFSEN 1928; BACHRACH e YOUNG 1928; LUNDSTROM 1955).

Outros estudos mostram uma chance maior de ocorrência de problemas oclusais entre familiares do que na população em geral (LITTON et al. 1970; CHUNG e NISWANDER 1975). Porém, é preciso evidenciar que membros de uma mesma familia compartilham de mesmos hábitos comportamentais, o que levaria a questionar a forte atribuição etiológica aos fatores genéticos, para o estabelecimento das oclusopatias (CORRUCCINI e POTTER 1980).

Além disso, se as questões genéticas têm papel determinante na presença das oclusopatias, então tornam-se extremamente limitadas as intervenções preventivas com relação a estes problemas. Por outro lado, se os fatores comportamentais durante a infância influenciam o desenvolvimento das arcadas dentárias e o adequado posicionamento dos dentes, então medidas de prevenção precoce podem contribuir para o estabelecimento de uma oclusão satisfatória.

\section{As condições socioeconômicas e as oclusopatias}

A determinação social de muitos problemas de saúde tem sido estudada há mais de um século. Em geral, as doenças infantis, principalmente as com poder de prevenção conhecido, distribuem-se desigualmente nas populações revelando que as condições socioeconômicas representadas pelas características domiciliares, a situação ocupacional do chefe da familia, a renda 
familiar, a escolaridade dos pais e o acesso a bens e serviços, são as principais razões para a distribuição desigual dos agravos a saúde, principalmente nos países em desenvolvimento (VICTORA et al.1996; WILKINSON 1999).

O impacto das condições socioeconômicas sobre algumas doenças bucais, como a prevalência e gravidade da cárie dentária e das periodontopatias têm sido estudado, atribuindo-se à desigualdade social a determinação destes problemas (O'BRIEN 1994; BEAL 1996; FREIRE 2000; MOYSES 2000; PATUSSI et al. 2001; PERES 2002).

A influência das condições socioeconômicas sobre as oclusopatias é objeto de investigação bastante escasso, cujos resultados não apresentaram, até hoje, respostas conclusivas.

INFANTE (1975) analisando a oclusão de 680 crianças brancas entre 2,5 e 6 anos de idade nos Estados Unidos (EUA), entre 1969 e 1970, verificou diferentes prevalências de oclusopatias conforme a situação socioeconômica da população estudada. A prevalência de relação classe 2 de molar nas meninas de baixa condição socioeconômica foi maior $(18,4 \%)$ do que a encontrada nas meninas de situação socioeconômica intermediária $(15,3 \%)$. No total da amostra estudada, observou uma maior prevalência de mordida cruzada posterior entre as crianças pertencentes ao estrato social intermediário, quando comparadas com as crianças do estrato social mais baixo.

Em Boston, EUA, o grau de educação formal dos pais de 487 crianças entre 10 e 12 anos de um subúrbio foi estudado como potencial fator de risco para as oclusopatias. As oclusopatias foram medidas através da necessidade 
de tratamento ortodôntico mencionada pelos pais sendo que, através de análise de regressão logística múltipla, os autores não observaram associação entre grau de instrução dos pais e a necessidade de tratamento ortodôntico (MEYERS e HERTZBERG 1988).

A influência do nível socioeconômico, analisado segundo tipo de escola, sobre a prevalência de oclusopatias foi estudada na cidade de Bauru, SP, em 2416 crianças entre 7 e 11 anos de idade. Após estratificação das escolas, de acordo com a sua localização geográfica, os autores verificaram que a proporção de crianças com má-oclusão do tipo I de Angle foi maior entre as do nível socioeconômico baixo do que entre as de nível socioeconômico médiobaixo. Por outro lado, nenhuma diferença foi encontrada quanto ao nível socioeconômico ao se analisar as más-oclusões do tipo classe II e III de Angle (SILVA FILHO et al. 1990).

Condições sócio-demográficas, como o tamanho da família, localização de escola, tipo de escola e ocupação dos pais não foram fatores de risco para o desenvolvimento de caracteristicas oclusais como o apinhamento e espaçamento dentário, em 1608 escolares entre 5 e 7 anos de idade em Delhi, Índia (KHARBANDA et al. 1994).

Uma amostra de 443 crianças representativa dos pré-escolares de 3 a 6 anos de idade do município de Maracaibo, Venezuela, foi definida para um estudo transversal sobre oclusopatias na dentição decídua e mista. Os autores observaram que um número maior de crianças pertencentes às escolas privadas $(64,0 \%)$ apresentaram as arcadas dentárias com espaços primatas, 
condição esta mais favorável para o desenvolvimento da oclusão permanente, do que as crianças de escolas públicas $(50,0 \%)$. Além disso, uma proporção maior de crianças com mau posicionamento dentário foi encontrada entre as crianças de escolas públicas $(78,1 \%)$ do que entre as de escolas privadas (63,9\%). A prevalência de mordida aberta anterior não foi diferente entre as crianças dos dois tipos de escola, porém $12,4 \%$ das crianças de escolas privadas apresentaram mordida cruzada posterior contra apenas $5,5 \%$ das de escolas públicas (MORON B. et al. 1995).

TOMITA (1997), estudando a oclusão da dentição decídua de 2139 crianças de 3 a 5 anos de idade na cidade de Bauru, SP, não encontrou associação estatisticamente significativa entre o nível socioeconômico e a presença de oclusopatias. O autor utilizou o tipo de escola (pública ou privada), como proxy da condição socioeconômica.

Utilizando o mesmo parâmetro de referência para a condição social, FRAZÃO (1999) corroborou os achados de TOMITA (1997) ao evidenciar que o tipo de escola, se pública ou privada, freqüentado por crianças de 5 anos de idade no município de São Paulo não influenciou a distribuição de oclusopatias moderada/severa, definidas conforme critérios da OMS (WHO 1987).

NIETO GARCIA et al. (2001) não encontraram diferenças estatisticamente significativas na prevalência de oclusopatias entre as crianças cujos pais apresentavam-se desempregados ou não, a partir de um estudo transversal realizado em Ceuta, região pertencente a Espanha e localizada no Norte da África com 347 crianças de 7, 12 e 14 anos de idade. 


\section{Características biológicas da criança}

Medidas antropométricas das crianças como o peso ao nascer, o perímetro cefálico, a relação peso/altura, dentre outras, têm sido consideradas como fatores que influenciam o desenvolvimento dos indivíduos, predispondoos às doenças na infância e na vida adulta (BARKER 1992; BARKER 1994; KUH .e BEN-SCHLOMO 1997; WADSWORTH e KUH 1997), inclusive às doenças bucais como a cárie dentária (ALVAREZ 1995; PERES 2002).

Com relação às oclusopatias existem poucos estudos e poucas evidências científicas do papel das medidas antropométricas no desenvolvimento dos problemas oclusais. Estes fatores podem estar associados a deficiências no crescimento esquelético como, por exemplo, a presença de um plano palatal inclinado, a sobreerupção dos dentes posteriores maxilares e a rotação póstero-inferior da mandíbula, que predispõem um mau posicionamento dentário. As deficiências nestas medidas podem, também, interferir no desenvolvimento cranio-facial, através da variação na intensidade de crescimento e desenvolvimento, na interferência dos tecidos moles e da musculatura da região e no desenvolvimento dento-alveolar individual, ocorridos nos primeiros anos de vida da criança (BJORK 1969; NGAN e FIELDS 1997).

\section{Características e comportamento das crianças}

Dentre os vários fatores comportamentais que podem levar ao desenvolvimento de oclusopatias estão os hábitos bucais, particularmente os hábitos de sucção não nutritiva. Estes hábitos podem variar de acordo com 
diversos fatores, dentre eles, a cultura na qual as crianças estão inseridas. Em muitos países ocidentais é comum o hábito de sucção de bico (chupeta) em até 95\% das crianças. Entretanto, em partes da Ásia e da África e em populações muito particulares como os esquimós, este comportamento pode ser raro ou mesmo desconhecido (LEVINE 1999).

O efeito confortante obtido pelos bebês e crianças através da sucção é observado pelos pais ou responsáveis pelas crianças há séculos. RAVN (1974) relatou que a referência sobre objetos de sucção aparecem na literatura médica da Alemanha desde o final do século XV e início do século XVI. WINTER (1980) lembrou a confecção de uma "bolsa de sucção" contendo leite, açúcar e pão, usada para alimentar e confortar os bebês em 1801.

O uso de bico é o hábito mais comum de sucção nas crianças, mas seu uso declina com o passar da idade, tornando-se mais raro após os 3 anos (LEVINE 1999). Porém, a persistência deste hábito tem sido associada com problemas no desenvolvimento das estruturas oro-faciais e da oclusão na dentição decídua, com uma prevalência de oclusopatias variando de $38 \%$ a 94\% (KHOLER e HOIST 1973; LARSSON 1983; ADAIR et al. 1995).

WARREN et al. (2000) identificaram, através de um estudo longitudinal realizado em lowa, EUA, que cerca de $20 \%$ das crianças nascidas entre março de 1992 e fevereiro de 1993, apresentavam o hábito de sucção não nutritiva entre os 36 e os 48 meses de idade.

O uso prolongado de bico tem sido associado a diferentes problemas oclusais. A presença de mordida aberta anterior na dentição decídua, pode 
manifestar-se como um espaço simétrico entre os arcos superior e inferior de $0,5 \mathrm{~cm}$ e está associada ao uso de bico, segundo diferentes pesquisas nacionais e internacionais (OLIVEIRA 1981; SCHLOMER 1984; DE VIS et al. 1984; CASTELANI et al. 1987; KEROSUO 1990; PAUNIO et al. 1993; ADAIR et al. 1995; FARSI e SALAMA 1997; SERRA-NEGRA et al. 1997; TOMITA 1997; KARJALAINEN et al. 1999). Outros problemas oclusais têm sido associados ao uso prolongado de bico como, por exemplo, a presença de mordida cruzada posterior (KISLING e KREBS 1976; SCHLOMER 1984; PAUNIO et al. 1993; OGAARD et al. 1994; ADAIR et al. 1995; LINDSTEN et al. 1996; SERRANEGRA et al. 1997; WAINIO et al. 2000), a presença de relação classe 2 de caninos (CASTELANI et al. 1987; ADAIR et al. 1992; ADAIR et al. 1995; WAINIO et al. 2000), a presença de classe 2 de molares (CASTELANI et al. 1987; ADAIR 1992; ADAIR et al. 1995; WAINIO et al. 2000), e o encurtamento e deformação das arcadas dentárias (BOWDEN 1966; LINDSTEN et al. 1996).

O efeito da sucção digital sobre a dentição decidua tem sido um assunto de interesse dos odontólogos, porém, poucos trabalhos têm avaliado o efeito longitudinal deste hábito bucal sobre a oclusão (POPOVIC e THOMPSON 1973). Alguns autores (NANDA et al. 1972; POPOVICH e THOMPSON 1973; MOORE 1996; LEVINE 1999) apontaram a sucção digital como responsável por problemas oclusais, porém ainda não estão bem estabelecidas como ocorre a relação causa-efeito entre as estruturas envolvidas, como a postura de lingua, a sucção e deglutição, bem como sua intensidade e freqüência, necessitando-se de mais estudos à respeito (LARSSON 1983; O'BRIEN et al. 1996). 
Alguns autores relataram que $50 \%$ das crianças com 1 ano de idade apresentam o hábito de sucção digital, porém esta proporção decresce rapidamente de 4 a 5 anos de idade (KLACKENBERG 1949; KUROSUO et al. 1978). KELLY et al. (1973) relataram uma prevalência de $10 \%$ a $15 \%$ de hábito de sucção digital até a idade escolar em Washington, EUA. Já na Arábia Saudita, apenas $6,5 \%$ das crianças mantiveram o hábito de sucção digital após os 3 anos de idade (FARSI e SALAMA 1997).

A sucção digital tem sido associada à presença de mordida aberta anterior, na maioria das vezes, através de estudos transversais (LARSSON 1978; SCHLOMER 1984; KEROSUO 1990; LARSSON 1994; FUKUTA et al. 1996; SERRA-NEGRA et al. 1997; KARJALAINEN et al. 1999), à mordida cruzada posterior (INFANTE 1976; SCHLOMER 1984; KEROSUO 1990; OGAARD et al. 1994; WAINIO et al. 2000), à presença de relação classe 2 de caninos (NANDA et al. 1973; INFANTE 1976; FUKUTA et al. 1996), à presença de relação II de molares (NANDA et al. 1972; POPPOVICH e THOMPSON 1973; INFANTE 1976; FUKUTA et al. 1996) e à outras oclusopatias como o overjet. (LARSSON 1978; NANDA et al. 1972; FUKUTA et al. 1996).

O Quadro 3 apresenta um resumo dos principais achados dos estudos que avaliaram associação entre hábitos de sucção não nutritiva e a presença de diferentes oclusopatias. Apesar de outras oclusopatias terem sido pesquisadas nos estudos apresentados, apenas aquelas que apresentaram associação estatisticamente significativa com o referido hábito foram apresentadas. 
Quadro 3: Estudos nacionais e internacionais sobre associação entre hábitos de sucção não nutritiva e oclusopatias na dentição decídua. 1972-2000.

\begin{tabular}{|c|c|c|c|c|c|c|c|}
\hline Autor (es) & País & Ano & Delineamento & $n$ & Idade & $\begin{array}{c}\text { Características/comportamento } \\
\text { (Prevalência em \%) }\end{array}$ & Tipo de Oclusopatia \\
\hline Nanda et al. & Índia & 1972 & Transversal & 2500 & 2 a 6 & Sução digital $(17,0)$ & $\begin{array}{l}\text { Overjet, classe } 2 \text { (caninos e } \\
\text { molar) }\end{array}$ \\
\hline $\begin{array}{l}\text { Popovich e } \\
\text { Thompson }\end{array}$ & Canada & 1973 & Longitudinal & 1258 & 3 a 12 & Sução digital $(30,0)$ & Classe 2 molar \\
\hline Infante & USA & 1976 & Transversal & 680 & 2,5 a 6 & Sução digital $(18,7)$ & M. cruzada, classe 2 caninos \\
\hline Kisling e Krebs & Dinamarca & 1976 & Transversal & 1624 & - & $\operatorname{Bico}(86,0)$ & M. cruzada \\
\hline $\begin{array}{l}\text { Zadik } \\
\text { et al }\end{array}$ & Israel & 1977 & Transversal & 333 & 0 a 7 & Sucção digital $(95,0)$ e bico $(69,0)$ & $N I^{*}$ \\
\hline Oliveira & Brasil & 1981 & Transversal & 790 & 3 a 5 & $\operatorname{Bico}\left(\mathrm{NI}^{*}\right)$ & M. aberta \\
\hline De Vis et al. & Bélgica & 1984 & Transversal & 510 & 3 a 6 & Bico $(45,0)$ & M. aberta \\
\hline Schlomer & Alemanha & 1984 & Transversal & 582 & 3 a 6 & Sucção digital $\left(\mathrm{NI}^{\star}\right)$ e bico $\left(\mathrm{N} I^{\star}\right)$ & M. aberta e M. cruzada \\
\hline Castelani et al. & Itália & 1987 & Transversal & 400 & 3 a 5 & $\operatorname{Bico}(67,8)$ & M. aberta e classe 2 molar \\
\hline Kerosuo & Finlândia & 1990 & Transversal & 580 & $3 a 8$ & Sução digital $(14,0)$ & M. aberta e M. cruzada \\
\hline Adair et al. & EUA & 1992 & Transversal & 79 & 2 a 5 & $\operatorname{Bico}\left(N I^{\star}\right)$ & Classe 2 molar \\
\hline
\end{tabular}

${ }^{*} \mathrm{NI}=$ NAO INFORMADO 
Continuação:

\begin{tabular}{|c|c|c|c|c|c|c|c|}
\hline Autor (es) & País & Ano & Delineamento & $n$ & Idade & $\begin{array}{c}\text { Características/comportamento } \\
\text { (Prevalência, \%) }\end{array}$ & Tipo de Oclusopatia \\
\hline Ogaard et al. & Suécia & 1994 & Transversal & 445 & 3 & Sucção digital $\left(\mathrm{NI}^{*}\right)$ e bico $\left(\mathrm{NI}{ }^{*}\right)$ & M. cruzada \\
\hline Adair et al. & EUA & 1995 & Transversal & 218 & 2 a 4 & $\operatorname{Bico}(55,0)$ & $\begin{array}{l}\text { Overjet, classe } 2 \text { molar, M. } \\
\text { aberta e M. cruzada }\end{array}$ \\
\hline Fukuta et al. & Japão & 1996 & Transversal & 930 & 3 a 5 & Sução digital $(19,8)$ & $\begin{array}{l}\text { Overjet, M. aberta, classe } 2 \\
\text { molar }\end{array}$ \\
\hline Lindsten et al. & Noruega & 1996 & Transversal & 40 & 3 & $\operatorname{Bico}\left(\mathrm{NI}^{*}\right)$ & $\begin{array}{l}\text { Encurtamento de arco, M. } \\
\text { cruzada }\end{array}$ \\
\hline Farsi e Salama & $\begin{array}{l}\text { Arábia } \\
\text { Saudita }\end{array}$ & 1997 & Transversal & 520 & 3 a 5 & $\operatorname{Bico}(37,9)$ & M. aberta \\
\hline Tomita & Brasil & 1997 & Transversal & 618 & 3 a 5 & $\operatorname{Bico}\left(\mathrm{NI}^{*}\right)$ & M. aberta \\
\hline Serra Negra et al. & Brasil & 1997 & Transversal & 289 & 3 a 5 & Bico, Onicofagia, Sucção digital & $\begin{array}{l}\text { M. aberta, M cruzada, sobre- } \\
\text { saliência. }\end{array}$ \\
\hline Karjalainen et al & Finlândia & 1999 & Transversal & 148 & 3 & Sucção digital e bico $(20,0)$ & M. aberta \\
\hline Wainio et al. & Finlândia & 2000 & Transversal & 509 & 3 & $\operatorname{Bico}\left(\mathrm{NI}^{*}\right)$ & Classe 2 molar, M. cruzada \\
\hline
\end{tabular}

${ }^{*} \mathrm{NI}=$ NAO INFORMADO 


\section{As características maternas e as oclusopatias}

Nas últimas décadas, o aleitamento materno tem sido encorajado em todas as partes do mundo devido aos inúmeros benefícios que este ato proporciona ao crescimento e desenvolvimento das crianças. As vantagens do aleitamento materno estão relacionadas ao amadurecimento do sistema imunológico dos bebês, à menor reação alérgica das crianças aos nutrientes do leite materno, à proteção contra desnutrição, diarréia e doenças respiratórias, ao beneficio nutricional através de sua composição, ao bem estar psicológico da criança, além de substancial vantagem econômica (VICTORA et al. 1987; LEGOVIC e OSTRIC 1991; HORTA et al. 1996; GALE e MARTYN 1996, CESAR et al. 1999).

Estudos têm demonstrado que a amamentação natural promove o bom desenvolvimento dos maxilares, fortificando os músculos envolvidos no processo de sucção do leite materno. Além disso, o formato da aréola do seio materno adapta-se ao formato interno da cavidade bucal, permitindo um perfeito selamento bucal (PICARD 1959; BOSMA 1963; ESCOTT 1989; DRANE 1996).

Por outro lado, o bico artificial das mamadeiras são confeccionados com material mais rígido, o que pode "forçar" o interior da cavidade bucal provocando alterações no seu formato, deixando seqüelas permanentes no seu desenvolvimento, visto que os músculos também podem estar afetados (PICARD 1959; BOSMA 1963; DRANE 1996).

O posicionamento do lábio inferior e da língua ao apreender o seio materno, desenvolve um hábito de deglutição fisiológico, solidificando este 
padrão de deglutição na vida adulta. Na utilização da mamadeira, o fluxo de leite ocorre num volume e velocidade maior, fazendo com que a criança posicione a língua no sentido de controlar este fluxo, passando a projetá-la para frente, podendo, desta forma, desenvolver o hábito de deglutição não fisiológica ou deglutição atípica (DRANE 1996).

Nos estágios precoces de desenvolvimento, tanto a cavidade bucal como o palato são estruturas maleáveis que quando pressionados por qualquer objeto, podem ser moldadas e adquirem um formato determinado por este contato. A maior parte do crescimento e desenvolvimento destas estruturas ocorre nos primeiros 4 anos de vida da criança e $90 \%$ destas se completam aos 12 anos de idade. Sendo assim, a compressão da aréola materna junto ao palato, proporciona a "moldagem" deste, em uma forma considerada fisiológica, a forma de "U", que favorece um bom posicionamento dentário. Por outro lado, ao utilizar a mamadeira um outro tipo de padrão de palato pode se estabelecer, conhecido como formato em " $\mathrm{V}$ ', mais estreito e muito encontrado em individuos portadores de oclusopatias (MALAGOLA et al. 1986; MINCHIN 1989; DAVIS e BELL 1991; SHEPARD et al. 1991; LARSSON 1998, PALMER 1998),

LABBOK e HENDERSHOT (1987) verificaram, através de um estudo de coorte retrospectiva com 9698 indivíduos entre 3 e 17 anos de idade que, entre aqueles que foram amamentadas no seio materno num periodo de 3 meses ou menos, a prevalência de oclusopatias foi igual a $32,5 \%$, enquanto que entre as crianças cuja amamentação natural foi maior do que 12 meses, a prevalência de oclusopatias foi igual a $15,9 \%$. Crianças que utilizaram mamadeira tiveram 
1,84 vezes a chance de desenvolverem algum problema oclusal quando comparadas com aquelas amamentadas naturalmente.

KARJALAINEN et al. (1999) descreveram um dos poucos estudos que relacionou o desmame precoce com um tipo específico de oclusopatia na dentição decidua. Os tempos médios de amamentação exclusiva e total entre as crianças que apresentaram mordida cruzada posterior foram iguais a $3,6 \mathrm{e}$ 4,7 meses, respectivamente, enquanto que, entre as crianças com oclusão normal, estes períodos foram iguais a 6,1 e 7,6 meses, respectivamente, diferenças estas estatisticamente significativas.

Apesar da amamentação ter sido sugerida como um fator de proteção às oclusopatias, nem todos os estudos caminham para esta direção. MEYERS e HERTZBER (1988) encontraram uma associação significativa marginal $(p=0,058)$ entre necessidade de tratamento ortodôntico e uso de mamadeira em 737 crianças entre 10 e 12 anos de idade em Boston, EUA.

O tipo de aleitamento, natural ou artificial através de mamadeira, não teve influência no desenvolvimento de mordida cruzada posterior num estudo transversal realizado com 445 crianças suecas e norueguesas de 3 anos de idade (OGAARD et al. 1994).

WAINIO et al. (2000) não conseguiram esclarecer a relação entre o tempo de amamentação e a presença de oclusopatias na dentição decídua através de um estudo transversal realizado com 509 crianças em Turku, Finlândia. 


\section{As doenças na infância e as oclusopatias}

A cárie dentária tem sido associada à presença de oclusopatias na dentição permanente (SALZMANN 1950; ADLER 1956; AST et al. 1962; ALMEIDA et al. 1970; PERIN et al. 1997), porém a relação entre estes dois problemas não está bem estabelecida no que se refere à dentição decídua.

A perda precoce dos primeiros molares decíduos pode acarretar em deslocamento dos segundos molares decíduos no sentido mesial, porém esta situação é difícil de ser detectada quando a criança é muito jovem. Da mesma forma, se os segundos molares decíduos são perdidos antes da erupção dos primeiros molares permanentes, é muito difícil evitar o movimento no sentido mesial destes dentes, o que acarretaria numa diminuição do espaço presente. A perda precoce dos incisivos decíduos parece influenciar pouco o aparecimento de problemas oclusais, principalmente se a dentição decídua apresentar espaçamento na região anterior. Caso contrário, a presença de apinhamento dentário na região anterior, já seria um indicativo de problemas oclusais na dentição permanente (FIELDS 1991; GORDON 1996).

É a partir da dentição mista que a perda precoce dos dentes decíduos começa a provocar impacto no alinhamento satisfatório dos dentes, especialmente se a dentição decídua apresentar regiões de apinhamento. Neste caso, o apinhamento existente tende a se tornar mais evidente, inclusive na região dos dentes incisivos e também na região de erupção do primeiro molar permanente (RICHARDSON 1965; HOUSTON 1992). 
A maioria dos estudos evidencia uma menor prevalência de oclusopatias na dentição permanente em regiões que apresentam água fluoretada, devido à ação preventiva sobre a cárie dentária que esta medida promove. Uma taxa menor de prevalência de problemas oclusais em regiões com água fluoretada quando comparada às regiões sem flúor na água foi relatada por diversos pesquisadores: 9,2\% (MURRAY 1969), 9,3\% (PERIN et al. 1997), 15,3\% (ERICKSON e GRAZIANO 1966), 17,03\% (HILL et al. 1959), 23,3\% (REBELLO JUNIOR e TOLEDO 1975) e até 30\% (PLATTER 1949) entre os dois tipos de região.

Com relação a dentição decídua, VISKOVIC et al. (1990) observaram, através de um estudo transversal em 301 pré-escolares entre 3 e 6 anos de idade em Zadar, Croácia, que não houve nenhuma relação entre a prevalência e gravidade da cárie dentária e os problemas oclusais nesta população.

BEN-BASSSAT et al. (1997) encontraram diferenças estatisticamente significativas quando comparadas as prevalências de oclusopatias em grupos de crianças com $(n=234)$ e sem $(n=703)$ cárie dentária de 6 a 13 anos de idade, em uma comunidade ortodoxa judaica Askenazi. Os autores verificaram mais apinhamento dentário $(56,1 \%)$, menos espaçamento $(15,5 \%)$, mais relação assimétrica entre os primeiros molares $(44,2 \%)$ e também entre os caninos $(32,7 \%)$ no grupo de crianças com cárie dentária, quando comparadas às crianças livres de cárie $(35,5 \%, 34,3 \%, 28,9 \%, 22,1 \%$, respectivamente) .

FRAZÃO (1999) ao analisar os dados relativos as condições bucais das crianças de 5 anos de idade do município de São Paulo, encontrou uma 
prevalência igual a $21,2 \%$ de oclusopatias moderada e/ou severa, na população livre de cárie, comparada com $33,2 \%$ na população com algum ataque de cárie dentária. O risco estimado da população estudada portadora de dentição decídua e com alguma experiência de cárie apresentar oclusopatias moderadas severas, ou ambas, foi igual a $22 \%$.

Por outro lado, a presença de mordida aberta anterior, mordida cruzada posterior e má-oclusão relacionada a classificação de Angle e adaptada para a dentição decídua, não apresentaram associação estatisticamente significativa com relação a prevalência e gravidade de cárie dentária, em um estudo transversal realizado em 253 escolares de 6 anos de idade do município de Joaçaba, SC (BORTOLUZZI 2001).

Coincidente com o estudo anterior, NIETO GARCIA et al. (2001) não encontraram diferença estatisticamente significativa entre a prevalência e gravidade (ceo-d e CPO-D) da cárie dentária e a distribuição de oclusopatias em 347 escolares de Ceuta, região espanhola, de 7, 12 e 14 anos de idade.

Outros estudos avaliaram a prevalência de oclusopatias e de cárie dentária, porém sempre relacionados a outros eventos e não realizando análise entre estes desfechos (STECKSEN-BLICKS e HOLM 1995; MORÓN B et al. 1997; ANELLI e MONTARULLI 1998).

Além da cárie dentária, outros problemas de saúde na infância têm sido estudados como fatores de risco para a presença de oclusopatias. Alguns autores sugerem uma estreita relação entre respiradores bucais e crianças portadoras de doenças respiratórias e a presença de oclusopatias (LINDER- 
ARONSON 1970; BEHLFELT et al.; 1989; WOODSIDE et al. 1991). Outros estudos questionaram a afirmação que a respiração bucal causada pela obstrução aérea provoca problemas oclusais, já que as mesmas oclusopatias podem ser encontradas em crianças sem este problema (HULTCRANTZ et al. 1991).

A respiração normal é considerada aquela que se desenvolve através dos tratos nasal e naso-faringeo. Os problemas respiratórios podem ser decorrentes de obstruções nasais de origem infecciosa, alérgica ou causadas pela hipertrofia das adenóides, hipertrofia das tonsilas, desvios do septo nasal, cornetos alongados dentre outros problemas. Conseqüentemente, a respiração bucal pode se desenvolver gerando uma alteração no posicionamento da mandibula, com um aumento da altura facial anterior inferior e uma distribuição desequilibrada das forças musculares (MOYERS 1959; SCHNEIDER e PETERSON 1982; EGERMARK-ERIKSSON et al. 1990).

TOMITA (1997), ao comparar a presença de má-oclusão em escolares de 3 a 5 anos de idade de Bauru, SP, com relação a presença de doenças respiratórias, não verificou associação estatisticamente significativa entre problemas oclusais e presença de infecção respiratória e bronquite.

Significativa correlação estatística foi encontrada entre presença de máoclusão de molar do tipo classe I divisão 2 e classe II de Angle e crianças respiradoras bucais, em um estudo epidemiológico realizado em 4590 escolares de 3 a 16 anos de idade em Mangalore, Índia (SHETTY e MUNSHI 1998). 
Outros estudos analisam problemas de saúde na infância relacionados às oclusopatias, porém na relação inversa, ou seja, as oclusopatias como fator de exposição para as doenças infantis, como por exemplo a otite média, ora associando-as a presença de mordida aberta (NIEMELA et al. 1994), ora não encontrando associação significativa com a presença de problemas oclusais (WATASE et al. 1998).

\subsection{0 acúmulo de riscos durante a vida}

A partir do exposto pôde-se verificar que algumas características e comportamentos relacionados à vida da criança aparecem como possiveis fatores de risco para a presença de problemas oclusais na dentição decídua. Estes fatores referem-se às diversas circunstâncias ocorridas desde o nascimento e durante a primeira infância, sugerindo que se existisse um acúmulo de riscos, este poderia acarretar, direta ou indiretamente, o estabelecimento das oclusopatias na dentição decídua.

A teoria de acúmulo de riscos durante a vida e sua importância no período infantil é conhecida como "life course approach". Esta teoria parte da hipótese de que as doenças ou problemas de saúde crônicos nos indivíduos são decorrentes do acúmulo de riscos no curso da vida, como os riscos sociais, as doenças na infância, os fatores ambientais e o comportamento (KUH e BEMSHLOMO 1997). A exposição gradual às situações de injúrias acumulam-se através de episódios de doenças, condições ambientais e de comportamentos adversos, aumentando a chance dos indivíduos desenvolverem problemas 
crônicos no futuro. A teoria do acúmulo de riscos durante a vida procura compreender como os fatores de risco ocorridos durante a vida se interagem predispondo o desenvolvimento de problemas futuros.

Inúmeros estudos têm apontado as condições estruturais da vida, como a classe social ao nascimento do indivíduo, as condições econômicas, o tempo de freqüência na escola, a época de inserção no mercado de trabalho, como fatores que fortemente influenciaram nas condições de saúde na vida adulta (BARTLEY et al. 1997; SMITH et al. 1997; POWER e HERTZMAN 1997; POWER e MATTHEWS 1997; HART et al. 1998; POWER et al. 1998; WILKINSON 1999).

Diversas investigações evidenciaram que situações relacionadas à saúde ao nascimento, como por exemplo, o baixo peso ao nascer, poderiam ser fator de risco para problemas relacionados à pressão arterial em crianças entre 5 e 7 anos de idade (WHINCUP et al. 1989) e em jovens de 14 e 15 anos de idade (BARROS e VICTORA 1999). O impacto da desnutrição no desenvolvimento físico e intelectual na idade escolar também foi estudado e apontado como fator que interfere no desempenho escolar e no quociente de inteligência das crianças (COLOMBO et al. 1992; IVANOVIC et al. 2000).

Com relação a algumas doenças e problemas bucais, está bem estabelecida na literatura a influência dos fatores sociais e existem indícios da influência dos eventos que acometem os primórdios da infância no seus desenvolvimentos. Pesquisadores afirmam que o estilo de vida dos indivíduos não é meramente uma opção pessoal de comportamento, mas uma expressão 
das circunstâncias sociais e culturais que condicionam e constrangem tais comportamentos (SHEIHAM e WATT 2000; SHEIHAM 2000). Assim como os problemas sistêmicos de saúde, o ambiente social e as atitudes a que os indivíduos estão expostos precocemente podem determinar o desenvolvimento das doenças bucais.

Em se tratando das oclusopatias, apesar de alguns fatores e condições serem apontados como causadores destes problemas, ainda não está bem definido como a relação entre eles acontece, sugerindo um campo de pesquisa amplo para se compreender de maneira mais aprofundada o aumento da prevalência destes problemas. 
3 Hipótese 
O presente estudo parte da hipótese de que a oclusão da dentição decídua das crianças de 6 anos de idade está relacionada às condições estabelecidas nos primeiros anos de vida, como os fatores gerais de saúde, o tempo de exposição ao aleitamento materno, a introdução de hábitos bucais, a cárie dentária e problemas bucais e respiratórios crônicos; e que estas condições, por sua vez, são precedidas pelas características sociais e econômicas da vida materna como sua inserção no trabalho, o número de filhos, seu estado marital e a sua situação familiar e na sociedade; características estas influenciadas pelas condições socioeconômicas da família. A presença de oclusopatias na dentição decídua, portanto, é conseqüência do acúmulo de fatores de risco durante os primeiros anos de vida da criança. 
4 Objetivos 


\subsection{Geral}

Conhecer a prevalência das principais oclusopatias na dentição decídua e os seus determinantes do nascimento à primeira infância nas crianças de 6 anos de idade do município de Pelotas.

\subsection{Específicos}

a) estimar as prevalências de mordida aberta anterior, mordida cruzada posterior e oclusopatias de caninos;

b) verificar se existe associação entre as oclusopatias estudadas;

c) verificar se existe associação entre a presença de mordida aberta anterior e as condições socioeconômicas, o trabalho e as características maternas, as caracteristicas biológicas da criança e as condições de saúde e comportamento das crianças, utilizando modelo hierárquico de determinantes;

d) verificar se existe associação entre a presença de mordida cruzada posterior e as condições socioeconômicas, o trabalho e as características maternas, as características biológicas da criança e as condições de saúde e comportamento das crianças, utilizando modelo hierárquico de determinantes;

e) verificar se existe associação entre a presença de relação classe 2 ou 3 de caninos e as condições socioeconômicas; o trabalho e as características maternas, as características biológicas da criança e as condições de saúde e comportamento das crianças, utilizando modelo hierárquico de determinantes. 
5 Procedimentos Metodológicos 


\subsection{Local do estudo: O município de Pelotas}

Pelotas, município do estado do Rio Grande do Sul, está situado no extremo sul do Brasil, distando cerca de $250 \mathrm{Km}$ de Porto Alegre e do Arroio Chuí e fazendo, ao sul, fronteira com o Uruguai (Figura 1). Possui uma área territorial com aproximadamente $1647 \mathrm{Km}^{2}$, que abriga uma população de 323.158 habitantes, divididos em igual proporção entre homens e mulheres. Grande parte da população reside em área considerada urbana $(93,2 \%)$ e uma pequena parcela vive na área rural (IBGE 2000). A cidade é polo regional da região sul, tendo sua economia baseada na industria da alimentação e nos serviços (FACCHINI 1995). Pelotas possui um índice de alfabetização igual a 94,2\% e a situação da infância em Pelotas, segundo relatório do UNICEF, situa o município em $83^{\circ}$ no ranking do Índice de Desenvolvimento Infantil (IDI), dentre as cidades do estado do Rio Grande do Sul, e em $406^{\circ}$ dentre as cidades brasileiras, com um IDI de 0,653 (UNICEF 2001).
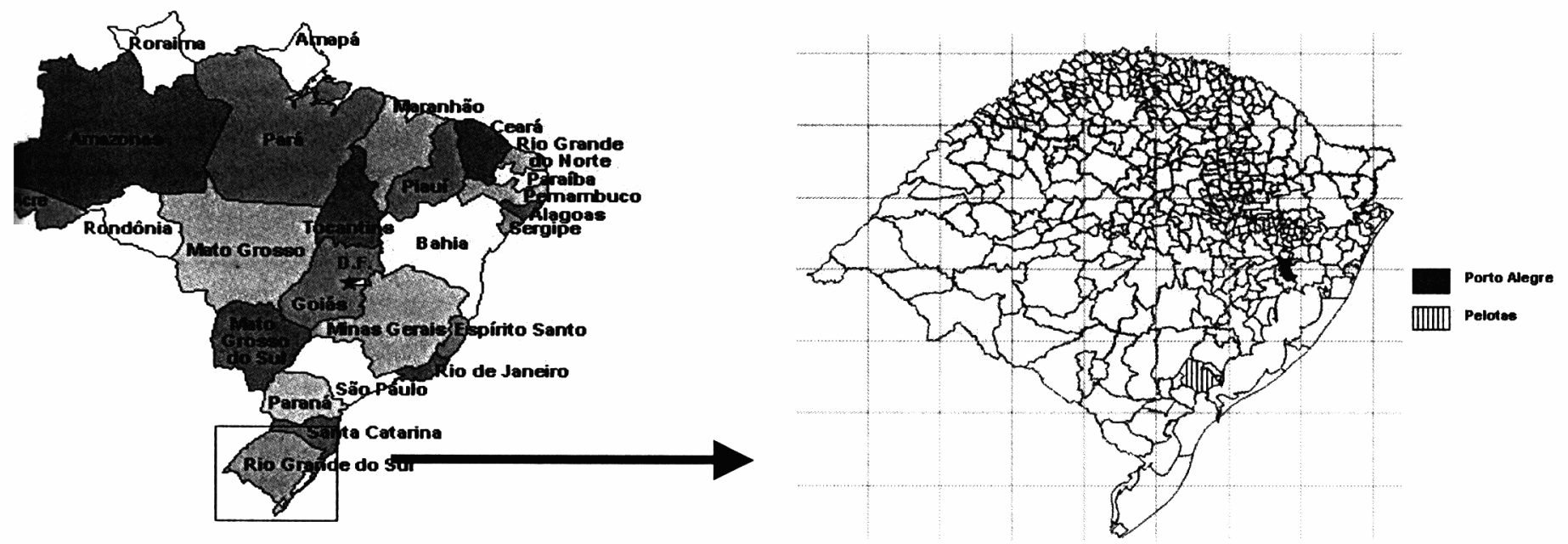

Figura 1: Localização do município de Pelotas 


\subsection{A coorte de 1993}

Em 1993 foi iniciado, na cidade de Pelotas, um estudo de coorte de nascidos vivos, cujo objetivo foi estudar a saúde perinatal e infantil das crianças (BARROS e VICTORA 1996). Cinco subprojetos constituíram este estudo: o subprojeto perinatal, o de acompanhamento das crianças, o de mortalidade infantil, o de hospitalizações e o de desenvołvimento psicomotor.

Para a realização do subprojeto perinatal, "as cinco maternidades da cidade foram visitadas diariamente de $1^{\circ}$ de janeiro a 31 de dezembro de 1993 , sendo as mães entrevistadas mediante um questionário padronizado com perguntas acerca de variáveis socioeconômicas, demográficas, reprodutivas, comportamentais, assistenciais e morbidade" (VICTORA et al. 1996). Os recém-nascidos foram pesados, medidos e examinados ao nascer pela equipe da pesquisa. Para o estabelecimento da idade gestacional foi utilizado o método de Dubowitz. As mães foram pesadas e medidas no primeiro dia após - parto pela equipe de entrevistadores que incluiu médicos residentes e estudantes de Medicina, previamente treinados (VICTORA et al. 1996).

O subprojeto de acompanhamento foi concentrado no primeiro ano de vida no qual foi estudada uma amostra sistemática de $20 \%$ dos nascidos vivos, além de todas as crianças com peso ao nascer inferior a $2500 \mathrm{~g}$. Estas crianças foram acompanhadas ao completarem 1, 3, 6 e 12 meses de idade, em seus domicilios, mediante os endereços coletados durante a entrevista hospitalar. As visitas incluiam a aplicação de um questionário e o exame antropométrico das crianças (VICTORA et al. 1996). 
"O subprojeto de morbidade hospitalar incluiu a monitorização de todas as admissões hospitalares das crianças da coorte. De janeiro de 1993 a dezembro de 1994 , os hospitais da cidade foram visitados regularmente. A causa da internação foi determinada por 2 pediatras independentes, com base nas informações do prontuário, da entrevista com as mães e, se necessário, da entrevista com o pediatra. Em caso de discordância, um terceiro árbitro emitia o parecer final após uma reunião conjunta com os 2 outros pediatras. Os diagnósticos foram codificados conforme a $9^{a}$ Revisão da Classificação Internacional de Doenças" (VICTORA et al. 1996).

O subprojeto de desenvolvimento psicomotor incluiu visitas domiciliares no ano no qual as crianças completaram 5 anos de idade. Detalhes acerca da metodologia empregada no estudo de coorte podem ser vistos em VICTORA et al. (1996).

Este estudo de coorte, somado a outro, realizado pelos mesmos pesquisadores a partir de 1982, são os dois únicos estudos de coortes de base populacional realizados no Brasil encontrando similar apenas nos estudos iniciados em 1946, 1958 e 1970 na Inglaterra (BARROS e VICTORA 1996).

\subsection{O subprojeto de saúde bucal}

Em 1999, quando as crianças da coorte completaram 6 anos de idade foi desenvolvido o Estudo de Saúde Bucal (ESB) realizado através de uma parceria entre o Centro de Pesquisa Epidemiológica da Universidade Federal de Pelotas e dois pesquisadores de Florianópolis, um deles autora desta tese. 


\subsubsection{Delineamento do Estudo de Saúde Bucal - ESB}

O ESB foi um estudo transversal inserido na coorte de nascidos vivos de 1993 em Pelotas, Rio Grande do Sul.

\subsubsection{População de estudo}

\subsubsection{A amostra}

Em 1993, nasceram vivas na cidade de Pelotas 5249 crianças. Destas, 18 crianças $(0,3 \%)$ não foram pesadas ao nascimento e foram consideradas perdas. Do total de 5231 crianças pesadas ao nascimento, $512(9,8 \%)$ nasceram com peso inferior a $2500 \mathrm{~g}$ e o restante, $4719(90,2 \%)$ crianças, nasceram com peso considerado adequado.

Para o estudo de acompanhamento infantil foi obtida uma amostra sistemática de $20 \%$ dos nascidos vivos, composta por todos os nascidos de baixo peso, totalizando 401 crianças, pois este grupo havia sido identificado como de alto risco na coorte de 1982. Além destas crianças, compuseram a amostra para o estudo de acompanhamento infantil, 963 crianças nascidas com peso adequado. Com a inclusão na amostra de todas as crianças nascidas com baixo peso tornou necessário estabelecer um fator de ponderação para todas as análises decorrentes desta amostra. Para amostra final, foram excluídas as 111 mortes infantis que ocorreram e $336(6,6 \%)$ crianças que não foram localizadas (HORTA et al. 1996). 


\subsubsection{Cálculo da sub-amostra para o Estudo de Saúde Bucal}

A partir do subprojeto de acompanhamento, obteve-se uma subamostra sistemática para o ESB. Para o cálculo do tamanho desta subamostra foi utilizada a fórmula que permite testar hipóteses de diferenças entre duas proporções populacionais (LWANGA e LEMESHOW 1991):

Hipótese:

$$
\left\{\begin{array}{l}
P_{1}-P_{2}=0 \% \\
P_{1}-P_{2} \neq 0 \%
\end{array}\right.
$$

Os parâmetros utilizados para cada desfecho estudado estão relacionados no Quadro 4 e foram definidos baseados no estudo de Tomita (TOMITA 1997). 
Quadro 4: Parâmetros utilizados para o cálculo da amostra e tamanho da amostra (n) resultante considerando-se os desfechos estudados separadamente.

\begin{tabular}{|l|cc|}
\hline \multicolumn{1}{|c|}{ Desfecho } & Parâmetros & $\boldsymbol{p}$ \\
& $\mathrm{P}=30 \%$ & 329 \\
& $\mathrm{P}_{1}=35 \%$ & \\
& $\mathrm{P}_{2}=25 \%$ & \\
& $\alpha=5 \%$ & 141 \\
& $1-\beta=20 \%$ & \\
\hline Mordida Cruzada Posterior & $\mathrm{P}=10 \%$ & \\
& $\mathrm{P}_{1}=15 \%$ & \\
& $\mathrm{P}_{2}=5 \%$ & \\
& $\alpha=5 \%$ & \\
\hline Relação de caninos & $1-\beta=80 \%$ & \\
classe 2 e 3 & $\mathrm{P}=20 \%$ & \\
& $\mathrm{P}_{1}=25 \%$ & \\
& $\mathrm{P}_{2}=15 \%$ & \\
& $\alpha=5 \%$ & \\
& $1-\beta=80 \%$ & \\
\hline
\end{tabular}

Considerando-se eventuais perdas, foram acrescidas 33 crianças, o que totalizaria um número de 362 indivíduos. Como o ESB pesquisou outros problemas bucais como a cárie dentária e a presença de lesões em tecidos moles, o número final foi definido pelo maior tamanho da amostra obtido a partir dos desfechos calculados separadamente, ficando o tamanho final da amostra igual a 400 crianças.

No estudo de saúde bucal ocorreram 41 perdas $(10,3 \%)$ devido a três recusas e a 38 pessoas não localizadas em virtude de mudança para outro município, ficando, portanto, o tamanho da amostra final igual a 359 crianças. 
Quando se realiza a distribuição de freqüência da variável peso ao nascer observa-se que $28,7 \%$ (103) das 359 crianças efetivamente estudadas no ESB apresentam baixo peso. Entretanto, sabe-se que a verdadeira proporção de crianças de baixo peso ao nascer entre as crianças nascidas em 1993 foi de 9,8\% (HORTA et al. 1996). Sendo assim ao se dividir a verdadeira proporção $(9,8 \%)$ pela encontrada nas 359 crianças $(28,7 \%)$ encontra-se um fator de ponderação de 0,341463 . Da mesma forma, ao dividir a verdadeira proporção de crianças nascidas com peso adequado $(90,2 \%)$ pela proporção encontrada nas 359 crianças $(71,3 \%)$ encontra-se o fator de ponderação para as crianças nascidas com peso adequado igual a 1,265077. A descrição do cálculo do fator de ponderação encontra-se na Tabela 1.

Tabela 1: Cálculo do fator de ponderação da amostra para o estudo de saúde bucal. Pelotas, 1999.

\begin{tabular}{|c|c|c|c|c|c|c|c|c|}
\hline \multirow[t]{2}{*}{ Variável } & \multicolumn{2}{|c|}{$\begin{array}{l}\text { Coorte } \\
\text { Original }\end{array}$} & \multicolumn{2}{|c|}{$\begin{array}{l}\text { Estudo de } \\
\text { Acompanhamento }\end{array}$} & \multicolumn{2}{|c|}{$\begin{array}{l}\text { Amostra } \\
\text { ESB }\end{array}$} & \multirow[t]{2}{*}{ Cálculo } & \multirow[t]{2}{*}{$\begin{array}{l}\text { Fator de } \\
\text { Ponderação }\end{array}$} \\
\hline & $n$ & $\%$ & $n$ & $\%$ & $n$ & $\%$ & & \\
\hline $\mathrm{BPN}^{*}$ & 512 & 9,8 & 403 & 29,5 & 103 & 28,7 & $9,8 / 28,7=$ & 0,341 \\
\hline$P A^{\star \star}$ & 4719 & 90,2 & 961 & 70,5 & 256 & 71,3 & $90,2 / 71,3=$ & 1,265 \\
\hline Total & 5231 & 100,0 & 1364 & 100,0 & 359 & 700,0 & & \\
\hline
\end{tabular}

*BPN: Baixo peso ao nascer; **AA: Peso adequado

Estes fatores de ponderação foram aplicados para todas as análises realizadas. 


\subsubsection{Análise das perdas}

Na Tabela 2 encontra-se a distribuição de algumas variáveis importantes como renda familiar, sexo da criança, peso ao nascer e duração da amamentação no grupo efetivamente estudado (amostra) e no grupo constituído pelas perdas. Pode-se verificar que não houve diferenças estatisticamente significativas entre os dois grupos, mostrando que as perdas ocorreram aleatoriamente e, portanto, não interferiram nos resultados.

Tabela 2: Teste de associação entre a amostra estudada e as perdas do estudo.

\begin{tabular}{lllllll}
\hline Variável & \multicolumn{2}{c}{ Amostra } & \multicolumn{2}{c}{ Perdas } & $\chi^{2}$ & $\mathrm{p}$ \\
& $\mathrm{n}$ & $(\%)$ & $\mathrm{n}$ & $(\%)$ & \\
\hline Sexo & & & & & 0,87 & 0,352 \\
Masculino & 190 & $(52,9)$ & 18 & $(43,9)$ & & \\
Feminino & 169 & $(47,1)$ & 23 & $(56,1)$ & & \\
Renda familiar (SM*) & & & & & 5,83 & 0,213 \\
$>10,0$ & 20 & $(5,6)$ & 6 & $(14,6)$ & & \\
$6,1-10,0$ & 28 & $(7,8)$ & 2 & $(4,9)$ & & \\
$3,1-6,0$ & 86 & $(24,0)$ & 9 & $(22,0)$ & & \\
$1,1-3,0$ & 161 & $(44,8)$ & 19 & $(46,3)$ & & \\
$\leq 1,0$ & 64 & $(17,8)$ & 5 & $(12,2)$ & & \\
Amamentação (meses) & 78 & $(21,7)$ & 10 & $(24,4)$ & & \\
9 ou mais & 78 & $(21,7)$ & 9 & $(22,0)$ & & \\
$4-8,9$ & 130 & $(36,2)$ & 16 & $(39,0)$ & & \\
$1-3,9$ & 71 & $(19,8)$ & 6 & $(4,6)$ & & \\
$<1$ & & & & & 0,30 & 0,585 \\
Peso nascer & 256 & $(71,3)$ & 27 & $(65,9)$ & & \\
Adequado & 103 & $(28,7)$ & 14 & $(34,1)$ & & \\
Baixo & & & & & & \\
\hline
\end{tabular}

* SM= salário mínimo 


\subsection{METODOLOGIA}

Inicialmente, o projeto foi submetido e aprovado pelo Comitê de Ética da Universidade Federal de Pelotas. Uma vez definida a amostra e selecionadas as crianças, o primeiro passo foi localizar seus responsáveis para obter autorização para a realização do ESB. Este contato foi realizado pela equipe de apoio do estudo da coorte de 1993, que possuía as informações necessárias para a localização das crianças. Num primeiro momento, a tentativa de localizá-las foi feita pelo telefone e, quando frustrada, diretamente no endereço informado na ficha arquivada de cada uma delas. Neste contato foi solicitada a autorização para visita domiciliar pela equipe de pesquisa do ESB, informando aos pais ou responsáveis, os objetivos do presente estudo e solicitando o consentimento para a entrevista e realização dos exames.

Uma vez obtida a autorização, as crianças foram visitadas no período de dezembro de 1998 a junho de 1999 período quando foram obtidas informações clínicas e não clínicas de interesse do estudo. Cada um dos domicílios onde a criança, a mãe ou responsável, ou ambas, não se encontravam, foi revisitado até quatro vezes antes do mesmo ser considerado como perda, incluindo pelo menos uma visita noturna e uma nos finais de semana. 


\subsubsection{Coleta de dados não clínicos.}

Parte das informações não clínicas utilizadas foram obtidas do período do nascimento das crianças, do primeiro, terceiro, sexto e décimo segundo meses de vida e aos 5 anos de idade. Para isto utilizou-se o banco de dados já existente da pesquisa realizada por VICTORA et al. (1996).

Além disso, foi construído um instrumento de coleta de dados em forma de um questionário estruturado, com o objetivo de obter informações a respeito dos hábitos alimentares e hábitos de sucção da criança. Este questionário foi aplicado juntamente com o exame clínico durante a visita domiciliar (Anexo 1). O questionário foi pré-testado por um dos examinadores da equipe, antes da realização do ESB.

\subsubsection{Coleta de dados clínicos}

Os dados clínicos sobre a saúde bucal das crianças foram obtidos durante a visita domiciliar e anotados em ficha clínica epidemiológica elaborada especificamente para esta pesquisa (Anexo 2).

Previamente à coleta de dados foi realizada a calibração dos examinadores e dos entrevistadores entre dezembro de 1998 e maio de 1999 seguindo metodologia descrita por PERES et al. (2001) adotando-se como examinador padrão um dos participantes do ESB.

Os objetivos da calibração são assegurar a uniformidade, a compreensão e a aplicação dos critérios das condições sob investigação. Além disso objetiva assegurar que cada examinador possa diagnosticar consistentemente com o padrão adotado. A calibração é obtida através da 
execução de exames repetidos de um mesmo grupo de pessoas por vários examinadores (no caso cirurgiões-dentistas) (WHO 1993).

Em uma primeira etapa, apresentou-se `a equipe de campo os objetivos e características do estudo e discutiram-se os critérios e índices utilizados.

Num segundo momento (2 dias ou $16 \mathrm{~h}$ ) realizou-se a parte prática do estudo, selecionando-se previamente 6 crianças nascidas em 1993 e matriculadas em uma creche municipal da cidade de Pelotas, para participar de um exercício clínico. Os critérios para a seleção das crianças foram a presença das condições bucais a serem encontradas no estudo propriamente dito. As crianças foram examinadas pelos três examinadores ocorrendo, em seguida, a comparação e discussão dos resultados. Uma segunda rodada de exames com as mesmas crianças examinadas foi realizada, a fim de obter-se a fixação dos critérios e elucidarem-se as dúvidas ainda persistentes.

Finalmente, foi efetuada a calibração propriamente dita, onde 16 crianças nascidas em 1993 foram examinadas, independentemente pelos três examinadores, sem nenhum tipo de comunicação entre eles.

Foi utilizado o teste Kappa (LANDIS e KOCH 1977), para medir a reprodutibilidade diagnóstica dos examinadores, realizada para cada tipo de oclusopatia estudada. Na primeira calibração (dezembro de 1998) o menor valor obtido foi 0,57 para tipo de oclusão entre os caninos decíduos do lado direito e na segunda calibração (maio de 1999) igual a 0,63 para a condição tipo de oclusão entre os caninos decíduos do lado esquerdo, sendo que a maioria dos valores obtidos para as oclusopatias examinadas foi igual a 1,0. 


\subsubsection{Critérios de diagnóstico das oclusopatias}

Adotaram-se os critérios propostos por Foster e Hamilton (1969) para diagnóstico de oclusopatias na dentição decídua e que encontram-se em anexo (Anexo 3).

\subsubsection{Estudo Piloto}

Um estudo piloto foi realizado para adequar as possíveis situações que pudessem ocorrer durante a coleta de dados propriamente dita. Um examinador da equipe realizou o estudo piloto, visitando 40 domicilios do município de Pelotas, onde o questionário foi pré-testado e exames foram realizados para verificação da rotina. Foram realizados pequenos ajustes no questionário para melhor compreensão das perguntas e o tempo total da visita domiciliar foi estimado em $30 \mathrm{~min}$.

\subsubsection{Exame odontológico propriamente dito}

Os exames odontológicos foram realizados por três entrevistadores e três examinadores. Foram formados três pares compostos por um examinador e um anotador cada, que ao chegarem nas regiões de realização da coleta de dados, separavam-se para garantir os exames de todas as crianças.

Os exames foram realizados sob luz artificial (auxilio de lanterna portátil), no domicílio da criança, preferencialmente em espaço aberto com o examinador e o(a) examinado(a) sentados.

Foram utilizados espelhos clínicos planos, espátulas de madeira para afastamento dos tecidos moles e sondas clínicas para remoção dos eventuais 
detritos. Primeiramente foi aplicado o questionário e, em seguida, realizado o exame odontológico.

\subsubsection{Variáveis em estudo}

\subsubsection{Variáveis dependentes}

As variáveis dependentes foram a presença das seguintes oclusopatias, diagnosticadas segundo os critérios adotados (FOSTER \& HAMILTON; 1969):

a) mordida aberta anterior: sim/não

$Y=0$, presença de mordida aberta

$Y=1$, ausência de mordida aberta

b) mordida cruzada posterior: sim/não

$Y=0$, presença de mordida cruzada

$Y=1$, ausência de mordida cruzada

c) relação de caninos: Classe I/ Classe II ou III

$Y=0$, presença de Classe 1

$Y=1$, presença de Classe 2 ou 3

Através destas variáveis dependentes, pesquisou-se os fatores de risco para os três tipos oclusopatias separadamente. 


\subsubsection{Variáveis independentes}

\section{Condições socioeconômicas}

a) classe social do principal responsável pelo sustento familiar no momento do nascimento da criança: esta classificação foi obtida através das informações sobre a renda aferida, escolaridade, inserção no trabalho (propriedade ou não dos meios de produção) e, se empregador, o número de empregados. A forma de operacionalizar este conceito foi descrita por LOMBARDI et al. (1988). Apuradas estas informações, as famílias foram classificadas em:

- burguesia: proprietários de meios de produção que empregam força de trabalho assalariada. São exemplos os proprietários de estabelecimentos industriais ou comerciais.

- nova pequena burguesia: pessoas que ocupam postos gerenciais, de alto nivel técnico e de tomada de decisões, exercendo funções próprias do capital como, por exemplo, administradores assalariados (diretores e gerentes), professores universitários, médicos, cirurgiões-dentistas e outros profissionais liberais.

- pequena burguesia tradicional: é composta por aqueles que dispõem dos próprios meios de produção e baseia-se na mão de obra familiar, tais como proprietários de estabelecimentos de pequeno porte e profissionais autônomos como eletricistas e encanadores.

- proletariado típico: são pessoas que vivem exclusivamente da venda de sua força de trabalho, desempenhando atividades ligadas diretamente a 
produção e o transporte de mercadorias, como os trabalhadores de manutenção de maquinário, mineiros, metalúrgicos e operadores de máquinas.

- proletariado não típico: os membros desta fração de classe vivem exclusivamente da venda de sua força de trabalho, porém não têm vínculos diretos com a produção. Compõem esta fração de classe, por exemplo, os bancários, funcionários públicos e trabalhadores em escritórios.

- subproletariado: inclui todos os agentes sociais que desempenham atividade predominantemente não assalariada, em geral instável, com a qual obtém rendimentos inferiores aos custos mínimos de reprodução da força de trabalho. Tem-se como exemplo as empregadas domésticas, os serventes da construção civil e os "biscateiros";

b) renda familiar ao nascimento da criança: constituída pela soma dos salários ou aposentadoria de todas as pessoas que habitam a casa onde mora a criança pesquisada convertida em salários mínimos vigentes;

c) escolaridade do pai e escolaridade da mãe ao nascimento da criança: anos de estudos concluídos na escola. Se, por exemplo, a mãe cursou metade da $4^{\mathrm{a}}$ série do $1^{\circ}$ grau, foram registrados 3 anos de escolaridade; d) estado marital da mãe: perguntado à mãe após o parto, se ela vivia com o marido ou companheiro. 


\section{Caracteristicas do trabalho da mãe}

a) trabalho da mãe durante a gravidez: número de meses que a mãe trabalhou durante a gravidez;

b) trabalho da mãe aos 12 meses de idade da criança: situação de trabalho da mãe (se trabalhando ou não) quando a criança tinha 12 meses de idade;

c) trabalho da mãe no $5^{\circ}$ ano de vida da criança: situação de trabalho da mãe e número de meses trabalhados nos últimos 12 meses anteriores aos 4 anos da criança;

d) Trabalho doméstico: perguntado à mãe da criança que tipo de trabalho em casa ela realizou após o parto;

\section{Comportamento e características da mãe}

a) altura da mãe: medida após o parto em centímetros;

b) índice de massa corporal da mãe (IMC) no início da gravidez: peso $(\mathrm{Kg})$ dividido pela altura da mãe $\left(\mathrm{m}^{2}\right)$. Utilizou-se nesta pesquisa os pontos de corte recomendados pela Organização Mundial da Saúde (OMS 1995), a saber: baixo peso $\left(<18,5 \mathrm{Kg} / \mathrm{m}^{2}\right.$ ), peso normal (de 18,5 $\mathrm{Kg} / \mathrm{m}^{2}$ a menos de $\left.25,0 \mathrm{Kg} / \mathrm{m}^{2}\right)$ e sobrepeso/obeso $\left(25,0 \mathrm{Kg} / \mathrm{m}^{2}\right.$ ou mais);

c) fumo na gestação: sim ou não;

d) primiparidade: se a criança pesquisada era ou não o primeiro filho;

e) Número de filhos: número filhos após o parto, nascidos vivos ou mortos (incluindo o recém-nascido) 
f) Intervalo interpartal: tempo decorrido entre os dois últimos partos;

g) Idade da mãe: idade da mãe em anos completos ao nascimento da criança;

h) Tempo de amamentação no peito (aos 12 meses): menos de um mês, de 1 a 3,9 meses, de 4 a 8,9 meses e 9 meses e mais. Considerado o período em que a amamentação no peito foi predominante, ou seja, a criança mamava todos os dias, mesmo alimentando-se de outra forma também;

i) Intenção da mãe em oferecer bico (chupeta): perguntado à mãe da criança logo após o parto se ela tinha intenção de oferecer bico à criança.

Sexo, crescimento e desenvolvimento infantil

a) sexo da criança;

b) peso ao nascer: adequado $(2500 \mathrm{~g}$ ou mais) ou baixo (abaixo de 2500g);

c) perímetro cefálico: medida do perímetro que passa pela protuberância occipital externa, pavilhão auricular e lida na linha média da região frontal do recém-nascido;

d) idade gestacional: medida através do método de Dubowitz, sendo considerado adequado com 37 semanas ou mais e inadequado com menos do que 37 semanas; 
Cuidado com a criança e hábitos relativos à saúde bucal

a) início de uso de bico: nunca usou, iniciou antes dos 3 meses, iniciou entre 3 e 6 meses ou após os 6 meses de vida;

b) usava bico aos 12 meses e aos 5 anos de idade : sim ou não;

c) usava bico entre os 12 meses e 5 anos de idade: não usava ou usava parcialmente e usava o tempo todo;

d) usava bico: sim ou não;

e) freqüência à creche aos 6 e 12 meses e $5^{\circ}$ ano de vida: sim ou não;

f) responsável pelo cuidado da criança: mãe elou pai ou outras pessoas;

g) presença de dentes comprometidos pela cárie dentária: indice ceo$d=0$ ou ceo- $d \geq 1$;

h) gravidade da cárie dentária: indice ceo-d $\leq 3$ ou ceo $>3$;

i) presença de dentes perdidos ou com cárie: Componente " $\mathrm{C}$ "+ componente " $e$ " do indice ceo-d $(c+e=0$ ou $c+e \geq 1)$;

j) sucção digital: sucção de dedo (sim ou não) perguntado aos 6 anos de idade;

k) uso de mamadeira ao nascimento e aos 5 anos de idade: sim ou não;

I) problema com nariz entupido e canseira ou falta de ar aos 12 meses de idade: sim ou não; 
m) dormir na mesma cama ou quarto que a mãe e o pai aos 12 meses de idade da criança: sim ou não.

\subsubsection{Digitação dos dados}

Os dados foram digitados por profissional experiente no programa Epiinfo versão 6.04 (DEAN et al. 1994) e posteriormente exportados para o programa SPSS para Windows versão 10.0 (NIE et al. 1975).

\subsubsection{Análise dos dados}

Para a determinação das proporções relativas às variáveis dependentes e independentes na amostra, foi usado um fator de ponderação igual a 1,265077 para as crianças nascidas com peso adequado e de 0,341463 para as crianças com baixo peso ao nascer, conforme demonstrado na Tabela 1. Isto possibilitou a recomposição da amostra de acordo com as características da população de origem, permitindo a inferência dos resultados para a coorte de nascidos vivos.

Após o ajuste pelos fatores de ponderação, o primeiro passo para a análise dos dados foi a realização da distribuição de freqüências dos elementos da coorte com cada variável estudada permitindo, assim, a caracterização da população.

Foram calculados os testes de associação pelo qui-quadrado com correção de Yates para avaliar o relacionamento entre cada variável 
dependente e as variáveis independentes, estimando-se as razões de chance (odds ratio) e respectivos intervalos de confiança.

A seguir foi feita a análise dos fatores de risco utilizando modelos de regressão logística não condicional univariados e múltiplos.

$\mathrm{Na}$ análise dos fatores de risco para a presença de mordida aberta e de mordida cruzada, utilizou-se o modelo hierárquico à semelhança do proposto por FUCHS et al. (1996) e por VICTORA et al. (1997b) (Figura 2). Para o desfecho relação de caninos não foi possível utilizar o modelo hierárquico, devido ao pequeno número de variáveis com significância estatística nos diferentes blocos, optando-se, portanto, pelo modelo logístico múltiplo sem hierarquia dos blocos. 


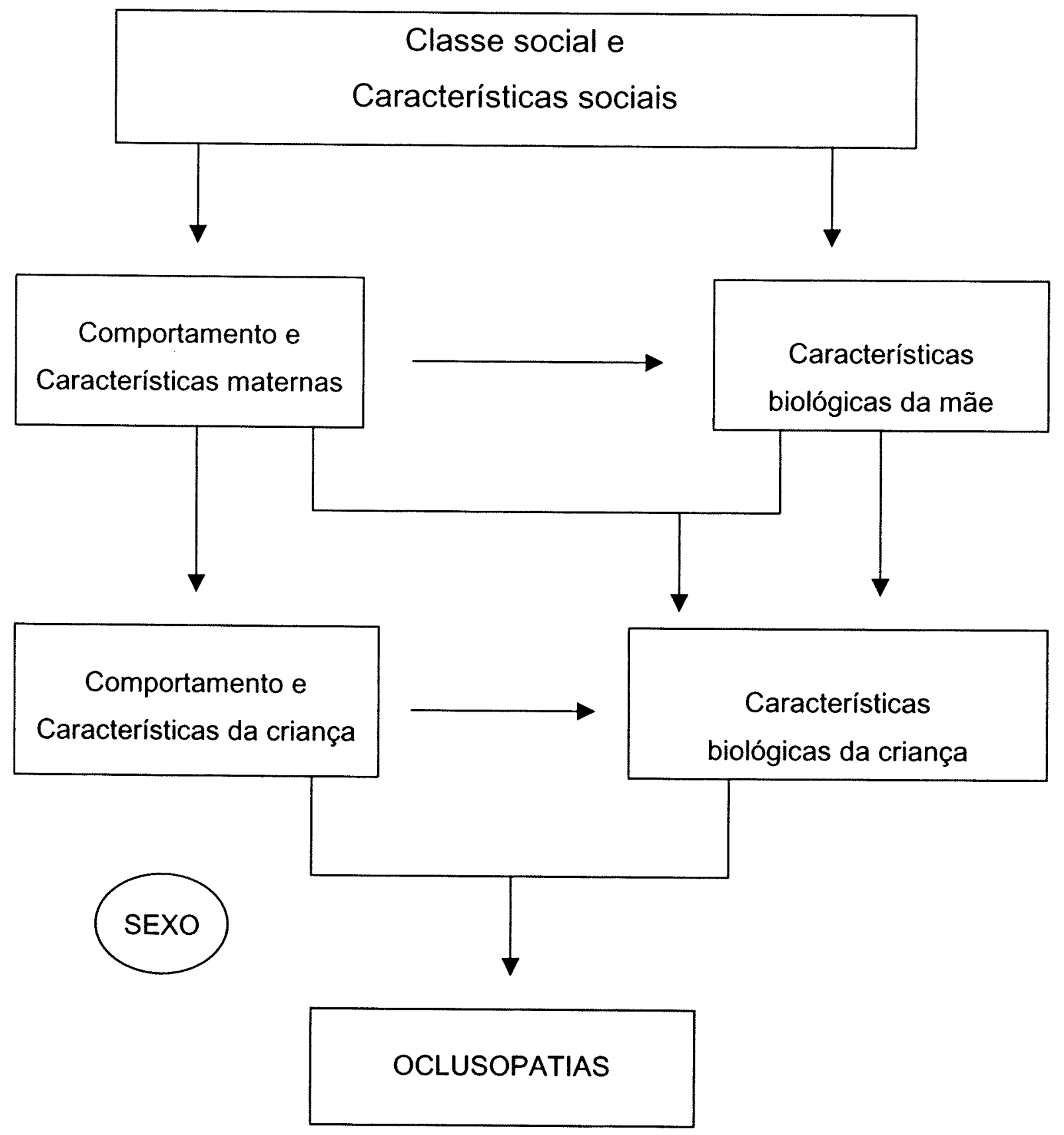

Figura 2: Modelo hierárquico teórico para as oc/usopatias 
No modelo proposto constituíram-se nos determinantes distais as variáveis que compuseram o bloco socioeconômico. Estas condicionaram os demais blocos de fatores de risco: caracteristicas biológicas e comportamentais da mãe, crescimento e desenvolvimento infantil (determinantes intermediários) e hábitos e cuidados com a criança (determinantes proximais).

As variáveis com nivel de significância menor do que 0,20 observados na análise univariada, entraram na análise de regressão logística múltipla (HOSMER e LEMESHOW 1989) dentro de cada bloco de variáveis. Utilizou-se o procedimento passo a passo para a modelagem estatistica (stepwise forward selection), ou seja, iniciou-se o modelo pela variável com maior significância estatística na análise univariada, e, a seguir, foram acrescentadas as outras variáveis, uma a uma, por ordem decrescente de significância estatistica. A nova variável foi mantida no modelo múltiplo caso fosse estatisticamente significativa $(p<0,05)$, fosse variável de confusão, ou ambas as situações.

A variável sexo foi utilizada para controle independentemente da significância estatística.

Foram selecionadas para comporem a análise de regressão logística hierarquizada (modelo final), as variáveis de cada bloco que permaneceram com significância estatística $(p<0,05)$ quando da análise de regressão múltipla interna a cada bloco. No modelo hierárquico, as variáveis do bloco socioeconômico foram as primeiras a serem incluídas e permaneceram como fatores de ajuste para os blocos hierarquicamente inferiores. O mesmo acontecendo com as variáveis dos blocos seguintes. 
Para avaliar o ajuste do modelo final foi utilizado o teste de Hosmer e Lemeshow (HOSMER e LEMESHOW 1989). Neste teste quanto mais próximo de 1 for o valor no nível descritivo, melhor o ajuste do modelo.

\subsubsection{Questões éticas}

Foi solicitado a cada um dos pais ou responsáveis pelas crianças consentimento para a realização da pesquisa e o protocolo da pesquisa foi aprovado pelo Comitê de Ética da Universidade Federal de Pelotas.

O diagnóstico das oclusopatias foi realizado através de exame visual, utilizando-se o auxílio de espátulas de madeira descartáveis.

As crianças que apresentaram algum tipo de problema oclusal foram encaminhadas para a clínica odontológica da Faculdade de Odontologia da Universidade Federal de Pelotas.

\subsubsection{Artigo cientifico}

O esboço de um dos artigos cientificos resultantes desta teste encontrase em anexo ( Anexo 5). 
6 Resultados 
Este capitulo inicia-se com a parte descritiva da coorte de crianças nascidas em Pelotas, 1993, apresentando os resultados da distribuição de freqüência das variáveis de interesse do estudo, a partir das porcentagens ponderadas. Em seguida, as variáveis de desfecho mordida aberta anterior, mordida cruzada posterior e oclusopatia de caninos foram analisadas separadamente, apresentando-se os resultados das associações, sempre ponderadas, entre cada desfecho e as caracteristicas familiares, as maternas e as da criança.

\section{1 Caracterização da amostra}

\section{Condições socioeconômicas familiares}

$\mathrm{Na}$ Tabela 3 observa-se que o maior grupo de crianças concentrou-se na classe denominada de Proletariado Não Típico $(39,3 \%)$ e pouco menos da metade das famílias apresentaram um rendimento familiar mensal entre 1,1 a 3 salários minimos (44,6\%). Por outro lado, apenas $6,5 \%$ das famílias tinham uma renda familiar mensal maior ou igual a 10 salários mínimos. Ao nascimento da criança, $90,5 \%$ das mães tinham marido ou companheiro. 
Tabela 3: Distribuição da amostra (número, \% e porcentagem ponderada), segundo classe social, renda familiar e estado marital da mãe ao nascimento da criança. Pelotas, 1999.

\section{Classe Social}

Burguesia

Nova pequena burguesia

Pequena burguesia tradicional

Proletariado não típico

Proletariado típico

Subproletariado

Ignorado

Renda familiar (SM)*

$\geq 10,0$ SM

6,1 a $10,0 \mathrm{SM}$

3,1 a 6,0 SM

1,1 a $3,0 \mathrm{SM}$

$\leq 1,0 \mathrm{SM}$

\section{Estado Marital}

Tem marido ou companheiro

Sem marido ou companheiro

Total

* SM: salários mínimos

$\begin{array}{ccc}\boldsymbol{n} & \% & \text { \% ponderada } \\ 3 & 0,8 & 1,1 \\ 16 & 4,5 & 5,4 \\ 58 & 16,2 & 17,9 \\ 137 & 38,2 & 39,3 \\ 91 & 25,3 & 23,3 \\ 30 & 8,3 & 7,5 \\ 24 & 6,7 & 5,8\end{array}$

$\begin{array}{ccc}20 & 5,6 & 6,5 \\ 28 & 7,8 & 8,3 \\ 86 & 24,0 & 23,4 \\ 161 & 44,8 & 44,6 \\ 64 & 17,8 & 17,2\end{array}$

$321 \quad 89,4 \quad 90,5$

$38 \quad 10,6 \quad 9,5$

$359 \quad 100,0 \quad 100,0$

Na Tabela 4 pode-se observar que pouco menos da metade das mães $(47,6 \%)$ e $38,8 \%$ pais completaram entre 5 e 8 anos de estudo, enquanto que em torno de $25 \%$ dos pais e mães não ultrapassaram 4 anos de estudo. 
Tabela 4: Distribuição da amostra (número, \% e porcentagem ponderada), segundo escolaridade do pai e da mãe ao nascimento da criança. Pelotas, 1999.

$\begin{array}{lccc}\text { Escolaridade da materna (anos) } & \mathbf{n} & \% & \text { \% ponderada } \\ \geq 9 & 86 & 24,0 & 27,0 \\ 5 \text { a } 8 & 170 & 47,4 & 47,6 \\ 1 \text { a } 4 & 93 & 25,8 & 22,4 \\ \text { Não estudou } & 10 & 2,8 & 3,0\end{array}$

Escolaridade paterna (anos)

$\begin{array}{lccc}\geq 9 & 93 & 25,9 & 28,4 \\ 5 \text { a } 8 & 143 & 39,8 & 38,8 \\ 1 \text { a } 4 & 90 & 25,1 & 24,2 \\ \text { Não estudou } & 6 & 1,7 & 1,9 \\ \text { Ignorado } & 27 & 7,5 & 6,7 \\ \text { Total } & \mathbf{3 5 9} & \mathbf{1 0 0 , 0} & \mathbf{1 0 0 , 0}\end{array}$

\section{Comportamento e caracteristicas maternas}

Mais da metade das mães $(65,7 \%)$ não trabalhou logo após o nascimento da criança, sendo que esta proporção diminuiu no decorrer da vida, com $57,4 \%$ e $48,8 \%$ das mães sem atividade remunerada aos 12 meses e 5 anos de idade da criança, respectivamente (Tabela 5). 
Tabela 5: Distribuição da amostra (número, \% e porcentagem ponderada), segundo trabalho materno durante a vida da criança. Pelotas, 1999.

$\begin{array}{lccr}\text { Trabalho materno após o nascimento } & \boldsymbol{n} & \text { \% } & \text { \% ponde } \\ \text { Sim } & 117 & 32,6 & 34,3 \\ \text { Não } & 242 & 67,4 & 65,7 \\ \text { Trabalho materno aos 12 meses } & & & \\ \text { Sim } & 145 & 40,4 & 42,6 \\ \text { Não } & 214 & 59,6 & 57,4\end{array}$

Trabalho materno aos 5 anos

Sim, durante o ano todo

$79 \quad 22,0 \quad 23,7$

Sim, parcialmente durante $o$ ano

$95 \quad 26,5 \quad 26,8$

Não trabalhou

183

50,9

48,8

Ignorado

2

0,6

0,7

Quem faz o trabalho doméstico (nascimento)

Outras pessoas

160

44,6

45,1

Mãe

199

55,4

54,9

Total

$359 \quad 100,0$

100,0

Apenas $29,2 \%$ das mães fumavam durante gestação (Tabela 6 ). Do total, $34,1 \%$ das mães não tinham tido outros filhos e a grande maioria $(82,1 \%)$ teve menos de 3 filhos. De maneira geral, as mães eram jovens, entre 20 e 29 anos de idade $(56,9 \%)$ com apenas $3,0 \%$ delas com mais de 40 anos. Mais da metade das mães amamentou seus filhos por menos de 4 meses $(52,0 \%)$. Grande parte delas já tinha a intenção de oferecer bico artificial para o filho desde o nascimento da criança $(88,8 \%)$. 
Tabela 6: Distribuição da amostra (número \%, porcentagem ponderada), segundo comportamento e características maternas ao nascimento da criança. Pelotas, 1999.

\begin{tabular}{|c|c|c|c|}
\hline Fumo na gestação & $n$ & $\%$ & $\%$ ponderada \\
\hline Não & 241 & 67,1 & 70,8 \\
\hline Sim & 118 & 32,9 & 29,2 \\
\hline \multicolumn{4}{|l|}{ Primíparas } \\
\hline Não & 233 & 64,9 & 65,9 \\
\hline Sim & 126 & 35,1 & 34,1 \\
\hline \multicolumn{4}{|l|}{ Paridade } \\
\hline 0 & 126 & 35,1 & 34,1 \\
\hline 1 & 96 & 26,7 & 27,1 \\
\hline 2 & 76 & 21,2 & 20,9 \\
\hline 3 & 25 & 7,0 & 7,8 \\
\hline 4 & 36 & 10,0 & 10,1 \\
\hline \multicolumn{4}{|c|}{ Intervalo interpartal (meses) } \\
\hline$>18$ & 191 & 53,2 & 55,1 \\
\hline$\leq 18$ & 15 & 4,2 & 4,3 \\
\hline Ignorado & 153 & 42,6 & 40,6 \\
\hline \multicolumn{4}{|c|}{ Idade materna (anos) } \\
\hline 14 a 19 & 55 & 15,3 & 14,0 \\
\hline 20 a 29 & 203 & 56,5 & 56,9 \\
\hline 30 a 39 & 90 & 25,1 & 26,1 \\
\hline 40 a 46 & 11 & 3,1 & 3,0 \\
\hline \multicolumn{4}{|c|}{ Amamentação (meses) } \\
\hline 9,0 ou mais & 78 & 21,7 & 23,7 \\
\hline 4,0 a 8,9 & 78 & 21,7 & 23,9 \\
\hline 1,0 a 3,9 & 130 & 36,2 & 36,3 \\
\hline$<1,0$ & 71 & 19,8 & 15,7 \\
\hline Ignorado & 2 & 0,6 & 0,4 \\
\hline \multirow{2}{*}{\multicolumn{4}{|c|}{$\begin{array}{l}\text { Intenção de dar bico } \\
\text { (nascimento) }\end{array}$}} \\
\hline & & & \\
\hline Não & 28 & 7,8 & 7,3 \\
\hline $\operatorname{Sim}$ & 317 & 88,3 & 88,8 \\
\hline Ignorado & 14 & 3,9 & 3,9 \\
\hline Total & 359 & 100,0 & 100,0 \\
\hline
\end{tabular}


Características biológicas e comportamentais da criança

Pode-se observar que a distribuição das crianças apresentou-se equilibrada quanto ao sexo, a maioria delas nasceu com idade gestacional adequada $(91,0 \%)$ e com peso e perímetro cefálico adequados $(90,3 \%$ e $81,8 \%$, respectivamente) (Tabela 7 ).

Tabela 7: Distribuição da amostra (número, \%, porcentagem ponderada), segundo características biológicas da criança. Pelotas, 1999.

$\begin{array}{lccc}\text { Sexo } & \boldsymbol{n} & \% & \% \text { ponderada } \\ \text { Masculino } & 190 & 52,9 & 53,8 \\ \text { Feminino } & 169 & 47,1 & 46,2 \\ \text { Idade gestacional (semanas) } & & & \\ 37 \text { a } 42 & 295 & 82,2 & 91,0 \\ <37 & 60 & 16,7 & 8,3 \\ \text { Ignorado } & 4 & 1,1 & 0,7 \\ \text { Peso ao nascimento } & & & \\ \text { Adequado }(\geq 2500 \mathrm{~g}) & 256 & 71,3 & 90,3 \\ \text { Baixo peso (<2500 g) } & 103 & 28,7 & 9,7 \\ \text { Perímetro cefálico ao nascimento (percentil 10) } & & & \\ >10 & 245 & 68,2 & 81,8 \\ \leq 10 & 110 & 30,6 & 17,9 \\ \text { Ignorado } & 4 & 1,2 & 0,3 \\ \text { Total } & \mathbf{3 5 9} & \mathbf{1 0 0 , 0} & \mathbf{1 0 0 , 0}\end{array}$

É importante observar que a maioria das crianças iniciou o uso de bico antes dos 3 meses de idade $(76,4 \%)$ e apenas $13,6 \%$ nunca o utilizaram (Tabela 8). Aos 12 meses apenas 18,2\% não utilizara bico, passando para $8,2 \%$ a proporção de crianças aos 5 anos de idade na mesma condição. 
Destaca-se que, do total das crianças, $58,7 \%$ fizeram uso contínuo do bico entre 12 meses e 5 anos de idade.

Tabela 8: Distribuição da amostra (número, \% e porcentagem ponderada), segundo uso de bico e mamadeira. Pelotas, 1999.

$\begin{array}{lccc}\text { Inicio do uso de bico } & \boldsymbol{n} & \% & \text { \% ponderada } \\ \text { Nunca usou } & 46 & 12,8 & 13,7 \\ \text { Após } 6 \text { meses } & 04 & 1,1 & 1,4 \\ \text { Entre 3 e 6 meses } & 30 & 8,4 & 8,0 \\ \text { Antes dos 3 meses } & 276 & 76,9 & 76,4 \\ \text { Ignorado } & 3 & 0,8 & 0,5 \\ \text { Uso de bico (12 meses) } & & & \\ \text { Não } & 62 & 17,3 & 18,2 \\ \text { Sim } & 297 & 82,7 & 81,8 \\ \text { Uso de bico (5 anos) } & & & \\ \text { Não } & 29 & 8,1 & 8,2 \\ \text { Sim } & 326 & 90,8 & 91,2 \\ \text { Ignorado } & 4 & 1,1 & 0,6 \\ \text { Uso de bico entre 12 meses e 5 anos } & & & \\ \text { Não usou ou usou parcialmente } & 142 & 39,6 & 41,3 \\ \text { Usou o tempo todo } & 217 & 60,4 & 58,7 \\ \text { Total } & 359 & \mathbf{1 0 0 , 0} & \mathbf{1 0 0 , 0}\end{array}$

\section{Cuidados com a criança}

Grande parte das crianças não freqüentou creche $(94,8 \%, 94,6 \%$, $79,6 \%$ aos 6 meses, 12 meses e 5 anos de idade, respectivamente) (Tabela 9). O pai, a mãe, ou ambos foram os responsáveis pelas crianças em $84,0 \%$ dos casos aos 6 meses de vida. 
Tabela 9: Distribuição da amostra (número, \% e porcentagem ponderada), segundo cuidados durante a vida. Pelotas, 1999.

Freqüentou a creche aos 6 meses

Sim

Não

Ignorado

Freqüentou a creche aos 12 meses

Sim

Não

Freqüentou a creche aos 5 anos

Sim

Não

Quem cuida da criança (6 meses)

Mãe ou pai, ambos

Outros

Ignorado

Total

$\begin{array}{ccc}n & \% & \text { \% ponderada } \\ 17 & 4,7 & 4,7 \\ 339 & 94,5 & 94,8\end{array}$

3

0,8

0,5

$22 \quad 6,1 \quad 5,4$

337

93,9

94,6

$68 \quad 19,0 \quad 20,4$

$291 \quad 81,0 \quad 79,6$

$304 \quad 84,7 \quad 84,0$

$52 \quad 14,5 \quad 15,5$

$3 \quad 0,8 \quad 0,5$

$359 \quad 100,0 \quad 100,0$

Hábitos e problemas relacionados à cavidade bucal

Verificou-se que $37,5 \%$ das crianças estavam livres de cárie e que $63,1 \%$ apresentava três dentes ou menos cariados, perdidos ou restaurados aos 6 anos de idade (Tabela 10). Com relação à composição do índice ceo-d, 61,4\% apresentavam dentes cariados e/ou perdidos devido à cárie dentária. 
Tabela 10: Distribuição da amostra (número, \% e porcentagem ponderada), segundo problema relacionados a cavidade bucal. Pelotas, 1999.

$\begin{array}{lccc}\text { ceo-d (ataque de cárie) } & \boldsymbol{n} & \% & \% \text { ponderada } \\ \text { Zero } & 129 & 35,9 & 37,5 \\ \text { 1 a } 2 & 68 & 18,9 & 18,6 \\ 3 & 26 & 7,3 & 7,1 \\ \text { 4 e mais } & 136 & 37,9 & 36,8 \\ \text { Gravidade da cárie } & & & \\ \text { ceo-d } \leq 3 & 223 & 62,1 & 63,1 \\ \text { ceo-d > } & 136 & 37,9 & 36,9 \\ \text { Presença de dentes cariados e/ou perdidos } & & & \\ \text { Não } & 133 & 37,0 & 38,6 \\ \text { Sim } & 226 & 63,0 & 61,4 \\ \text { Total } & 359 & \mathbf{1 0 0 , 0} & \mathbf{1 0 0 , 0}\end{array}$

Ao nascimento, uma pequena proporção de crianças utilizava mamadeira $(1,5 \%)$, enquanto que aos 5 anos esta porcentagem aumentou consideravelmente $(64,9 \%)$ (Tabela 11). "Apenas $10,0 \%$ das crianças apresentavam sucção de dedo aos 6 anos de idade. 
Tabela 11: Distribuição da amostra (número, \% e porcentagem ponderada), segundo hábitos e problemas de saúde. Pelotas, 1999.

Sucção de dedo (6 anos)

Não

Sim

Uso de mamadeira ao nascimento

Não

Sim

Ignorado

Uso de mamadeira (5 anos)

Não

Sim

Nariz entupido (12 meses)

Não

Sim

Ignorado

Canseira ou falta de ar (12 meses)

Não

Sim

Ignorado

Total

$\begin{array}{ccc}n & \% & \text { \% ponderada } \\ 327 & 91,1 & 90,0 \\ 32 & 8,9 & 10,0\end{array}$

$350 \quad 97,5 \quad 98,4$

$8 \quad 2,2 \quad 1,5$

$1 \quad 0,3 \quad 0,1$

$\begin{array}{lll}123 & 32,3 & 35,1 \\ 236 & 65,7 & 64,9\end{array}$

$\begin{array}{ccc}257 & 73,2 & 71,8 \\ 94 & 26,8 & 26,2 \\ 8 & 2,2 & 2,0\end{array}$

$315 \quad 89,7 \quad 88,9$

$36 \quad 10,3 \quad 9,1$

$8 \quad 2,2 \quad 2,0$

$359 \quad 100,0 \quad 100,0$

Pode- se observar na Tabela 12 que a prevalência de oclusopatia foi igual a $59,1 \%$, enquanto que $3,3 \%$ das crianças apresentaram mordida aberta, mordida cruzada e mau posicionamento de caninos ao mesmo tempo. Cerca de metade das crianças apresentou mordida aberta $(46,3 \%)$ e apenas $18,2 \%$ e $15,2 \%$ das crianças apresentaram mordida cruzada e oclusopatia de caninos, respectivamente. 
Tabela 12: Distribuição da amostra (número, \% e porcentagem ponderada), segundo presença de mordida aberta anterior, mordida cruzada posterior e classificação da relação de caninos. Pelotas, 1999.

$\begin{array}{lccc}\text { Presença de oclusopatias } & \boldsymbol{n} & \mathbf{\%} & \text { \% ponderada } \\ \text { Nenhuma } & 143 & 39,8 & 40,9 \\ \text { Um tipo } & 147 & 40,9 & 40,5 \\ \text { Dois tipos } & 53 & 14,8 & 14,3 \\ \text { Três tipos } & 13 & 3,6 & 3,3 \\ \text { ignorado } & 3 & 0,9 & 1,0 \\ \text { Mordida aberta } & & & \\ \text { Não } & 186 & 51,8 & 53,7 \\ \text { Sim } & 173 & 48,2 & 46,3 \\ \text { Mordida cruzada } & & & \\ \text { Não } & 295 & 82,2 & 81,8 \\ \text { Sim } & 64 & 17,8 & 18,2 \\ \text { Relação de caninos } & & & \\ \text { Classe 1 } & 299 & 83,3 & 83,7 \\ \text { Classe 2 ou 3 } & 57 & 15,9 & 15,2 \\ \text { Ignorado } & 3 & 0,8 & 1,1 \\ \text { Total } & 359 & \mathbf{1 0 0 , 0} & \mathbf{1 0 0 , 0}\end{array}$




\subsection{Associação entre os desfechos}

Houve associação estatística entre presença de mordida aberta e mordida cruzada $(p=0,031)$, o mesmo ocorrendo entre a presença de mordida cruzada e posicionamento de caninos classe 2 ou $3 \quad(p<0001)$ (Tabela 13).

Tabela 13: Distribuição da amostra, segundo oclusopatias estudadas (porcentagem ponderada). Pelotas, 1999.

\begin{tabular}{|c|c|c|c|c|c|}
\hline \multirow[t]{2}{*}{ Variável } & \multirow[t]{2}{*}{$\boldsymbol{n}$} & \multicolumn{2}{|c|}{ Mordida aberta } & \multirow[t]{2}{*}{$O R\left[I C_{95 \%}(O R)\right]$} & \multirow[t]{2}{*}{$p^{*}$} \\
\hline & & $\begin{array}{l}\text { Não } \\
\% p^{*}\end{array}$ & $\operatorname{Sim}_{\% p^{*}}$ & & \\
\hline Mordida Cruzada & & & & & 0,031 \\
\hline Não & 295 & 56,3 & 43,7 & 1,0 & \\
\hline Sim & 64 & 41,5 & 58,5 & $1,9[1,1 ; 3,1]$ & \\
\hline Relação de caninos & & & & & 0,220 \\
\hline Classe I & 299 & 55,3 & 44,7 & 1,0 & \\
\hline Classe II ou III & 57 & 46,3 & 53,7 & $1,4[0,8 ; 2,6]$ & \\
\hline Variável & & $\begin{array}{r}\text { Mordi } \\
\text { Não } \\
\% \text { p }^{*}\end{array}$ & $\begin{array}{c}\text { uzada } \\
\text { Sim } \\
\% p^{*}\end{array}$ & $O R\left[I C_{95 \%}(O R)\right]$ & $p^{*}$ \\
\hline Relação de caninos & & & & & $<0,001$ \\
\hline Classe 1 & 299 & 84,7 & 15,3 & 1,0 & \\
\hline Classe 2 ou 3 & 57 & 63,6 & 36,4 & $3,1[1,6 ; 5,9]$ & \\
\hline
\end{tabular}

*\%p $=$ porcentagem ponderada

\#p: nivel descritivo do teste de associação pelo $\chi^{2}$ com correção de Yates

$\mathrm{Na}$ análise dos fatores de risco (análise univariada) para as variáveis dependentes mordida aberta anterior, mordida cruzada e oclusopatias de caninos foram realizadas algumas recategorizações de variáveis independentes, respeitando-se os marcos teóricos adotados. 


\subsection{Fatores de risco para mordida aberta}

Na Tabela 14 observa-se que nenhuma característica socioeconômica foi associada estatisticamente com a presença de mordida aberta.

Tabela 14: Distribuição da amostra, segundo presença de mordida aberta anterior (porcentagem ponderada) e fatores de risco socioeconômicos ao nascimento da criança. Pelotas, 1999.

Variável

Classe Social

Burguesia

Proletariado

Renda familiar $\left(S M^{*}\right)^{*}$

$>6,0$

1,1 a 6,0

$\leq 1,0$

Estado marital da mãe

Com marido ou com companheiro

Sem marido ou companheiro

Escolaridade da mãe (anos)

Mais do que 8

Até 8

Escolaridade do pai (anos)

Mais do que 8

Atè 8 n Mordida aberta

$$
\begin{array}{ll}
\text { Não } & \text { Sim } \\
\% p^{*} & \% p^{*}
\end{array}
$$

$O R\left[I C_{95 \%}(O R)\right]$

$P^{*}$

0,510

$\begin{array}{cccc}77 & 57,5 & 42,5 & 1,0 \\ 258 & 53,4 & 46,6 & 1,2[0,7 ; 1,9]\end{array}$

0,529

$48 \quad 59,3 \quad 40,7 \quad 1,0$

$247 \quad 51,6 \quad 48,4 \quad 1,4[0,8 ; 2,5]$

$64 \quad 56,5 \quad 43,5 \quad 1,1[0,5 ; 2,3]$

0,172

$321 \quad 55,1 \quad 44,9 \quad 1,0$

$38 \quad 41,2 \quad 58,8 \quad 1,7[0,9 ; 3,6]$

0,221

$86 \quad 58,8 \quad 41,2 \quad 1,0$

$273 \quad 51,9 \quad 48,1 \quad 1,3[0,8 ; 2,1]$

0,354

$93 \quad 57,8 \quad 42,2 \quad 1,0$

$239 \quad 52,4 \quad 47,6 \quad 1,2[0,8 ; 2,0]$

$\% p=$ porcentagem ponderada

- $S M=$ salários minimos

${ }^{\#}$ p: nivel descritivo do teste de associação pelo $\chi^{2}$ com correção de Yates 
Das medidas antropométricas maternas (Tabela 15), apenas a baixa altura da mãe da criança mostrou-se associada positivamente com a presença de mordida aberta $(p=0,006)$.

Tabela 15: Distribuição da amostra, segundo presença de mordida aberta anterior (porcentagem ponderada) e medidas antropométricas da mãe. Pelotas, 1999.

Variável

Índice de massa corporal $\left(\mathrm{Kg} / \mathrm{m}^{2}\right)$

0,006

Altura da mãe $(\mathrm{cm})$

156 ou mais

$<156$

240

115

$76 \quad 63,1 \quad 36,9$

$227 \quad 49,8 \quad 50,2$

$44 \quad 60,5 \quad 39,5$

$n$ Mordida aberta $\mathrm{OR}\left[\mathrm{IC} \mathrm{C}_{\mathbf{9 5} \%}(\mathrm{OR})\right]$

Não Sim

$\% p^{\star} \quad \% p^{*}$

0,080

$0,6[0,4 ; 1,1]$

1,0

$0,7[0,3 ; 1,3]$

*\%p = porcentagem ponderada

* $\mathrm{p}$ : nivel descritivo do teste de associação pelo $\chi^{2}$ com correção de Yates

A Tabela 16 pode-se observar que nenhuma condição de trabalho da mãe ao longo da vida da criança apresentou-se associada com a presença de mordida aberta anterior. 
Tabela 16: Distribuição da amostra, segundo presença de mordida aberta anterior (porcentagem ponderada) e fatores de risco relacionados ao trabalho materno durante a vida da criança. Pelotas, 1999.

\begin{tabular}{|c|c|c|c|c|c|}
\hline \multirow{2}{*}{ Variável } & \multirow[t]{2}{*}{$n$} & \multicolumn{2}{|c|}{ Mordida aberta } & \multirow[t]{2}{*}{ OR $\left[\mathrm{IC}_{95 \%}(\mathrm{OR})\right]$} & \multirow[t]{2}{*}{$P^{*}$} \\
\hline & & $\begin{array}{l}\text { Não } \\
\% \mathbf{p}^{\star}\end{array}$ & $\begin{array}{l}\text { Sim } \\
\% \mathrm{p}^{*}\end{array}$ & & \\
\hline Trabalho materno após o & & & & & 0,802 \\
\hline \multicolumn{6}{|l|}{ nascimento } \\
\hline Sim & 117 & 54,2 & 45,8 & 1,0 & \\
\hline Não & 242 & 52,8 & 47,2 & $1,0[0,6 ; 1,5]$ & \\
\hline Trabalho materno aos 12 meses & & & & & 0,218 \\
\hline Sim & 145 & 49,7 & 50,3 & 1,0 & \\
\hline Não & 214 & 56,8 & 43,2 & $0,8[0,5 ; 1,2]$ & \\
\hline Trabalho materno aos 5 anos & & & & & 0,331 \\
\hline Sim, durante todo o ano & 79 & 60,5 & 39,5 & 1,0 & \\
\hline Sim, parcialmente durante $o$ ano & 95 & 51,0 & 49,0 & $1,5[0,8 ; 2,7]$ & \\
\hline Não trabalhou & 183 & 51,4 & 48,6 & $1,5[0,9 ; 2,5]$ & \\
\hline Quem fez o trabalho doméstico & & & & & 0,468 \\
\hline (nascimento) & & & & & \\
\hline Outras pessoas & 160 & 56,2 & 43,8 & 1,0 & \\
\hline Mãe & 199 & 51,8 & 48,2 & $1,2[0,8 ; 1,8]$ & \\
\hline
\end{tabular}

$\% \mathrm{p}=$ porcentagem ponderada

* p: nivel descritivo do teste de associação pelo $\chi^{2}$ com correção de Yates

Dentre o comportamento e as caracteristicas maternas durante a vida da criança (Tabela 17), o tempo de amamentação no seio mostrou-se associado com a presença de mordida aberta $(p=0,001)$ e a intenção da mãe em dar bico para a criança desde o nascimento $(p=0,035)$. 
Tabela 17: Distribuição da amostra, segundo presença de mordida aberta anterior (porcentagem ponderada) e fatores de risco relacionados ao comportamento e características maternas. Pelotas, 1999.

\section{Variável}

Fumo na gestação

Não

Sim

Primiparas

Não

Sim

Paridade

$<4$

$\geq 4$

Intervalo interpartal (meses)

$>18$ meses

$\leq 18$ meses

Idade materna (anos)

14 a 19

20 a 29

30 a 39

40 a 46

Amamentação (meses)

9 ou mais

4 a 8,9

1 a 3,9

$<1$

Intenção de dar bico (ao nascer)

Não

Sim

\section{$n$}

$$
\begin{array}{lc}
\text { Mordida aberta } \\
\text { Näo } & \text { Sim } \\
\% p^{\star} & \% p^{\star}
\end{array}
$$

$\begin{array}{cccc}241 & 56,7 & 43,3 & 1,0 \\ 118 & 46,7 & 53,3 & 1,5[1,0 ; 2,4]\end{array}$

$\begin{array}{cccc}233 & 51,5 & 48,5 & 1,0 \\ 126 & 58,2 & 41,8 & 0,8[0,5 ; 1,2]\end{array}$

$\begin{array}{cccc}323 & 53,6 & 46,4 & 1,0 \\ 36 & 55,6 & 44,4 & 0,9[0,5 ; 1,8]\end{array}$

$\begin{array}{cccc}191 & 49,2 & 50,8 & 1,0 \\ 15 & 60,0 & 40,0 & 0,6[0,2 ; 1,9]\end{array}$

0,129

$\begin{array}{cccc}\cdot 55 & 60,0 & 40,0 & 1,0 \\ 203 & 56,4 & 43,6 & 1,2[0,7 ; 2,2] \\ 90 & 43,6 & 56,4 & 1,9[1,0 ; 3,8] \\ 11 & 63,6 & 36,4 & 0,9[0,2 ; 3,3]\end{array}$

0,001

$\begin{array}{cccc}78 & 71,8 & 28,2 & 1,0 \\ 78 & 48,2 & 51,8 & 2,8[1,5 ; 5,2] \\ 130 & 45,8 & 54,2 & 3,0[1,7 ; 5,4] \\ 71 & 53,6 & 46,4 & 2,2[1,1 ; 4,5]\end{array}$

0,035

$317 \quad 51,6 \quad 48,4 \quad 2,4[1,0 ; 5,8]$

*\%p = porcentagem ponderada

\# $\mathrm{p}$ nivel descritivo do teste de associação pelo $\chi^{2}$ com correção de Yates 
Nenhuma característica biológica da criança foi estatisticamente significativa como fator de risco para mordida aberta (Tabela 18).

Tabela 18: Distribuição da amostra, segundo presença de mordida aberta anterior (porcentagem ponderada) e fatores de risco biológicos da criança. Pelotas, 1999.

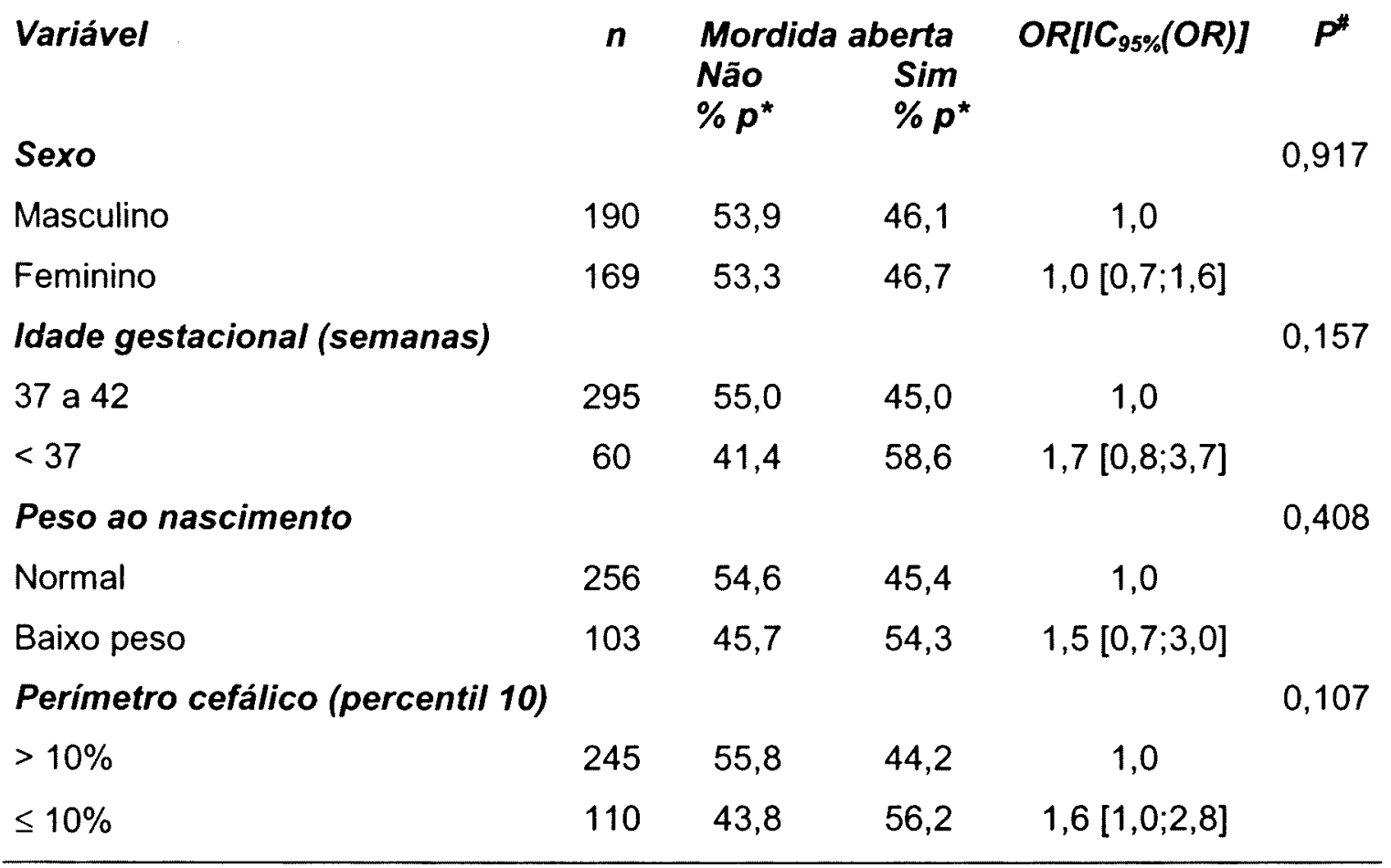

*\%p = porcentagem ponderada

* p: nivel descritivo do teste de associação pelo $\chi^{2}$ com correção de Yates

Todas as variáveis relativas ao hábito de sucção da criança foram associadas com mordida aberta anterior (Tabela 19). Embora o início tardio de uso de bico (após os 6 meses de vida) não esteja associado com a presença de mordida aberta, observou-se que o início precoce do uso de bico, isto é, antes dos 6 meses, foi fator de risco para este desfecho. O tempo de utilização do bico 
e a continuidade deste hábito mostraram-se fortemente associados com a presença de mordida aberta $(p<0,001)$.

Tabela 19: Distribuição da amostra, segundo presença de mordida aberta anterior (porcentagem ponderada) e fatores de risco relacionados ao uso de bico. Pelotas, 1999.

\begin{tabular}{|c|c|c|c|c|c|}
\hline \multirow{3}{*}{$\begin{array}{l}\text { Variável } \\
\text { Inicio do uso do bico }\end{array}$} & \multirow[t]{3}{*}{$n$} & \multicolumn{2}{|c|}{ Mordida aberta } & \multirow[t]{2}{*}{$O R\left[I C_{95 \%}(O R)\right]$} & \multirow[t]{2}{*}{$P^{\#}$} \\
\hline & & $\begin{array}{l}\text { Nao } \\
\% p^{*}\end{array}$ & $\begin{array}{l}\operatorname{Sim} \\
\% p^{*}\end{array}$ & & \\
\hline & & & & & 0,050 \\
\hline Nunca usou & 46 & 77,6 & 22,4 & 1,0 & \\
\hline Antes dos 3 meses & 276 & 50,0 & 50,0 & $3,3[1,6 ; 6,6]$ & \\
\hline Entre 3 e 6 meses & 30 & 51,7 & 48,3 & $3,0[1,1 ; 8,2]$ & \\
\hline Após 6 meses & 04 & 50,0 & 50,0 & $3,3[0,6 ; 21,2]$ & \\
\hline Uso de bico (12 meses) & & & & & $<0,00$ \\
\hline Não & 62 & 80,3 & 19,7 & 1,0 & \\
\hline $\operatorname{Sim}$ & 297 & 47,6 & 52,4 & $4,6[2,4 ; 8,8]$ & \\
\hline Uso de bico (5 anos) & & & & & $<0,001$ \\
\hline Não & 29 & 90,0 & 10,0 & 1,0 & \\
\hline Sim & 326 & 50,2 & 49,8 & $11,5[2,8 ; 38,8]$ & \\
\hline Uso de bico ( 12 meses a 5 anos) & & & & & $<0,001$ \\
\hline Não usou ou usou parcialmente & 142 & 81,8 & 18,2 & 1,0 & \\
\hline Usou o tempo todo & 217 & 34,1 & 65,9 & $8,6[5,2 ; 14,2]$ & \\
\hline
\end{tabular}

*\% $=$ porcentagem ponderada

\#p: nivel descritivo do teste de associação pelo $\chi^{2}$ com correção de Yates

Nenhuma variável relativa aos cuidados com a criança ao longo da vida foi associada à presença de mordida aberta (Tabela 20). O cuidado para com a criança realizado por outras pessoas no lugar do pai ou da mãe, apresentou-se próximo da significância estatística $(p=0,078)$. 
Tabela 20: Distribuição da amostra, segundo presença de mordida aberta anterior (porcentagem ponderada) e fatores de risco relacionados aos cuidados da criança. Pelotas, 1999.

\section{Variável}

Freqüentou a creche (6 meses)

$\operatorname{Sim}$

Não

Freqüentou a creche (12 meses)

Sim

Não

Freqüentou a creche aos 5 anos Sim

Não

Quem cuida da criança ( $6^{\circ}$ mês)

Mãe, pai, ambos

Outros n Mordida aberta OR[IC $\left.{ }_{95 \%}(O R)\right]$ Não Sim

$\% p^{\star} \quad \% p^{*}$

$17 \quad 68,8 \quad 31,3 \quad 1,0$

$339 \quad 52,9 \quad 47,1 \quad 1,9[0,7 ; 5,2]$

0,120

$22 \quad 73,7 \quad 26,3 \quad 1,0$

$337 \quad 52,6 \quad 47,4 \quad 2,3[0,8 ; 6,3]$

0,553

$68 \quad 57,5 \quad 42,5 \quad 1,0$

$291 \quad 52,8 \quad 47,2 \quad 1,2[0,7 ; 2,0]$

0,078

*\% $=$ porcentagem ponderada

\#p: nivel descritivo do teste de associação pelo $\chi^{2}$ com correção de Yates

Dos problemas de saúde que podem gerar conseqüências na cavidade bucal, apenas os relacionados à cárie dentária foram fatores de risco para mordida aberta (Tabela 21). Crianças que apresentaram algum comprometimento pela cárie dentária tiveram 1,7 vezes a chance de apresentarem mordida aberta $(p=0,022)$ em relação àquelas sem experiência de cárie. Além disso, a presença de dentes cariados e sem tratamento e/ou a perda de dentes devido a cárie, também foi fator de risco para o mesmo desfecho $(p=0,017)$. A gravidade da cárie dentária mostrou-se próxima da significância estatística $(p=0,068)$. 
Tabela 21: Distribuição da amostra, segundo presença de mordida aberta anterior (porcentagem ponderada) e problemas de saúde da criança. Pelotas, 1999.

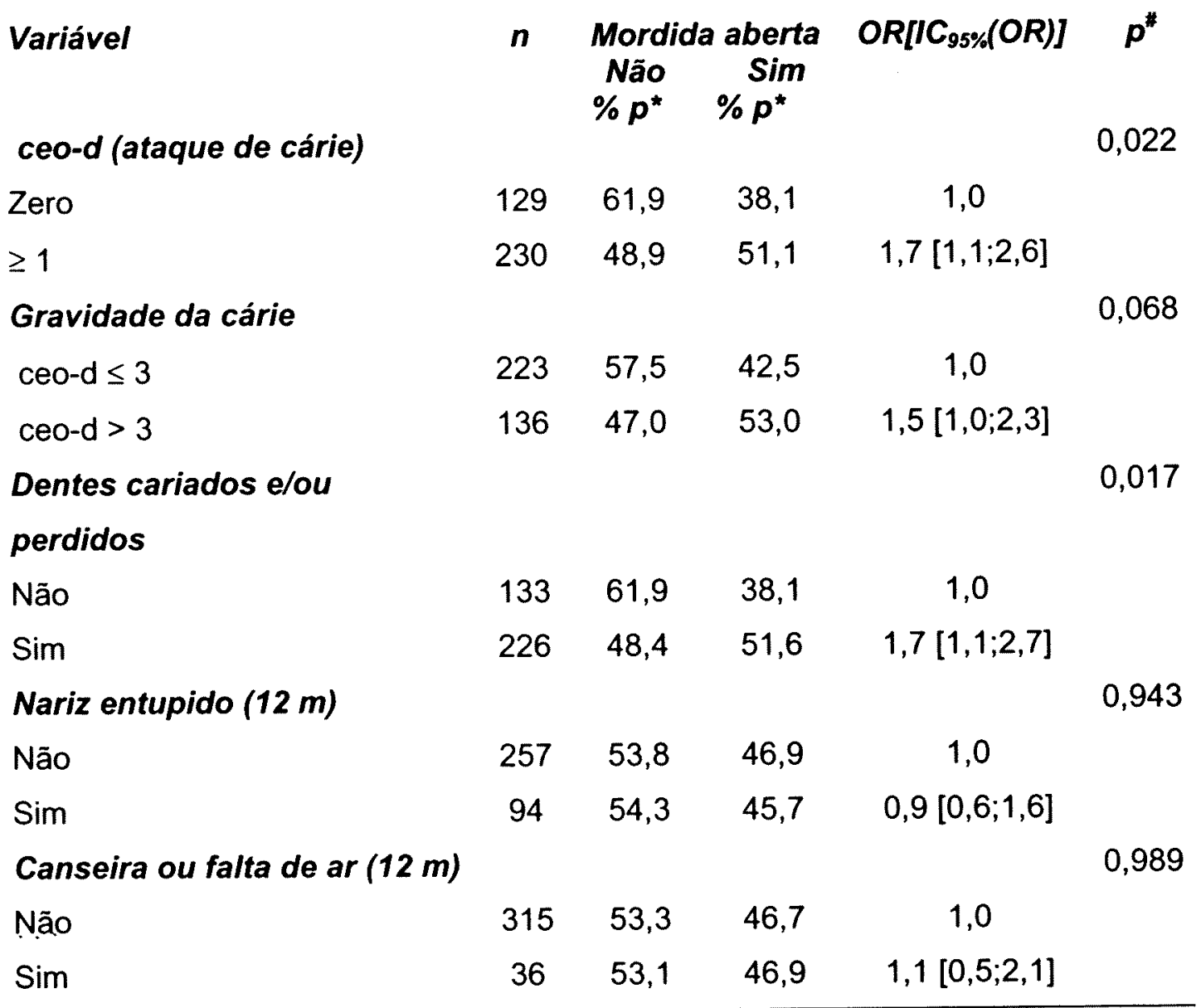

*\%p $=$ porcentagem ponderada

\# p: nivel descritivo do teste de associação pelo $\chi^{2}$ com correção de Yates

Os hábitos comportamentais da criança que mostraram-se como fatores de risco para mordida aberta foram: a utilização de mamadeira aos 5 anos de idade $(p<0,001)$ e o fato da criança dormir no mesmo quarto da mãe aos 12 meses de idade $(p=0,004)$ (Tabela 22). 
Tabela 22: Distribuição da amostra, segundo presença de mordida aberta anterior (porcentagem ponderada) e fatores de risco relacionados ao comportamento da criança. Pelotas, 1999.

\section{Variável}

Dorme no quarto do pai (12 m)

Não

Sim

Dorme no quarto da mãe $(12 \mathrm{~m})$

Não

$\operatorname{Sim}$

Dorme na cama da mãe (12 m)

Não

$\operatorname{Sim}$

Sucção de dedo (6 anos)

Não

Sim

Uso de mamadeira (nascimento)

Não

Sim

Uso de mamadeira aos 5 anos

Não

Sim

\section{n Mordida aberta \\ Não Sim \\ $\%^{*} \% p^{*}$}

$O R\left[I C_{95 \%}(O R)\right] \quad p^{\#}$

0,233

$\begin{array}{cccc}88 & 59,8 & 40,2 & 1,0 \\ 269 & 51,7 & 48,3 & 1,4[0,9 ; 2,3]\end{array}$

0,004

$33 \quad 78,8 \quad 21,2 \quad 1,0$

$324 \quad 51,1 \quad 48,2 \quad 3,4[1,5 ; 8,0]$

0,987

$\begin{array}{cccc}212 & 53,8 & 46,2 & 1,0 \\ 145 & 53,1 & 46,9 & 1,0[0,7 ; 1,6]\end{array}$

0,130

$327 \quad 55,1 \quad 44,9 \quad 1,0$

$32 \quad 41,7 \quad 58,3 \quad 1,7[0,9 ; 3,5]$

0,186

$350 \quad 54,2 \quad 45,8 \quad 1,0$

$8 \quad 20,0 \quad 80,0 \quad 5,2[0,6 ; 44,5]$ $<0,001$

$123 \quad 66,7 \quad 33,3 \quad 1,0$

$236 \quad 46,8 \quad 53,2 \quad 2,2[1,4 ; 3,5]$

*\%p = porcentagem ponderada

\# p: nivel descritivo do teste de associação pelo $\chi^{2}$ com correção de Yates

Após a análise univariada para escolha dos potenciais fatores de risco para mordida aberta anterior, foi realizada a análise múltipla. A análise de regressão logística múltipla foi realizada para cada bloco isoladamente, de acordo com o modelo hierárquico adotado. Todas as variáveis que apresentaram valores de $p<0,20$ na análise univariada foram selecionadas 
para a análise múltipla dos blocos e mantidas no modelo final do bloco se, após ajuste pelas outras variáveis, mantivessem a significância estatística $(p<0,05)$.

\subsection{Análise múltipla para mordida aberta anterior}

Dentre as variáveis socioeconômicas, nenhuma apresentou significância estatística e nem valores $p<0,20$ na análise univariada para o desfecho mordida aberta anterior. Entretanto, optou-se em manter a variável escolaridade da mãe nas etapas de análises subseqüentes a fim de controlar os niveis hierárquicos posteriores.

O resultado da análise de regressão múltipla para o bloco das medidas antropométricas da mãe é apresentado na Tabela 23. Ao ajustar o indice de massa corporal da mãe pela a altura materna, pode-se observar que as mães menores do que $156 \mathrm{~cm}$ tiveram filhos com mordida aberta $\left\{O R\left[I C_{O R 95 \%}\right]=1,9[1,2 ; 3,1]\right\}$ e mães com sobrepeso caracterizaram-se como fator de proteção para o mesmo desfecho $\left\{\mathrm{OR}\left[\mathrm{IC}_{\mathrm{OR} 95 \%}\right]=0,6[0,4 ; 1,0]\right\}$. 
Tabela 23: Associação entre presença de mordida aberta anterior e medidas antropométricas da mãe. Modelo de regressão múltipla. Pelotas, 1999.

\begin{tabular}{|c|c|c|c|c|}
\hline \multicolumn{5}{|c|}{$\begin{array}{l}\text { Indice de massa corporal } \\
\left(\mathrm{Kg} / \mathrm{m}^{2}\right)\end{array}$} \\
\hline 25,0 ou mais & $0,6[0,4 ; 1,1]$ & 0,046 & $0,6[0,4 ; 1,0]$ & 0,032 \\
\hline 18,5 a 24,9 & 1,0 & & 1,0 & \\
\hline menos que 18,5 & $0,7[0,3 ; 1,3]$ & 0,267 & $0,7[0,4 ; 1,5]$ & 0,359 \\
\hline \multicolumn{5}{|l|}{ Altura da mãe $(\mathrm{cm})$} \\
\hline 156 ou mais & 1,0 & & 1,0 & \\
\hline$<156$ & $1,9[1,2 ; 3,1]$ & 0,006 & $1,9[1,2 ; 3,1]$ & 0,015 \\
\hline
\end{tabular}

$\mathrm{Na}$ Tabela 24 observa-se os resultados da regressão múltipla do bloco das variáveis relacionados ao trabalho e às características maternas durante a vida da criança. O menor tempo de amamentação natural apresentou-se associado com a presença de mordida aberta, independentemente das outras características maternas como fumo na gestação e idade materna, assim como a intenção de oferecer bico à criança desde o nascimento manteve-se associada ao desfecho, mesmo após ajustada pelas mesmas variáveis e pelo tempo de amamentação natural $(p=0,014)$. A faixa etária da mãe, entre 30 e 39 anos, também, manteve-se associada significativamente com a presença de mordida aberta após ajuste pelo tempo de amamentação e pela intenção de oferecer bico ao nascimento $(p=0,031)$. A variável fumo na gestação e estado marital foram retiradas do modelo final do bloco das características maternas, após ajuste pelas outras variáveis, pois não foram significativas. 
Tabela 24: Associação entre presença de mordida aberta anterior e fatores de risco relacionados ao trabalho e às caracteristicas da mãe. Modelo de regressão múltipla. Pelotas, 1999.

\section{Variável}

Trabalho materno (nascimento)

Sim

Não

Trabalho materno aos 12 meses

Sim

Não

Trabalho materno aos 5 anos

Sim, durante todo o ano

Sim, parcialmente durante o ano

Não trabalhou

Quem fez o trabalho doméstico

Outras pessoas

Mãe

Fumo na gestação

Não

Sim

Primíparas

Não

Sim

Paridade

$<4$

$\geq 4$

Intervalo interpartal (meses)

$>18$ meses

$\leq 18$ meses

Idade materna (anos)

14 a 19

20 a 29

30 a 39

40 a 46

Amamentação (meses)

9 ou mais

4 a 8,9

1 a 3,9

$<1$

Intenção de dar bico

Não

Sim

* não incluida na análise ( $p>0,20$ na análise univariada)

- não significativa na análise múltipla,

$\mathrm{p}^{\mathrm{b}}$ : valor de $\mathrm{p}$ na análise bruta,

$\mathrm{p}^{a}$ : valor de $\mathrm{p}$ ajustado pelo tempo de amamentação, intenção de dar bico e idade materna.

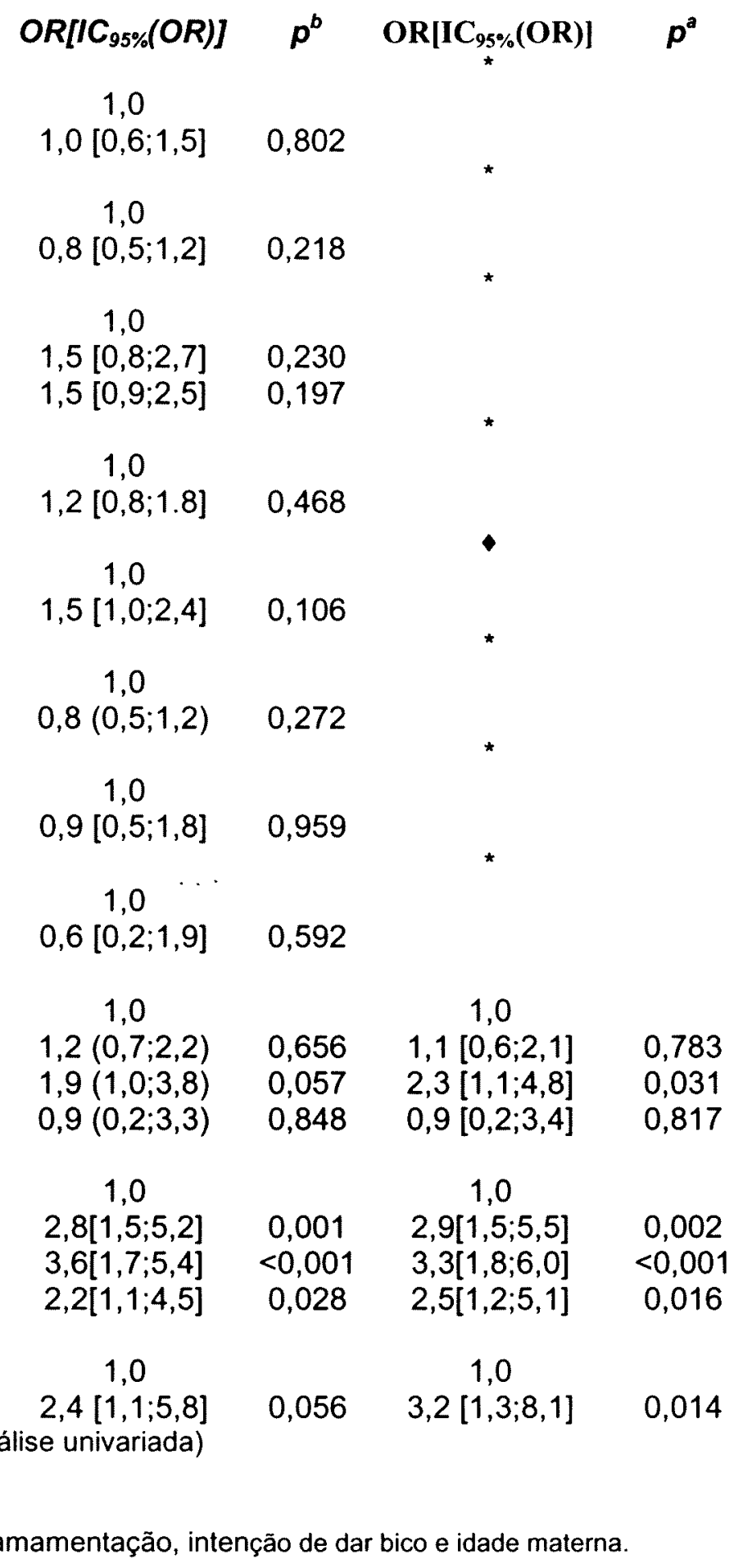


No modelo múltiplo para as variáveis biológicas das crianças nenhuma foi significativa, porém, optou-se por deixar a variável perímetro cefálico para avaliar seu comportamento quando ajustada pelos blocos anteriores. Além disso a variável sexo foi mantida no modelo final como ajuste dos blocos seguintes (Tabela 25).

Tabela 25: Associação entre presença de mordida aberta anterior e fatores de risco biológicos da criança. Modelo de regressão múltipla. Pelotas, 1999.

Variável

Sexo

Masculino

Feminino

Tipo de parto

Normal

Cesariana

Peso ao nascimento

Normal

Baixo peso

Perímetro cefálico (percentil 10)

$>10 \%$

$\leq 10 \%$

Idade gestacional (semanas)

37 a 42

$<37$

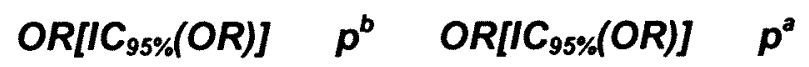

1,0

1,0

$1,0[0,7 ; 1,6] \quad 0,917 \quad 1,1[0,7 ; 1,5]$

0,943

$$
0,8[0,5 ; 1,3] \quad 0,555
$$

$$
1,5[0,7 ; 3,0] \quad 0,408
$$

1,0

1,0

$1,6[1,0 ; 2,8] \quad 0,107 \quad 1,6[0,9 ; 2,8] \quad 0,091$

1,0

$1,7[0,8 ; 3,7] \quad 0,157$

* não incluída na análise ( $p>0,20$ na análise univariada)

- não significativa na análise múltipla

$p^{b}$ : valor de $p$ na análise bruta

$\mathrm{p}^{\mathrm{a}}$ : valor de $\mathrm{p}$ ajustado entre as variáveis sexo e perímetro cefálico

(Teste Wald) 
O último bloco analisado para o desfecho mordida aberta foi o referente às características comportamentais e aos problemas de saúde da criança. As informações relacionadas ao hábito de suç̧ão de bico foram analisadas de diferentes maneiras quanto ao periodo e a freqüência de uso, o que tornou necessário testar suas inter-relações para ajudar a realizar a escolha mais apropriada. Como as variáveis relacionadas ao uso de bico foram fortemente associadas à presença de mordida aberta anterior, optou-se em iniciar a modelagem deste bloco respeitando-se a seqüência cronológica do uso de bico. A variável inicio do uso de bico perdeu a significância estatística após a introdução no modelo da variável uso de bico aos 12 meses de idade, que também perdeu a significância estatística após a inserção da variável uso de bico entre 12 meses e 5 anos de idade. Finalmente, a variável uso de bico aos 5 anos de idade perdeu a significância estatística quando controlada pelo uso de bico entre 12 meses e 5 anos de idade, variável esta que manteve-se associada à mordida aberta anterior.

Após a modelagem para uso de bico, todas as outras variáveis pertencentes a este bloco e que apresentaram $p<0,20$ foram inseridas, por ordem crescente do valor de $p$.

$\mathrm{Na}$ tabela 26 pode-se observar o resultado da análise múltipla para o último bloco hierárquico relativo às variáveis comportamentais da criança. Neste bloco, permaneceram significativas as variáveis uso de bico entre 12 meses e 5 anos de idade, presença de dentes comprometidos pela cárie dentária (ceo-d) e a sucção digital aos 6 anos de idade. A presença de 
mordida cruzada perdeu a significância estatística após ajuste pelas variáveis uso de bico entre 12 meses e 5 anos de idade, ceo-d e a sucção digital.

Tabela 26: Associação entre presença de mordida aberta anterior e fatores de risco relacionados ao cuidado e hábitos da criança. Modelo de regressão múltipla. Pelotas, 1999.

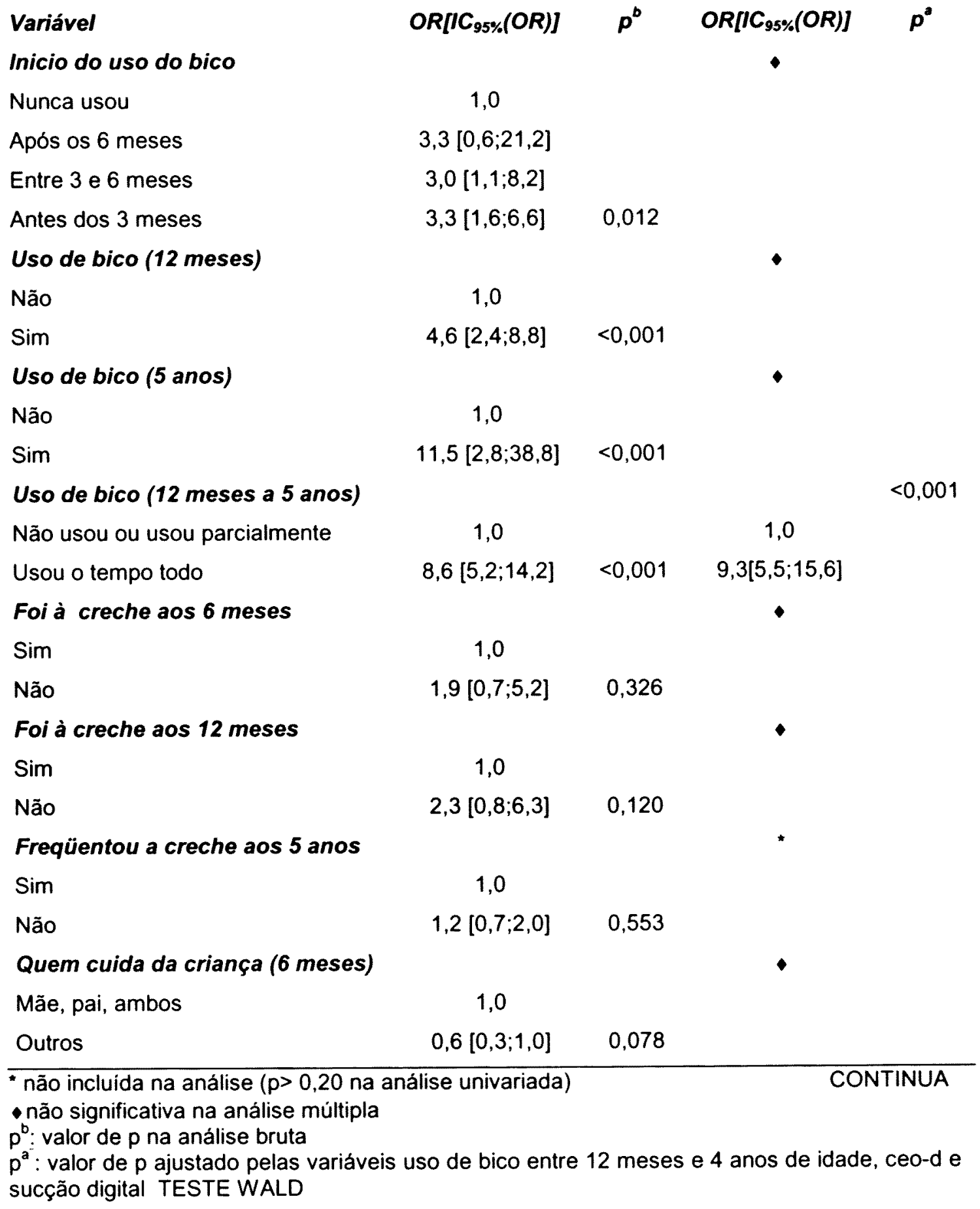


Tabela 26 - continuação

\begin{tabular}{|c|c|c|c|c|}
\hline Variável & $O R\left[I C_{95 \%}(O R)\right]$ & $p^{b}$ & $O R\left[I C_{95 \%}(O R)\right]$ & $p^{2}$ \\
\hline $\begin{array}{l}\text { ceo-d } \\
\text { Zero }\end{array}$ & 1,0 & & 1,0 & \\
\hline$\geq 1$ & $1,7[1,1 ; 2,6]$ & 0,022 & $1,7[1,1 ; 2,8]$ & 0,029 \\
\hline Gravidade da cárie & & & $\bullet$ & \\
\hline $\begin{array}{l}\text { ceo-d } \leq 3 \\
\text { ceo-d }>3\end{array}$ & $\begin{array}{c}1,0 \\
1,5[1,0 ; 2,3]\end{array}$ & 0,068 & & \\
\hline Tem dentes cariados e/ou perdidos & & & - & \\
\hline Não & 1,0 & & & \\
\hline Sim & $1,7[1,1 ; 2,7]$ & 0,017 & & \\
\hline Nariz entupido (12 meses) & & & * & \\
\hline Não & 1,0 & & & \\
\hline Sim & $0,9[0,6 ; 1,6]$ & 0,943 & & \\
\hline Canseira ou falta de ar (12 meses) & & & * & \\
\hline Não & 1,0 & & & \\
\hline $\operatorname{Sim}$ & $1,0[0,5 ; 2,1]$ & 0,989 & & \\
\hline Dorme no quarto que o pai (12 meses) & & & * & \\
\hline Não & 1,0 & & & \\
\hline Sim & $1,4[0,9 ; 2,3]$ & 0,233 & & \\
\hline Dorme no quarto que a mãe (12 meses) & & & - & \\
\hline Não & 1,0 & & & \\
\hline Sim & $3,4[1,5 ; 8,0]$ & 0,004 & & \\
\hline Dorme na cama que a mãe (12 meses) & & & * & \\
\hline Não & 1,0 & & & \\
\hline Sim & $1,0[0,7 ; 1,6]$ & 0,987 & & \\
\hline Sucção de dedos (6 anos) & & & & \\
\hline Não & 1,0 & & 1,0 & \\
\hline Sim & $1,7[0,9 ; 3,5]$ & 0,130 & $2,5[1,1 ; 5,8]$ & 0,026 \\
\hline Mamadeira ao nascimento & & & $\bullet$ & \\
\hline Não & 1,0 & & & \\
\hline Sim $\ldots$ & $5,2[0,6 ; 44,5]$ & 0,186 & & \\
\hline Mamadeira aos 5 anos & & & $\bullet$ & \\
\hline $\begin{array}{l}\text { Não } \\
\text { Sim }\end{array}$ & $\begin{array}{c}1,0 \\
2,2[1,4 ; 3,5]\end{array}$ & $<0,001$ & & \\
\hline $\begin{array}{l}\text { Sim } \\
\text { Mordida cruzada }\end{array}$ & & & - & \\
\hline Não & 1,0 & & & \\
\hline Sim & $1,9[1,1 ; 3,1]$ & 0,031 & & \\
\hline Relação de caninos & & & * & \\
\hline Classe 1 & 1,0 & & & \\
\hline Classe II ou III & $1,4[0,8 ; 2,6]$ & 0,220 & & \\
\hline \multicolumn{5}{|c|}{$\begin{array}{l}\text { " não incluída na análise ( } p>0,20 \text { na análise univariada) } \\
\text { - não significativa na análise múltipla } \\
\mathrm{p}^{\mathrm{b}} \text { : valor de } p \text { na análise bruta } \\
\mathrm{p}^{\mathrm{a}} \text { : valor de } \mathrm{p} \text { ajustado pelas variáveis uso de bico entre } 12 \text { meses e } 4 \text { anos de idade, ceo-d } \\
\text { e sucção digital } \\
\text { (Teste Wald) }\end{array}$} \\
\hline
\end{tabular}


Após a análise múltipla em cada bloco, foi realizada a modelagem final com os fatores de risco de todos os níveis hierárquicos (Tabela 27). $\mathrm{O}$ nível mais distal, composto pelas variáveis socioeconômicas e representado pelo nivel de escolaridade da mãe foi mantido até o final do modelo para controle dos outros niveis.

Em seguida foram acrescentadas ao modelo as medidas antropométricas maternas, IMC e altura. O IMC materno ao ser ajustado pelo nível de escolaridade e pela altura da mãe perdeu a significância estatística e foi retirado do modelo. A altura materna manteve a significância estatística, independente do nível de escolaridade. Mães com menos de 156 cm de altura tiveram 1,9 vezes a chance de terem filhos com mordida aberta do que aquelas mais altas $(p=0,007)$.

Independentemente do nivel de escolaridade e da altura da mãe, a faixa etária materna entre 30 e 39 anos, o tempo de amamentação e a intenção de dar bico desde o nascimento foram associados com a presença de mordida aberta. Observou-se que as crianças amamentadas de 1 a 3,9 meses e de 4 a 8,9 meses tiveram cerca de 3 vezes a chance de apresentarem mordida aberta anterior quando comparadas com aquelas que foram amamentadas 9 meses ou mais $(p<0,001)$ e as crianças que receberam menos de 1 mês de amamentação natural tiveram 2,4 vezes a chance de apresentarem mordida aberta em relação àquelas que mamaram mais de 9 meses $(p=0,022)$. Mães que tinham a intenção de dar bico desde o nascimento da criança tiveram 3 vezes a chance de seu filho apresentar 
mordida aberta quando comparada com aquelas que não tinham a mesma intenção $(p=0,022)$.

O perímetro cefálico da criança foi inserido no modelo e ao perder a significância estatística foi retirado do mesmo.

No último nível, o mais proximal, a presença de mordida cruzada perdeu a significância estatística e, portanto, foi retirada do modelo final. As variáveis uso de bico no período entre 12 meses e 5 anos de idade, a presença de dentes comprometidos pela cárie e a sucção digital permaneceram estatisticamente significativos quando controlados pelas variáveis nível de escolaridade da mãe, altura materna, idade da mãe, tempo de amamentação, intenção de dar bico e sexo da criança. Crianças que utilizaram bico no periodo todo entre os 12 meses e 5 anos de idade tiveram 10,6 vezes a chance de apresentarem mordida aberta do aquelas que não utilizaram ou utilizaram parcialmente o bico neste periodo $(p<0,001)$. As crianças que apresentaram dentes comprometidos pela cárie tiveram 2 vezes a chance de apresentarem mordida aberta quando comparadas àquelas que não apresentavam esta condição $(p=0,013)$. Crianças com sucção digital aos 6 anos de idade apresentaram 3,1 vezes a chance de mordida aberta em relação àquelas que não tinham este hábito $(p=0,010)$. 
Tabela 27: Mordida aberta anterior e fatores de risco. Resultados da análise de regressão múltipla hierarquizada. Pelotas, RS, 1999.

\begin{tabular}{|c|c|c|c|c|}
\hline Modelo & {$\left[I C_{95 \%}(O R)\right]$} & $p^{b}$ & {$\left[I C_{95 \%}(O R)\right]$} & $p^{a}$ \\
\hline \multicolumn{5}{|l|}{ Fatores socioeconômicos } \\
\hline \multicolumn{5}{|l|}{ Escolaridade da mãe (anos) } \\
\hline Mais do que 8 & 1,0 & & 1,0 & \\
\hline Até 8 & $1,3[0,8 ; 2,1]$ & 0,221 & $1,3[0,8 ; 2,1]$ & 0,221 \\
\hline \multicolumn{5}{|l|}{ Medidas antropométricas da mãe } \\
\hline \multicolumn{5}{|l|}{ Altura $(\mathrm{cm})$} \\
\hline $156 \mathrm{~cm}$ ou mais & 1,0 & & 1,0 & \\
\hline$<156 \mathrm{~cm}$ & $1,9[1,2 ; 3,1]$ & 0,006 & $1,9[1,2 ; 3,0]$ & 0,007 \\
\hline \multicolumn{5}{|l|}{ Fatores comportamentais da mãe } \\
\hline \multicolumn{5}{|l|}{ Idade da mãe } \\
\hline 14 a 19 & 1,0 & & 1,0 & \\
\hline 20 a 29 & $1,2[0,7 ; 2,2]$ & 0,656 & $1,2[0,6 ; 2,3]$ & 0,626 \\
\hline 30 a 39 & $1,9[1,0 ; 3,8]$ & 0,057 & $2,4[1,1 ; 5,5]$ & 0,023 \\
\hline 40 a 46 & $0,9[0,2 ; 3,3]$ & 0,848 & $0,7[0,2 ; 2,9]$ & 0,639 \\
\hline \multicolumn{5}{|l|}{ Amamentação (meses) } \\
\hline 9 ou mais & 1,0 & & 1,0 & \\
\hline 4 a 8,9 & $2,8[1,5 ; 5,2]$ & 0,001 & $3,0[1,7 ; 5,9]$ & 0,001 \\
\hline 1 a 3,9 & $3,0[1,7 ; 5,4]$ & $<0,001$ & $3,1[1,7 ; 5,6]$ & $<0,001$ \\
\hline$<1$ & $2,2[1,1 ; 4,5]$ & 0,028 & $2,4[1,1 ; 4,9]$ & 0,022 \\
\hline \multicolumn{5}{|l|}{ Intenção de dar bico (nascimento) } \\
\hline Não & 1,0 & & 1,0 & \\
\hline Sim & $2,4[1,0 ; 5,8]$ & 0,056 & $3,0[1,2 ; 7,9]$ & 0,022 \\
\hline \multicolumn{5}{|l|}{$\begin{array}{l}\text { Características e comportamento da } \\
\text { criança }\end{array}$} \\
\hline \multicolumn{5}{|l|}{ Sexo } \\
\hline Masculino & 1,0 & & 1,0 & \\
\hline Feminino & $1,1[0,7 ; 1,5]$ & 0,943 & $1,1[0,7 ; 1,8]$ & 0,546 \\
\hline \multicolumn{5}{|l|}{ Uso de bico entre 12 meses e 5 anos } \\
\hline Não usou ou usou parcialmente & 1,0 & & 1,0 & \\
\hline \multicolumn{5}{|l|}{ ceo-d (ataque de cárie) } \\
\hline 0 & 1,0 & & 1,0 & \\
\hline \multirow{2}{*}{\multicolumn{5}{|c|}{ Sucção digital (6 anos) }} \\
\hline & & & & \\
\hline Não & 1,0 & & 1,0 & \\
\hline Sim & $1,7[0,9 ; 3,5]$ & 0,130 & $3,1[1,3 ; 7,2]$ & 0,010 \\
\hline \multicolumn{5}{|c|}{$\mathrm{p}^{\mathrm{b}}: \mathrm{p}$ da análise univariada, } \\
\hline \multicolumn{5}{|c|}{$\mathrm{p}^{\mathrm{a}}$ : ajustado pela (s) variável (eis) do (s) nível (eis) anterior (es) } \\
\hline Teste de Hosmer e Lemeshow $(p=0,701)$ & & & & \\
\hline
\end{tabular}




\subsection{Fatores de risco para mordida cruzada posterior}

O segundo desfecho analisado foi a presença de mordida cruzada posterior. Como pode ser observado, nenhuma característica socioeconômica foi associada estatisticamente com a presença de mordida cruzada (Tabela 28).

Tabela 28: Distribuição da amostra, segundo presença de mordida cruzada posterior (porcentagem ponderada) e fatores de risco socioeconômicos ao nascimento da criança. Pelotas, 1999.

Variável

Classe Social

Burguesia

Proletariado

Renda familiar $\left(S M^{+}\right)$

$>6,0$

1,1 a 6,0

$\leq 1,0$ n Mordida cruzada

$\begin{array}{lc}\text { Não } & \text { Sim } \\ \% \mathbf{p}^{\star} & \% \mathbf{p}^{*}\end{array}$

Estado marital da mãe

Com marido ou com companheiro 321

$38 \quad 82,4 \quad 17,6$

OR $\left[\mathrm{IC}_{95 \%}(\mathrm{OR})\right]$

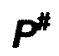

Sem marido ou companheiro

$\begin{array}{ccc}77 & 76,7 & 23,3 \\ 258 & 83,2 & 16,8\end{array}$

1,0

Escolaridade da mãe (anos)

48

77,8

22,2

0,246

0,242

$247 \quad 84,0 \quad 16,0$

1,0

$64 \quad 75,8 \quad 24,2$

$0,7[0,3 ; 1,4]$

$1,1[0,5 ; 2,7]$

0,901

Mais do que 8

$86 \quad 83,5 \quad 16,5$

0,121

Até 8

273

$80,8 \quad 19,2$

1,0

Escolaridade do pai (anos)

Mais do que 8

$93 \quad 86,1 \quad 13,9$

1,0

Até 8

$239 \quad 78,1 \quad 28,9$

+ $\mathrm{SM}=$ salários mínimos

* $\% p=$ porcentagem poderada

\# $p$ : nivel descritivo do teste de associação pelo $\chi^{2}$ com correção de Yates 
O segundo bloco de variáveis refere-se às medidas antropométricas da mãe, onde o sobrepeso materno mostrou-se próximo da significância estatística $(p=0,075)$. (Tabela 29)

Tabela 29: Distribuição da amostra, segundo presença de mordida cruzada posterior (porcentagem ponderada) e medidas antropométricas da mãe. Pelotas, 1999.

\begin{tabular}{|c|c|c|c|c|c|}
\hline Variável & $n$ & $\begin{array}{c}\text { Mordida } \\
\text { Não } \\
\% p^{*}\end{array}$ & $\begin{array}{l}\text { ruzada } \\
\text { Sim } \\
\% p^{\star}\end{array}$ & $O R\left[I C_{95 \%}(O R)\right]$ & $\boldsymbol{P}^{\#}$ \\
\hline $\begin{array}{l}\text { Indice de massa corporal } \\
\left(I M C-K g / m^{2}\right)\end{array}$ & & & & & 0,075 \\
\hline 25,0 ou mais & 76 & 80,0 & 20,0 & $0,5[0,2 ; 1,1]$ & \\
\hline 18,5 a 24,9 & 227 & 88,0 & 12,0 & 1,0 & \\
\hline menos que 18,5 & 44 & 71,1 & 28,9 & $1,6[0,7 ; 3,5]$ & \\
\hline Altura da mãe $(\mathrm{cm})$ & & & & & 0,628 \\
\hline 156 ou mais & 240 & 82,3 & 17,7 & 1,0 & \\
\hline$<156$ & 115 & 80,4 & 19,6 & $1,2[0,6 ; 2,1]$ & \\
\hline
\end{tabular}

\#p: nivel descritivo do teste de associação pelo $\chi^{2}$ com correção de Yates

*\%p: porcentagem ponderada

Nenhuma variável referente ao trabalho materno durante a vida da criança mostrou-se associada para a presença de mordida cruzada na criança (Tabela 30). 
Tabela 30: Distribuição da amostra, segundo presença de mordida cruzada posterior (porcentagem ponderada) e fatores de risco relacionados ao trabalho materno durante a vida da criança. Pelotas, 1999.

\begin{tabular}{|c|c|c|c|c|c|}
\hline Variável & $n$ & Mordid & ruzada & $\left.O R / I C_{95 \%}(O R)\right]$ & $p^{\#}$ \\
\hline & & $\begin{array}{l}\text { Não } \\
\% p^{*}\end{array}$ & $\underset{\% p^{*}}{\operatorname{Sim}}$ & & \\
\hline Trabalho materno ao nascer & & & & & 0,091 \\
\hline Sim & 117 & 77,2 & 22,8 & 1,0 & \\
\hline Não & 242 & 84,3 & 15,7 & $0,6[0,4 ; 1,1]$ & \\
\hline Trabalho materno -12 meses & & & & & 0,184 \\
\hline Sim & 144 & 78,4 & 21,6 & 1,0 & \\
\hline Não & 214 & 84,5 & 15,5 & $0,7[0,4 ; 1,1]$ & \\
\hline Trabalho materno - 5 anos & & & & & 0,333 \\
\hline Sim, durante todo o ano & 79 & 87,1 & 12,9 & 1,0 & \\
\hline Sim, parcialmente durante $\circ$ ano & 95 & 79,2 & 20,8 & $1,6[0,7 ; 3,6]$ & \\
\hline Não trabalhou & 183 & 80,6 & 19,4 & $1,5[0,7 ; 3,2]$ & \\
\hline $\begin{array}{l}\text { Quem fez o trabalho } \\
\text { doméstico }\end{array}$ & & & & & 0,748 \\
\hline Outras pessoas & 160 & 80,9 & 19,1 & 1,0 & \\
\hline Mãe & 199 & 82,7 & 17,3 & $0,9[0,5 ; 1,5]$ & \\
\hline
\end{tabular}

\#p: nivel descritivo do teste de associação pelo $\chi^{2}$ com correção de Yates

*\%p: porcentagem ponderada

A Tabela 31 apresenta as associações com mordida cruzada relacionados às características e comportamento materno. De todas as variáveis estudadas, apenas o tempo de amamentação natural foi estatisticamente associado com a presença de mordida cruzada $(p=0,030)$. 
caninos classe 2 ou 3 teve 3,8 vezes a chance de apresentar mordida cruzada do que aquelas com a relação classe 1 de caninos $(p<0,001)$.

Pode se observar que o tempo de uso de bico entre 12 meses e 5 anos de idade perdeu a significância estatística após ajuste pelas variáveis mais distais $(p=0,110)$. 
Tabela 31: Distribuição da amostra, segundo presença de mordida cruzada posterior (porcentagem ponderada) e fatores de risco relacionados ao comportamento e características maternas. Pelotas, 1999.

Variável

Fumo na gestação

Não

Sim

Primíparas

Não

$\operatorname{Sim}$

Paridade

$<4$

$\geq 4$

Intervalo interpartal (meses)

$>18$ meses

$\leq 18$ meses

Idade materna (anos)

14 a 19

20 a 29

30 a 39

40 a 46

Amamentação (meses)

9 ou mais

4 a 8,9

1 a 3,9

$<1$

Intenção de dar bico

(nascimento)

Não

Sim n Mordida cruzada Não Sim

$\% p^{*} \quad \% p^{*}$

$O R\left[I C_{95 \%}(O R)\right] \quad P^{*}$

0,821

$241 \quad 82,3 \quad 17,7 \quad 1,0$

$118 \quad 80,6 \quad 19,4 \quad 1,1[0,6 ; 2,1]$

0,736

233

82,6

17,4

1,0

126

80,5

19,5

$1,1[0,6 ; 2,0]$

0,303

323

36

80,7

19,3

1,0

89,2

10,8

$0,5[0,1 ; 1,4]$

0,558

191

82,9

17,1

1,0

15

73,3

26,7

$1,8[0,5 ; 5,8]$

0,200

$$
55
$$

76,0

24,0

1,0

203

85,4

14,6

$0,5[0,2 ; 1,1]$

90

77,4

22,6

$0,9[0,4 ; 2,1]$

11

72,7

27,3

$1,1[0,2 ; 1,9]$

0,030

$\begin{array}{llll}78 & 91,8 & 8,2 & 1,0\end{array}$

$78 \quad 77,9 \quad 22,4 \quad 3,0[1,2 ; 7,5]$

$130 \quad 76,9 \quad 23,1 \quad 3,2[1,4 ; 7,5]$

$71 \quad 84,2 \quad 15,8 \quad 2,0[0,7 ; 5,6]$

0,860

\#p: nivel descritivo do teste de associação pelo $\chi^{2}$ com correção de Yates

*\%p: porcentagem ponderada 
A Tabela 32 apresenta os fatores risco biológicos da criança, onde verifica-se que nenhuma das caracteristicas estudadas mostraramse como fator de risco para mordida cruzada.

Tabela 32: Distribuição da amostra, segundo presença de mordida cruzada posterior (porcentagem ponderada) e fatores de risco biológicos da criança. Pelotas, 1999.

\begin{tabular}{|c|c|c|c|c|c|}
\hline Variável & $n$ & $\begin{array}{c}\text { Mordida } \\
\text { Não } \\
\% p^{\star}\end{array}$ & $\begin{array}{c}\text { ruzada } \\
\text { Sim } p^{\star}\end{array}$ & $O R\left[I C_{95 \%}(O R)\right]$ & $p^{*}$ \\
\hline Sexo & & & & & 0,806 \\
\hline Masculino & 190 & 82,3 & 17,7 & 1,0 & \\
\hline Feminino & 169 & 80,7 & 19,3 & $1,1[0,6 ; 1,9]$ & \\
\hline Peso ao nascimento & & & & & 0,947 \\
\hline Normal & 256 & 81,5 & 18,5 & 1,0 & \\
\hline Baixo peso & 103 & 82,8 & 17,2 & $0,9[0,5 ; 1,9]$ & \\
\hline $\begin{array}{l}\text { Perímetro cefálico } \\
\text { (percentil 10) }\end{array}$ & & & & & 0,315 \\
\hline$>10 \%$ & 245 & 82,5 & 17,5 & 1,0 & \\
\hline$\leq 10 \%$ & 110 & 73,3 & 26,7 & $1,8[0,7 ; 4,1]$ & \\
\hline $\begin{array}{l}\text { Idade gestacional } \\
\text { (semanas) }\end{array}$ & & & & & 0,835 \\
\hline 37 a 42 & 295 & 81,4 & 18,6 & 1,0 & \\
\hline$<37$ & 60 & 82,9 & 17,1 & $0,9[0,3 ; 2,2]$ & \\
\hline
\end{tabular}

+ $p$ : nivel descritivo do teste de associação pelo $\chi^{2}$ com correção de Yates * $\mathrm{p}$ : porcentagem ponderada

Pode-se observar na Tabela 33 as associações com mordida cruzada, relacionados ao uso de bico pela criança. Tanto o período de início do uso de bico, quanto o uso do bico todo o período entre 12 
meses e 5 anos de idade foram fatores de risco para mordida cruzada (respectivamente $p=0,002$ e $p=0,040$ ).

Tabela 33: Distribuição da amostra, segundo presença de mordida cruzada posterior (número e porcentagem) e fatores de risco relacionados ao uso de bico. Pelotas, 1999.

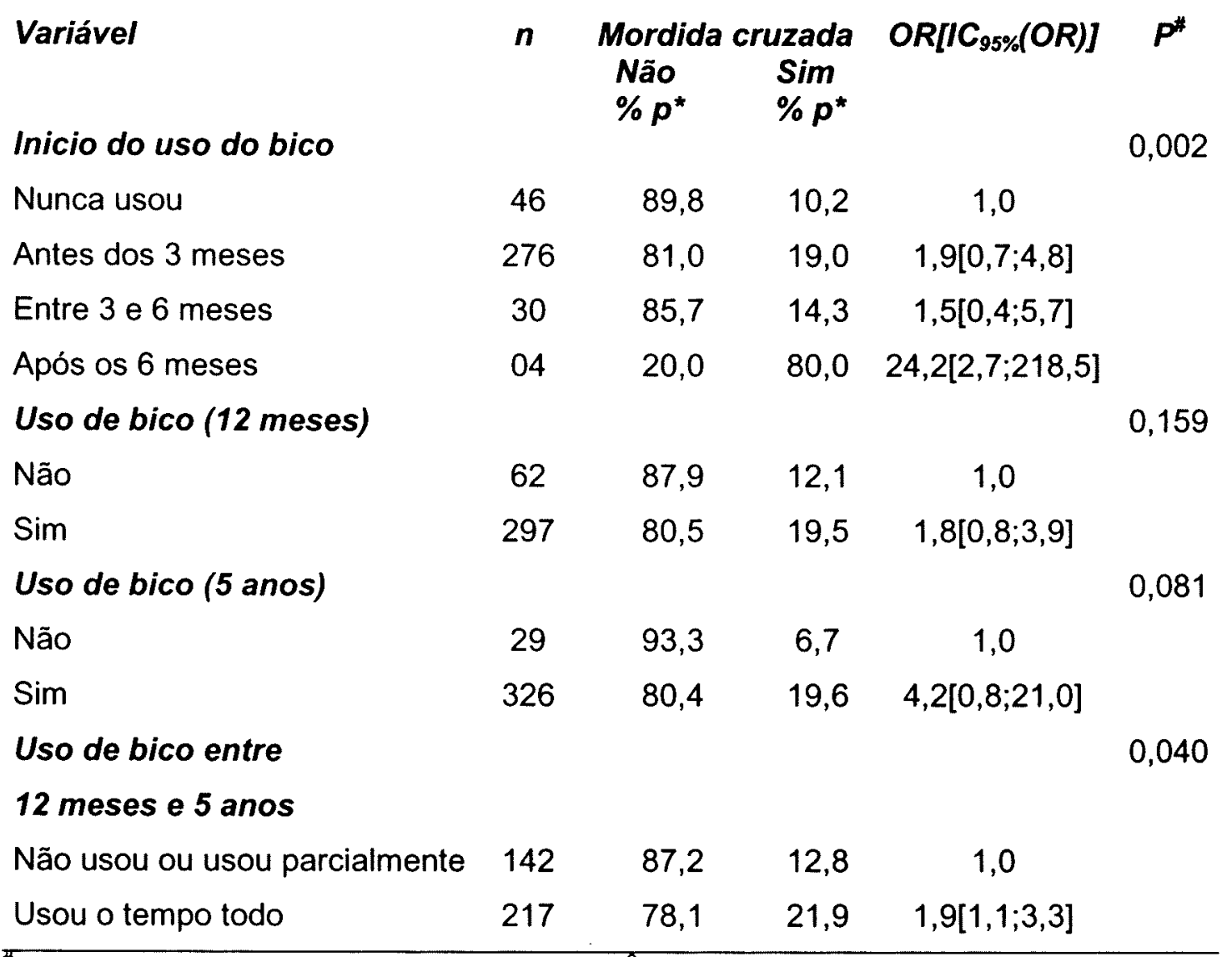

\#p: nivel descritivo do teste de associação pelo $\chi^{2}$ com correção de Yates

*\%p: porcentagem ponderada

Os cuidados com a criança ao longo da vida são apresentados na Tabela 34, onde pode-se observar que a única condição estudada que mostrou-se próxima da significância estatística foi o responsável pela criança aos 6 meses de vida $(p=0,055)$. 
Tabela 34: Distribuição da amostra, segundo presença de mordida cruzada posterior (porcentagem ponderada) e fatores de risco relacionados ao cuidado com a criança. Pelotas, 1999.

\begin{tabular}{|c|c|c|c|c|c|}
\hline Variável & $n$ & Mordid & ruzada & OR $\left[I_{95 \%}(\mathrm{OR})\right]$ & $P^{\#}$ \\
\hline & & $\begin{array}{l}\text { Não } \\
\% \text { p p* }\end{array}$ & $\underset{\% \mathbf{p}^{*}}{\text { Sim }}$ & & \\
\hline Foi à creche aos 6 meses & & & & & 1,000 \\
\hline Sim & 17 & 82,4 & 17,6 & 1,0 & \\
\hline Não & 339 & 81,7 & 18,3 & $1,1[0,3 ; 4,0]$ & \\
\hline Foi à creche aos 12 meses & & & & & 0,980 \\
\hline Sim & 22 & 78,9 & 21,1 & 1,0 & \\
\hline Não & 337 & 82,0 & 18,0 & $0,7[0,2 ; 2,2]$ & \\
\hline Foi à creche aos 5 anos & & & & & 1,000 \\
\hline Sim & 68 & 81,9 & 18,1 & 1,0 & \\
\hline Não & 291 & 81,8 & 18,2 & $0,9[0,5 ; 1,9]$ & \\
\hline Quem cuida da criança (6 meses) & & & & & 0,055 \\
\hline Mãe, pai, ambos & 304 & 83,3 & 16,7 & 1,0 & \\
\hline Outros & 52 & 71,4 & 28,6 & $2,0[1,0 ; 3,8]$ & \\
\hline
\end{tabular}

* $p$ :nivel descritivo do teste de associação pelo $\chi^{2}$ com correção de Yates

*\%p: porcentagem ponderada

A Tabela 35 observa-se que dos problemas de saúde bucal que podem gerar conseqüências na cavidade bucal, nenhum foi fator de risco para mordida cruzada. 
Tabela 35: Distribuição da amostra, segundo presença de mordida cruzada posterior (porcentagem ponderada) e problemas de saúde da criança. Pelotas, 1999.

\begin{tabular}{|c|c|c|c|c|c|}
\hline Variável & $n$ & $\begin{array}{l}\text { Mordida } \\
\text { Não } \\
\% p^{\star}\end{array}$ & $\begin{array}{l}\text { ruzada } \\
\text { Sim } \\
\% p^{\star}\end{array}$ & $O R\left[I C_{95 \%}(O R)\right]$ & $P^{*}$ \\
\hline ceo-d (ataque de cárie) & & & & & 0,626 \\
\hline Zero & 129 & 83,5 & 16,5 & 1,0 & \\
\hline$\geq 1$ & 230 & 80,8 & 19,2 & $0,8[0,5 ; 1,4]$ & \\
\hline Gravidade da cárie & & & & & 0,880 \\
\hline ceo-d $\leq 3$ & 223 & 81,3 & 18,7 & 1,0 & \\
\hline ceo-d $>3$ & 136 & 82,6 & 17,4 & $0,9[0,5 ; 1,6]$ & \\
\hline Dentes cariados e/ou perdidos & & & & & 0,472 \\
\hline Não & 133 & 84,1 & 15,9 & 1,0 & \\
\hline Sim & 226 & 80,5 & 19,5 & $1,3[0,7 ; 2,4]$ & \\
\hline Nariz entupido (12 meses) & & & & & 0,345 \\
\hline Não & 257 & 82,8 & 17,2 & 1,0 & \\
\hline Sim & 94 & 77,7 & 22,3 & $1,4[0,8 ; 2,4]$ & \\
\hline $\begin{array}{l}\text { Canseira ou falta de ar } \\
\text { (12 meses) }\end{array}$ & & & & & 1,000 \\
\hline Não & 315 & 81,8 & 18,2 & 1,0 & \\
\hline Sim & 36 & 81,3 & 18,8 & $1,1[0,4 ; 2,7]$ & \\
\hline
\end{tabular}

\#p: nivel descritivo do teste de associação pelo $\chi^{2}$ com correção de Yates

*\%p porcentagem ponderada

A Tabela 36 apresenta as variáveis relativas ao comportamento da criança mostrando que nenhuma foi associada com a presença de mordida cruzada. 
Tabela 36: Distribuiçāo da amostra, segundo presença de mordida cruzada posterior (porcentagem ponderada) e fatores de risco relacionados ao comportamento da criança. Pelotas, 1999.

\section{Variável}

Dorme no quarto do pai

(12 meses)

Não

Sim

Dorme no quarto da mãe (12 meses)

Não

Sim

Dorme na cama da mãe (12 meses)

Não

Sim

Sucção de dedo (6 anos)

Não

Sim

Uso de mamadeira (ao nascer)

Não

Sim

Uso de mamadeira aos 5 anos

Não

Sim

\section{.}

$n$

$\begin{array}{cccc}88 & 83,9 & 16,1 & 1,0 \\ 269 & 81,0 & 19,0 & 1,2[0,6 ; 2,3]\end{array}$

0,741

$\begin{array}{cccc}33 & 85,3 & 14,7 & 1,0 \\ 324 & 81,4 & 18,6 & 1,4[0,5 ; 3,7]\end{array}$

0,076

$\begin{array}{cccc}212 & 78,2 & 21,8 & 1,0 \\ 145 & 86,2 & 13,8 & 0,6[0,3 ; 1,0]\end{array}$

0,693

$\begin{array}{cccc}327 & 85,7 & 14,3 & 1,0 \\ 32 & 81,4 & 15,6 & 0,8[0,3 ; 2,0]\end{array}$

$350 \quad 100 \quad-\quad 1,0$

$8 \quad 81,5 \quad 18,5 \quad 3,4[0,1 ; 112,5]$

0,298

$\begin{array}{cccc}123 & 78,6 & 21,4 & 1,0 \\ 236 & 83,6 & 16,4 & 0,7[0,4 ; 1,2]\end{array}$

\#p: nivel descritivo do teste de associação pelo $\chi^{2}$ com correção de Yates

* \%p: porcentagem ponderada 


\subsection{Análise múltipla para mordida cruzada posterior}

A partir dos resultados encontrados na análise univariada, não houve necessidade de realizar a análise múltipla para cada bloco, pois obteve-se, no máximo, apenas um potencial fator de risco em cada nível hierárquico de análise.

Analisando-se todas as variáveis que apresentaram $p<0,20$, obtevese o modelo final para mordida cruzada que está representado na Tabela 37. O nivel de escolaridade da mãe foi mantido no modelo para ajuste dos niveis posteriores. O IMC materno foi ajustado pelo nivel de escolaridade da mãe e retirado do modelo por perder a significância estatística.

O trabalho materno no início da vida da criança apresentou-se no limite da significância estatística após ajuste pelo nível de escolaridade da mãe. Mães que não tinham trabalho remunerado aos 6 meses de vida da criança tiveram 1,7 vezes a chance de seus filhos apresentarem mordida cruzada comparadas com aquelas que trabalhavam no referido periodo $(p=0,063)$.

O tempo de amamentação permaneceu no modelo final após ajuste pelo nível de escolaridade da mãe e o trabalho materno. Crianças amamentadas menos do que 9 meses tiveram cerca de 3 vezes a chance de apresentar mordida cruzada em relação àquelas que foram amamentadas mais tempo $(p=0,011)$.

A presença de má posição de caninos manteve-se associada com a presença de mordida cruzada após ajuste pelas variáveis dos blocos mais

distais e pelo sexo da criança. A criança que apresentava a relação de 
caninos classe II ou III teve 3,8 vezes a chance de apresentar mordida cruzada do que aquelas com a relação classe I de caninos $(p<0,001)$.

Pode se observar que o tempo de uso de bico entre 12 meses e 5 anos de idade perdeu a significância estatística após ajuste pelas variáveis mais distais $(p=0,110)$. 
Tabela 37: Mordida cruzada posterior e fatores de risco. Resultados da análise de regressão múltipla hierarquizada. Pelotas, 1999.

\begin{tabular}{|c|c|c|c|c|}
\hline Modelo & $O R\left[I C_{95 \%}(O R)\right]$ & $p^{b}$ & $O R\left[I C_{95 \%}(O R)\right]$ & $p^{a}$ \\
\hline \multicolumn{5}{|c|}{ Fatores socioeconómicos } \\
\hline \multicolumn{5}{|c|}{ Escolaridade da mãe (anos) } \\
\hline Mais do que 8 & 1,0 & & 1,0 & \\
\hline Até 8 & $1,2[0,7 ; 2,3]$ & 0,121 & $1,2[0,7 ; 2,3]$ & 0,121 \\
\hline \multicolumn{5}{|c|}{ Fatores comportamentais da mãe } \\
\hline \multicolumn{5}{|c|}{ Trabalho materno (ao nascer) } \\
\hline Sim & 1,0 & & 1,0 & \\
\hline Não & $0,6[0,4 ; 1,1]$ & 0,091 & $1,7[1,0 ; 3,0]$ & 0,063 \\
\hline \multicolumn{5}{|c|}{ Amamentação (meses) } \\
\hline 9 ou mais & 1,0 & & 1,0 & \\
\hline 4 a 8,9 & $3,0[1,2 ; 7,5]$ & 0,020 & $3,0[1,2 ; 7,5]$ & 0,022 \\
\hline 1 a 3,9 & $3,2[1,4 ; 7,5]$ & 0,008 & $3,1[1,3 ; 7,3]$ & 0,011 \\
\hline$<1$ & $2,0[0,7 ; 5,6]$ & 0,196 & $2,1[0,7 ; 5,9]$ & 0,169 \\
\hline
\end{tabular}

Características e comportamento

da criança

\section{Sexo}

Masculino

Feminino

Relação de caninos

Classe I

Classe II ou III

Uso de bico entre 12 meses e 5

anos

Não usou ou usou parcialmente

Usou o tempo todo

$\mathrm{p}^{\mathrm{b}}: \mathrm{p}$ da análise univariada,

$\mathrm{p}^{\mathrm{a}}$ : ajustado pelas variáveis nivel de escolaridade da mãe, trabalho materno tempo de amamentação, sexo, relação de caninos e uso de bico entre 12 meses e 5 anos.

Teste de Hosmer e Lemeshow $(p=0,021)$
1,0

1,0

$1,1[0,6 ; 1,9] \quad 0,806 \quad 1,1[0,6 ; 2,0] \quad 0,657$

1,0

1,0

$3,1[1,6 ; 5,9] \quad<0,001$

$3,8[1,9 ; 7,4] \quad<0,001$

1,0

1,0

$1,9[1,1 ; 3,3] \quad 0,040 \quad 1,7[0,9 ; 3,2] \quad 0,110$ 


\subsection{Fatores de risco para oclusopatia de caninos}

O terceiro desfecho analisado foi a presença de mau posicionamento de caninos, caracterizado pela presença de classe 2 ou 3. A Tabela 38 apresenta os fatores de risco socioeconômicos. Observou-se que apenas a categoria de renda familiar menor ou igual a 1 salário minimo apresentou-se associada estatisticamente com oclusopatia de caninos $(p=0,040)$.

Tabela 38: Distribuição da amostra, segundo presença oclusopatia de caninos (porcentagem ponderada) e fatores de risco socioeconômicos ao nascimento da criança. Pelotas, 1999.

\begin{tabular}{|c|c|c|c|c|c|}
\hline Variável & $n$ & $\begin{array}{l}\text { Relaçã } \\
\text { Classe I } \\
\% p^{\star}\end{array}$ & $\begin{array}{c}\text { de caninos } \\
\text { Classe IIIIII } \\
\% p^{\star}\end{array}$ & $O R\left[I C_{95 \%}(O R)\right]$ & $P^{*}$ \\
\hline Classe Social & & & & & 0,256 \\
\hline Burguesia & 77 & 89,4 & 10,6 & 1,0 & \\
\hline Proletariado & 258 & 83,5 & 16,5 & $1,6[0,8 ; 3,4]$ & \\
\hline Renda familiar $\left(\mathrm{SM}^{+}\right)$ & & & & & 0,081 \\
\hline$>6,0$ & 48 & 92,3 & 7,7 & 1,0 & \\
\hline 1,1 a 6,0 & 247 & 84,8 & 15,2 & $2,1[0,7 ; 6,0]$ & \\
\hline$\leq 1,0$ & 64 & 77,0 & 23,0 & $3,4[1,1 ; 11,0]$ & \\
\hline $\begin{array}{l}\text { Estado marital da mãe } \\
\text { Com marido ou com }\end{array}$ & & & & & 0,931 \\
\hline companheiro & 321 & 84,7 & 15,3 & 1,0 & \\
\hline $\begin{array}{l}\text { Sem marido ou companheiro } \\
\text { Escolaridade da mãe (anos) }\end{array}$ & 38 & 85,3 & 14,7 & $1,0[0,4 ; 2,7]$ & 0,251 \\
\hline Mais do que 8 & 86 & 88,7 & 11,3 & 1,0 & \\
\hline Até 8 & 273 & 83,0 & 17,0 & $1,6[0,8 ; 3,3]$ & \\
\hline Escolaridade do pai (anos) & & & & & 0,081 \\
\hline Mais do que 8 & 93 & 88,9 & 11,1 & 1,0 & \\
\hline Até 8 & 239 & 82,3 & 17,7 & $1,6[0,8 ; 3,3]$ & \\
\hline
\end{tabular}

* $\mathrm{SM}=$ número de salários minimos

* p: nivel descritivo do teste de associação pelo $\chi^{2}$ com correção de Yates

$\%$ p: porcentagem ponderada 
O segundo bloco de variáveis, refere-se às medidas antropométricas da mãe. A Tabela 39 mostra que nenhuma característica estudada esteve associada estatisticamente à oclusopatia de caninos.

Tabela 39: Distribuição da amostra, segundo presença de oclusopatia de caninos (porcentagem ponderada) e medidas antropométricas da mãe. Pelotas, 1999.

\begin{tabular}{|c|c|c|c|c|c|}
\hline Variável & $n$ & $\begin{array}{l}\text { Relação } \\
\text { Classe I } \\
\% p^{\star}\end{array}$ & $\begin{array}{l}\text { zaninos } \\
\text { sse IIIIII } \\
\% p^{*}\end{array}$ & OR[IC $\left.{ }_{95 \%}(O R)\right]$ & $P^{*}$ \\
\hline $\begin{array}{l}\text { Indice de massa corporal } \\
\left(I M C-K g / m^{2}\right)\end{array}$ & & & & & 0,745 \\
\hline 25,0 ou mais & 76 & 85,1 & 14,9 & 1,0 & \\
\hline 18,5 a 24,9 & 227 & 86,9 & 13,1 & $0,8[0,4 ; 1,8]$ & \\
\hline menos que 18,5 & 44 & 81,6 & 18,4 & $1,3[0,5 ; 3,2]$ & \\
\hline Altura da mãe $(\mathrm{cm})$ & & & & & 0,728 \\
\hline 156 ou mais & 240 & 84,1 & 15,9 & 1,0 & \\
\hline$<156$ & 115 & 86,3 & 13,7 & $0,8[0,4 ; 1,6]$ & \\
\hline
\end{tabular}

$\left(I M C-K g / m^{2}\right)$

* \%p: porcentagem ponderada

A associação entre as variáveis de trabalho materno durante a vida da criança e oclusopatia de caninos é apresentada na Tabela 40 , onde pode se observar nenhuma associação estatística significativa entre elas. 
Tabela 40: Distribuição da amostra, segundo presença de oclusopatia de caninos (porcentagem ponderada) e fatores de risco relacionados ao trabalho materno. Pelotas, 1999.

\begin{tabular}{|c|c|c|c|c|c|}
\hline Variável & $n$ & $\begin{array}{c}\text { Relação c } \\
\text { Classe I } \\
\% p^{*}\end{array}$ & $\begin{array}{c}\text { Je caninos } \\
\text { Classe II/III } \\
\% p^{*}\end{array}$ & $O R\left[I C_{95 \%}(O R)\right]$ & $P^{*}$ \\
\hline $\begin{array}{l}\text { Trabalho materno ao } \\
\text { nascimento }\end{array}$ & & & & & 0,323 \\
\hline Sim & 242 & 83,0 & 17,0 & 1,0 & \\
\hline Não & 117 & 87,6 & 12,4 & $0,7[0,4 ; 1,3]$ & \\
\hline $\begin{array}{l}\text { Trabalho materno } \\
\text { (12 meses) }\end{array}$ & & & & & 0,853 \\
\hline Sim & 144 & 840 & 16,0 & 1,0 & \\
\hline Não & 214 & 85,3 & 14,7 & $0,9[0,5 ; 1,6]$ & \\
\hline $\begin{array}{l}\text { Trabalho materno } \\
\text { (5 anos) }\end{array}$ & & & & & 0,922 \\
\hline Sim, durante todo o ano & 79 & 84,1 & 15,9 & 1,0 & \\
\hline Sim, parcialmente durante o ano & 95 & 84,2 & 15,8 & $1,0[0,4 ; 2,2]$ & \\
\hline Não trabalhou & 183 & 85,7 & 14,3 & $0,9[0,4 ; 1,8]$ & \\
\hline $\begin{array}{l}\text { Quem fez o trabalho } \\
\text { doméstico }\end{array}$ & & & & & 0,147 \\
\hline Outras pessoas & 160 & 88,0 & 12,0 & 1,0 & \\
\hline Mãe & 199 & 81,8 & 18,2 & $1,6[0,9 ; 3,0]$ & \\
\hline
\end{tabular}

\#p: nivel descritivo do teste de associação pelo $\chi^{2}$ com correção de Yates

*\%p: porcentagem ponderada

A Tabela 41 apresenta os fatores associados à oclusopatia de caninos relacionados às características e comportamento materno. Observa-se que nenhuma variável estudada foi associada estatisticamente com referido desfecho. 
Tabela 41: Distribuição da amostra, segundo presença de oclusopatia de caninos (porcentagem ponderada) e fatores de risco relacionados ao comportamento materno. Pelotas, 1999.

Variável

Fumo na gestação

Não

Sim

Primíparas

Não

$\operatorname{Sim}$

Paridade

$<4$

$\geq 4$

Intervalo interpartal

$>18$ meses

$\leq 18$ meses

Idade materna (anos)

14 a 19

20 a 29

30 a 39

40 a 46

Amamentação (meses)

9 ou mais

4 a 8,9

1 a 3,9

$<1$

Intenção de dar bico

(nascimento) n Relação de caninos Classe I Classe IIIIII $\% p^{\star} \quad \% p^{*}$

$\begin{array}{lllc}241 & 83,7 & 16,3 & 1,0 \\ 118 & 86,5 & 13,5 & 0,8[0,4 ; 1,5]\end{array}$

$233 \quad 86,7$

13,3

1,0

$126 \quad 80,5$

19,5

$1,6[0,9 ; 2,8]$

0,997

$323 \quad 84,9$

15,1

1,0

$36 \quad 83,3$

16,7

$1,1[0,4 ; 2,8]$

0,633

19186,2

13,8

1,0

1593,8

6,3

$0,3[0,1 ; 3,4]$

0,627

$\begin{array}{cccc}55 & 80,0 & 20,0 & 1,0 \\ 203 & 86,6 & 13,4 & 0,6[0,3 ; 1,3] \\ 90 & 82,6 & 17,4 & 0,8[0,3 ; 1,9] \\ 11 & 83,3 & 16,7 & 0,6[0,1 ; 3,9]\end{array}$

0,178

$\begin{array}{cccc}78 & 80,5 & 19,5 & 1,0 \\ 78 & 90,5 & 9,5 & 0,4[0,2 ; 1,1] \\ 130 & 82,3 & 17,7 & 0,9[0,4 ; 1,8] \\ 71 & 89,5 & 10,5 & 0,5[0,2 ; 1,3]\end{array}$

0,385

Não

$317 \quad 92,3$

7,7

1,0

Sim

$28 \quad 83,8$

16,2

$2,4[0,5 ; 10,7]$

\#p: nivel descritivo do teste de associação pelo $\chi^{2}$ com correção de Yates

* \%p: porcentagem ponderada 
Verifica-se na Tabela 42, que nenhuma característica biológica da criança estudada mostrou-se associada com oclusopatia de caninos.

Tabela 42: Distribuição da amostra, segundo presença de oclusopatia de caninos (porcentagem ponderada) e fatores de risco biológicos da criança. Pelotas, 1999.

\begin{tabular}{|c|c|c|c|c|c|}
\hline Variável & $n$ & $\begin{array}{l}\text { Relação } \\
\text { Classe I }\end{array}$ & $\begin{array}{l}\text { aninos } \\
\text { sse IIIIII }\end{array}$ & OR[I $\left.C_{95 \%}(O R)\right]$ & $P^{*}$ \\
\hline Sexo & & $\% p^{x}$ & $\%$ & & 0,767 \\
\hline Masculino & 190 & 85,3 & 14,7 & 1,0 & \\
\hline Feminino & 169 & 83,6 & 16,4 & $1,1[0,6 ; 2,0]$ & \\
\hline Peso ao nascer & & & & & 0,596 \\
\hline Normal & 256 & 84,1 & 15,9 & 1,0 & \\
\hline Baixo peso & 103 & 87,7 & 12,3 & $0,7[0,3 ; 1,6]$ & \\
\hline $\begin{array}{l}\text { Perímetro cefálico } \\
\text { (percentil 10) }\end{array}$ & & & & & 0,864 \\
\hline$>10 \%$ & 245 & 84,5 & 15,5 & 1,0 & \\
\hline$\leq 10 \%$ & 110 & 83,3 & 16,7 & $1,1[0,4 ; 2,9]$ & \\
\hline $\begin{array}{l}\text { Idade gestacional } \\
\text { (semanas) }\end{array}$ & & & & & 0,875 \\
\hline 37 a 42 & 295 & 85,0 & 15,0 & 1,0 & \\
\hline$<37$ & 60 & 82,4 & 17,6 & $1,3[0,5 ; 3,2]$ & \\
\hline
\end{tabular}

Pode-se observar na Tabela 43 que nenhuma variável relacionada ao uso de bico apresentou-se associada a oclusopatia de caninos. 
Tabela 43: Distribuição da amostra, segundo presença de oclusopatia de caninos (porcentagem ponderada) e fatores de risco relacionados ao uso de bico. Pelotas, 1999.

Variável

Inicio do uso do bico

Nunca usou

Antes dos 3 meses

Entre 3 e 6 meses

Após os 6 meses

Uso de bico (12 meses)

Não

Sim

Uso de bico (5 anos)

Não

Sim

Uso de bico entre

12 meses e 5 anos

Não usou ou usou

parcialmente

$142 \quad 81,6$

18,4

1,0

Usou o tempo todo n Relação de caninos

Classe

$\% p^{*}$

Classe IIIIII

$\% p^{*}$

25,0

$276 \quad 86,3$

13,7

17,9

$30 \quad 82,1$

100,0

79,7

20,3

14,4

$0,7[0,3 ; 1,3]$

0,906

29

82,1

17,9

1,0

15,1
1,0

$0,5[0,2 ; 1,0]$

0,166

$0,7[0,2 ; 2,2]$

$0,0[0,0 ; 0,0]$

0,324

Nivel descritivo do teste de associação pelo $\chi^{2}$ com correção de Yates

* porcentagem acumulada

Os cuidados com a criança ao longo da vida são apresentados na Tabela 44, onde pode se observar que nenhuma variável estudada foi estatisticamente significativa para oclusopatia de caninos. 
Tabela 44: Distribuição das crianças, segundo presença de oclusopatia de caninos (porcentagem ponderada) e fatores de risco relacionados ao cuidado com a criança.

Pelotas, 1999.

Variável

Foi à creche aos 6 meses

Sim

Não

Foi à creche (12 meses)

Sim

Não

Foi à creche aos 5 anos

Sim

Não

Quem cuida da criança

(6 meses)

Mãe e/ou pai

Outros n Relação de caninos Classe I Classe IIIIII $\% p^{*}$ $\% p^{*}$

$17 \quad 100,0$

83,7

83,7

$16,3 \quad 0,0[0,0 ; 0,0]$

$6,3 \quad 0,0[0,0 ; 0,0]$

0,404

OR[IC $\left.C_{95 \%}(O R)\right]$

$P^{*}$

$\begin{array}{cccc}22 & 94,4 & 5,6 & 1,0 \\ 337 & 84,3 & 15,7 & 2,5[0,4 ; 15,7]\end{array}$

1,000

$\begin{array}{llll}68 & 84,3 & 15,7 & 1,0\end{array}$

$291 \quad 84,9$

15,1

$0,9[0,5 ; 2,0]$

1,000

"p: nivel descritivo do teste de associação pelo $\chi^{2}$ com correção de Yates

*\%p: porcentagem ponderada

A Tabela 45 mostra que dos problemas de saúde analisados, apenas a ocorrência de cárie dentária $(p=0,044)$ e a presença de dentes cariados ou perdidos devido a cárie $(\mathrm{p}=0,029)$ apresentaram-se associados significativamente com a presença de oclusopatia de caninos. 
Tabela 45: Distribuição da amostra, segundo presença de oclusopatia de caninos (porcentagem ponderada) e fatores de risco relacionados aos problemas de saúde da criança. Pelotas, 1999.

\begin{tabular}{|c|c|c|c|c|c|}
\hline Variável & $n$ & $\begin{array}{l}\text { Relação } \\
\text { Classe I } \\
\% p^{*}\end{array}$ & $\begin{array}{c}\text { de caninos } \\
\text { Classe III III } \\
\% p^{\star}\end{array}$ & $O R\left[I C_{95 \%}(O R)\right]$ & $P^{\prime \prime}$ \\
\hline ceo-d & & & & & 0,044 \\
\hline Zero & 129 & 90,2 & 9,8 & 1,0 & \\
\hline$\geq 1$ & 230 & 81,6 & 18,4 & $2,1[1,1 ; 4,0]$ & \\
\hline Gravidade da cárie & & & & & 0,330 \\
\hline ceo- $d \leq 3$ & 223 & 86,2 & 13,8 & 1,0 & \\
\hline ceo- $d>3$ & 136 & 81,7 & 18,3 & $1,4[0,8 ; 2,5]$ & \\
\hline $\begin{array}{l}\text { Dentes cariados e/ou } \\
\text { perdidos }\end{array}$ & & & & & 0,029 \\
\hline Não & 133 & 90,4 & 9,6 & 1,0 & \\
\hline Sim & 226 & 81,3 & 18,7 & $2,2[1,1 ; 4,3]$ & \\
\hline $\begin{array}{l}\text { Nariz entupido } \\
\text { (12 meses) }\end{array}$ & & & & & 0,523 \\
\hline Não & 257 & 85,4 & 14,6 & 1,0 & \\
\hline Sim & 94 & 81,9 & 18,1 & $1,4[0,7 ; 2,5]$ & \\
\hline $\begin{array}{l}\text { Canseira ou falta de ar } \\
\text { (12 meses) }\end{array}$ & & & & & 0,175 \\
\hline Não & 315 & 83,2 & 16,8 & 1,0 & \\
\hline Sim & 36 & 93,9 & 6,1 & $0,3[0,1 ; 1,3]$ & \\
\hline
\end{tabular}

\#p: nível descritivo do teste de associação pelo $\chi^{2}$ com correção de Yates

*\%p: porcentagem ponderada

$\mathrm{Na}$ Tabela 46 mostra que nenhuma das características relacionadas ao comportamento da criança estudadas, esteve associada com a presença de oclusopatia de caninos. 
Tabela 46: Distribuição da amostra, segundo presença de oclusopatia de caninos (porcentagem ponderada) e fatores de risco relacionados ao comportamento da criança. Pelotas, 1999.

Variável

Dorme quarto do pai

(12 meses)

Não

Sim

Dorme no quarto da mãe

(12 meses)

Não

Sim

Dorme na cama da mãe

(12 meses)

Não

Sim

Sucção de dedo (6 anos)

Não

Sim

Uso de mamadeira ao

nascimento

Não

Sim

Uso de mamadeira aos 5 anos

Não

Sim n Relação de caninos Classe I Classe II/ III $\% p^{*} \quad \% p^{*}$

$O R\left[I C_{95 \%}(O R)\right]$ 0,304

88

269

88,5

11,5

1,0

83,1

16,9

$1,6[0,8 ; 3,4]$

0,060

$33 \quad 97,1$

2,9

1,0

$324 \quad 83,1$

16,9

$9,8[0,9 ; 110,8]$

0,933

$212 \quad 84,8$

15,2

1,0

145

83,9

16,1

$1,1[0,6 ; 1,9]$

0,654

$\begin{array}{cr}327 & 85,0 \\ 32 & 80,6\end{array}$

15,0

1,0

19,4

$1,3[0,5 ; 3,2]$

0,126

$\begin{array}{cccc}350 & 84,9 & 15,1 & 1,0 \\ 8 & 60,0 & 40,0 & 3,5[0,5 ; 25,3]\end{array}$

0,501

\# p: nivel descritivo do teste de associação pelo $\chi^{2}$ com correção de Yates

* $p$ : bporcentagem ponderada 


\subsection{Análise múltipla para oclusopatia de caninos}

A partir dos resultados encontrados na análise univariada, optou-se por elaborar um modelo final múltiplo não hierárquico, já que um número muito pequeno de variáveis mostrou-se associado ao desfecho oclusopatia de caninos.

Todas as variáveis que apresentaram valores de $p<0,20$ foram introduzidas no modelo sendo que a renda familiar, a escolaridade do pai, a primiparidade, o tempo de amamentação, o início do uso de bico, a freqüência em creche aos 6 meses de idade, a canseira, a presença da mãe dormindo no mesmo quarto da criança e o uso de mamadeira ao nascimento foram retiradas do modelo após perder a significância estatística.

O modelo final para oclusopatia de caninos está representado na Tabela 47. A presença de dentes cariados ou perdidos por cárie e a presença de mordida cruzada mantiveram a significância estatística após controladas pelo sexo da criança. Crianças com dentes comprometidos pela cárie e sem tratamento ou com dentes perdidos devido a cárie tiveram 2,1 vezes a chance de apresentarem mau posicionamento de caninos comparadas àquelas sem cárie ou com dentes tratados $(p=0,026)$. Crianças com mordida cruzada apresentaram 3 vezes a chance de apresentarem mal posicionamento de caninos quando comparadas com aquelas sem esta condição $(p=0,010)$. 
Tabela 47: Associação entre oclusopatia de caninos e fatores de risco. Resultados da análise de regressão múltipla. Pelotas, 1999.
Modelo
OR[IC $\left.{ }_{95 \%}(O R)\right] \quad p^{b} \quad O R\left[I C_{95 \%}(O R)\right] \quad p^{a}$

Sexo

Masculino

1,0

1,0

Feminino

$1,1[0,6 ; 2,0]$

0,767

$1,1[0,6 ; 2,1]$

0,676

Dentes cariados e/ou perdidos

Não

1,0

Sim

$2,2[1,1 ; 4,3]$

0,029

$2,1[1,1 ; 4,2]$

0,026

Mordida cruzada

Não

1,0

1,0

Sim

$3,1[1,6 ; 5,9]$

$<0,01$

$3,0[1,6 ; 5,8]$

0,010

$\mathrm{p}^{\mathrm{b}}: \mathrm{p}$ da análise bruta,

$p^{a}$ : ajustado por sexo, presença de dentes cariados e/ou perdidos mordida cruzada

Teste de Hosmer e Lemeshow $(p=1,00)$

O Quadro 5 apresenta o resumo da ànálise para os três desfechos estudados. 
Quadro 5: Resumo da análise hierárquica para os três desfechos estudados. Fatores de risco para as oclusopatias mordida aberta anterior, mordida cruzada posterior e relação de caninos.

\begin{tabular}{|c|c|c|c|c|}
\hline Bloco & Variáveis & $\begin{array}{l}\text { Mordida } \\
\text { aberta }\end{array}$ & $\begin{array}{c}\text { Mordida cruzada } \\
\text { posterior }\end{array}$ & $\begin{array}{l}\text { Oclusopatia } \\
\text { de caninos }\end{array}$ \\
\hline \multirow{5}{*}{$\begin{array}{l}\text { Características da } \\
\text { mãe }\end{array}$} & Altura $<156 \mathrm{~cm}$ & & & \\
\hline & $\begin{array}{l}\text { Idade entre } 30 \text { e } 39 \\
\text { anos }\end{array}$ & & & \\
\hline & $\begin{array}{l}\text { Aleitamento natural } \\
<9 \text { meses }\end{array}$ & & & \\
\hline & $\begin{array}{l}\text { Trabalho ao } \\
\text { nascimento }\end{array}$ & & & \\
\hline & Intenção de dar bico & & & \\
\hline \multirow{6}{*}{$\begin{array}{l}\text { Características da } \\
\text { criança }\end{array}$} & ceo-d $\geq 1$ & & & \\
\hline & $\begin{array}{l}\text { Dentes cariados ou } \\
\text { perdidos }\end{array}$ & & & \\
\hline & Sucção digital & $5+x+2=328$ & & \\
\hline & Mordida cruzada & & & $96 x^{2} \times 5$ \\
\hline & Relação de caninos & & 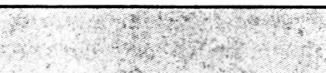 & \\
\hline & $\begin{array}{l}\text { Uso de bico entre } 12 \\
\text { meses e } 5 \text { anos }\end{array}$ & & & \\
\hline
\end{tabular}


7 Discussão 


\subsection{Aspectos metodológicos}

A presente pesquisa apresenta algumas vantagens sobre a maioria dos estudos que investigaram os fatores de risco para as oclusopatias na dentição decídua, em especial as referentes ao delineamento do estudo. Trata-se de um estudo transversal de saúde bucal aninhado à uma coorte de nascidos vivos de base populacional com altas taxas de respostas em todos os períodos da pesquisa. Este delineamento garante o conhecimento da seqüência cronológica dos eventos estudados e, também, a maior precisão das informações coletadas ao longo da vida da criança.

$\mathrm{Na}$ literatura consultada, verificou-se a existência de poucos estudos sobre o tema com o mesmo delineamento notando-se ausência de pesquisas brasileiras de base populacional, o que confere o caráter inédito deste estudo. Além disso, estudou-se múltiplas dimensões envolvidas na etiologia das oclusopatias o que não se observou na literatura sobre o tema. A grande maioria dos estudos encontrados (Quadro 4) apresentou um desenho do tipo transversal, no qual as exposições pesquisadas dependem da lembrança do entrevistado, podendo, assim, originar um tipo comum de viés: o viés de memória. Estudos transversais apresentam dificuldades em estabelecer a relação cronológica entre as exposições e os desfechos, além de apresentarem a possibilidade das exposições pesquisadas no momento da entrevista serem diferentes das que ocorreram em períodos anteriores da vida (BEAGLEHOLE et al. 1996, ROTHMAN e GREENLAND 1998). 
A amostra estudada foi obtida a partir de todos o nascidos vivos em Pelotas no ano de 1993, incluindo-se, por razões de interesse de outros pesquisadores da área médica, todas as crianças nascidas com baixo peso. Para garantir a validade dos achados, aplicou-se um fator de ponderação para o estudo de saúde bucal, de forma que a proporção de nascidos vivos com baixo peso eqüivalesse à proporção original na população. O total de perdas ocorridas neste estudo encontra-se dentro do estimado e não comprometeu os resultados devido a sua distribuição equilibrada nos principais grupos de variáveis estudados (Tabela 2 ).

Uma possível limitação do estudo, refere-se ao insuficiente tamanho da amostra para o estudo de algumas exposições, o que, possivelmente, excluiu da análise múltipla algumas variáveis. Por exemplo, a variável peso ao nascer apresentou um Odds Ratio diferente de um para o desfecho mordida aberta anterior, mas o intervalo de confiança incluiu o valor 1 . Por outro lado, as variáveis que se apresentaram associadas estatisticamente neste tamanho de amostra, isto é, um intervalo de confiança não que não incluiu o valor 1 , podem ser consideradas potenciais fatores de risco.

Além disso, todo treinamento teórico e prático da equipe que participou da pesquisa foi realizado de forma a garantir a adequada concordância diagnóstica das situações clínicas de interesse, bem como da aplicação da entrevista.

Os principais achados desta pesquisa como, por exemplo, a distribuição de freqüência da escolaridade materna, da renda familiar e da idade materna, a 
altura mediana da mãe e o tempo mediano de amamentação natural, coincidem com os resultados obtidos em outros estudos que analisaram a mesma população (GIGANTE et al. 2000). Desta forma, assegurou-se a validade interna do estudo.

Outra potencial limitação em estudos epidemiológicos que também diz respeito a validade externa do estudo, refere-se a capacidade de generalização dos resultados de um estudo para outras populações (BEAGLEHOLE et al. 1996; ROTHMAN e GREENLAND 1998). Neste caso, as particularidades da população estudada devem ser consideradas. Pelotas é um município cujas condições sociais e de saúde são representadas por melhores indicadores do que os do Brasil ou de outras regiões brasileiras. Além disso, o padrão cultural de sua população é bastante distinto quando comparado aos parâmetros nacionais ou da maioria das regiões do país. Portanto, estas diferenças devem ser consideradas antes de se generalizar os resultados encontrados.

Outros possiveis tipos de viéses, como erros de classificação e potenciais variáveis de confusão ((BEAGLEHOLE et al. 1996; ROTHMAN e GREENLAND 1998)) foram controlados e/ou evitados. O primeiro, ao se assegurar a boa reprodutibilidade diagnóstica através da padronização de critérios e da calibração dos examinadores. Possíveis variáveis de confusão foram controladas estatisticamente, como pôde-se observar ao longo da apresentação dos resultados e que serão discutidos no decorrer deste capitulo.

A investigação de fatores de risco para as oclusopatias implica na coleta de um número de informações bastante grande, com a possibilidade de que 
uma ou mais variáveis de confusão possam explicar total ou parcialmente o efeito detectado. Portanto, tornou-se indispensável o emprego de análise multivariada para garantir a independência dos fatores de risco.

A utilização do modelo hierárquico e a análise estatística realizada através da regressão logística múltipla permitiu identificar fatores de risco independentes para as oclusopatias na dentição decídua em diferentes períodos do desenvolvimento infantil. A modelagem hierarquizada é uma alternativa utilizada em estudos epidemiológicos que apresentam um grande número de variáveis (FUCHS 1993; OLINTO 1993), sendo que a hierarquização das mesmas é estabelecida no marco conceitual. O modelo hierarquizado permite ainda, um modelo com um número de fatores de risco suficiente para se testar as associações, porém não saturado pelo excesso de variáveis.

Apesar de amplamente utilizado, o modelo estatístico de regressão logística múltipla apresenta algumas limitações quando empregado em estudos transversais. Este modelo estima a razão de chances (Odds Ratio - OR). Em se tratando de estudo transversal, a medida de associação apropriada é a Razão de Prevalência (RP) do efeito/ evento entre os indivíduos expostos e nãoexpostos aos fatores de interesse do estudo e não o $O R$. Sabe-se que o $O R$ sempre superestima o valor da RP e somente quando a prevalência do evento estudado é baixa, isto é, menor do que $10 \%$, o valor de $O R$ encontrado aproxima-se da RP. As diferenças nos valores da $O R$ e da RP repercutem diretamente na interpretação das medidas de efeito como, por exemplo, quando queremos estimar o risco atribuivel populacional, atribuindo efeitos de risco ou 
de proteção maiores do que verdadeiramente os são (ZOCCHETTI et al. 1995; DAVIES et al. 1998; THOMPSON et al. 1998; ZHANG e YU 1998; HIRAKATA 1999, citados por PINHO 2002).

Entretanto, a utilização do $O R$ refere-se a magnitude da associação obtida através da regressão logística múltipla, porém não afeta a interpretação qualitativa da associação. Neste estudo o OR foi utilizado apenas como medida de associação, não havendo comparações quanto a sua magnitude.

\subsection{A prevalência das oclusopatias}

Algumas variações metodológicas para se medir mordida aberta anterior foram encontradas entre os estudos analisados mas, acredita-se, pouco influenciaram na análise deste tipo de desfecho, permitindo algumas comparações. Estas variações foram relacionadas ao critério de diagnóstico para a presença de mordida aberta, como, por exemplo, a estimativa em milímetros do espaço encontrado entre os incisivos superiores e inferiores, ou apenas o registro da existência de falta de contato entre este dentes. Nesta pesquisa, a presença de mordida aberta nas crianças que se apresentavam em processo de exfoliação, e/ou erupção dos incisivos inferiores, foi medida a partir de uma linha de oclusão que teve como referência, a cúspide dos caninos decíduos. Nenhuma criança apresentou-se em processo de exfoliação e/ou erupção dos incisivos superiores.

A prevalência de oclusopatias na população de estudo apresentou uma grande variação conforme o tipo de problema analisado. 
A presença de mordida aberta anterior, encontrada em $46,3 \%$ da amostra $\left(I C_{95 \%}=[41,2 \%-51,4 \%]\right)$, foi mais alta do que a observada na maioria dos estudos internacionais e nacionais como pode-se observar nos Quadros 2 e 3.

Prevalência maior de mordida aberta foi encontrada por KISLING e KREBS (1976) em Copenhagen e resultados semelhantes foram observados nas pesquisas de STECKSEN-BLICKS e HOLM (1995) na Suécia. No Brasil, todas as pesquisas encontradas na literatura mostraram prevalências mais baixas, variando entre $20 \%$ e $29 \%$ como a de SILVA e ARAÚJO (1983) na llha do Governador (RJ), de VALENTE e MUSSOLINO (1989) em Ribeirão Preto (SP) e de TOMITA (1997) em Bauru (SP).

Uma importante variação observada nestes estudos, refere-se a idade ou faixa etária pesquisada. Este fator pode estar influenciando as diferentes prevalências encontradas, visto que a exposição a fatores de risco para a mordida aberta anterior, como a presença de sucção digital ou de bico artificial, pode variar conforme a idade da criança, no que se refere ao tempo e freqüência do hábito. Além disso, as diferenças culturais que determinam maior ou menor exposição aos fatores de risco para mordida aberta, podem estar contribuindo para as diferenças nas prevalências entre os estudos analisados.

Ao comparar a prevalência de mordida cruzada posterior encontrada nesta pesquisa com os estudos internacionais e nacionais, verifica-se algumas semelhanças. Da amostra estuda, $18,2 \%\left(\mathrm{IC}_{95 \%}=[14,2 \%-22,2 \%]\right)$ apresentaram mordida cruzada, resultado que corrobora os achados das pesquisas realizadas 
por KISLING e KREBS (1976), STECKSEN-BLICKS e HOLM (1995), TSCHILL et al. (1997) e BAEZ et al. (1999).

Por outro lado, um número maior de estudos internacionais mostrou prevalências bem mais baixas deste tipo de problema, com uma variação entre $2 \%$ e $13,5 \%$ nos estudos realizados por INFANTE (1975), DE VIS et al. (1983), GHEZZI et al. (1986), WOON (1988), JONES et al. (1993), PAUNIO et al. (1993), KABUE et al. (1995), TROTMAN e ESLBACH (1996), OTUYEMI et al. (1997), CARVALHO et al. (1998), NAVARRETE e SPINOZA (1998) e KARJALAINEN et al. (1999).

Pesquisa realizada em Santiago, Chile por AGURTO et al. (1999), mostraram uma prevalência de mordida cruzada posterior igual a $28 \%$, ou seja, mais alta do que os outros estudos e também quando comparada a esta pesquisa.

Entre as pesquisas brasileiras que avaliaram a presença de mordida cruzada na dentição decídua encontrou-se resultado semelhante no estudo realizado por MATHIAS (1984), em São Paulo, SP. Uma menor prevalência foi observada no estudo de SILVA e ARAÚJO (1983), na llha do Governador, RJ e na pesquisa realizada por TOMITA (1997), em Bauru, SP.

É importante ressaltar que estas diferenças podem ser atribuídas, parte aos diferentes métodos de diagnóstico e, também, a variação nas faixas etárias estudadas, o que poderia estar influenciando a exposição a diferentes fatores de risco para a mordida cruzada posterior. 
A prevalência de classes 2 e 3 de caninos foi baixa, com apenas 15,2\% das crianças apresentando esta condição $\left(\mathrm{IC}_{95 \%}=[11,5 \%-18,9 \%]\right)$. Os estudos encontrados na literatura mostram uma grande variação, alguns apontando uma prevalência mais baixa (WOON 1988; FARSI e SALAMA 1996, OTUYEMI et al. 1997) e outros maiores prevalências com relação ao mau posicionamento de caninos (WOON 1988; BAEZ et al. 1999).

\subsection{Condições socioeconômicas e as oclusopatias}

Nesta pesquisa, as condições socioeconômicas analisadas não apresentaram associação com as oclusopatias estudadas.

Apesar dos poucos estudos existentes sobre o tema, a influência dos fatores socioeconômicos sobre os problemas oclusais é percebida de duas diferentes maneiras.

A primeira representada por um pequeno número de pesquisas que encontraram associação entre a presença de oclusopatias específicas, como a mordida cruzada posterior e a relação de molar e a condição socioeconômica. Estas pesquisas mostram resultados conflitantes, ora apontando uma prevalência maior de oclusopatias em crianças de nível socioeconômico mais baixo, como por exemplo a presença de relação classe 1 (SILVA FILHO et al. 1990) e de classe 2 de molar (INFANTE 1975), ora relacionando este problema com crianças de escolas privadas, condição esta utilizada como proxy de boa condição socioeconômica (MORON et al. 1995). 
A segunda forma, que envolve um maior número de estudos, não revela associação significativa entre condição socioeconômica e presença de oclusopatias (CALISTI et al. 1960; MEYERS e HERTZMBERG 1988; SILVA FILHO et al. 1990; KHARBANDA et al. 1994; TOMITA 1997; FRAZÃO 1999; NIETO GARCIA et al. 2001), o que corrobora os achados desta pesquisa.

A saúde infantil, particularmente nos países em desenvolvimento, é determinada por várias características socioeconômicas. Como exemplo, as doenças infecciosas têm sido associadas com indivíduos com menor renda familiar, com baixa escolaridade e com aqueles que vivem em precárias condições de saneamento básico, onde inexistem água tratada e esgoto. Esta condições não são responsáveis diretas pela ocorrência de doença, mas favorecem a proximidade de alguns determinantes (EGBUONU e STARFIELD 1982; MOSLEY e CHEN 1984, CÉSAR et al. 1997).

As mães pobres e com baixa escolaridade iniciam a vida reprodutiva mais precocemente, estando menos aptas a se beneficiar da estrutura assistencial durante a gestação. Além disso, mães menos favorecidas socialmente podem apresentar um estado nutricional deficiente prévio à gestação, provocando ganho de peso reduzido na gestação e, conseqüentemente, criando um ambiente intra-uterino desfavorável ao crescimento fetal (FUCHS et al. 1996, GIGANTE, et al. 2000), inclusive os relacionados às estruturas oro-faciais.

Com relação a saúde bucal infantil, a cárie dentária apresenta uma determinação social bem estabelecida na literatura, representada pela classe 
social à qual ocupam os indivíduos, ou pelos atributos sociais e econômicos individuais como a renda e a escolaridade (BEAL 1996; WATT e SHEIHAM 1999; PERES 2002). O mesmo não foi observado com relação as oclusopatias, fato este reforçado por este estudo.

Nesta pesquisa, a escolaridade do pai igual ou inferior a 8 anos de estudo apresentou-se no limite da significância estatística para a presença de mordida cruzada $(p=0,079)$ e a renda familiar igual a um salário mínimo ou menos também manteve-se na mesma condição para o desfecho oclusopatia de caninos $(p=0,081)$, ambas nas análises univariadas, porém na análise múltipla não foram fatores de risco independentes.

Uma particularidade deste estudo que não foi esclarecida, foi que o nivel de escolaridade dos pais (limite da significância estatística) mostrou-se mais importante que o das mães na análise univariada, o mesmo ocorrendo quando outros problemas bucais, como a gravidade de cárie dentária, foram analisados (PERES 2002). Este achado fez com que se tentasse manter a escolaridade dos pais no modelo multivariado ao invés da escolaridade das mães. $O$ resultado final foi o mesmo, optando-se em manter a escolaridade da mãe.

Pelo exposto, escolaridade da mãe, representante do nivel socioeconômico, foi mantida até o final da análise com o objetivo de ajustar a análise das outras variáveis estudadas nos niveis hierárquicos mais proximais, independentemente de sua significância estatística. 


\subsection{Características maternas e as oclusopatias}

As características biológicas da mãe, como o baixo índice de massa corporal, apresentou-se no limite da associação estatística para a presença de mordida aberta e para mordida cruzada na análise univariada, enquanto a altura materna menor do que $156 \mathrm{~cm}$ mostrou-se estatisticamente associada com a presença de mordida aberta, na análise univariada e mesmo após controlada por todos fatores socioeconômicos estudados. O mesmo não ocorreu com índice de massa corporal quando relacionado com a presença de mordida aberta e cruzada, pois perdeu a significância após ajuste pela escolaridade da mãe .

Estudos mostram que a altura materna está diretamente associada a melhores condições sociais como, por exemplo, a renda e a escolaridade (TOMASI et al. 1996). Neste estudo, a altura materna também foi um marcador da posição social da mãe, pois uma forte associação foi encontrada entre esta variável e as condições socioeconômicas como a renda familiar e a escolaridade materna (dados não apresentados). Como o efeito da altura materna não desapareceu, após controlado pelos fatores socioeconômicos, sugere-se que fatores biológicos outros que não foram estudados, poderiam estar contribuindo para melhor esclarecer o potencial genético deste desfecho sobre as oclusopatias.

Neste estudo também foram fatores de risco independentes para a presença de mordida aberta a idade da mãe entre 30 e 39 anos, o tempo de aleitamento natural predominante menor do que 9 meses e a intenção da mãe 
em oferecer bico à criança desde o nascimento, após ajustados pela escolaridade e altura maternas.

As mães que trabalhavam ao nascimento da criança tiveram mais chance de terem filhos com mordida cruzada do que aquelas que não trabalhavam, no limite da significância estatística. Esta situação ajustou-se ainda mais, após controlada pela escolaridade da mãe e o tempo de aleitamento materno, mas manteve o limite da significância estatística. $O$ aleitamento natural predominante menor do que 9 meses também apresentouse como fator de risco para a presença de mordida cruzada após ajuste pela escolaridade e trabalho da mãe ao nascimento da criança.

FACCHINI (1995) mostrou que o trabalho materno não foi prejudicial à saúde infantil e que o trabalho assalariado em populações proletárias contribuiu para o crescimento das crianças filhos de mães trabalhadoras, o que foi observado através do ganho de peso ocorrido no primeiro ano de vida da criança. O resultado deste estudo aponta para uma característica favorável à saúde infantil relacionada ao trabalho materno.

PERES (2002) também não identificou nenhum fator de risco relacionado ao trabalho materno com relação a prevalência e gravidade de cárie dentária na mesma população analisada deste estudo.

O trabalho materno ao nascimento da criança apresentou-se fortemente associado ao tempo de amamentação neste estudo. Crianças cujas mães trabalhavam ao nascimento receberam aleitamento materno predominantemente por menos tempo do que aquelas em que as mães não 
tinham atividade fora de casa, diferença esta estatisticamente significativa $(p<$ 0,001). Isso talvez pudesse explicar a associação entre o trabalho materno ao nascimento e a presença de mordida cruzada posterior aos 6 anos de idade. Esta variável seria uma proxy do tempo de aleitamento natural.

O tipo e duração do aleitamento nos primeiros anos de vida da criança parecem sofrer influências de fatores sociais e culturais. Além disso a percepção do público sobre o senso comum e o padrão "normal" de atitudes a respeito do aleitamento natural ou artificial sofre grande impacto da mídia em diversas partes do mundo (HENDERSON et al. 2000).

Utilizando a mais importante e representativa fonte dos Estados Unidos, o National Maternal and Infant Health Survey (NMIHS), VISNESS e KENNEDY (1997) realizaram uma pesquisa a fim de explorar os fatores associados com o início e duração do aleitamento materno na população americana no ano de 1988. Os resultados sugeriram que mães brancas, mais velhas e com mais alta renda, tiveram maior probabilidade de amamentar naturalmente seus filhos. A baixa taxa de início de aleitamento materno não foi atribuída à participação da mãe na força de trabalho; entretanto, o retorno da mãe ao trabalho esteve associado com o desmame precoce entre as mães que estavam amamentando. As mães que apresentavam mais autonomia no trabalho, foram as que mais amamentavam após o retorno ao trabalho.

A duração da amamentação foi estudada em 556 mulheres que tiveram seus filhos em 2 maternidades na Austrália. Foi observada associação positiva entre tempo de amamentação e nivel de educação da mãe e idade da mãe 
(SCOTT et al. 1999). Melhor nivel de educação da mãe também foi associado com a duração da amamentação num estudo realizado na Itália (RIVA et al. 1999). Mães mais velhas amamentaram por mais tempo seus filhos do que as mães mais jovens, num estudo de coorte realizado com 191 crianças em São Francisco, EUA (HAMMER et al. 1999).

Esta situação corrobora os achados desta e de outras pesquisas (PICADO et al. 1997; BRANGER et al. 1998) que mostram o desmame precoce inversamente associado a situação socioeconômica das mães e positivamente associado ao retorno ao trabalho logo após o nascimento da criança e a idade das mães.

SABULSKY et al. (1995) não encontraram diferenças significativas nos padrões de amamentação natural com relação ao trabalho materno fora de casa, nivel de educação dos pais e condições socioeconômicas.

O trabalho materno ao nascimento pode estar influenciando a presença de oclusopatias nas crianças, particularmente a presença de mordida cruzada, devido a dificuldade de se manter o aleitamento materno por um período adequado ao desenvolvimento oro-facial, ou seja, o trabalho materno ao nascimento pode ser um marcador de tempo de aleitamento natural. A ausência da mãe devido ao trabalho acarretaria, hipoteticamente, insegurança emocional à criança, a qual seria compensada através da introdução de hábitos deletérios, como o bico, que por sua vez, intensificaria a presença de oclusopatias. A intenção de oferecer bico para a criança desde o nascimento parece ser um 
padrão cultural muito forte na população estudada, já que uma proporção muito pequena das mães não pretendia adotar esta medida junto a criança.

Uma menor prevalência e gravidade das oclusopatias têm sido observadas em crianças cujo periodo de aleitamento natural foi maior do que nas crianças que foram amamentadas por pouco tempo, devido ao impacto desta atitude sobre o desenvolvimento dos tecidos oro-faciais (LABBOK e HENDERSDHOT 1987; AUERBACH 1990, NOWAK 1991; DAVIS e BELL 1991; DEGANO e DEGANO 1993, O'BRIEN et al. 1996).

Estudos que não encontraram associação entre presença de mordida cruzada e tempo de amamentação atribuem os achados à extremamente baixa prevalência de aleitamento natural nos paises pesquisados (OGAARD et al. 1994).

Pesquisas que avaliaram o tempo de amamentação e a presença de oclusopatias corroboram os achados deste estudo, enfatizando a associação parcial do aleitamento materno com a presença de problemas oclusais, como por exemplo, diastemas entre os dentes decíduos anteriores, situação esta não avaliada na presente pesquisa (LEGOVIC e OSTRIC 1991) e uma associação estatística marginal entre desmame precoce e necessidade de tratamento ortodôntico (MEYERS e HERTZBERG 1988).

KARJALAINEN et al. (1999) encontraram resultados semelhantes a esta pesquisa com relação a presença de mordida cruzada, sendo, provavelmente o primeiro estudo que mostrou esta associação. Do total de 148 crianças, observaram-se que o tempo de aleitamento materno exclusivo e predominante 
foram, ambos, mais curtos naquelas crianças que apresentavam mordida cruzada posterior.

ALLEN e PELTO (1985) classificaram as variáveis consideradas determinantes para a duração do aleitamento em dois grupos: o grupo dos fatores sócio- comportamentais e o grupo dos fatores bio-culturais. O primeiro, seriam identificados pelas atitudes, o apoio social e a situação de trabalho e o segundo, seriam aqueles que têm um efeito mediado, provavelmente, por interações dos processos biológicos com os sócio - comportamentais como a experiência prévia, as práticas de alimentação no hospital, a idéia que a mãe tem a respeito da suficiência do leite materno, o horário de alimentação entre outros.

Considerando a classificação descrita anteriormente, PICADO et al. (1997) encontraram a experiência prévia em amamentar como um importante fator para a amamentação exclusiva e com o tempo total de amamentação. As atitudes, o apoio social e a situação de trabalho da mãe foram importantes fatores preditivos para a duração total da amamentação. Este estudo foi realizado em Manágua, Nicarágua, com 556 mães moradoras de bairros considerados pobres da cidade.

A renda familiar mostrou associação com a prevalência de amamentação aos 6 meses de idade, embora sem apresentar uma tendência linear, no estudo realizado por GIGANTE et al. (2000) na mesma população da presente pesquisa. As mães com renda familiar mais alta apresentaram maior prevalência de amamentação, enquanto que as mães de renda intermediária - 
entre 3,1 e 6 salários mínimo- foram as que apresentaram a menor prevalência de amamentação de todos os grupos de renda.

O outro achado importante deste estudo mostrou que as mães mais velhas e não fumantes durante a gestação amamentaram mais tempo. Além disso, tanto o peso pré-gestacional com a altura materna estiveram associados com a amamentação, confirmando os achados na literatura (BROWN et al. 1986; BARBOSA et al. 1997; GONZALES-COSSIO 1998).

Em síntese, existem características e comportamentos maternos que influenciam o tempo de aleitamento natural, o que pode prejudicar o desenvolvimento as arcadas dentárias.

\subsection{Os fatores biológicos das crianças e as oclusopatias}

A idade gestacional menor do que 37 semanas, o baixo peso ao nascer e o perímetro cefálico menor ou igual a $10 \%$ foram fatores de risco para a presença de mordida aberta anterior na análise univariada, porém não apresentaram significância estatística, o mesmo ocorrendo para os outros desfechos estudados

Os mesmos resultados foram encontrados por TOMITA (1997) que não observou associação estatisticamente significativa entre má oclusão e baixo peso ao nascer e entre presença de mordida aberta e baixo peso ao nascer.

Poucas pesquisas têm explorado a relação das oclusopatias com os fatores biológicos, sendo que o enfoque tem sido feito de duas maneiras. A primeira delas, investigando os efeitos sobre a oclusão dentária de intervenções 
específicas, como por exemplo, a utilização de intubação oral ao nascimento decorrente da prematuridade da criança. Esta medida tem sido associada positivamente ao desenvolvimento de mordida cruzada posterior e ao aprofundamento do palato ao longo da vida da criança. Estes efeitos foram observados em uma amostra de crianças entre 3 e 5 anos e entre 7 e 10 anos de idade em Tokio, Japão, onde compararam-se dois grupos distintos de crianças nascidas com baixo peso e que diferenciavam pelo fato de terem ou não sido intubadas por via oral ao nascimento. As crianças que foram submetidas a este procedimento apresentaram uma prevalência maior de mordida cruzada posterior e aprofundamento de palato (KOPRA e DAVIS 1991). Outra pesquisa realizada em uma amostra de crianças entre 2 e 5 anos de idade em Chicago, EUA, também mostrou uma associação positiva entre presença de mordida cruzada e uso de intubação oral ao nascimento devido a prematuridade (FADAVI 1992). No presente estudo não foram pesquisados procedimentos como a intubação oral ao nascimento.

outro enfoque adotado para se investigar os fatores biológicos da criança, refere-se ao impacto que estas condições poderiam provocar no crescimento e desenvolvimento das estruturas oro-facias, direta ou indiretamente, e conseqüente estabelecimento das oclusopatias. Esta hipótese norteou a análise desta pesquisa sobre os fatores biológicos da criança, observando-se uma associação forte e inversa entre o baixo peso ao nascer e tempo de amamentação (dados não apresentados). Um maior tempo de amamentação foi fator protetor para a presença de mordida aberta anterior e 
mordida cruzada posterior independente do peso ao nascer. Além disso, ao ser controlado pelo tempo de amamentação, o baixo peso ao nascer perdeu totalmente a significância estatística, mostrando a importância da amamentação no estímulo do crescimento e desenvolvimento oro-facial.

\subsection{As características das crianças e as oclusopatias}

Os resultados deste estudo mostraram que não houve diferença estatisticamente significativa entre a presença de qualquer oclusopatia estudada e o sexo da criança. Estes achados corroboram os resultados da maioria das pesquisas realizadas com relação a dentição decídua (PAUNIO et al. 1993; OGAARD et al. 1994; KHARBANDA et al. 1997; FARSI e SALAMA 1997; TOMITA 1997; FRAZÃO 1999).

O uso de bico entre 12 meses e 5 anos de idade, a presença de dentes atacados pela cárie e a sucção digital foram fatores de risco para mordida aberta anterior, após controlados pelas variáveis mais distais e pelas variáveis do mesmo bloco.

A análise do uso de bico no decorrer da vida da criança mostrou que a criança que inicia precocemente este hábito tem um alto risco de desenvolver mordida aberta, porém este risco desaparece quando se considera o tempo e a freqüência do hábito, sugerindo que o tempo de duração e a intensidade deste hábito é mais importante do que o seu início precoce. Estes resultados corroboram os achados de outras pesquisas que também evidenciaram o uso 
prolongado do bico como fator mais importante para o desenvolvimento de mordida aberta anterior e mordida cruzada posterior, do que o inicio de seu uso precocemente (LARSSON 1983; ADAIR et al. 1995; O'BRIEN 1996; KARJALAINEN et al. 1999).

Os fatores de risco para o desenvolvimento de hábitos de sucção prolongados pelas crianças foram identificados por WARREN et al. (2000), em um dos poucos estudos longitudinais realizados sobre o tema. Os autores encontraram, através de análise multivariada, que mães mais velhas, com alto nivel de instrução e primiparas, apresentaram mais chances dos seus filhos manterem os hábitos de sucção não nutritiva até os 5 anos de idade, do que aquelas em condições diferentes das citadas. Outras pesquisas também apontam as mães mais velhas (PAUNIO et al. 1993) e as mães e pais com melhor nível de escolaridade (FARSI e SALAMA 1997), com maior probabilidade de terem filhos com hábito prolongado de sucção de bico.

Outros estudos têm mostrado associação positiva, estatisticamente significativa, entre nível socioeconômico alto e presença de hábitos de sucção não nutritiva prolongados (CALISTI et al. 1960; INFANTE 1976; ADAIR 1995). $\mathrm{Na}$ presente pesquisa o uso prolongado do bico apresentou-se associado positivamente ao maior nivel de escolaridade da mãe (dados não apresentados).

Neste estudo, o uso prolongado de bico mostrou-se positivamente associado ao fato da criança dormir no quarto e/ou na cama da mãe (dados não apresentados). As crianças que dormiam nos seus próprios quartos, tiveram 
menos chance de utilizar prolongadamente o bico do que aquelas que dividiam ao quarto e/ou a cama com a mãe. Ao inserir o uso de bico no modelo múltiplo para os desfechos mordida aberta anterior e oclusopatia de caninos, o local em que a criança dormia perdeu a significância estatística mostrando a dependência desta variável com o uso de bico. Este achado corrobora o resultado encontrado em outra pesquisa (PAUNIO et al. 1993); contudo, outros estudos poderiam ser realizados para melhor compreender as razões desta associação.

Identificar os fatores que levam ao prolongamento do uso de bico pode contribuir para direcionar as ações às populações mais suscetíveis, através de aconselhamento destas mães nos primeiros anos de vida da criança, o que poderia ser realizado pelo pediatra, agentes de saúde, auxiliares de enfermagem e, também, nas clínicas odontológicas especializadas em bebês.

Outra questão importante é o incentivo ao aleitamento natural, o máximo de tempo possivel, visto que a chance de se utilizar o bico por mais tempo e mais intensamente foi maior entre as crianças cujo tempo de amamentação natural foi menor.

Evitar o uso de bico foi um dos 10 passos recomendados para se obter sucesso no aleitamento natural na década de 90 nos EUA (WHO 1989, UNICEF 1996). Embora a maioria das evidências indiquem que o uso de bicos artificiais entre crianças que estão sendo amamentadas no peito está associado com um significativo declinio na duração da amamentação (VICTORA et al. 1993), dois outros estudos contestam estes achados, afirmando que a associação entre 
estes dois desfechos é apenas casual (VICTORA et al. 1997a; SCHUBIGER et al. 1997).

Outros estudos levantaram a hipótese de que o que influencia no aleitamento natural é o ritmo e o período em que o bico é introduzido na vida criança; ou seja, quando a criança inicia o uso de bico antes da estabilização da amamentação o risco de desmame é maior do que quando isto acontece após a amamentação natural estar estabilizada (NEWMAN 1990; RIGHARD e ALADE 1992; RIGHARD 1996).

Em um estudo de coorte, 265 duplas de mães e filhos foram seguidos para analisar situações relacionadas a amamentação como duração, problemas e freqüência, bem como o efeito do uso de bico. Os autores verificaram que o uso de bico foi associado, independentemente de outros fatores, com o declínio da amamentação exclusiva ou predominante. A duração da amamentação durante os três primeiros meses após o parto não foi afetada pelo uso de bico (HOWARD et al. 1999)

VICTORA et al. (1993) observaram que, entre 249 crianças que ainda foram amamentadas no primeiro mês de idade, o risco de desmame no período entre 1 e 24 meses foi mais alto entre aquelas que utilizavam bico do que as que não utilizavam, independentemente do sexo da criança, idade, peso ao nascer, condições socioeconômicas e época de introdução da mamadeira.

AARTS et al. (1999) corroboram os achados do estudo de VICTORA et al. (1993). Através dos resultados de um estudo prospectivo com 506 pares de mães e crianças acompanhados desde o nascimento, os autores evidenciaram 
a relação do uso de bico com a curta duração da amamentação exclusiva e predominante, mesmo entre as mães que se apresentavam altamente motivadas para o aleitamento. Esta associação não foi encontrada entre as crianças que apresentavam a sucção de dedo.

A sucção digital prolongada aos 6 anos de idade demonstrou alterar a arcada dentária favorecendo a mordida aberta e atuando como um fator local independente das características biológicas da criança e do tempo de aleitamento natural, o que corrobora os achados de outras pesquisas (FUKUTA et al. 1996; TOMITA 1997). Por outro lado, a sucção digital não foi fator de risco para as outras oclusopatias, o que não coincide com o resultado de outro estudo que encontrou uma associação estatisticamente significativa entre sucção digital e presença de relação classe 2 de caninos (FARSI e SALAMA 1997).

FRIMAN e SCHMITT (1989) relataram que crianças na pré-escola que possuiam o hábito de sucção digital, pareciam menos felizes, menos atrativas e menos simpáticas. Fatores emocionais relacionados a este hábito poderiam ser mais investigados no intuito de esclarecer o que desencadeia o prolongamento da sucção digital durante a vida de alguns indivíduos.

A presença de mordida cruzada foi fator de risco para mordida aberta, porém ao se inserir no modelo o uso de bico entre 12 meses e 5 anos de idade, a presença de mordida cruzada perdeu a significância estatística. Provavelmente, a mordida cruzada esteve associada com o desfecho mordida 
aberta e com o uso de bico entre 12 meses e 5 anos de idade, ou seja, comportou-se como uma variável de confusão.

Com relação à mordida cruzada, a presença de oclusopatia de caninos permaneceu como fator de risco independente da criança utilizar bico entre 12 meses e 5 anos de idade, o que pode estar indicando, hipoteticamente, uma causa semelhante para os dois tipos de oclusopatias não investigada nesta pesquisa.

O uso de bico entre 12 meses e 5 anos de idade mostrou-se associado a presença de mordida cruzada, porém perdeu a significância estatística ao ser controlado pelas variáveis mais distais, entre elas, o tempo de amamentação. Este resultado foi semelhante ao achado de FARSI e SALAMA (1997) que também não encontraram associação entre presença de hábitos de sucção não nutritivas e mordida cruzada posterior em um grupo de 383 crianças de 3 a 5 anos de idade na Arábia Saudita.

OGAARD et al. (1994) encontraram resultados diferentes, com uma alta prevalência de mordida cruzada posterior entre as crianças que utilizaram bico aos 3 anos de idade, porém observaram a mesma inter-relação entre a presença de mordida cruzada posterior e a relação de caninos, mostrando que em crianças que utilizam bico, a mordida cruzada posterior foi fator predisponente para oclusopatia de canino e conseqüente encurtamento dos arcos superiores e inferiores. Maior probabilidade de desenvolvimento de mordida cruzada, devido ao encurtamento dos arcos dentários, também foi 
constatada por LINDSTEN et al. (1996), entre as crianças 3 anos de idade que usaram bico na Noruega.

Os resultados encontrados na presente pesquisa sugerem que a mordida cruzada posterior pode estar mais relacionada ao crescimento e desenvolvimento da arcada dentária que, por sua vez, pode ser promovido pelo aleitamento natural, como mostra o estudo realizado por KARJALAINEN et al. (1999). Estes autores encontraram tempo de aleitamento natural exclusivo mais curto entre as crianças com mordida cruzada posterior quando comparado às crianças sem este problema, em um grupo de crianças com 3 anos de idade, em Turku, Finlândia.

A introdução da mamadeira pode implicar num desmame precoce e, conseqüentemente, promover um menor impacto na atividade muscular, interferindo no desenvolvimento pleno dos órgãos mastigatórios. Desta forma, as oclusopatias poderiam se estabelecer. Nesta pesquisa a utilização da mamadeira apresentou-se associada positivamente com a presença de mordida aberta, porém perdeu a significância estatística ao ser controlada pelas outras variáveis do mesmo nível hierárquico. O uso de mamadeira não foi fator de risco para nenhuma oclusopatia estudada.

Estudo de LABBOK et al. (1987) mostrou a relação entre o uso da mamadeira e o tempo de aleitamento natural, o que corrobora os achados desta pesquisa de que o efeito da utilização da mamadeira depende do tempo em que a criança foi amamentada naturalmente. MEYERS e HERTZBERG (1988) encontraram apenas uma significância estatística marginal entre a utilização de 
mamadeira e a presença de oclusopatias quando controlado pelo tempo de amamentação em um grupo de 454 crianças em Boston, EUA.

Durante um simpósio internacional realizado em Bruxelas (1986) e em Chicago (1988), pesquisadores concluíram que estava havendo um aumento na prevalência de hábitos de sucção não nutritiva em crianças de paises industrializados, possivelmente devido às alterações ocorridas com relação à responsabilidade e atitudes dos pais; estas, por sua vez, são fortemente influenciadas pelas pressões econômicas e sociais.

O efeito do uso prolongado de bicos ou chupetas e sua influência no desenvolvimento das oclusopatias tem sido controverso. Ainda mais controverso tem sido como realizar a prevenção destes hábitos e/ou qual o período mais apropriado para intervir e interromper este hábito.

O Simpósio internacional realizado em 1990 em Oslo, Noruega, no qual participaram pesquisadores de diversos paises como Dinamarca, Noruega, Suécia, Bélgica, Alemanha, Itália e os EUA, foi um importante marco para melhor compreender o papel dos hábitos de sucção não nutritiva sobre as oclusopatias. O propósito deste Simpósio foi o de estabelecer se estes hábitos estariam aumentando nos paises industrializados, documentar seus efeitos sobre as relações dentais, discutir prevenção e tratamento precoce e identificar áreas para futuras investigações.

Dentre as conclusões obtidas no referido encontro, uma das mais importantes foi que pressões sociais e econômicas influenciaram fortemente na freqüência e duração dos hábitos de sucção não nutritiva. Além disso, os 
pesquisadores evidenciaram que estes hábitos podem estar presentes ou não, de acordo com as diferenças culturais existentes.

Crianças suecas com hábito de sucção aos 3 anos de idade apresentaram uma prevalência de mordida cruzada igual $21 \%$, enquanto que as crianças sem estes hábitos, a prevalência desta oclusopatia foi igual $5 \%$ (NOWAK 1991).

A distância entre caninos também mostrou-se alterada nas crianças que usavam bico ou apresentavam sucção digital quando comparada às crianças sem estes hábitos. Estudo longitudinal demonstrou a tendência de encurtamento dos arcos maxilares em crianças com 4 anos de idade com hábitos de sucção (NOWAK 1991).

Neste estudo, os hábitos bucais influenciaram parcialmente a presença de oclusopatias. Apesar do início precoce de bico estar fortemente associado à presença de mordida aberta, verificou-se que, quando ajustado pelo tempo total de uso de bico, esta variável perdeu a significância estatística, permanecendo no modelo final apenas o tempo de duração total de uso de bico, entre 12 meses e 5 anos de idade, ajustado pelas variáveis mais distais. Provavelmente, as crianças que iniciam tardiamente o uso de bico tendem a abandonar este hábito mais precocemente, evitando-se, desta forma, a mordida aberta aos 6 anos de idade. Considerando-se os resultados desta pesquisa, utilizar o bico até 1 ano de idade, parece não influenciar na presença de mordida aberta aos 6 anos de idade. A intenção da mãe de oferecer bico para a criança desde o nascimento manteve-se fortemente associada à mordida aberta, mesmo 
ajustada pelas variáveis mais distais e pelas mais proximais. Este fato pode estar evidenciando a influência sociocultural na decisão de utilizar bico mesmo antes da criança nascer.

Os resultados obtidos com relação à cárie dentária mostraram que a presença deste problema aumenta duas vezes a chance da criança apresentar mordida aberta e oclusopatia de caninos quando comparadas às crianças livres de cárie, independentemente dos outros fatores mais distais. PLATER (1949), há mais de 50 anos, afirmou que os indivíduos que residiam em área cujo teor de flúor nas águas de abastecimento foi considerado ótimo, apresentaram uma redução de $30 \%$ na prevalência de oclusopatias devido, provavelmente, à prolongada vida funcional dos dentes decíduos ausentes de cárie dentária.

Este achado remete à discussão de que os indivíduos que estão mais expostos a um determinado problema de saúde, também estão para outros problemas. Sendo assim, medidas mais amplas de promoção de saúde e melhoria das condições sociais que provaram ser eficazes na redução da cárie dentária, por exemplo, também estariam contribuindo, mesmo que indiretamente, para evitar outros problemas como as oclusopatias.

Apesar de não estar esclarecido na literatura em qual direção a relação cárie dentária - oclusopatia se estabelece, o modelo logístico sugere que a presença de cárie pode estar propiciando a instalação do problema oclusal, corroborando o resultado de outras pesquisas (BEN-BASSAT et al. 1997; FRAZÃO 1999). 
FRAZÃO (1999) encontrou a mesma associação entre cárie dentária e oclusopatias, sendo que a presença deste problema, foi o que exerceu maior influência na análise da dentição decídua, embora a faixa de prevalência de cárie da população estudada fosse baixa. Na presente pesquisa, a associação positiva entre cárie e oclusopatias, foi reforçada, pois a prevalência de cárie encontrada foi mais alta do que no estudo de FRAZÃO (1999).

Outros estudos não encontraram associação entre a prevalência e/ou gravidade da cárie dentária com a prevalência de oclusopatias, talvez por abordarem diferentes idade ou faixa etária, o que influenciaria na manifestação deste problemas (VISCOVIC et al. 1990; BORTOLUZZI 2001; NIETO-GARCIA et al. 2001).

A associação entre oclusopatia e outros problemas de saúde da criança tem sido estudada, mostrando uma relação positiva entre a presença de mordida aberta anterior e otite média em crianças de 5 anos de idade, provavelmente devido à sucção de bico que agiria prejudicialmente às estruturas envolvidas, como a trompa de Eustáquio (NIEMELA et al. 1994). Por outro lado WATASE et al. (1998) não encontraram associação entre otite média e a presença de qualquer oclusopatia.

Crianças com respiração bucal mostraram ter mais chances de desenvolverem um relação classe 3 de molar e maior sobressaliência (overjet) quando comparadas às crianças sem este hábito, num estudo realizado com 2500 crianças entre 2 e 6 anos de idade, em Lucknow, India (NANDA et al. 1972). 
$\mathrm{Na}$ presente pesquisa nenhuma associação foi encontrada entre problemas respiratórios e presença de oclusopatias, resultado este que vai ao encontro dos achados do estudo de TOMITA (1997).

A falta de consistência entre os estudos e a dificuldade de comparação entre eles ocorre, principalmente, devido às diferenças de critérios estabelecidos para se diagnosticar os problemas respiratórios. Estas diferenças podem ser observadas entre os estudos de NANDA et al. (1972) cujos autores definiram as crianças respiradoras bucais através de um teste com espelho ou algodão colocado na frente da criança, no estudo de BEHFELT et al. (1989) que definiram as crianças com problemas respiratórios aquelas que apresentaram problemas de infecção respiratória ou resfriados relatados, 6 vezes ou mais ao ano e também no estudo de TOMITA (1997) que definiu a presença de problemas respiratórios diversos através de um questionário direcionado ao responsável pela criança.

Neste estudo, a presença de problemas respiratórios considerados, foram aqueles relatados pela mãe ou responsável pela criança quando esta tinha 12 meses de idade (Anexo 4).

As doenças e os problemas relacionados à saúde costumam ser tratados, na maioria das vezes, como entidades particulares, independentes uma das outras, gerando abordagens ou programas especificos.

Alguns pesquisadores apontam determinantes comuns para a maioria dos problemas, como as situações sociais e econômicas desfavoráveis, as desigualdades, baixos níveis de educação, condições de moradias precárias, 
entre outros (CHEN 1995; WILKINSON 1999). As condições de vida acabam por determinar estilos de vida e de comportamento que são fatores de risco estabelecidos para muitos problemas de saúde.

As doenças e os problemas bucais podem ser considerados neste contexto, já que muitos dos fatores de risco, diretos ou indiretos, relacionados à saúde bucal, são também fatores de risco para outros problemas de saúde.

Os fatores de riscos proximais para as oclusopatias estudadas foram o uso prolongado de bico e a prevalência e gravidade da cárie dentária.

Como pode-se observar, o primeiro fator, uso de bico, pode estar associado aos fatores e situações ocorridas desde o nascimento da criança, como, por exemplo, o tempo e a duração do aleitamento materno.

O tempo que as mães amamentaram predominantemente no peito sofreu um importante aumento, passando de 3,1 meses em 1982 para 4 meses em 1993. Apesar deste aumento, o aleitamento materno em Pelotas, na época deste estudo, ainda foi muito inferior às recomendações da OMS e do UNICEF (UNICEF 1981; WHO 1981).

Ainda com relação ao tempo de aleitamento natural, outro fator que influencia o desmame precoce é a introdução de outros líqüidos e de alimentação, precocemente na vida das crianças (JELIFFE e JELIFFE 1979; AKRE 1989). Estes fatores, além de não serem necessários do ponto de vista nutricional (VICTORA et al. 1992), podem acarretar na ingestão de determinados alimentos, como certos cereais ou vegetais, que podem interferir na absorção de ferro, que a longo prazo, aumenta o risco para outros 
problemas de saúde como, por exemplo, a obesidade, a hipertensão, a arteriosclerose e a alergia alimentar.

Outros importantes diferenciais, desta vez biológicos e socieconômicos, reforçam a teoria dos riscos comuns. Trata-se do menor periodo de aleitamento durante os primeiros meses de vida, entre as crianças de baixa renda e as nascidas com baixo peso.

Apesar da ausência de significância estatística entre as crianças com baixo peso ao nascer e a presença de oclusopatias neste estudo, as crianças com baixo peso ao nascer podem ser consideradas indivíduos de risco para diversos problemas de saúde geral e também para saúde bucal, merecendo estudos mais aprofundados à respeito.

O segundo fator proximal associado às oclusopatias, trata-se da cárie dentária, que pode ser enfrentada no contexto da prevenção de doenças crônicas como por exemplo, atuando-se contra exposições nocivas ligadas à dieta, poderíamos prevenir a cárie dentária, a obesidade, as doenças coronarianas e o diabetes. Desta forma, segundo resultados obtidos nesta pesquisa, também prevenir-se-iam as oclusopatias.

Medidas dirigidas à promoção de saúde geral são mais importante para reduzir a cárie dentária do que medidas especificas como tratamento odontológico e medidas preventivas de caráter individual (SHEIHAM 1990).

As políticas intersetoriais destinadas a toda a população e com enfoque na redução das exposições comuns nocivas à saúde, parecem ser as estratégias mais adequadas para a promoção de saúde bucal em geral. 
Espaços já estabelecidos para outras ações na sociedade como as consultas de pré-natal, a neonatologia, a pediatria, a escola, os locais de trabalho, o governo nas suas diferentes instâncias e a mídia, poderiam estar incorporando medidas de promoção de saúde geral que acabariam por beneficiar os individuos.

A abordagem intersetorial abrange diferentes estratégias. Por exemplo, as medidas amplas governamentais que estabelecem metas de saúde a serem atingidas para a população (DEPARTMENT OF HEALTH AND SOCIAL SECURITY 1989, 1994; FRAZIER e HOROWITZ 1995) e o aumento do período de licença-maternidade, a fim de promover um maior tempo de aleitamento natural, são iniciativas que beneficiariam o crescimento e desenvolvimento das crianças.

Além disso, o estabelecimento de incentivo à agricultura apoiando a produção de alimentos mais saudáveis e a modificação de leis que regem as informações nas etiquetas de produtos consumidos principalmente por crianças, alertando sobre sua composição, também contribuem para promover a saúde geral e a saúde bucal das pessoas (SHEIHAM 1990).

As atividades de promoção de saúde na abordagem de riscos comuns e ações intersetoriais poderiam incluir ainda outras iniciativas como o treinamento para médicos obstetras sobre recomendações sistemáticas para as gestantes à respeito da saúde bucal e informações para os pediatras sobre grupos de indivíduos de risco comuns à diferentes problemas de saúde, como as crianças de baixo peso ao nascimento. 
Do ponto de vista da Saúde Pública, a estratégia de abordagem de risco comuns é mais econômica e eficaz na prevenção das oclusopatias na dentição decidua. Diminuindo-se os problemas oclusais ou tornando-os menos severos, possibilitaria maior e melhor resolutividade destes problemas pelo sistemas públicos de saúde, além de proporcionar menos gastos de recursos em geral. 


\section{Conclusões}


De acordo com os resultados obtido conclui-se que:

1) A prevalência de mordida aberta anterior encontrada nas crianças de 6 anos de idade de Pelotas em 1999 foi igual a 46,3\% (IC $95 \%[41,2 \%$ $51,4 \%]$ ) o que demonstra uma prevalência maior do que a de outros estudos nacionais e internacionais.

2) A prevalência de mordida cruzada posterior foi igual a $18,2 \%$ (IC $95 \%$ $[14,2 \%-22,2 \%])$ semelhante à apenas alguns estudos nacionais.

3) A prevalência de oclusopatia de caninos do tipo 2 ou 3 foi igual a $15,2 \%$ (IC $95 \%[11,5 \%-18,9 \%])$ sendo difícil a comparação com outros estudos, devido à grande variação entre as prevalências encontradas na literatura.

4) Verificou-se associação estatisticamente significativa entre a presença de mordida aberta anterior e mordida cruzada posterior, porém esta associação não foi independente do uso de bico, presença de cárie e sucção digital aos 6 anos de idade.

5) A presença de oclusopatias de caninos apresentou-se associada à presença de mordida cruzada posterior independente da escolaridade e 
trabalho maternos, tempo de amamentação natural, sexo e uso de bico entre 12 meses e 5 anos de idade.

6) Os fatores independentes associados à presença de mordida aberta foram as mães com menos de $156 \mathrm{~cm}$ de altura, mães entre 30 e 39 anos de idade, tempo de aleitamento materno menor do que 9 meses, a intenção da mãe em oferecer o bico para a criança desde o nascimento, ceod $\geq 1$, uso de bico entre 12 meses e 5 anos de idade e a sucção digital prolongada.

7) Os fatores independentes associados à presença de mordida cruzada posterior foram o trabalho materno ao nascimento da criança, o tempo de aleitamento materno menor do que 9 meses e a presença de oclusopatias de caninos.

8) Os fatores associados com a presença de oclusopatias de caninos foram a presença de dentes cariados ou perdidos devido à cárie dentária e a presença de mordida cruzada.

9) As oclusopatias foram associadas à fatores considerados fatores de risco para outros problemas de saúde, o que reforça a teoria de riscos comuns. Desta forma, políticas intersetoriais destinadas a toda 
população e com o enfoque na redução das exposições comuns nocivas à saúde, parecem ser estratégias mais adequadas para a promoção de saúde bucal em geral, inclusive as oclusopatias na dentição decídua. 
9 Referências Bibliográficas 
1. Aarts C, Hörnell A, Kylberg E, Hofvander Y, Gebre-Medhin M. Breastfeeding patterns in relation to thumb sucking and pacifier use. Paediatrics 1999; 104(4):1-10.

2. Acheson D. Public Health in Egland: Report of the Committee of inquiry in the future development of the Public health function. London: HSMO; 1988.

3. Adair SM, Milano M, Dushku JC. Evaluation of the effects orthodontics pacifiers on the primary dentitions of 24-59 month old children: preliminary study. Pedaitric Dent 1992; 14:13-18.

4. Adair SM, Milano M, Lorenzo I, Russel C. Effects of current and former pacifier use on the dentition of 24- to 59- month-old children. Pediatr Dent 1995; 17(7):437-444.

5. Adler $P$. The incidence of dental caries in adolescents with different occlusion. $J$ Dent Res 1956; 35:344-348.

6. Agurto PV, Diaz RM, Cádiz OD, Bobenrieth FK. Frecuencia de malos hábitos orales y su associación con el desarrollo de anomalias dentomaxilares en ninos de 3 a 6 anos del área oriente de Santiago. Rev Chil Pediatr 1999; 70(6):470482.

7. Akre J. Infant feeding: the physiological basis. Geneva: World Health Organization; 1989. Apud: Horta BL, $1996^{106}$

8. Alamoudi N. The prevalence of crowding, attrition, midline discrepancies and premature tooth loss in the primary dentition of children in Jeddah, Saudi Arabia. J Clin Pediatr Dent 1999; 24(1):53-58.

9. Allen LH, Pelto GH. Research on determinants of breastfeeding duration: suggestions for biocultural studies. Med Anthropol 1985; 9:97-105. [Abstract] 
10. Almeida RR, Fêo PS, Martins DR. Influência da fluoretação na prevalência de más oclusões. Estomatol Cult 1970; 4(1):35-42.

11. Alvarez JO. Nutrition, tooth development, and dental caries. Am J Clin Nutr 1995; 61(suppl):401s-406s.

12. Andreasen JO, Andreasen FM. Traumatismo dentário: soluções clínicas. São Paulo: Panamericana, 1991. p.141-154.

13. Anelli G, Montarulli G. Caries and malocclusion. A statistical-epidemiological study performed on 5399 children between 3 and 10 years old in the schools of Bari. Minerva Stomatol 1998; 47(10):489-497.

14. Angle EH. Classification of malocclusion. Dent Cosmos 1899; 41:248-64, 350357.

15. Antunes JLF, Frazão P, Narvai PC, Bispo CM, Pegoretti T. Spatial analysis to identify differentials in dental needs by area based measures. Community Dent and Oral Epidemiol 2002; 30(2):133-142.

16. Ast DB, Allaway N, Draker HL. The prevalence of malocclusion related to dental caries and lost first permanent molars, in a fluoridated city and a fluoridedeficient city. Am J Orthod 1962; 48:106-113.

17. Auerbach KG. Breastfeeding fallacies: their relationship to understanding lactation. Birth 1990; 17:44-9.

18. Bachrach $\mathrm{H}$, Young $\mathrm{M}$. A comparasion of the degree of resemblance in dental characters shown in pairs of twins of identical and fraternal types. Dental Cosmos 1928; 70:465-466. 
19. Báez A, Morón B, Alexis V, Lucchese E, Salazar CRV, Rivera L, Rivera FR de. Aproximación al perfil de occlusión dentaria en preescolares del municipio Maracaibo: estudio piloto. Acta Odontol Venez 1999; 37(2):11-20.

20. Barker DJP. Foetal and infant origin of adult disease. London: BMJ Publishing Group; 1992.

21. Barker DJP. Mothers, babies and disease in later life. London: BMJ Publishing Group; 1994.

22. Barros FC, Victora CG. [Editorial]. Cad. Saúde Pública 1996; 12 (supl 1):4-5.

23. Barros FC, Victora CG. Incresead blood pressure in adolescents who were small for gestacional age at birth: a cohort study in Brazil. International Journal of Epidemiology 1999; 28:676-681.

24. Bartley M, Blane D, Montgomery S. Socioeconomic determinants of health: Health and the life course: why safety nets matter. BMJ 1997; 314:1194-1201.

25. Baume LJ. Physiological tooth migration an its significance for the development of occlusion. I. The biogenetic course of the deciduous dentition. J Dent Rès $1950 ; 29(2): 123-132$.

26. Baume LJ. Uniform methods for the epidemiologic assessment of malocclusion. Results obtained with the World Health Organization standart methods (1962 and 1971) in South Pacific Populations. Am J Orthod 1974; 66(3):251-272.

27. Beaglehole R, Bonita R, Kjellsrom T. Epidemiologia básica. Santos: São Paulo; 1996.

28. Beal JF. Social factors and preventive dentistry. In: Murray JJ. Prevention of oral diseases. Oxford, New York, Tokyo: Oxford University Press; 1996. p. 217233. 
29. Behlfelt K, Linder-Aronson S, Mc Willian J, Neander P, Laage-Hellman J. Dentition in children with enlarged tonsils compared to control children. Eur $J$ Orthod 1989; 11(4):416-429.

30. Ben-Bassat $Y$, Harari D, Brin I. Occlusal traits in a group of school children in an isolated society in Jerusalem. Br J Orthod 1997;24(3):229-235.

31. Beshnilian V. Occlusion \& Rehabilittion. Montevideo; 1971. p.15-38.

32. Bezroukov V, Freer TJ, Helm S, Kalamkarov H, Sardo Infirri J, Solow B. Basic methods for recording occlusal traits. Bull World Health Organ 1979; 57(6):955961.

33. Bjork A, Helm S. Need for orthodontic treatment as reflected in the prevalence of malocclusion in various ethnic groups. Acta Odontol Scand. 1964; 22:27-41.

34. Bjork A. A prediction of mandibular growth rotation. Am J Orthod 1969; 55:585599.

35. Bogue EA. Some results from orthodontia in decíduos teeth. J Am Med Assoc $1908 ; 1: 267-269$.

36. Bortoluzzi DA. Prevalência de cárie e oclusopatias em escolares de 6 anos de idade de escolas públicas no município de Joaçaba, Santa Catarina. Joaçaba 2001. [Monografia de Especialização - Faculdade de Odontologia de Joaçaba da Universidade do Oeste de Santa Catarina]. Brasil, 2001.

37. Bosma J. Maturation of function of the oral and pharyngeal region. Am J Orthod $1963 ; 49: 94-104$.

38. Bowden B. The effect of digital and dummy sucking on arch widths, overbite and overjet: a longitudinal study. Aust Dent J 1966; 11:396-404. 
39. Branger B, Cebron M, Picherot G, Cornulier M. Facteurs influençant la durée de l'allaitement maternel chez 150 femmes. Arch Pédiatr 1998; 5:489-496.

40. Brin I, Zwilling-Sellam O, Harari D, Koyoumdjisky E, Ben-Bassat Y. Does secular trends exist in the distribution of oclusal patterns? The Angle Orthodontist 1998; 68(1):81-84.

41. British Dental Association. Memorandum on Orthodontic Services. British Dental Association, London, 1954. Apud Pine $\mathrm{CM}^{195}$.

42. Broadbent BH. A new x-ray technique and its applications to orthodontics. Angle Orthod 1931; 1:45-49.

43. Brook PH, Shaw WC. The development of an index of orthodontic treatment priority. Eur J Orthod 1989; 11;309-320.

44. Burdi AR, Moyers RE. Os dentes decíduos e a oclusão. In: Moyers RE. Ortodontia. Rio de Janeiro: Artes Médicas, 4 ed.; 1988. cap. 6.

45. Calisti LJP, Cohen MM, Fales MH. Correlation between malocclusion, oral habits, and socio-economic level of preschool children. J Dent Res 1960; 39:450-454.

46. Capistrano Filho D. In: Narvai PC. Odontologia e Saúde Bucal Coletiva. São Paulo: Hucitec; 1994. Prefácio.

47. Carvalho JC, Vinker F, Declerck D. Malocclusion, dental injuries and dental anomalies in the primary dentition of Belgian children. Int J Paediatr Dent 1998; $8(2): 137-141$.

48. Case CS. Principles of occlusion and dentofacial relations. Dent ltems Int 1905; 27:489-493. 
49. Castelanni G, Bertele GP, Zerman N. Indagine epidemiologica nelle scuole materne del Comune di Verona sull'incidenza della carie, delle malocclusioni e delle abitudini viziate che possono influire sul normale sviluppo delle strutture scheletriche facciali del bambino. Minerva Stomat 1987; 36(3):121-125.

50. César JA, Victora CG, Santos IS, Barros FC, Albernaz EP, Oliveira LM, et al. Hospitalização por pneumonia: influência de fatores socioeconômicos e gestacionais em uma coorte de crianças no Sul do Brasil. Rev Saúde Pública 1997; 31(1):53-61.

51. César JÁ. Victora CG, Barros FC, Santos IS, Flores JÁ. Impact of breastfeeding on admission for pneumonia during postneonatal period in Brazil: nested case-control study. BMJ 1999; 318(15):1316-1320.

52. Chaves MM. Problemas: Chaves MM. Odontologia Social. 3 ed. Rio de Janeiro: Artes Médicas; 1986. p.23-28.

53. Chen M. Oral health of disadvantaged populations. In: Cohen LK, Gift HC. Disease prevention and oral health promotion -social dental sciences in action. Copenhagen:Munksgaard/FDI; 1995. p.153-212.

54. Chiavaro A. Malocclusion of the temporary teeth. Int J Orthod 1915; 1:171-189.

55. Chung CS, Niswander JD. Genetic and epidemiologic studies of oral characteristics in Hawaii's schoolchildren. V. Sibling correlations in occlusal traits. J Dent Res 1975; 54:324-329.

56. Clinch LM. Variations in the mututal relationships of the maxillary and mandibular gum pads in the newborn child. Int $J$ Orthod 1934; 20:359-374.

57. Cohen MI. Reconocimiento del desarrolo de la maloclusion. Odont Clin N Amer $1961 ; 8: 39-53$. 
58. Colombo M, de la Parra A, Lopez I. Intellectual and physical outcome of children undernourished in early life is influenced by later environmental conditions. Dev Med Chil Neurol 1992; 34(7):611-622.

59. Corruccini Rs, Potter RHY. Genetic analysis of occlusal variation in twins. Am J Orthod 1980; 78(2):141-155.

60. Corruccini RS, Towsend GC, Richards LC, Brown T. Genetic and environmental determinants of dental oclusal variation in twins of different nationalities. Human Biology 1990; 62(3):353-367.

61. Corruccini RS. An epidemiologic transition in dental occlusion in world populations. Am J Orthod 1984; 86(5):419-426.

62. Davies HTO, Crombie K, Tavakoli M. When can odds rations mislead? BMJ 1998; 316:989-991. Apud: Pinho AA $2002^{196}$

63. Davis DW, Bell PA. Infant feeding practices and occlusal outcomes: a longitudinal study. J Canad Dent Ass 1991; 57(7):593-594.

64. De Vis H, De Boever JA, Van Cauwenberghe P. Epidemiolgic survey of functional conditions of the mastigatory system in Belgian children aged 3-6 years. Communiy Dent Oral Epidemiol 1984; 12(3):203-207.

65. Dean K. Editorial: Creating a new knowledge base for the new public health. $J$ Epidemiol Community Health 1994; 48:217-219.

66. Dearing, SG. Overbite, overjet, lip-drape and incisor tooth fracture in children. N. Z Dent J 1984; 80(360):50-52.

67. Degano MP, Degano RA. Breastfeeding and oral health. A primer for the dental practitioner. N Y St Dent J 1993; 59(2):30-32. 
68. Department of Health and Social Security. The occlusal index committee. London: HMSO; 1987. Apud Richmond et apos.

69. Detlefsen JA. Intrinsic or hereditary factors versus extrinsic or environmental factors in the determination of tooth and oral peculiarities. J Dent Res 1928; 8:419-420.

70.Downer MC, Gelbier S, Gibbons DE. Introduction to Dental Public Health. London: FDI World Press; 1994.

71. Dracker HL. Handicapping labio-lingual deviations: a proposed index for public health purpose. Am J Orthod 1960; 46(4):295-305.

72. Drane D. The effect of use of dummies and teats on orofacial development. Breastfeeding Review. 1996; 4:59-64.

73. Egbuonu L, Starfield B. Child health and social status. Pediatrics 1982; 69:550557.

74. Egermark - Eriksson I, Carlsson GE, Magnusson T, Thilander B. A longitudinal study on malocclusion in relation to signs and symptoms of cranio-mandibular disorders in children and adolescents. Eur J Orthod 1990; 12(4):399-407.

75. Elsasser WA. Studies of dentofacial morphology. I. A simple instrument for appraising variations. Angle Orthod. 1951; 21:163-171.

76. Erickson DM, Graziano FW. Prevalence of malocclusion in seventh grade children in two North Carolina cities. J Am Dent Assoc 1966; 391:124-127.

77. Escott R. Positioning attachment and milk transfer. Breastfeeding Review. $1989 ; 1: 31-37$

78. Facchini LA. Trabalho materno e ganho de peso infantil. Pelotas: UFPel; 1995. 
79. Fadavi S, Adeni S, Dziedzic K, Punwani I, Vidyasagar D. The oral effects of orotracheal intubation in prematurely born preschoolers. ASDC J Dent Child 1992; 59(6):420-424 .

80. Farsi NMA, Salama FS. Characteristics of primary dentition occlusion in a group of Saudi children. Int J Pad Dent 1996; 6:253-259.

81. Farsi NMA, Salama FS. Sucking habits in children: prevalence, contributing factors and effects on the primary dentition. Pediatr Dent 1997; 19(1):28-33.

82. Fields HW. Craniofacial growth from infancy through adulthood. Background and clinical implications. Pediatr Clin North Am 1991; 38(5):1053-1088.

83. Foster TD, Hamilton MC. Occlusion in the primary dentition. Brit Dent J 1969; 21:76-79.

84. Foster TD, Menezes DM. The assesment of occlusal features for public health planning purposes. Am J Orthod 1976; 69(1):83-90.

85. França-Junior I. Mudança secular das estruturas de jovens na cidade de São Paulo, 1950-1976: Uma abordagem pàrà discutir a saúde. São Paulo, 1998. [Tese de Doutora- Fac. de Medicina da Universidade de São Paulo].

86. Frazão P. Epidemiologia da oclusão dentária na infância e os sistemas de saúde. São Paulo 1999. [Tese de doutorado - Faculdade de Saúde Pública da Universidade de São Paulo].

87. Frazier PJ, Horowitz AM. Prevention: a pubic health perspective. In: Cohen LK, Gift HC. Disease prevention and oral health promotion -social dental sciences in action. Copenhagen:Munksgaard/FDI; 1995. p.110-152.

88. Freire MCM. Prevalência de cárie e fatores socioeconômicos em pré-escolares - Revisão de literatura. Rev Bras Odont Saúde Coletiva 2000; 1(1):43-49. 
89. Friman PC, Schmitt BD. Thumb sucking: pediatricians guidelines. Clinical Pediatrics 1989; 28(10):438-440.

90. Fuchs SC, Victora CG, Fachel J. Modelo hierarquizado: uma proposta de modelagem aplicada à investigação de fatores de risco para diarréia grave. Rev Saúde Pública 1996; 30(2):168-178.

91. Fuchs SC. Fatores de risco para diarréia complicada por desidratação moderada a grave. Um estudo de casos e controles. Porto Alegre, 1993. [Tese de doutorado- Faculdade de Medicina da UFGRS].

92. Fukuta O, Braham RL, Yokoi K, Kurosu K. Damage to the primary dentition resulting from thumb and finger (digit) sucking. ASDC $J$ Dent Child 1996; 63(6):403-407.

93. Gale CR, Martyn CN. Breastfeeding, dummy use, and adult intelligence. The Lancet 1996; 347(20):1072-1075.

94. Ghezzi F, Zallio F, Mazzarello GP, Tampelloni C. Indagine epidemiological sulla incidenza di carie e malocclusioni della dentatura decídua nèi bambini delle scuole materne della USL 16 (Genova-Levante). Minerva Stomatologica 1986; $35: 107-112$.

95. Gigante DP, Victora CG, Barros FC. Nutrição materna e duração da amamentação em uma coorte de nascimento de Pelotas, RS. Rev Saúde Pública 2000; 34(3):259-265.

96. Graber TM. Orthodontics principles and practice. Philadelphia: WB Saunders; 1962. p.160-162. 
97. Grainger RM. Orthodontic treatment priority index. Washington, D.C: Public Health Service Publication $N^{\circ} 1000$, series 2, $n^{\circ} 25$, U.S. Government Printing Office, 1967. p.49. Apud Foster e Menezes ${ }^{84}$

98. Hammer LD, Bryson S, Agras S. Development of feeing practices during the first 5 years of life. Arch Pediatr Adolesc Med 1999; 153:189-194.

99. Hart CL, Smith GD, Blane D. Inequalities in mortality by social class measured at 3 stages of the lifecourse. American Journal of Pubic Health 1998; 88(3):471474.

100. Helm S. Etiology and treatment need of malocclusion. J Can Dent Assoc $1979 ; 12: 673-676$.

101. Helmman M. The face and teeth of man. J Dent Res 1929; 9:179-182.

102. Henderson L, Kitzinger J, Green J. Representig infant feeding: content analysis of British media portrayals of bottle feeding and breast feeding. BMJ 2000; 321(11):1196-1198.

103. Hill IN, Blayney JR, Wolf W. The Evanston Dental caries study: prevalence of malocclusion of children in a fluoridated and control area. J Dent Res 1959; $38: 782-794$

104. Hirakata VN. Alternativas de análise para um desfecho binário em estudos transversais e longitudinais. Pelotas: 1999. [ Dissertação de Mestrado Universidade Federal de Pelotas]. Apud: Pinho ${ }^{196}$.

105. Horta BL, Barros FC, Halpern R, Victora CG. Baixo peso ao nascer em duas cortes de base populacional no Sul do Brasil. Cad Saúde Publ 1996; 12 (Supl 1): $27-31$ 
106. Horta BL, Olinto MTA, Victora CG, Barros FC, Guimarães PRV. Amamentação e padrões alimentares em crianças de duas coortes de base populcional no Sul do Brasil: tendências e diferenciais. Cad Saúde Públ 1996; 12(supl. 1):43-48.

107. Hosmer DW, Lemeshow S. Applied logistic regression. New York: Wiley; 1989.

108. Howard CR, Howard FM, Lanphear B, deBlieck EA, Eberly S, Lawrence R. The effects of early pacifier use on breastfeeding duration. Pediatrics 1999;103(3):1-6.

109. Hulcrantz E, Larson M, Hellquist R, Ahlqust-Rastad J, Svanholm H, Jakobsson OP. The influence of tonsillar obstruction and tonsillectomy on facial growth and dental arch morphology. Int J Pediatr Otorhinolaryngol 1991; 22(2):125-134.

110. IBGE. Fundação Instituto Brasileiro de Geografia e Estatística [Dados obtidos em www.ibge.gov.br, 10/04/2002].

111. Infante PF. Malocclusion in the deciduos dentition in white, black, and Apache Indian children. Angle Orthod. 1975; 45(3):213-218.

112. Infante PF. An epidemiologic study of finger habits in preschool children, as relates to malocclusion, socioeconomic status, race, Sex, and size of community. J Dent Child 1976; 43(165):33-38.

113. Ivanovic DM, Leva BP, Perez HT, Inzunza NB, Almagiá AF, Toro TD, et al. Long-term effects of severe undernutrition during the first year of life on brain development and learning in Chilean high school graduates. Nutrition 2000; 16(11/12): 1054-1063. 
114. Jeliffe DB, Jeliffe EFP. "Breast is best". Moderm meanings. New England Journal of Medicine 1977; 297:912-915.

115. Johannsdottir B, Wisth PJ, Magnusson TE. Prevalence of malocclusion in 6year-old Iceland children. Acta Odontol Scand 1997; 55(6):398-402.

116. Jones ML, Mourino AP, Bowden TA. Evaluation of occlusion, trauma, and dental anomalies in African-American children of metropolitan Headstart programs. J Clin Ped Dent 1993; 18(1):51-54.

117. Kabue MM, Moracha JK, Ng'ang'a PM. Malocclusion in children aged 3-6 years in Nairobi, Kenya. East Afr Med J 1995; 72(4):210-212.

118. Karjalainen S, Rönning $\mathrm{O}$, Lapinleimu $\mathrm{H}$, Simmel $\mathrm{O}$. Association between early weaning, non-nutritive sucking habits and occlusal anomalies in 3 year-old Finnish children. Int J Paediatr Dent. 1999; 9:169-173.

119. Kelly JE, Sanchez M, Van Kirk LE. An assessment of the occlusion of the teeth of children 6-11 years. Rockville, Maryland: National center for health Statistics, 1973; DHEW publication no. (HRA)74-1612. Apud: Meyers e Hertzberg ${ }^{153}$.

120. Kerosuo $H$, Hausen $H$, Laine $T$, Shaw WC. The influence of incisal malocclusion on the social attractiveness of young adults in Finland. Eur $J$ Orthod 1995; 17(6):505-512.

121. Kerosuo $\mathrm{H}$. Occlusion in the primary and early mixed dentitions in a group of Tanzanian and Finnish children J Dent Child 1990; 57(4):293-298.

122. Kharbanda OP, Sidhu SS, Shukla DK, Sundaram KR. A study of the etiological factors associated with the development of malocclusion. $J$ Clin Ped Dent 1994; 18(2):95-98. 
123. Kholer L, Hoist K. Malocclusion and sucking habits of four-year-old children. Acta Paediatr Scand 1973; 62:373-379.

124. Kisling E, Krebs G. Patterns of occlusion in 3-year-old Danish children. Community Dent Oral Epidemiol 1976; 4:152-159.

125. Klackemberg G. Thumbsucking frequency and etiology. Pediatrics 1949; $4: 418-423$.

126. Kopra DE, Davis EL. Prevalence of oral defects among neonatally intubed 3 to 5 and 7 to 10 year old children. Pediatr Dent 1991; 13(6): 349-355. [Abstract]

127. Kuh D, Bem-Shlomo Y. A life course approach to chronic disease epidemiology. Oxford: Oxford University Press; 1997.

128. Kurosu K, Fukuta O, Yoshioka T. et al. A study of the psychosimatic odontology of oral habits. Jap J Pediatr Dent 1978; 16:123-136. Apud: Fukuta et $a^{p 2}$.

129. Labbok MH, Hendershot $G$. Does breastfeeding protect against malocclusion? An analysis of the 1981 Child Health Supplement to the National Health Interview Survey. Am J Prev Med 1987; 3(4):227-232.

130. Lallo R, Myburgh NG, Hobdell MH. Dental caries, socio-economic development and national oral health profiles. Int Dent J 1999; 49:196-202.

131. Landis JR, Koch GG. The measurement of observer agreement for categorical data. Biometrics $1977 ; 33: 159-174$.

132. Laor A, Cohen L, Danon YL, Effects of time, Sex, ethnic origin and area of residence on prevalence of asthma in Israeli adolescents. BMJ 1993; 307:841844. 
133. Larsson E. Artificial sucking habits: Etiology, prevalence and effect on occlusion. Int. J Oro Miol 1994; 20:10-21.

134. Larsson E. Dummy and finger sucking habits with special attention to their significance for facial growth and occlusion. The effect of early dummy and finger -sucking habit in 16 year old children compared with children without earlier sucking habit. Swed Dent J 1978; 1:23-33.

135. Larsson E. Orthodontic aspects on feeding of young children. Swed Dent J 1998; 22(3):117-121.

136. Larsson E. Prevalence of crossbite among children with prolonged dummyand finger- sucking habit. Swed Dent J 1983; 7:117-119.

137. Larsson EF, Dahlin KG. The prevalence and the etiology of the initial dummy and finger sucking habit. Am J Orthod 1985; 87:432-435.

138. Legovic M, Mady L, Ferreri S, Brekalo I, Zupan M, Mady b, Vancura I. Malocclusioni in dentizione decidua. Mondo Ortodontico. 1988; 23(1):31-36.

139. Legovic M, Mady I, Pelizzer S. Orthodontic anomalies in primary and permanent dentition - a longitudinal study. Coll Antropol. 1998; 22 (suppl):133137.

140. Legovic M. Ostric $L$. The effects of feeding methods on the growth of the jaws in infants. J Dent Child 1991; 58:253-255.

141. Levine RS. Briefing paper: Oral aspects of dummy an digit sucking. Br Dent J 1999; 186(3):108.

142. Linder-Aronson S. Adenoids: Their effects on mode of breathing and nasal airflow and their relationship to characteristics of the facial skeleton and the dentition. A biometric, rhino-monometric and cephalometro-radiographic study 
on children with and withouth adenoids. Acta Otolaryngol 1970, (suppl) 265:1132. [Abstract].

143. Lindsten R, Larsson E, Ogaard B. Dummy-sucking behaviour in 3-year old Norwegian and Swedish children. Eur J Orthod 1996; 18(2):205-209.

144. Lischer BE. Principles and methods of orthodontic. Philadelphia: Lea \& Febiger; 1912.

145. Litton SF, Ackermann LV, Isaacson RJ, Shapiro BL. A genetic study of class III malocclusion. Am J Orthod 1970; 58:565-577.

146. Lombardi AV, Bailit HL. Malocclusion in the Kwaio, a Melanesian group on Malaita, Solomon island. Am J Phys Anthropol, 1972; 36:283-294. Apud: Corruccini e Potter ${ }^{59}$.

147. Lombardi C, Bronfman M, Facchini LA, Victora CG, Barros FC, Béria JU, et al. Operacionalização de classe social em estudos epidemiológicos. Rev Saúde Pública 1988; 22(4):253-265.

148. Lundström A The significance of genetic and non genetic factors in the profile of the facial skeleton. Am J Orthod 1955; 41:910-916.

149. Lwanga SK, Lemeshow S. Sample size determination in health studies. A pratical manual. Geneva: World Health Organization; 1991.

150. Maia NG. Prevalência das más oclusões em pré-escolares da cidade do Natal, na fase de dentição decídua. Natal 1987. [Dissertação de mestrado Centro de Ciências da Saúde, Universidade Federal do Rio Grande do Norte].

151. Malagola C, Mandraffino AG, De Palis M, Ruolo dell'allanttamento nella genesi delle malocclusioni. Mondo Orthodontico 1986; 11:38-44. 
152. Mathias RS. Prevalência de algumas anomalias de oclusão na dentição decídua: mordida cruzada posterior, apinhamento anterior, mordida aberta anterior e relação terminal dos segundos molares decíduos. São Paulo, 1984. [Dissertação de mestrado- Faculdade de Odontologia de São Paulo, Universidade de São Paulo].

153. Meyers A, Hertzberg J. Bottle feeding and malocclusion: Is there an association? Am. J. Dentofac Orthop 1988; 93:149-152.

154. Minchin MK. Positioning for breastfeeding. Birth 1989; 16:67-80.

155. Moore MB. Digits, Dummies and Malocclusions. Dent Update 1996; 23(10):415-422.

156. Moron BA, Baez A, Rivera L, Hernandez N, Rivera N, Luchese E. Perfil de la occlusion del niño en edad preescolar. Factores de beneficio y riesgo. Acta Odontol Venez 1995; 35(1):12-15.

157. Mosley WH, Chen LC. An analytical framework for the study of child survival in developing countries. Popul Develop Rev 1984; 10 (supl):25-48.

158. Moura MS, Simplício AHM, Moura LFAD, Moura WL. Alterações na relação molar entre as dentaduras decidua e mista. Rev ABO Nac 1994; 2(5):333-339.

159. Moyers RE. Handbooks. Handbooks of orthodontics. Chicago: Year Book Pub;1959.

160. Moyses SJ. Oral health and health cities: an analysis of intra-urban differentials in oral health outcomes in relation to "Healthy cities" policies in Curitiba, Brazil. [PhD Thesis. Department of Epidemiology and Public Health. The Royal Free and University College medical School. University of London]. London 2000. 
161. Murray JJ. Prevalence of malocclusion in fifteen-year-old children from fluoride and non-fluoride communities. Dent Practit Dent Rec 1969; 19(11):395400.

162. Nadanovsky P, Sheiham A. Relative contribution of dental services to the changes in caries levels of 12 year-old-children in 18 industrialized countries in the 1970s and early 1980s. Community Dent Oral Epidemiol 1995; 23:331-339.

163. Nanda RS, Khan I, Anand R. Age changes in the occlusal pattern of deciduos dentition. J Dent Res 1973; 52(2):221-224.

164. Nanda RS, Khan I, Anand R. Effect of oral habits on the occlusion in preschool children. J Dent Child 1972; 39:449-452.

165. Narvai PC. Odontologia e Saúde Bucal Coletiva. São Paulo: Hucitec; 1994.

166. Navarrete M, Espinoza AR. Prevalencia de anomalias dentomaxilares y sus características en ninos de 2-4 anos. Odontol. Chil. 1998; 46(1): 27-33.

167. Newman GV, Newmark NJ. Prevalence of malocclusion in children six to fourteen years of age and treatment in preventable cases. J Am Dent Assoc 1956; 52(5):566-575.

168. Newman GV. Prevalence of malocclusion in children six to fourteen years of age and treatment in preventable cases. J Am Dent Assoc 1956; 52(5):566575.

169. Newman J. Breastfeeding problems associated with the early introduction of bottles and pacifiers. J Hum Lact 1990; 6:59-63.

170. Ngan P, Fields HW. Open bite: a review of etiology and management. Pediatr Dent 1997; 19(7):91-98. 
171. Nguyen QV, Bezemer PD, Habets L, Pral.-Andersen B. A systematic review of the relationship between overjet size and traumatic dental injuries. Eur $J$ Orthod 1999; 21(5):503-515.

172. Nie N, Hull CH, Jenkis JG, Steinbrenner K, Brent DH. SPSS: Statistical Package for the Social Sciences, 2 ed. New York: Mc Graw Hill; 1975.

173. Niemela M, Uhari M, Hannuksela A. Pacifier and dental structure as risk factors fot otitis media. Int. J. Pediatri. Otorhinolaryngol. 1994; 29:121-127.

174. Nieto Garcia VM, Nieto Garcia MA, Lacalle Remigio JR, Abdel-Kader ML. Oral health of school children in ceuta. Influences of age, Sex, ethnic background and socioeconomic level.Rev Esp Salud Publica 2001; 75(6):541549.

175. Nijhuis HGJ, Van der Maesen LJG. The philosophical foundations of public health: an invitation to debate. J. of Epidemiol and Community Health 1994; $48: 1-3$

176. Niswander JD. Further studies on the Xavantes Indians. VII. The oral status of the Xavantes of Simoes Lopes. Am J Hum Genet 1967; 19: 543-553. Apud: Corruccini e Potter ${ }^{59}$.

177. Nowak AJ. Conference report: Feeding and dentofacial development. J Dent Res 1991; 70(2):159-160.

178. O'Brien H T, Lachapelle D, Gagnon PF, Larocque I, Maheu-Robert LF. Nutritive and nonnutritive sucking habits: a review. ASDC J Dent Child 1996; $63(5): 321-327$ 
179. O'Brien M. Children's dental health in the United Kingdom 1993. Office of Population Censuses and Surveys. Her majesty Stationary Office. London, 1994.

180. O'Mullane DM. Some factors predisposing to injuries of permanent incisors in schoolchildren. Brit Dent J 1973; 134(8):328-332.

181. Ogaard B, Larsson E, Lindsten R. The effect of sucking habits, cohort, sex, intercanine arch widths, and breast or bootle feeding on posterior crossbite in Norwegian an Swedish 3-year-old children. Am J Orthod 1994; 106:161-166.

182. Olinto MT. Epidemiologia da desnutrição infantil em Pelotas. Pelotas, 1993. [Dissertação de mestrado- Faculdade de Medicina da UFPel].

183. Oliveira SF. Oclusão e hábitos de sucção: estudo em pré-escolares de Piracicaba. Piracicaba, 1981. [Dissertação de Mestrado - Faculdade de Odontologia da Piracicaba, Universidade Estadual de Campinas].

184. Otuyemi OD, Sote EO, Isiekwe MC, Jones SP. Occlusal relationships and spacing or crowding of teeth in the dentitions of 3-4- year-old Nigerian children. Int J Paediatr Dent 1997; 7:155-160.

185. Palmer B. The influence of breastfeeding on the development of the oral cavity: a commentary. J. Hum. Lact. 1998; 14(2):93-98.

186. Patussi M. Marcenes W, Croucher R, Sheiham A. Social deprivation, income inequality and dental caries in Brazilian school children. Social science and Medicine 2001; 53:915:925.

187. Paunio $P$, Rautava $P$, Sillanpää $M$. The finnish family competence study: the effects of living conditions on sucking habits in 3-year-old Finnish children and 
the association between these habits and dental occlusion. Acta Odontol Scand $1993 ; 51: 23-29$.

188. Peres KGA, Traebert ESA, Marcenes W. Diferenças entre auto- percepção e critérios normativos na identificação das oclusopatias. Revista de Saúde Pública 2002; 36(2): 230-236.

189. Peres MA, Peres KGA, Mario GJ, Pezzini A, Panizzi M. Prevalência de doenças bucais e necessidade de tratamento odontológico em crianças de 6 a 2 anos de idade do município de Chapecó, SC, 1996. Relatório final.

190. Peres MA, Traebert JL, Marcenes W. Calibração de examinadores para estudos epidemiológicos de cárie dentária. Cad Saúde Pública 2001; $17(1): 153-159$.

191. Peres MA. Determinantes sociais e biológicos do período perinatal e da primeira infância na prevalência e severidade da cárie dentária em crianças de 6 anos de idade. Pelotas 1999. [Tese de doutorado - Faculdade de Saúde Pública da Universidade de São Paulo]. São Paulo 2002.

192. Perin PCP, Bertoz FA, Saliba NA. Influência da fluoretação da água de abastecimento público na prevalência de cárie dentária e maloclusão. Rev Fac Odontol Lins 1997; 10(2):10-15.

193. Picado JI, Olson CM, Rasmussen KM. Metodología combinada para entender la duración del amamantamiento en barriios pobres de Managua, Nicaragua. Rev Panam Salud Publica/Pan Am J Public Health 1997; 2(6):398407.

194. Picard PJ. Bottle feeding as preventive orthodontics. J. Calif State Dent Assoc 1959; 35:90-95. 
195. Pine CM. Community Oral Health. Oxford: Wright; 1997. p. 1-10.

196. Pinho AA. Fatores associados a realização do teste de papanicolau.2002.. [Tese de Doutorado, Faculdade de Saúde Pública da Universidade de São Paulo].

197. Platter WR. Caries control: its influence and effects on malocclusion. Am J Orthod 1949; 35:790-796.

198. Popovich F, Thompson GW. Thumb and finger sucking: its relation to malocclusion. Am J Orthod 1973; 63(2):148-155.

199. Power C, Hertzman C. Social and biological pathways linking early life and adult disease. Br Med Bull 1997; 53(1):210-221.

200. Power C, Mattews S, Manor O. Inequalities in self-rated health: explanations from different stages of life. Lancet 1998; 351(9108):1009-1014.

201. Power C, Matthews S. Origins of health in a national population sample. The Lancet 1997; 350:1584-1589.

202. Proffit WR, Fields HW, Moray LJ. Prevalence of malocclusion and orthodontic treatment need in the United States: Estimates from the NHANES III survey. Int J Adult Orthodon Orthognath Surg 1998; 13(2):97-106.

203. Proffit WR, Fields HW. Contemporany Orthodontics. Saint Louis: C. V. Mosby, 1995.

204. Proffit WR. On the etiology of malocclusion. Br J Orthod 1986; 13(1):1-11.

205. Ravn JJ. The prevalence of dummy and finger sucking habits in Copenhagen children until the age 3 years. Community Dent Oral Epidemiol $1974 ;$ 2:316-322. 
206. Rebello Jr W, Toledo OA. Influência da fluoretação da água de consumo na prevalência das anormalidades de oclusão na dentição decídua de préescolares brancos da cidade de Araraquara. Rev Fac Odontol Araraquara $1975 ; 9(1): 9-15$.

207. Richardson ME. The relationship between amount of space present in the deciduous dental arch and the rate and degree of space closure subsequent to the extraction of deciduous molar. Dent Pract Dent Rec 1965; 16(3):111-118.

208. Richmond S, Buchanan IB, Burden JB, O'Brien KD, Andrews M, Roberts CT, Turbill EA. Calibration of dentist in the use of occlusal indices. Community Dent Oral Epidemiol 1995 23:173-176.

209. Righard L, Alade MO. Sucking technique and its effect on success of breastfeeding. Birth 1992; 19:185-189.

210. Righard I. Early anhanced of successful breastfeeding. World Health Forum 1996; 17:92-97. Apud: Howard et al. ${ }^{108}$.

211. Riva E, Bànderali G, Agostoni C, Silano M, Radaelli G, Giovannini M. Factors asociated with initiation and duration o breastfeeding in Italy. Acta Paediatr 1999; 88(4):411-415.

212. Rothman KJ, Greenland S. Precision and validity in epidemiology studies. In: Rothman KJ, Greenland S. Modern Epidemiology. 2ed. Philadelphia: Lippincott Willians \& Wilkins; 1998. 
213. Russel AL. An appraisal of the value of indices proposed as epidemiologic aids in the practice of dental public health. I op. 40. p.69. Apud: Chaves ${ }^{52}$.

214. Sabulsky J, Batrouni L, Carballo R, Reyna S, Quiroga D, de Roitter H, et al. Feeding in the first month of life, by social strata in Cordoba, Argentina. Bull of PAHO 1995; 294):338-351.

215. Salzman JÁ. Principles of orthodontics. Philadelphia: J. B. Lippincott Co.; 1950. P.395-456.

216. Saturno LD. Características de la oclusión de 3.630 escolares del area metropolitana de Caracas. Acta Odoltol Venezol 1980; 18(2):237-261.

217. Schlomer R. Influence of thumb sucking and pacifiers on deciduous teeth. Fortschr Klefenor Thop 1984; 45(2):141-148. [Abstract]

218. Schneider PE, Peterson J. Oral habits: considerations in management. Pediat Clin North Am 1982; 29(3): 523-546.

219. Schubiger G, Schuarz U, Tonz O . UNICEF/WHO baby-friendly hospital initiative: does the use of bottles and pacifiers in the neonatal nursery prevent successful breastfeeding? Eur J Pediatr 1997; 156:874-877.

220. Scott JÁ, Aitkin I, Binns CW, Aroni RA. Factors associated with the duration of breastfeeding amongst women in Perth, Australia. Acta Paediatr 1999; 88(4):416-421.

221. Secretaria da Saúde e do Desenvolvimento Social do município de Florianópolis, SC, 1995. Saúde bucal na população de 3 a 12 anos de idade no município de Florianópolis, SC, Brasil, 1995. Relatório final. 
222. Serra-Negra JMC, Pordeus IA, Rocha Jr JF. Estudo da associação entre aleitamento, hábitos bucais e maloclusões. Rev Odontol Univ São Paulo 1997; 11(2):79-86

223. Shaw WC, Lewis HG, Robertson NRE. Perception of malocclusion. Brit Dent J 1975; 138(6):211-216.

224. Shaw WC. Dentofacial irregularities. In: Pine CM. Community Oral Health. Oxford: Wright; 1997. p.104-111.

225. Shaw WC. Factors influencing the desire for orthodontic treatment. Eur $J$ Orthod 1981; 3(3):151-162.

226. Shaw WC. Orthodontic and occlusal management. In: Shaw WC. Terminology, prevalence and aetiology of malocclusion, 1993. p.73-82.

227. Sheiham A, Watt RG. The common risk approach: a rational for promoting oral health. Community Dent Oral Epidemiol 2000; 28:399-406.

228. Sheiham A Public health approaches to the promotion of periodontal health. Monograph series 1990, n.3, Joint Department of Community Dental Health and Dental Practice, University College London and the London Hospital Medical College, London, 1990.

229. Sheiham A. Improving oral health for all: focusing on determinants and conditions. Health Education Journal 2000; 59:351-363.

230. Shepard JWJ, Gefter WB, Guilleminault C, Hoffman EA, Hoffstein DW, Hudgel DW, et al. Evaluation of the upper airway in patients with obstructive sleep apnea. Sleep 1991; 14:361-371. 
231. Shetty SR, Munshi AK. Oral habits in children - a prevalence study. J Indian Soc Pedod Prev Dent. 1998; 16(2):61-66.

232. Sillman $\mathrm{JH}$. A serial study on occlusion from birth to three years. Am J Orthod 1940; 26:207-227.

233. Silva CHT, Araújo TM. Prevalências das más oclusões em escolares na llha do Governador, Rio de Janeiro. Parte I: Classes I, II e III (Angle) e mordida cruzada. Ortodontia 1983; 16(3):10-16.

234. Silva Filho OG, Freitas SF, Cavassan AO. Prevalência de oclusão normal e má oclusão em escolares da cidade de Bauru (São Paulo). Parte II: Influência da estratificação sócio-econômica. Rev Odont USP 1990; 4(3):189-196.

235. Simões WA. Prevenção de oclusopatias. Ortodontia 1978; 11:117-125.

236. Simon P. Fundamental principles of a systematic diagnosis of dental anomalies. Boston: Stratford; 1926.

237. Smith GD, Hart C, Blane D, Gillis C, Hawthorne V. Lifetime socioeconomic position and mortality: prospective observational study. BMJ 1997; 314:547558.

238. Smyth KC. Some notes on the dentitions of Anglo-Saxon skulls from Bidford-on-Avon with special reference to malocclusion. Dental Record 1934; $54: 1-28$

239. Souza SMD de. CPO-D brasileiro aos 12 anos de idade tem redução de $53,22 \%$. Jornal da $A B O$, Rio de Janeiro, novembro/dezembro, 1996. p.8b.

240. Stecksen-Blicks C, Holm AK. Dental caries, tooth trauma, malocclusion, fluoride usage, toothbrushing and dietary habits in 4-year-old Swedish children: changes between 1967 and 1992. Int J Paediatr Dent 1995; 5(3):143-148. 
241. Steigman S, Weinberg Y. Spaced dentition. An epidemiologic study. Angle Orthod 1985; 55:167-176.

242. Stiz AL. Prevalência da doença periodontal e da má oclusão dentária em escolares de 5 a 12 anos de idade de Camboriú -SC, 2000. São Paulo, 2001. [Dissertação de mestrado- Departamento de Prática de Saúde Pública, Faculdade de Saúde Pública, Universidade de São Paulo].

243. Summers CJ. The occlusal index: a system for identifying and scoring occlusal disorders. Am J Orthod 1971; 59(6):552-67.

244. Taylor VJ, Cook PA. The prevalence of dummy sucing in two socioeconomic grous in Leeds. J Dent Res 1989; 68:592 [abstr 72]

245. Thilander B, Pena L, Infante C, Parada SS, de Mayorga C. Prevalence of malocclusion and orthodontic treatment need in children and adolescent in Bogota, Colombia. An epidemiological study related to different stages of dental development. Eur J Orthod 2001; 23(2):153-167.

246. Thompson ML, Myres JE, Kriebel MD. Prevalence odds ratio or prevalence ratio in the analysis of cross sectional data: What is to be done? Occup Environ Med 1998; 55:272-277. Apud: Pinho' ${ }^{196}$.

247. Tomasi E, Barros FC, Victora CG. As mães e suas gestações: comparações de duas coortes de base populacional no sul do Brasil. Cad Saúde Públ 1996; 12 (supl. 1):21-25.

248. Tomita NE. Relação entre determinantes sócio-econômicos e hábitos bucais: influência na oclusão de pré-escolares de Bauru-SP, Brasil. Bauru, 1996. [Tese de doutorado- Faculdade de Odontologia de Bauru, Universidade de São Paulo]. 
249. Trottman A, Elsbach BS. Comparasion of malocclusion in preschool black and white children. Am J Orthod Dent Orthop 1996; 110(1):69-72.

250. Tschill $P$, Willian B, Sonko A. Malocclusion in the decíduos dentition of Caucasian children. Europ J Orthod 1997; 19(4):361-367.

251. Tulloch JFC, Shaw WC, Underhill C, Smith A, Jones G, Jones M. A comparision of the attitudes toward orthodontic treatment in British and America communities. Am J Orthod 1984; 85(3):253-259.

252. UNICEF. United Nations Children's Fund. Breast-feeding and health. Assigment children. Geneva: Unicef. 1981. Apud: Howard et al ${ }^{108}$

253. UNICEF. United Nations Children's Fund. Division of information and Public Affairs. Feeding low birth weight babies. No,525 MTSE, 1996. Videotape.: Howard et al ${ }^{108}$.

254. UNICEF. United Nations Children's Fund. Situação da criança brasileira 2001. Brasilia: UNICEF - Brasil, 2001.

255. Universidade de São Paulo. Faculdade de Saúde Pública. Núcleo de Estudos e Pesquisas de Sistemas de Saúde. Secretaria de Estado da Saúde de São Paulo. Levantamento epidemiológico da cárie dentária, oclusopatias e fluorose dentária em crianças de 5 a 12 anos de idade, em escolas públicas e privadas do município de São Paulo, em 1996. São Paulo, 1997. [Relatório técnico] p.62-64.

256. Valente A., Mussolino ZM. Freqüência de sobressaliência, sobremordida e mordida aberta na dentição decídua. Rev. Odont. USP 1989; 3(3):402-407.

257. Van Der Linden FPGM. Genetic and environmental factors in dentofacial morphology. Am J Orthod 1966; 52(8):576-583. 
258. Van Der Linden FPGM. Ortodontia. Desenvolvimento da dentição. London:Quintessence; 1986. p.29.

259. Varrela J. Occurrence of malocclusion in attritive environment: a study of a skull sample from southwest Finland. Scand J Dent Res 1990; 98(3): 242-247.

260. Victora CG, Barros FC, Tomasi E, Menezes AM, Horta BL, Weiderpass E, et al. Tendências e diferenciais materno-infantil: delineamento e metodologia das coortes de 1982 e 1993 de mães e crianças de Pelotas, Rio Grande do Sul.Cad Saúde Pública 1996; 12 (supl 1):7-14.

261. Victora CG, Behague DP, Barros FC, Olinto MT, Weiderpass E. Pacifier use: cause, consequence or coincidence? Pediatrics 1997(a); 99:44-53.

262. Victora CG, Huttly SR, Fuchs SC, Olinto AMT. The role of conceptual frameworks in epidemiological analysis: a hierarquical approach. International Journal of Epidemiology 1997(b); 26(1):224-227.

263. Victora CG, Tomasi E, Olinto MT, Barros FC. Use of pacifiers and breastfeeding duration. The Lancet 1993; 341:404-406.

264. Victora CG, Vaughan JP, Lombardi C, Fuchs SM, Gigante LP, Smith PG, et al. Evidence for protection by breast-feeding against infant deaths from infectious diseases in Brazil. The lancet 1987; 8:319-321.

265. Victora CG. Exclusive breastfeeding: breast is best... but breast alone is best of all. Dialogue en Diarrhoea 1992; 49:2.

266. Viegas AR. Manual de Odontologia Sanitária: tomo IV. São Paulo: Massao Ohno; 1965. p.256. 
267. Viscovic R, Vujanovic M, Bricic V. Prevalence of orthodontic anomalies, analysis and evaluation of dental health in three groups of pre-school children in Zadar. Acta Stomatol Croatica 1990;24(4):271-280. [Abstract].

268. Visness $\mathrm{CM}$, Kennedy $\mathrm{KI}$. Maternal employment and breastfeeding: finding from the 1988 National Maternal and Infant Health Survey. Am J of Public Health 1997; 87(6):945-950.

269. Wadsworth MEJ, Kuh DJL. Chilhood influences on adult health: a review of recent work from the british 1946 national birth cohort study, the MRC National Survey of Health Development. Paediatric and Perinatology Epidemiology $1997 ; 11: 2-20$.

270. Wainio HL, Varrela J, Alanen P. Early oral sucking habits and occlusal development in the primary dentition. J Dent Res 2000; 79(5):1301.

271. Walther DP. Some of the causes and effects of malocclusion. Dent Pract $1960 ; 10: 139-154$

272. Warren JJ, Levy SM, Nowak AJ, Shenghui Tang MA. Non-nutritive sucking habits behaviors in preschool children: a longitudinal study. Pediatr Dent 2000; 22(3): 187-191.

273. Watase S, Mourino AP, Tipton GA. An analysis of malocclusion in children with otitis media. Am. Academ. Of Pediat. Dent. 1998; 20(5): 327-330.

274. Watt R, Sheiham A. Inequalities in oral health: a review of the evidence and recomendations for action. BDJ 1999; 187(1);

275. Weiland FJ, Jonke E, Bantleon HP. Secular trends in malocclusion in Austrian men. Eur J Orthod 1997; 19(4):355-359. 
276. Whincup PH, Cook DG, Shaper AG. Early life influences on blood pressure: a study of children aged 5-7 years. BMJ $1989 ; 587-591$.

277. Wilkinson RG. Health, hierarchy, and social anxiety. In: Adler NE, Marmot M, Mcewen BS, Stewart J. Socioeconomic status and health in industrial nations: social, psychological and biological pathways. Annals of the New York Academy of Science, vol. 896, New York; 1999. p. 48-63.

278. Wilkinson RG. Unhealthy societies. The afflictions of inequality. London: Routledge; 1997.

279. Winter GB. Problems involved with the use of comforters. Int Dent J 1980; 30:28-38.

280. Woodside DG, Linder-Aronson S, Stubbs DO. Relationship between mandibular incisor crowding and nasal mucosal swelling. Proc Finn Dent Soc 1991; 87(1):127-138. [Abstract]

281. Woon KC. Primary dentition occlusion in Chinese, Indian and Malay groups in Malaysia. Aust Orthod J 1988; 10(3): 183-185.

282. World Health Organization. Calibration of examiners for oral health surveys. Technical Report. Geneva: WHO; 1993.

283. World Health Organization. Contemporary patterns of breastfeeding: report on the WHO Collaborative study on breast -feeding. Geneve: WHO; 1981.

284. World Health Organization. Health through oral health: guidelines for planning and monitoring for oral health care. World Health Organization and Fédération Dentarie Internationale. London: Quintessence; 1989. 77p.

285. World Health Organization. Oral health surveys: basic methods. 4 ed. Geneva: WHO; 1997. 
286. World Health Organization. Oral Health Surveys: basic methods. Geneva: WHO; 1971.

287. World Health Organization. Oral Health surveys: basic methods. Third edition. Geneva: WHO; 1987. p.30-31

288. World Health Organization. Standardization of reporting of dental dideases and conditions, report of an expert committee on dental health. Techn. Rep. Ser. 242. Geneva: WHO; 1962.

289. Zadik D, Stern N, Litner M. Thumb-and pacifier-sucking habits. Am J Orthod 1977; 71(2):197-201.

290. Zhang J, Yu KF. What's the relative risk? A method of correcting the odds ratio in cohort studies of common outcomes. JAMA 1998; 280: 1690-1691.

291. Zochetti C, Consonni D, Bertazzi PA. Estimation of prevalence rate from cross-sectional data. [letter] Int J Epidemiol 1995; 24: 1064-1065. 
Anexo 1 


\section{ANEXO 1 \\ MODELO DE QUESTIONÁRIO UTILIZADO}

\section{I. - QUESTIONÁRIO PARA A MÃE OU RESPONSÁVEL}

1. A senhora (o senhor) sabe que todos ou a maioria dos dentes do seu filho(a) são de leite?
(1) $\operatorname{Sim}$
(2) Não

2. - A senhora (o senhor) acha que os dentes de leite são importantes ou não são importantes?
(1) Sāo
(2) Não são.
Se N.̃O Sĩo, pule para a pergunta 4.

- Se SÄO, por que?

\begin{tabular}{|lllll|}
\hline Ajudam a criança a crescer & (1) Sim & (2) Não & (8) NSA & (9) Ign. \\
Ajudam os dentes permanentes a nascer & (1) Sim & (2) Não & (8) NSA & (9) Ign \\
Favorecem à aparência do seu filho(a) & (1) Sim & (2) Não & (8) NSA & (9) Ign \\
Permitem o desenvolvimento da linguagem & (1) Sim & (2) Não & (8) NSA & (9) Ign \\
Participam na mastigação & (1) Sim & (2) Não & (8) NSA & (9) Ign \\
& & & & \\
\hline
\end{tabular}

4. - A sinhora (o senh(ir) sabe como estão os dentes do seu filho(a)?
(1) $\mathrm{Sim}$
(2) Não.
SE NĀO, pule para a pergunta 6 .

5. SE SIM, poderia dizer se está com problemas de:

Cáries (dentes estragados)

(1) $\operatorname{Sim}$

(2) Não

Sangramento da gengiva

(1) $\operatorname{Sim}$

(2) Não

Dentes tortos

(1) $\operatorname{Sim}$

(2) Não

6. - A senhora (o senhor) levou seu filho(a) alguma vez ao dentista ?.
(1) $\operatorname{Sim}$
(2) Não. SE NÃO, pule para a pergunta 11.

7. - A senhora (o senhor) levou seu fillio(a) ao dentista desde (MÉS) ao ano passado até agora?
(1) $\operatorname{Sim}$
(2) Não
(8) NSA 
8. SE SIM, quantas vezes? vezes. (88) NSA

9. Por que motivo?

(1) Consulta de revisão e controle

(2) Por dor de dente

(3) Por ter cárie

(4) Para fazer obturação que caiu ou quebrou

(5) Por traumatismo

(6) Os dentes estavam tortos

(7) Por outros motivos

(8) NSA

(7) Outros:

10 - Onde a senhora (o senhor) costuma levar seu filho(a) para ser atendido pelo dentista?

(1) Consultório Particular

(2)Consultóno de dentista de convênios

(3) Sindicatos

(4)Locais de Pronto Atendimento

(5)Faculdade de Odontologia

(6)Posto de Saúde

(7)Consultório nas escolas

(8)NSA

Agora vamos conversar sobre alguns hábitos do seu filho(a). Inicialmente gostariamos que senhora (o senhor) nos falasse sobre alguns hábitos alimentares do seu filho(a).

11. - Seu filho(a) mamou no peito?
(1) $\operatorname{Sim}$
(2) Não. SE NÃO, pule para a pergunta 13.

SE SIM, por quanto tempo?

_anos meses dias

(77)Ainda usa

(88) NSA 99) Ign. 
13. - Seu filho(a) usou mamadeira?
(1) $\mathrm{Sim}$
(2) Não. SE NÃO, pule para a pergunta 17.

14. - SE SIM, por quanto tempo?

anos meses dias

(77) Ainda usa

(88) NSA

(99) Ign.

15. - A senhora (o senhor) lembraria se o seu filho(a) tinha o hábito de tomar mamadeira de noite?
(1) $\operatorname{Sim}$
(2) Não. SE NÃO, pule para a pergunta 17.
(3) Às vezes

16 A - SE SIM, OU ȦS VEZES, a senhora (o senhor) lembraria como?
Mamadeira para dormir
(1) $\operatorname{Sim}$
(2) Não
(8)NSA
(9) Ign.
Dormia com a mamadeira
(1) $\operatorname{Sim}$
(2) Não
(8)NSA
(9) Ign.
Usava a mamadeira várias vezes durante a noite
(1) $\operatorname{Sim}$
(2) Não
(8)NSA
(9) Ign.

$16 \mathrm{~B}$ - Com que liquuido para beber?
Leite
(1) Com açúcar
(2) Sem açúcar
(3) Não tomava
(8) $\mathrm{N} \supset \mathrm{A}$
Chás
(1) Com açúcar
(2) Sem açúcar
(3) Não tomava
(8) NSA
Sucos
(1) Com açúcar
(2) Sem açúcar
(3) Não tomava
(8) NSA
Água
(1) Com açúcar
(2) Sem açúcar
(3) Não tomava
(8) NSA
Refrigerantes
(1) Com açúcar
(2) Sem açúcar
(3) Não tomava
(8) NSA
Bebida achocolatada
(1) Com açúcar
(2) Sem açúcar
(3) Não tomava
(8) NSA
Preparados $\mathrm{c} /$ farinha
(1) Com açúcar
(2) Sem açúcar
(3) Não tomava
(8) NSA

17. - Quantas vezes no dia seu filho(a) come? (9) Ign.

18. - Ele(a) costuma comer doces/chocolates entre as refeições? 
(1) $\operatorname{Sim}$

(2) Não. SE NÃO, pule para a pergunta 20.

19. - SE SIM, quantas vezes por dia? vezes

(77) Menos de uma vez por dia

(88) NSA

(99) Ign.

Agora nos vamos conversar sobre alguns hábitos que seu filho(a) teve ou tem, e que podem te modificado a posição dos dentes dele(a).

20. - Ele (a) chupou bico (chupeta)?
(1) $\operatorname{Sim}$
(2) Não. SE NÃO, pule para a pergunta 24.

21. - SE SIM, a senhora (o senhor) lembra até quando?

anos

(77) Ainda usa meses

22. - A senhora (o senhor) adoçava a chupeta?
(1) $\mathrm{Sim}$
(2) Não. SE NĀO, pule para a pergunta 24.
(8) NSA

23. SE SIM, com o que era mais adoçado?

(1) $\mathrm{Mel}$

(2) Açúcar

(3) Refrigerantes

(8) NSA

(9) Ign.

24. - Seu filho (a) chupou dedo ?
(1) $\mathrm{Sim}$
Não. SE NÃO, pule para a pergunta 27. 
25. - SE SIM, a senhora (o senhor) lembra até quando? anos meses

(77) Ainda chupa

(88) NSA

(99) $\lg n$

26. - A senhora (o senhor) saberia dizer qual o dedo que ele (a) chupou ou chupa?
(1) Polegar
(2) Outros dedos
(8) NSA
(9) Ign.

27. - Seu filho (a) teve ou tem o hábito de morder ou chupar o labio?
(1) $\mathrm{Sim}$
(2) Não
(9) Ign.

28. - Seu filho (a) teve ou tem o hábito de colocar objetos na boca?
(1) $\mathrm{Sim}$
(2) Nãc. SE NĀO OU IGN., pule para pergunta 30.
(9) Ign.

29. - SE SLM, a senhora (o senhor) poderia dizer o què ?
Panos ou fralda:
(1) $\operatorname{Sim}$
(2) Não
(8) NSA
(9) $\lg n$.
Utensilios (brinquedos)
(1) $\mathrm{Sim}$
(2) Não
(8) NSA
(9) ign.
Cabelo
(1) $\operatorname{Sim}$
(2) Não
(8) NSA
(9) Ign.

30. - A senhora (o senhor) observou se o seu filho (a) respira pela boca ?
(1) $\mathrm{Sim}$
(2) Não. SE NÃO, pule para a pergunta 32.

31. - SE SIM, quando isso acontece?
(1) Sempre
(2) Enquanto dorme
(3) Somente quando está gripado
(8)NSA 
Agora gostariamos que a senhora (o senhor) nos falasse sobre os hábitos de higiene bucal do seu filho (a).

32. Seu filho (a) limpa (escova) os dentes?
(1) $\operatorname{Sim}$
(2) Não. SE NĀO, pule para a pergunta 41.

33. - SE SMM, a senhora (o senhor) lembra quando iniciou a limpeza dos dentes/boca do seu (sua) filho ( ?

Com anos de idade.

(6) Antes de nascer os primeiros dentes

(7) Ao nascer os primeiros dentes

(8) NSA

(9) Ign.

34. - Quantas vezes por dia seu filho (a) escova os dentes? vezes

(6) Seis vezes ou mais

(7) $<1$ vez por dia

(8) NSA

(9) Ign.

35. - Seu filho (a) tem uma escova de dentes só dele (a)?
(1) $\mathrm{Sim}$
(2) Não
(8) NSA

36. - Seu filho (a) usa linha ou fio dental para ajudar a limpar entre os dentes ?
(1) $\mathrm{Sim}$
(2) Não
(3) Às vezes
(8) NSA

37. - Atualmente a senhora (o senhor) ajuda o (a) seu (sua) filho (a) a limpar os dentes?

(1) Sim. SE SIM, pule para a pergunta 39.

(2) Não

(3) Às vezes

(8) NSA 
38. - SE NÃO OU ÀS VEZES, porque a senhora (o senhor) não ajuda ?

(1) Porque ele (a) sabe/precisa limpar sozinho (a)

(2) Seu filho (a) não deixa

(3) Não tem tempo

(4) Acha dificil

(5) Não acha importante

(8) NSA

(9) Ign.

39. - Seu filho (a) costuma usar pasta de dentes para auxiliar na escovação ?
(1) $\operatorname{Sim}$
(2) Não. SE NĀO, pule para a pergunta 41.
(3) Às vezes
(8) NSA

40. - SE SIM, qual a marca da jasta de dente?

(8) NSA

Umas pergliatas finais para a senhora (o senhor).

41. - A senhora (ou sua esposa) sabe se tomou, quando estava grávida, algum comprimido (suplemento) que tivesse flúor, indicado especificamente para ajudar na formação dos dentes do seu filho (a).
(1) $\operatorname{Sim}$
(2) Não. SE NÃO, pule para a pergunta 43.

42. SE SIM, por quanto tempo?
(1) Durante toda a gestação
(2) No primeiro trimestre
(3) No segundo trimestre
(4) No terceiro trimestre
(5) No primeiro e segundo trimestres
(6) No segundo e terceiro trimestres
(7) No primeiro e terceiro trimestres 
(8) NSA

(9) Ign.

43. Como é a água com a qual se preparam os alimentos da criança ?

(1) Abastecimento público (encanada)

(2) Poço artesiano

(3) Água mineral industrializada

(4) Poço comum

(9) Ign.

44. - Como é a água que a criança bebe ?

(1) Abastecimento público (encanada)

(2) Poço artesiano

(3) Água mineral industrializada

(4) Pspo comum

(9) Ign.

45. - Desde que < nome da criança > nasceu, vocês sempre usaram o mesmo tipo de água para preparar os alimentos dele (a)?
(1) $\mathrm{Sim}$
(2) Não
(9) Ign.

Encerre a entrevista com a mãe (pai) ou responsável. 


\section{QUESTIONÁRIO PARA A CRIANÇA}

Inicialmente vamos conversar sobre os teus dentes.

1. - Tu achas teus dentes bonitos?
(1) Sim. SE SIM, pule para a pergunta 3
(2) Não

2. SE NÃO, por quê tu achas que eles não são bonitos ?
Por que são pretos (pigmentados)
(1) $\operatorname{Sim}$
(2) Não
(8) NSA
(9) Ign.
Por que estão com buracos (cárie)
(1) $\mathrm{Sim}$
(2) Não
(8) NSA
(9) Ign.
Por que são separados
(1) $\mathrm{Sim}$
(2) Não
(8) NSA
(9) Ign.
Por que estão quebrados
(1) $\mathrm{Sim}$
(2) Não
(8) NSA
(9) Ign.
Por que são tortos
(1) $\operatorname{Sim}$
(2) Não
(8) NSA
(9) Ign.
Por que são grandes
(1) $\mathrm{Sim}$
(2) Não
(S) NSA
(9) Ign.

3. - Tli escovas os teus dentes?
(1) $\mathrm{Sim}$
(2) Não. SE NÃO, pule para a pergunta 8.
(3) $\dot{A}$ S vezes

4. - SE SIM, tu usas pasta de dente ?
(1) $\operatorname{Sim}$
(2) Não
(3) Às vezes
(8) NSA

5. - Tu podes me mostrar quanto de pasta tu colocas na escova de dentes? (Pedir para pegar a escova e colocar a quantidade que costuma colocar).
(1) $0,4 \mathrm{~g}$
(2) $0,7 \mathrm{~g}$
(3) $1 \mathrm{~g}$
(8) NSA

6. - Tu costumas comer a pasta de dentes da escova?
(1) $\operatorname{Sim}$
(2) Não. SE NÃO, pule para a pergunta 8.
(3) Às vezes
(8) NSA 
7. - SE SIM E ÀS VEZES, por que tu engoles a pasta de dentes?
Por que o sabor é doce e gostoso
(1) $\operatorname{Sim}$
(2) Não
(8) NSA
Por que não consigo cuspir durante a escovação
(1) $\mathrm{Sim}$
(2) Não
(8) NSA
Por que gosto, porém não sei a razão
(1) $\mathrm{Sim}$
(2) Não
(8) NSA

8. - Já tivestes dor de dente ?
(1) $\operatorname{Sim}$
(2) Não. SE NÃO, pule para a pergunta 10.

9. - SE SIM, tua mãe (pai) te levou no dentista para ver o que tinha acontecido?
(1) $\operatorname{Sim}$
(2) Não
(8) NSA
(9) Ign.

10. - Tu já fostes no dentista alguma vez?
(1) $\operatorname{Sim}$
(2) Não. SE NÃO, pule para pergunta 13.

11. - Você gosta de ir ao dentista ?
(1) Sim. SE SIM, pule para a pergunta 13
(2) Não

12. SE NÃO, por quê?
Por que tenho medo
(1) $\operatorname{Sim}$
(2) Não
(8) NSA
Por que a anestesia e a caneta doem muito
(1) $\operatorname{Sim}$
(2) Não
(8) NSA
Por que o dentista não me trata bem
(1) $\operatorname{Sim}$
(2) Não
(8) NSA
Por que me disseram que doe muito
(1) $\operatorname{Sim}$
(2) Não
(8) NSA
Não sei
(1) $\operatorname{Sim}$
(2) Não
(8) NSA

13. - Alguém já te ensinou a cuidar dos teus dentes?
(1) $\mathrm{Sim}$
(2) Não. SE NÃO, pule para a pergunta 15.
(9) Ign. 
14. - SE SIM, quem?
Meus pais/irmãos/familiares
(1) $\operatorname{Sim}$
(2) Não
(8) NSA
Dentista no consultório
(1) $\operatorname{Sim}$
(2) Não
(8) NSA
Televisão ou rádio
(1) $\operatorname{Sim}$
(2) Não
(8) NSA
Meus colegas
(1) $\operatorname{Sim}$
(2) Não
(8) NSA
Palestras em escolas ou creches
(1) $\operatorname{Sim}$
(2) Não
(8) NSA

Agora gostaria que me falasses sobre o que tu gostas de comer.

15. - Tu gostas de comer doces?
(1) $\operatorname{Sim}$
(2) Não. SE NÃO, pule para a pergunta 17.
(3) Às vezes.

16. SE SIM OU ÀS VEZES, dos doces que vou dizer quais tu gostas de comer?
Chocolate
(1) $\operatorname{Sim}$
(2) Não
(3) Às vezes
Balas
(1) $\mathrm{Sim}$
(2) Não
(3) Às vezes
Bolachas recheadas
(1) $\operatorname{Sim}$
(2) Não
(3) Às vezes
Pudim
(1) $\mathrm{Sim}$
(2) Não
(3) Ás vezes
Sorvetes
(1) $\operatorname{Sim}$
(2) Não
(3) Às vezes
Pirulito
(1) $\mathrm{Sim}$
(2) Não
(3) Às rezes
Bolo/doces caseiros
(1) $\operatorname{Sim}$
(2) Não
(3) Às vezes

17. - E chicletes, tu gostas?
(1) $\mathrm{Sim}$
(2) Não

SE SIM, quantas vezes?

A: - Para quem masca todos os dias: vezes por dia

(77) menos de 1 vez por dia 
(88) NSA

(99) Ign.

B: - Para quem não masca todos os dias: vezes por semana

(77) menos de 1 vez por semana

(88) NSA

(99) Ign.

19. - Quando estás com sede, o que tu bebes geralmente?

(1) Leite com açúcar

(2) Leite sem açúcar

(3) Leite com chocolate

(4) Sucos com açúcar

(5) Sucos sem açúcar

(6) Refrigerantes

(7) Chás

(8) Água

(88) NSA 
Anexo 2 
ANEXO 2

\section{MODELO DE FICHA UTILIZADA PARA EXAME ODONTOLÓGICO}

III. MÉTOdO DE ESTUdO BÁSICO

1. - LESÕES DA CAVIDADE BUCAL

(1) $\operatorname{Sim} \quad$ (2) Não. SE NÃO, pule para o item 3.

2. SE SCM, qual?

Cistos ou hematomas de erupção

(1) $\mathrm{Sim}$

(2) Não

(8) NSA

Estomatite Herpética Aguda

(1) $\mathrm{Sim}$

(2) Não

(8) NSA

Hematomas traumáticos diversos

(1) $\mathrm{Sim}$

(2) Não

(8) NSA

Mucocele

(1) $\mathrm{Sim}$

(2) Não

(8) NSA

Candidiase/Queilite angular

(1) $\operatorname{Sim}$

(2) Não

(8) NSA

Lesão ulcerativa do lábio

(1) $\operatorname{Sim}$

(2) Não

(8) NSA

Lesão ulcerativa da mucosa buca!

(1) $\mathrm{Sim}$

(2) Não

(8) NSA

Fístula

(1) $\operatorname{Sim}$

(2) Não

(8) NSA

Fibrose

(1) $\operatorname{Sim}$

(2) Não

(8) NSA

Outros:

3. - Freio labial

(1) Inserção fisiológica

(2) Inserção patológica

4. - Freio lingual

(1) Inserção fisiológica

(2) Inserção patológica

\section{5. - ANÁLISE DA OCLUSÃO}

5.1. Chave de caninos

5.1.1.Direita
(1) Classe I
(2) Classe II
(3) Classe III
(4) Topo
(8) NSA

5.1.2. Esquerda
(1) Classe I
(2) Classe II
(3) Classe III
(4) Topo
(8) NSA

5.2. Espaço Primata Superior 

(1) Ausente Bilateral
(3) Presente Direito
(8) NSA
(2) Presente Bilateral
(4) Presente Esquerdo

5.3. Espaço Primata Inferior
(3) Ausente Bilateral
(3) Presente Direito
(8) NSA
(4) Presente Bilateral
(4) Presente Esquerdo

5.4. Tipo de arco superior
(1) Tipo I
(2) Tipo II
(8) NSA

5.5 Tipo de arco inferior
(1) Tipo I
(2) Tipo II
(8) NSA

5.6 Tipo de arco da criança
(1) Tipo I
(2) Tipo II
(3) Tipo misto
(S) NSA

5.7. Mordida aberta
(1) $\mathrm{Sim}$
(2) Não. GE NÃO, pule para o item 5.9

5.8. SE SIM, qual ?
(1) Anterior
(5) Posterior Esquerda
(2) Anterior e Posterior Direita
(6) Posterior Direita e Esquerda
(3) Anterior e Posterior Esquerda
(7) Total
(4) Posterior Direita
(8) NSA

5.9. Mordida Cruzada
(1) $\mathrm{Sim}$
(2) Não. SE NÄO, pule para o item 6.

5.10: SE SMM, qual?
(1) Anterior
(5) Posterior Esquerda
(2) Anterior e Posterior Direita
(6) Posterior Direita e Esquerda
(3) Anterior e Posterior Esquerda
(7) Total
(4) Posterior Direita
(8) NSA 
Anexo 3

Biblioteca/CIR

FACULDADEDE SAUUDE PÜBLICA

FACULDADEDESAL DE SAO PAVILO 


\section{ANEXO 3}

Critérios de maloclusão. Classificação segundo FOSTER DJ, HAMILTON MC. (Occlusion in the primary dentition. British Dent $J 1969 ; 126: 76-9$ ).

\section{Relacão de caninos}

- Classe 1: cúspide do canino decíduo superior encontra-se no mesmo plano vertical que a superficie distal do canino decíduo inferior, quando em oclusão cêntrica;

- Classe 2: cúspide do canino superior deciduo encontra-se anteriormente à superficie distal do c znino inferior decíduo, quando em oclusão cêntrica;

- Class 3: cúspide do canino superior decíduo encontra-se posteriormente à superficie distal do canino inferior decíduo, quando em oclusão cêntrica;

\section{Mordidas cruzadas posteriores}

Molares decíduos superiores ocluindo em relação linșilal com os molares decíduos inferiores, quando em oclusão cêntrica.

\section{Mordidas abertas anteriores}

Presença de espaço de mais de $2 \mathrm{~mm}$ entre os dentes superiores e inferiores, na região anterior (idem para a região posterior).

\section{Mordidas cruzadas anteriores}

Dentes anteriores superiores ocluindo em relação lingual aos dentes anteriores inferiores. 
Anexo 4 
CENTRO DE PESQUISAS EPIDEMIOLÓGICAS - UFPEL

ESTUDO LONGITUDINAL DAS CRIANÇAS NASCIDAS EM 1993 - PELOTAS

\section{QUESTIONÁRIO - 4 ANOS}

1. Número do questionário

Quest

2. Nome da mãe

3. Endereço completo

3.1. Ponto de referéncia

3.2. Telefone

3.3. Telefone para contato

3.4. Telefone Celular

$-\ldots-\cdots$

3.5. Outra forma de contato

3.6. Endereço de outro parente

4. 1 Nome da criança

4.2 Data de nascimento: ___ _ _ _ _

\section{ONDE CONSTAR <criança> SUBSTITUIR PELO NOME}

5. Quantos filhos a senhora teve depois de <criança> nascer? Todos nasceram vivos? _ nascidos vivos

- nascidos mortos

6. Qual a data de nascimento do(s) irmão(s) que nasceu depois de <criança>?

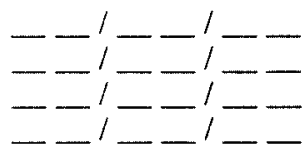

7. Quais são as pessoas que moram na casa?
Pai biológico
(1) $\mathrm{sim}$
Pai adotivo
(1) $\mathrm{sim}$
(0) nào
(3) falecido
Mãe biológica
(1) $\operatorname{sim}$
(0) não
(3) falecida
Mãe adotiva
(1) $\mathrm{sim}$
(0) não
(0) não

Irmãos menores que <criança> _ _

Outros irmãos

Outras pessoas

Nascriv _

Nasmor -

$$
\begin{array}{r}
\text { Paibio _ } \\
\text { Paiado _ } \\
\text { Maebio _ } \\
\text { Maeado - } \\
\text { Irmao1_ } \\
\text { Irmao2 } \\
\text { Outro_- } \\
\text { Nasc3 } \\
\times \text { Mor }
\end{array}
$$$$
\text { (NÃO INCLUIR A CRIANÇA QUE ESTÁ SENDO EXAMINADA) }
$$

\section{CONDIÇÕES DE MORADIA}

8. Tipo de casa (OBSERVAR)
(1) tijolo
(2) madeira
(3) mista
(4) papelão, lata
(5)outro: 


\section{Agora vamos conversar sobre sua casa.}

9. Quantas peças tem na casa? _ _ peças

10. E quantas são usadas para dormir?

11. Quantas pessoas dormem na peça junto com < criança>?

12. Onde <criança> dorme durante a noite?
$\rightarrow$ Em que lugar?
(1) quarto próprio
(2) quarto dos pais
( ) outra peça
(1) própria
(2) dos pais
(3) dos irmãos
$\rightarrow$ Em que cama?
(2) dos pais
(3) dos irmãos

13. No quarto onde <criança dorme:
Tem travesseiro ou acolchoado de penas?
(1) $\operatorname{sim}$
(0) não
Tem carpete ou tapete cobrindo o chão?
(1) $\operatorname{sim}$
(0) não
Tem cortinas?
(1) $\operatorname{sim}$
(0) nāo
Tem bichos de lã ou pelúcia?
(1) $\operatorname{sim}$
(0) não
Tem cachorro ou gato em casa?
(1) $\operatorname{sim}$
(0) não

14. A Sra. Fuma?
(0) não
(1) $\operatorname{sim}$
(2) ex-fumante
Quantos cigarros a Sra. fuma por dia? _ _ cig/dia
Quantos cigarros a Sra. fuma dentro de casa? _ cig/dia
(7) fuma ocasionalmente (menos que 1 cigarro por dia).
(9) IGN

15. Das outras pessoas que moram aqui, alguém fuma?
(1) $\operatorname{sim}$
(0) não,
(9)IGN

Alguefum

$\rightarrow$ SE SIM:

16. Quem fuma? Quantos cigarros dentro de casa?

\begin{tabular}{|l|l|}
\hline Quem fuma? & Quantos cigarros/dia \\
\hline $1^{\circ}$ Marido & -- \\
$2^{\circ}$ & -- \\
$3^{\circ}$ & -- \\
$4^{\circ}$ & -- \\
\hline $5^{\circ}$ & $\frac{-}{888=N S A)}$ \\
\hline
\end{tabular}

17. Tem água encanada?
(1) sim, dentro de casa
(2) sim, no pátio
(3) não

18. Como é a privada da casa?
(1) sanitário com descarga
(2) sanitário sem descarga
(3) casinha
(4) nāo tem
Paifum Oufum2 - Oufum3 Oufum4 Oufum5
(-

Fumdia Cigdia _ Cigdcasa -

Aguaen

Sanit 
19. Na sua casa tem: (CASO AFIRMATIVO): Está funcionando?

$\rightarrow$ Rádio
$\rightarrow$ Geladeira
$\rightarrow$ Aspirador de pó
$\rightarrow$ Máquina de lavar roupa
$\rightarrow$ Video cassete
$\rightarrow$ TV a cores
$\rightarrow$ Banheiro
$\rightarrow$ Carro
SOBRE EMPREGADA, PULAR PARA 21.
(1) sim, quantos?
(1) $\operatorname{sim}$
(1) $\operatorname{sim}$
(1) $\operatorname{sim}$
(1) $\operatorname{sim}$
(1) sim, quantos?
(1) sim, quantos?
(1) sim, quantos?

-
$?$ ? -
? -

(0) não

(0) nảo

(0) não

(0) nāo

(0) nāo

(0) não

(0) não

(0) não

$\rightarrow$ Na sua casa tem empregada dom./mês ?

(1) sim, quantas?

(0) não

$\rightarrow$ SE TEM CARRO:

20. Onde <criança> costuma sentar no carro?

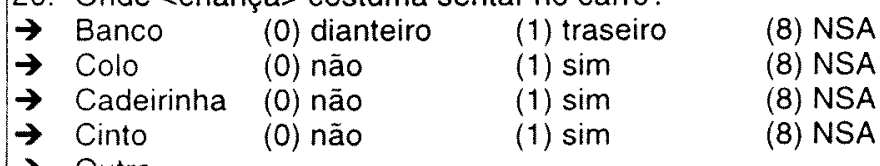

$\rightarrow$ Outro

(0) não

(1) $\operatorname{sim}$

(8) NSA

21. A familia tem motocicleta?
(1) $\operatorname{sim}$
(0) não $\rightarrow$ PULAR PARA 24.

\section{$\rightarrow$ SE TEM MOTOCICLETA:}

22. <criança $>$ anda de motocicleta junto com os pais?
(1) sim
(0) não
(8) NSA
(9) IGN

23. <criança $>$ usa capacete, quando anda de motocicleta?
(1) $\operatorname{sim}$
(0) não
(8) NSA
(9) IGN

24. A senhora pode me mostrar onde guarda os remédios?
(1) em um armário sem chave
(5) em gaveta com chave
(2) no roupeiro
(6) outros:
(3) em gaveta sem chave
(8) NSA
(4) em armário com chave ou alto
(9) IGN

25. A senhora pode me mostrar onde guarda os materiais de limpeza de sua casa?
(1) na cozinha em armário baixo ou sem chave ou à vista
(2) na área de serviço em armário baixo ou sem chave ou à vista
(3) em armário fechado fora do alcance das crianças
(4) em local alto
(5) outro:
(8) NSA (9) IGN

Agora gostaria de saber se a senhora e o pai de <criança> estudaram e onde trabalharam depois que <criança> fez 1 ano.

26. A senhora estudou na escola, depois da última visita que fizemos, quando <criança> tinha 1 ano?
(00) não
( ) sim. Até que série completou? _ série _ grau

27. E o pai de <criança>?
(00) nāo
( ) sim. Até que série.completou? série grau

Sermae
Radio

Gelad

Aspir
Roupa

Video

TV

Banh

Carro -

Emp

Banco

Colo

Cadeir

Cinto

Outcar -

Moto

Motopai

Capacete

Remed

Matlimp 
28. A senhora trabalhou nos últimos doze meses, desde <mês $>$ do ano passado?
(0) não
(1) sim
(2) sim em casa, para fora
(3) estudante
(4) outro:

\section{SE TRABALHOU:}

29. Quantos meses por ano trabalhou ? _ _ meses

30. Quantos dias por semana você trabalhou? _ dias

31. Quantas horas por dia você trabalhou ? _ _ horas

32. Qual o seu tipo de trabalho?

Trabmes

Trabsem

Trabhor

Tipotrab

Agora gostaria de the fazer algumas perguntas a respeito da renda atual da família

33. No mês passado, quanto receberam as pessoas da casa?

$\rightarrow$ Pessoa 1: R\$ por mês sal. mín.

$\rightarrow$ Pessoa 2: R\$ por mês sal. mín.

$\rightarrow$ Pessoa 3: R\$ sal. min.

Pessoa 4: R\$ sal. mín.

34. A familia tem outra fonte de renda, como aluguel, mesada, pensão, etc? $\rightarrow \mathrm{R} \$$ por mês salários mínimos

$\rightarrow \mathrm{R} \$$ por mês șalários mínimos 
47. Eu vou ler uma lista de alimentos e gostaria de saber se <criança> costuma comer?

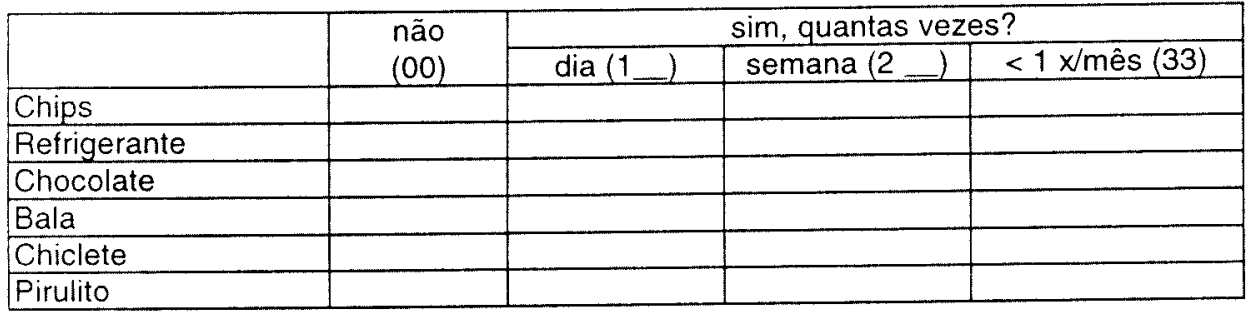

48. <criança> toma mamadeira?
(0) não
( ) $\operatorname{sim} \rightarrow$ Quantas vezes por dia?

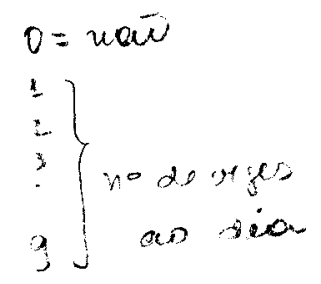
$\rightarrow$ Qual a quantidade de cada vez?
(0) não
(1) sim, só para dormir
(2) sim, durante o dia
(3) sim, para deitar e depois solta o bico
(4) sim, durante o dia e a noite
(5) outro:

49. <criança> chupa bico?

Agora vou the fazer algumas perguntas sobre asma, bronquite e chiado no peito.

50. Desde que nasceu, <criança> teve chiado no peito?
(0) não $\rightarrow$ PULAR PARA 59
(1) $\operatorname{sim}$
(9) IGN

\section{SE SIM:}

51. Com que idade teve a primeira crise de chiado no peito?
(1) antes de 6 meses
(2) 6 a 12 meses
(3) mais de 12 meses
(8) NSA
(9) IGN

AS PRÓXIMAS PERGUNTAS REFEREM-SE AOS ÚLTIMOS 12 MESES, ISTO É, DESDE<MÊS> DO ANO PASSADO.

52. Nos últimos 12 meses, isto é, desde <mês> do ano passado, <criança> teve chiado no peito?
(0) não
(1) $\operatorname{sim}$
$\rightarrow$ PULAR PARA54.
(9) IGN

53. Quando <criança> parou de ter crises de chiado no peito?
$\begin{array}{ll}\text { (8) NSA } & \text { meses } \\ \text { (9) IGN }\end{array}$
meses

\section{$\rightarrow$ SE RESPONDEU A 53, PULAR PARA 59 冈}

54. Desde<mês $>$ do ano passado, quantas crises de chiado no peito <criança $>$ teve?
(88) NSA
(99) IGN

55. Desde <mês > do ano passado, <criança $>$ teve seu sono perturbado por chiado no peito?
(0) não
(1) $\operatorname{sim}$
(8) NSA
(9) IGN

$\rightarrow$ SE SIM:

56. Quantas noites por semana? _ noites
(0)menos de uma
(1) uma noite ou mais
(8)NSA
Chips _ -
Refrig _ _
Choco _-
Bala _-
Chicle _-
Pirul __ _

Chiado

Chiaid

$\checkmark$ Chiatu

Paranos

Parmes

Numchi

Sonochi

Sonovez

57. Desde <mês> do ano passado, o chiado foi tão forte que <criança > não conseguia dizer mais de duas palavras entre cada respiração?
(1) $\operatorname{sim}$
(0) não
(8)NSA
(9)IGN 
58. Desde <mês $>$ do ano passado, <criança $>$ teve chiado no peito depois de correr?
(1) $\sin$
(0) não
(8) NSA
(9) IGN

Corrchi

Tosse

59. Desde <mês>do ano passado, <criança $>$ teve tosse seca à noite, sem estar gripado? \
(1) $\operatorname{sim}$
(0) não
(9) IGN

60. Alguma vez o médico disse que <criança> tinha asma ou bronquite? $\square$
Asma:
(0) não, $\rightarrow$ PULAR PARA 63
(1) $\operatorname{sim}$
(8) NSA
(9) IGN
Bronquite:
(0) não, $\rightarrow$ PULAR PARA 63
(1) $\sin$
(8) NSA
(9) IGN

62. Nos últimos 12 meses a criança teve asma ou bronquite?
Asma:
(0) não
(1) $\mathrm{sim}$
(8) NSA
(9) IGN
Bronquite:
(0) não
(1) $\mathrm{sim}$
(8) NSA
(9) IGN

AS PERGUNTAS SEGUINTES (63 a 70) SOMENTE SERÃO FEITAS PARA QUEM RESPONDEU SIM PARA AS PERGUNTAS $50,52,59,60$, OU SEJA, AS CRIANÇAS QUE TÊM OU TIVERAM CHIADO, TOSSE SECA À NOITE OU ASMA OU BRONQUITE CONFIRMADA PELO MÉDICO

63. <criança> internou por causa de chiado no peito ou tosse seca ou asma? $\square$
(00) não
(88) NSA
( ) sim $\rightarrow$ Quantas vezes?
(99) IGN

64. A senhora leva <criança> para fazer consultas de revisão por causa do chiado quando ela não está em crise?
(0) não $\rightarrow$ PULAR PARA 66
(1) $\operatorname{sim}$
(8)NSA

\section{$\rightarrow$ SE SIM}

65. Aonde leva ou levava <criança> para consultas de rotina?
(1) Posto de Saúde
(2) Médico particular
(3) Pronto Socorro
(4) Ambulatório de hospital ou Faculdade (5) Outro:
(8) NSA

66. O que a senhora faz ou fazia quando <criança > começa(va) a chiar o peito?
(10) já começa a medicar em casa
(20) não medica, espera melhorar sozinha
(3_) leva para consultar. $\rightarrow$ Onde?
(4_) outra:
(88) NSA

67. Desde <mês> do ano passado, <criança> foi ao médico, devido ao chiado?
(00) não
( ) sim, $\rightarrow$ Quantas vezes?
(88) NSA

68. Desde <mês> do ano passado, <criança > foi ao médico, devido ao chiado?
(00) não
() sim, $\rightarrow$ Quantas vezes?
(88) NSA

69. <criança> já usou algum medicamento, bombinha ou vacina para tratar asma, bronquite ou chiado no peito nos últimos 12 meses?
(1) $\operatorname{sim}$
(0) não
(8) NSA
(9) IGN

SE SIM

70. Qual(is) o(s) medicamento(s), bombinha (s) ou vacina(s)?

Medic1

(88)NSA (99)!GN

71. <criança> tem ou já teve crises de espirros ou nariz correndo quando não estava gripado ou resfriado?
(0) não
(1) $\operatorname{sim}$
(9) IGN 
Anexo 5 
Social and biological early life influences on the prevalence of open bite in children aged 5 to 6: a life course study in Brazil

Karen Glazer Peres', Maria do Rosário Dias de Oliveira Latorre', Aubrey Sheiham², Marco Aurélio Peres ${ }^{3}$, César Gomes Victora ${ }^{4}$, Pedro Gonsalez Hernandez ${ }^{5}$, Angela Maria Nunes Maas ${ }^{5}$, Ana Regina Romano.

Running title: Early life influences on malocclusion

${ }^{1}$ Department of Epidemiology Faculty of Public Health, University of Sao Paulo, São Paulo, Brazil, ${ }^{2}$ Department and Epidemiology and Public Health, Royal Free and University College London, London, UK; ${ }^{5}$ Department of Public Health, Federal University of Santa Catarina, Florianópolis, Brazil; ${ }^{4}$ Department of Social Medicine, Federal University of Pelotas, Pelotas, Brazil. ${ }^{5}$ Faculty of Dentistry, Federal University of Pelotas, Pelotas, Brazil

Correspondence to:

Karen Glazer de Anselmo Peres

Rua Manoel Isidoro da Silveira, 610, sala 201

Lagoa da Conceição - Florianópolis - SC

Brazil - CEP 88062-060

e-mail: karengp@ig.com.br 


\section{Introduction}

Several doubts remain about the etiology and the causes of malocclusions in the primary dentition. Some authors consider that the genetic factors influencing the skeletal development are the most important determinants for malocclusion ${ }^{10}$. On the other hand, anthropologic studies on the secular trends of malocclusion indicate that environmental conditions affect the variation in occlusal traits ${ }^{4,25}$. The most frequently mentioned environmental factors are the change in nutrition. These include the trend towards a more refined diet demanding less powerful masticatory action ${ }^{15}$; premature primary tooth loss due to caries ${ }^{4}$, non-nutritive sucking habits ${ }^{12}$; bottle-feeding ${ }^{18}$ and early ${ }^{\text {weaning12 }}{ }^{\text {. Therefore, }}$ the development of malocclusion depends on the effects of various orofacial functions in the early postnatal period. In addition, some studies have suggested that the parental behaviour in relation to breastfeeding and diet are determined by social and economic conditions $^{11}$.

However, when and how the acknowledged risk factors for malocclusions occur are not established. Therefore a study using early life approach was planned to understand the social and biological risks to malocclusion acquired during the course of life, especially in the first years of life. The objective of this study was to identify social and biological risk factors of malocclusion in six year- old children using a life course approach. 


\section{Methods}

This study was conducted in Pelotas, Rio Grande do Sul, Southern of Brazil. A birth cohort study was initiated in 1993 . The main objective was to assess perinatal and infant health, through five sub-projects: perinatal, follow-up, infant mortality, hospital admissions and psychological development ${ }^{25}$. In the perinatal sub-project, the hospitals in Pelotas were visited and all babies born between 01/01/1983 and 31/12/1983 were identified, including up to $99 \%$ of the live-born children of this municipality. Questionnaires about social and economic variables, demography, pregnancy, behavioural, health care and morbidity were administrated to mothers attending the hospital for childbirth. The mothers were weighed and measured and children were weighed, measured and examined. For the follow up study, a sample of children was selected and followed up at 1, 3, 6 and 12 months. The hospital morbidity sub-project included all children with hospital care needs from January 1993 to December 1994. The psychological sub-project included home visit to the child in 1998 when the children were 4 years old. The details and results of the five sub-projects have been reported ${ }^{25}$

The Oral Health Study (OHS) started in 1999 as a cross sectional study nested in the birth cohort study. A minimum random sample size of 359 children was obtained from among 5,249 live birth in 1993 in Pelotas. An addition $10 \%$ of the sample size was included because of the possibility of non-response. The final sample size was 400 children.

Firstly, the children's parents were informed about the objectives of the study and consent was obtained for interviews and dental examinations. Pelotas Federal University Ethics Committee approved the project. 
The dental examinations were carried out to measure malocclusion, dental caries and oral mucosal lesions by a dental team of three dentists and three scribes. Before the children were examined, the reliability of the examiners was assessed. The examiners were calibrated in December 1998 and May 1999. One of the authors was the standard examiner (MAP). The statistics kappa value was calculated for each type of malocclusion to assess the intra and inter examiner agreement.

The diagnosis of malocclusion was based on the following criteria: presence of openbite (anterior and/or posterior), crossbite unilateral or bilateral (anterior and/or posterior) considered as reverse buccal overjet with or without a midline shift and primary canines relationships on the right and left sides (class 1,2 , and 3$)^{10}$. The children were examined in their homes, sitting on a chair. When necessary, the child's mandible was gently guided into centric occlusion by the examiner. This paper shows the results about anterior open bite exclusively through the dependent dichotomous variable: openbite YES $\left(\mathrm{Y}_{0}=1\right)$ or $\mathrm{NO}\left(\mathrm{Y}_{0}=0\right)[\operatorname{Prob}(\mathrm{Y}=1)]$

A questionnaire was administered to the mothers after the child's dental examination. The questions were about bottle-feeding (yes, no, when), pacifier sucking (yes, no, when), thumb and digit sucking (yes, no, when) and mouth breathing (yes, no, when). The other independent variables were social and economic conditions such as social class, family income, parent's education, number of children under 5 years and household conditions. The maternal independent variables were age, parity, breast or bottle feeding, work, cigarette smoking, marital status, intention to give pacifier at birth and child care. The child's characteristics analysed were type of delivery, birthweight, number of teeth, non-nutritive sucking habits, sleeping arrangement and respiratory disease. Child's sex and dental caries were recorded as controlling variables. The data concerning perinatal, socio- 
economic and childhood health were obtained from the data on the large cohort study, at birth, $1^{\text {st }}, 3^{\text {rd }}, 6^{\text {th }}, 12^{\text {st }}$ months old and in the $5^{\text {th }}$ year of life $e^{25}$.

Univariate analysis between each dependent and independent variables were tested and the odds ratios were measured with $95 \%$ confidence intervals. Unconditional logistic regression analysis was performed for each dependent variable adjusted to a previously determined hierarchical framework, from distal to more proximal determinants (fig 1). The criterion for including each variable in the logistic regression model was $p$ value less than 0.20. The significance level for the inclusion of each variable in the model was measured by the likelihood ratio test. The final model included all variables that had a $p$ value up to 0.05 after adjustment for variables in the same and higher levels of the framework. The analyses were done using SPSS for Windows. 


\section{Results}

The response rate was $89,7 \%$ and the lack of response was mainly due to families moving out of the city. Anterior open bite was detected in $173(46,3 \%)$. The univariate analysis related to socioeconomic variables showed no significant association with anterior open bite (Table 1). Variable maternal education was selected to control the final posterior multiple regression analysis. Body mass index and maternal height was statistically associated with anterior open bite in the univariate analysis and remained statistically significant after adjusted for each other $(p=0,032$ and $p=0,007$, respectively) (Table 2$)$. The unadjusted and adjusted model showed that maternal behaviour variables associated with open bite were maternal age, breastfeeding duration and intention to give pacifier to child at birth. Children whose mother was between 30 and 39 years old had Odds Ratio of 2.3 of having anterior open bite compared to other maternal age in the adjusted model (Table 3 ). Children whose mother had intention to give pacifier at birth had Odds Ratio of 3.2 having anterior open bite compared to children whose mother did not have this intention (Table 3 ). Table 4 shows there was no association between the biological children variables and anterior open bite. Despite this the gender of children was maintained in the final multiple regression model for controlling possible confounders. The unadjusted and adjusted models related to children behaviour variables and anterior open bite are shown in the Table 5 . Despite a lot of childrens behaviour variables had presented association with anterior open bite, only pacifier sucking between aged 12 months and 5 years old, $\mathrm{dmf}-\mathrm{t}>1$ and digital sucking at 6 years old were statistically significant after controlling for each other (Odds Ratio $=9.3,2.7$ and 1.5 respectively) .

The data in Table 6 shows the hierarchical final model about the children' life course variables and anterior open bite. Each level was controlled by the level above 
according to the theoretical model. Children whose mother height was less than $165 \mathrm{~cm}$ showed Odds Ratio of $1.9\left(\mathrm{Cl}_{95 \%}[1,2 ; 3,0]\right)$ compared with children whose mothers were taller $(p=0,007)$. Children whose mother was between 30-39 years old showed Odds Ratio $2,4\left(\mathrm{CI}_{95 \%}[1,1 ; 5,5]\right)$ in relation to children whose mother was younger. Children that were breastfed between 4 and 8,9 months ( $\left.\mathrm{OR}=3,0, \mathrm{Cl}_{95 \%}[1,7 ; 5,9]\right)$, between 1 and 3,9 months $\left(\mathrm{OR}=3,1, \mathrm{Cl}_{95 \%}[1,7 ; 5,6]\right)$ and less than 1 month $\left(\mathrm{OR}=2,4, \mathrm{CI}_{95 \%}[1,1 ; 4,9]\right)$ showed more risk to develop anterior open bite than those that were breastfed 9 months or more. 


\section{Discussion}

This current research is a cross sectional malocclusion study nested in a birth cohort which have presented high response rates during the follow-up. The study design assured both more accurate understanding about chronological events and avoided recall bias.

The prevalence of open bite achieved $46.3 \%$ of the sample $\left(\mathrm{CI}_{95 \%}=[41.2 \%-51.4 \%]\right)$, which is higher than the majority of the international ${ }^{16}$ and Brazilian ${ }^{21,23,24}$ previous studies. The variation on the prevalence observed in international and Brazilian studies possibly should be explained by the difference in children's samples ages. It is known that the time and the frequency of harmful exposures such as digital and pacifier sucking habits may range according to a child's age. In addition, cultural habits may have influenced higher or lower risk factors exposure which should contribute to determine difference in the prevalence found among the studies analysed.

In our study, socio-economic conditions were not associated with the open bite corroborated results from other researchers ${ }^{2,9,14,18,21,23}$. In spite of our results, the socioeconomic influences on malocclusion, including open bite, remain unclear. A higher prevalence of malocclusion in children from low social class was identified by Silva Filho (1998) when Class I was the outcome analysed and by Infante (1975) when molar Class II was the dependent variable. On the other hand, Moron et al (1995) observed a higher proportion of malocclusion in schoolchildren enrolled in private school than those in public school.

Children's health is determined by socio-economic conditions as has been observed by the association between infectious diseases and low income, low schooling and low 
coverage of waste disposal and water supply. These conditions were not the direct cause of diseases but influence several proximąl determinants of diseases ${ }^{3,6}$.

Mothers whose height was lower than $156 \mathrm{~cm}$, was statistically associated with children who presented open bite, after controlled by all socio-economic variables studied. Several studies reported a relationship between mother's height and socio-economic conditions. The lower mother's height lower family income and lower schooling (TOMASI et al. 1996). In our study mother's height acted such as a socio-economic marker because a strong and statistically significant association was found between this variable and socio-economic conditions (data not shown). Even after all socio-economic variables were taken into consideration, mothers height was still influence on open bite. We may suggest that other biological factors exist which were not studied that could contribute to clarify the understanding about the genetic influence on malocclusion.

Mother's age between 30 to 39 years-old, the length of exclusive breastfeeding less than 9 months, the mother's intention to introduce a pacifier since the birth time, were risk factors for open bite after to be adjusted by mother's schooling and height.

A low prevalence and severity of malocclusion have been observed in children whose length of breastfeeding was longer. We can hypothesise that it was due to impact of nutritive sucking habit on oral facial tissue development ${ }^{5,17,19}$. Indeed, the kind and length of breastfeeding are influenced by social and cultural environment including the common sense about normal attitudes related to breastfeeding which are influenced by media (HENDERSON et al. 2000)

Birth weight, a key determinant in child health was not ässociated with open bite corroborate another Brazilian study conducted by Tomita (1997). 
The use of a pacifier in the children life course was also analysed. It could be noticed that when this habit is introduced earlier there is a high risk to develop open bite but this risk disappears after controlling by the length and frequency of the habit suggesting that these last variables are more important than earlier pacifier habit. These results are supported by other studies ${ }^{1,12,19}$.

WARREN et al. (2000), found that older mother, those with higher years of study and primiparas had a higher proportion of children with non nutritive sucking habits when compared with younger mothers, with lower years of study and with more than one child. These findings were also confirmed by $\left(\mathrm{PAUNIO}^{20}\right.$ et al. 1993) (FARSI e SALAMA ${ }^{7}$ 1997) and CALISTI ${ }^{2}$ et al. 1960). In our research the same pattern was observed when we analysed the association between a longer length of time of pacifier use and a mother's higher years of study (data not shown).

Identifying the factors that influence the longer length of pacifier use should contribute towards preventive and health promotion measures such as mother's warning about harmful habits in the children's early life through a multisectoral approach including paediatricians and nurses.

In fact, as the most chronic diseases, including malocclusion, share common risk factors such as dietetic habit, a common approach to prevent and to control these diseases is more effective. As seen, the first proximal risk factor for open bite was pacifier use which may be associated with the early events in the children life such as the length of breastfeeding which also influence other health problem, e.g., obesity, hypertension, arteriosclerosis, and food allergy. 
The second proximal risk factor for open bite was dental caries which also shared common risk factors, such as dietetic habits, with most common chronic disease such as diabetes, coronary heart disease, and obesity.

Strategies for oral health care should include intersectoral approaches to health promotion based upon a population strategy and a common risk factor approach. As examples of policies to promote general and oral health we can nominate the increase in the mother's licence after delivering in order to increase the length of breastfeeding, the incentive for production of healthy food, the laws to avoid an excess of consumption of unhealthy children's food, the use of clear warnings about food composition ${ }^{\text {(SHEIHAM 1990) }}$.

From a Public Health perspective the common risk approach is the most cost effective strategy to prevent malocclusion in primary dentition. 
Figure

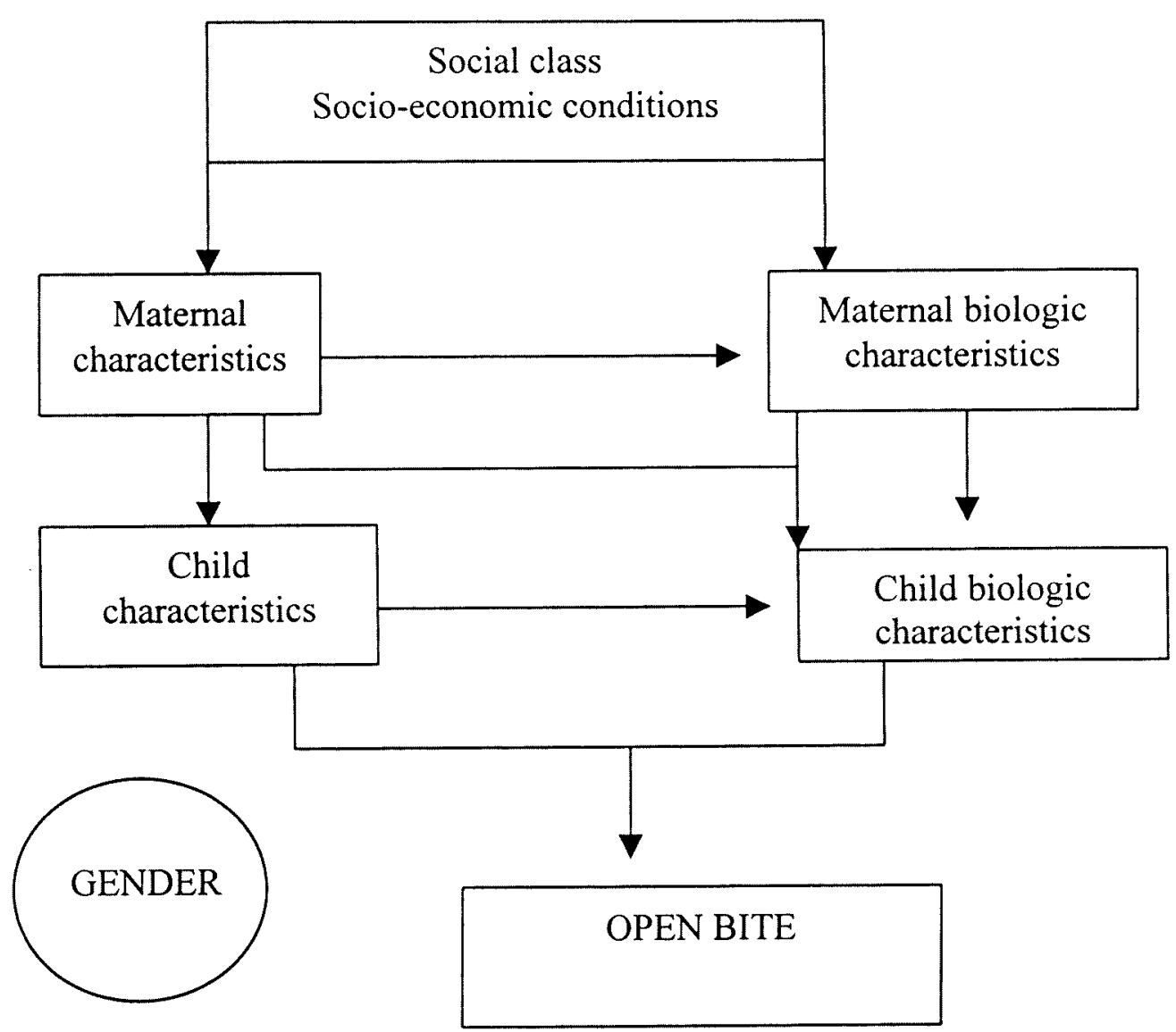




\section{Tables}

Table 1: Association between socio-economic variables and dental open bite in their children. Pelotas, Brazil, 1999.

\begin{tabular}{|c|c|c|c|c|c|c|c|}
\hline \multirow[t]{2}{*}{ Variable } & \multirow[t]{2}{*}{$\mathbf{N}$} & \multicolumn{2}{|c|}{ Open bite $(\%)$} & \multirow[t]{2}{*}{$\mathrm{OR}\left[\mathrm{CI}_{95 \%}(\mathrm{OR})\right]$} & \multirow[t]{2}{*}{$\overline{\mathbf{P}^{\mathbf{c}}}$} & \multirow[t]{2}{*}{$\mathrm{OR}\left[\mathrm{CI}_{95 \%}(\mathrm{OR})\right]$} & \multirow[t]{2}{*}{$\mathbf{P}^{2}$} \\
\hline & & No & & & & & \\
\hline Social class & & & & & 0,510 & $\#$ & \\
\hline Bourgeoise & 77 & 57,5 & 42,5 & 1,0 & & & \\
\hline Proletariat & 258 & 53,4 & 46,6 & $1,2[0,7 ; 1,9]$ & & & \\
\hline Family income (MW*) & & & & & 0,529 & \# & \\
\hline$>6,0$ & 48 & 59,3 & 40,7 & 1,0 & & & \\
\hline 1,1 a 6,0 & 247 & 51,6 & 48,4 & $1,4[0,8 ; 2,5]$ & & & \\
\hline$\leq 1,0$ & 64 & 56,5 & 43,5 & $1,1[0,5 ; 2,3]$ & & & \\
\hline Marital status & & & & & 0,172 & \# & \\
\hline & 321 & 55,1 & 44,9 & 1,0 & & & \\
\hline $\begin{array}{l}\text { Husband/partner } \\
\text { Without husand/partner }\end{array}$ & 38 & 41,2 & 58,8 & $1,7[0,9 ; 3,6]$ & & & \\
\hline Maternal schooling (years) & & & & & 0,221 & & 0,221 \\
\hline More than 8 & 86 & 58,8 & 41,2 & 1,0 & & 1,0 & \\
\hline 8 or less & 273 & 51,9 & 48,1 & $1,3[0,8 ; 2,1]$ & & $1,3[0,8 ; 2,1]$ & \\
\hline Paternal schooling (years) & & & & & 0,354 & \# & \\
\hline More than 8 & 93 & 57,8 & 42,2 & 1,0 & & & \\
\hline 8 or less & 239 & 52,4 & 47,6 & $1,2[0,8 ; 2,0]$ & & & \\
\hline
\end{tabular}

Table 2: Association between maternal biological variables and dental open bite in their children.

Pelotas, Brazil, 1999.

\begin{tabular}{|c|c|c|c|c|c|c|c|}
\hline \multirow[t]{2}{*}{ Variable } & \multirow[t]{2}{*}{$\mathbf{n}$} & \multicolumn{2}{|c|}{ Open bite (\%) } & \multirow[t]{2}{*}{$\mathrm{OR}\left[\mathrm{CI}_{95 \%}(\mathrm{OR})\right]$} & \multirow[t]{2}{*}{$\overline{\mathbf{P}^{c}}$} & \multirow[t]{2}{*}{$\mathrm{OR}\left[\mathrm{CI}_{95 \%}(\mathrm{OR})\right]$} & \multirow[t]{2}{*}{$\mathbf{P}^{2}$} \\
\hline & & No & Yes & & & & \\
\hline Body mass index $\left(\mathrm{Kg} / \mathrm{m}^{2}\right)$ & & & & & 0,080 & & \\
\hline 25,0 or more & 76 & 63,1 & 36,9 & $0,6[0,3 ; 1,0]$ & & $0,6[0,4 ; 1,0]$ & 0,032 \\
\hline $18,5-24,9$ & 227 & 49,8 & 50,2 & 1,0 & & 1,0 & \\
\hline less than 18,5 & 44 & 60,5 & 39,5 & $0,7[0,3 ; 1,4]$ & & $0,7[0,4 ; 1,5]$ & 0,359 \\
\hline Maternal height $(\mathrm{cm})$ & & & & & 0,012 & & 0,007 \\
\hline 156 or more & 240 & 58,7 & 41,3 & 1,0 & & 1,0 & \\
\hline less than 156 & 115 & 42,2 & 57,8 & $1,9[1,2 ; 3,1]$ & & $1,9[1,2 ; 3,0]$ & \\
\hline
\end{tabular}

${ }^{c} \mathrm{p}: \chi^{2}$ test, crude $\mathrm{p}$ value

${ }^{\mathrm{a}} \mathrm{p}$ : adjusted 
Table 3: Association between behavioural maternal variables and dental open bite in their children. Pelotas, Brazil, 1999.

\begin{tabular}{|c|c|c|c|c|c|c|c|}
\hline \multirow[t]{2}{*}{ Variable } & \multirow[t]{2}{*}{$\mathrm{n}$} & \multicolumn{2}{|c|}{ Open bite (\%) } & \multirow[t]{2}{*}{$\mathrm{OR}\left[\mathrm{CI}_{95 \%}(\mathrm{OR})\right]$} & \multirow[t]{2}{*}{$\mathrm{P}^{c}$} & \multirow[t]{2}{*}{ OR[CI(OR)] } & \multirow[t]{2}{*}{$\mathrm{P}^{\mathrm{a}}$} \\
\hline & & No & Yes & & & & \\
\hline Maternal work at birth & & & & & 0,802 & $\#$ & \\
\hline Yes & 117 & 54,2 & 45,8 & 1,0 & & & \\
\hline No & 242 & 52,8 & 47,2 & $1,0[0,6 ; 1,5]$ & & & \\
\hline Maternal work at 12 months age & & & & & 0,218 & \# & \\
\hline Yes & 144 & 49,7 & 50,3 & 1,0 & & & \\
\hline No & 214 & 56,8 & 43,2 & $0,8[0,5 ; 1,2]$ & & & \\
\hline Maternal work at 5 years old & & & & & 0,331 & \# & \\
\hline Yes, all period & 79 & 60,5 & 39,5 & 1,0 & & & \\
\hline Yes, partial period & 95 & 51,0 & 49,0 & $1,5[0,8 ; 2,7]$ & & & \\
\hline No & 183 & 51,4 & 48,6 & $1,5[0,9 ; 2,5]$ & & & \\
\hline Household work at child birth & & & & & 0,468 & \# & \\
\hline Others & 160 & 56,2 & 43,8 & 1,0 & & & \\
\hline Mother & 199 & 51,8 & 48,2 & $1,2[0,8 ; 1,8]$ & & & \\
\hline Mother smoked during pregnancy & & & & & 0,106 & $\#$ & \\
\hline Não & 241 & 56,7 & 43,3 & 1,0 & & & \\
\hline $\operatorname{Sim}$ & 118 & 46,7 & 53,3 & $1,5[1,0 ; 2,4]$ & & & \\
\hline First pregnancy & & & & & 0,272 & \# & \\
\hline No & 233 & 51,5 & 48,5 & 1,0 & & & \\
\hline Yes & 126 & 58,2 & 41,8 & $0,8[0,5 ; 1,2]$ & & & \\
\hline Parity & & & & & 0,959 & \# & \\
\hline More than 4 & 323 & 53,6 & 46,4 & 1,0 & & & \\
\hline 4 or less & 36 & 55,6 & 44,4 & $0,9[0,5 ; 1,8]$ & & & \\
\hline Intrapartum interval & & & & & 0,592 & \# & \\
\hline More than 18 months & 191 & 49,2 & 50,8 & 1,0 & & & \\
\hline 18 months or less & 15 & 60,0 & 40,0 & $0,6[0,2 ; 1,9]$ & & & \\
\hline Maternal age (years) & & & & & & & \\
\hline $14-19$ & 55 & 60,0 & 40,0 & 1,0 & & 1,0 & \\
\hline $20-29$ & 203 & 56,4 & 43,6 & $1,2[0,7 ; 2,2]$ & 0,656 & $1,1[0,6 ; 2,1]$ & 0,783 \\
\hline $30-39$ & 90 & 43,6 & 56,4 & $1,9[1,0 ; 3,8]$ & 0,057 & $2,3[1,1 ; 4,8]$ & 0,031 \\
\hline $40-46$ & 11 & 63,6 & 36,4 & $0,9[0,2 ; 3,3]$ & 0,848 & $0,9[0,2 ; 3,4]$ & 0,817 \\
\hline Breastfeeding (months) & & & & & & & \\
\hline 9 or more & 78 & 71,8 & 28,2 & 1,0 & & 1,0 & \\
\hline $4-8,9$ & 78 & 48,2 & 51,8 & $2,8[1,5 ; 5,2]$ & 0,001 & $2,9[1,5 ; 5,5]$ & 0,002 \\
\hline $1-3,9$ & 130 & 45,8 & 54,2 & $3,0[1,7 ; 5,4]$ & 0,001 & $3,3[1,8 ; 6,0]$ & $<0,001$ \\
\hline less than 1 & 71 & 53,6 & 46,4 & $2,2[1,1 ; 4,5]$ & 0,003 & $2,5[1,2 ; 5,1]$ & 0,016 \\
\hline Intention to give pacifier at birth & & & & & 0,035 & & 0,014 \\
\hline No & 28 & 73,1 & 26,9 & 1,0 & & 1,0 & \\
\hline Yes & 317 & 51,6 & 48,4 & $2,4[1,0 ; 5,8]$ & & $3,2[1,3 ; 8,1]$ & \\
\hline
\end{tabular}

$\mathrm{p}: \chi^{2}$ test, crude $\mathrm{p}$ value

a $\mathrm{p}$ : adjusted 
Table 4: Association between child's biological variables and dental open bite. Pelotas, Brazil, 1999.

\begin{tabular}{|c|c|c|c|c|c|c|c|}
\hline \multirow[t]{2}{*}{ Variable } & \multirow[t]{2}{*}{$\mathrm{n}$} & \multicolumn{2}{|c|}{ Open bite $(\%)$} & \multirow[t]{2}{*}{$\mathrm{OR}\left[\mathrm{Cl}_{95 \%}(\mathrm{OR})\right]$} & \multirow[t]{2}{*}{$\mathrm{P}^{c}$} & \multirow[t]{2}{*}{$\mathrm{OR}\left[\mathrm{CI}_{95 \%}(\mathrm{OR})\right]$} & \multirow[t]{2}{*}{$\mathrm{P}^{\mathrm{a}}$} \\
\hline & & No & Yes & & & & \\
\hline Gender & & & & & 0,917 & & 0,943 \\
\hline Male & 190 & 53,9 & 46,1 & 1,0 & & 1,0 & \\
\hline Female & 169 & 53,3 & 46,7 & $1,0[0,7 ; 1,6]$ & & $1,1[0,7 ; 1,5]$ & \\
\hline Type of delivery & & & & & 0,555 & \# & \\
\hline Normal & & & & 1,0 & & & \\
\hline Cesarean & & & & $0,8[0,5 ; 1,3]$ & & & \\
\hline Gestational age (months) & & & & & 0,157 & $\#$ & \\
\hline $37-42$ & 295 & 55,0 & 45,0 & 1,0 & & & \\
\hline less than 37 & 60 & 41,4 & 58,6 & $1,7[0,8 ; 3,7]$ & & & \\
\hline Birthweight & & & & & 0,408 & \# & \\
\hline Normal & 256 & 54,6 & 45,4 & 1,0 & & & \\
\hline Low & 103 & 45,7 & 54,3 & $1,5[0,7 ; 3,0]$ & & & \\
\hline Cefalic perimeter (percentil 10) & & & & & 0,107 & & 0,091 \\
\hline More than $10 \%$ & 245 & 55,8 & 44,2 & 1,0 & & 1,0 & \\
\hline $10 \%$ or less & 110 & 43,8 & 56,3 & $1,6[1,0 ; 2,8]$ & & $1,6[0,9 ; 2,8]$ & \\
\hline
\end{tabular}

p: $\chi^{2}$ test, crude $\mathrm{p}$ value

${ }^{\mathrm{a}} \mathrm{p}$ : adjusted 
Table 5: Association between child's behavioural variables and dental open bite. Pelotas, Brazil, 1999.

\begin{tabular}{|c|c|c|c|c|c|c|c|}
\hline \multirow[t]{2}{*}{ Variable } & \multirow[t]{2}{*}{$\mathrm{n}$} & \multicolumn{2}{|c|}{ Open bite $(\%)$} & \multirow[t]{2}{*}{$\mathrm{OR}\left[\mathrm{CI}_{95 \%}(\mathrm{OR})\right]$} & \multirow[t]{2}{*}{$\mathrm{P}^{\mathrm{c}}$} & \multirow[t]{2}{*}{$\mathrm{OR}\left[\mathrm{CI}_{95 \%}(\mathrm{OR})\right]$} & \multirow[t]{2}{*}{$\mathrm{P}^{\mathrm{c}}$} \\
\hline & & No & Yes & & & & \\
\hline When started pacifier & & & & & 0,050 & $\#$ & \\
\hline Never & 46 & 77,6 & 22,4 & 1,0 & & & \\
\hline Before 3 months age & 276 & 50,0 & 50,0 & $3,3[1,6 ; 6,6]$ & & & \\
\hline Between 3 and 6 months age & 30 & 51,7 & 48,3 & $3,0[1,1 ; 8,2]$ & & & \\
\hline After 6 months age & 04 & 50,0 & 50,0 & $3,3[0,6 ; 21,2]$ & & & \\
\hline Pacifier sucking at 12 months age & & & & & $<0,001$ & \# & \\
\hline No & 62 & 80,3 & 19,7 & 1,0 & & & \\
\hline Yes & 297 & 47,6 & 52,4 & $4,6[2,4 ; 8,8]$ & & & \\
\hline Pacifier sucking at 5 years old & & & & & $<0,001$ & \# & \\
\hline No & 29 & 90,0 & 10,0 & 1,0 & & & \\
\hline Yes & 326 & 50,2 & 49,8 & $11,5[2,8 ; 38,8]$ & & & \\
\hline Pacifier between 12 months and 5 years & & & & & $<0,001$ & & \\
\hline Never or partially & 142 & 81,8 & 18,2 & 1,0 & & 1,0 & \\
\hline All time & 217 & 34,1 & 65,9 & $8,6[5,2 ; 14,2]$ & & $9,3[5,5 ; 15,6]$ & \\
\hline Kindergarten at 6 months & & & & & 0,326 & \# & \\
\hline Yes & 17 & 68,8 & 31,3 & 1,0 & & & \\
\hline No & 339 & 52,9 & 47,1 & $1,9[0,7 ; 5,2]$ & & & \\
\hline Kindergarten at 12 months & & & & & 0,120 & \# & \\
\hline Yes & 22 & 73,7 & 26,3 & 1,0 & & & \\
\hline No & 337 & 52,6 & 47,4 & $2,3[0,8 ; 6,3]$ & & & \\
\hline Kindergarten at 5 years & & & & & 0,553 & \# & \\
\hline Yes & 68 & 57,5 & 42,5 & 1,0 & & & \\
\hline No & 291 & 52,8 & 47,2 & $1,2[0,7 ; 2,0]$ & & & \\
\hline Child care at 6 months & & & & & 0,078 & $\#$ & \\
\hline Mother and/or father & 304 & 51,5 & 48,5 & 1,0 & & & \\
\hline Others & 52 & 65,5 & 34,5 & $0,6[0,3 ; 1,0]$ & & & \\
\hline dmf-t & & & & & 0,022 & & \\
\hline Zero & 129 & 61,9 & 38,1 & 1,0 & & 1,0 & \\
\hline$\geq 1$ & 230 & 48,9 & 51,1 & $1,7[1,1 ; 2,6]$ & & $1,7[1,1 ; 2 ; 8]$ & \\
\hline Severity of dental caries & & & & & 0,068 & \# & \\
\hline $\mathrm{dmf}-\mathrm{t} \leq 3$ & 223 & 57,5 & 42,5 & 1,0 & & & \\
\hline $\mathrm{dmf}-\mathrm{t}>3$ & 136 & 47,0 & 53,0 & $1,5[1,0 ; 2,3]$ & & & \\
\hline $\begin{array}{l}\text { Missing + decay teeth at } 6 \text { years old } \\
\text { No }\end{array}$ & & & & & 0,017 & \# & \\
\hline Yes & 133 & 61,9 & 38,1 & 1,0 & & & \\
\hline & 226 & 48,4 & 51,6 & $1,7[1,1 ; 2,7]$ & & & \\
\hline Respiratory disease at 12 months & & & & & 0,943 & \# & \\
\hline No & 257 & 53,8 & 46,9 & 1,0 & & & \\
\hline Yes & 94 & 54,3 & 45,7 & $0,9[0,6 ; 1,6]$ & & & \\
\hline Sleeping in the same mother's room & & & & & 0,004 & \# & \\
\hline No & 33 & 78,8 & 21,2 & 1,0 & & & \\
\hline Yes & 324 & 51,1 & 48,2 & $3,4[1,5 ; 8,0]$ & & & \\
\hline Digital sucking at 6 years old & & & & & 0,130 & & \\
\hline No & 327 & 55,1 & 44,9 & 1,0 & & 1,0 & \\
\hline Yes & 32 & 41,7 & 58,3 & $1,7[0,9 ; 3,5]$ & & $2,5[1,1 ; 5,8]$ & \\
\hline Botlle feeding at birth & & & & & 0,186 & \# & \\
\hline No & 350 & 54,2 & 45,8 & 1,0 & & & \\
\hline Yes & 8 & 20,0 & 80,0 & $5,2[0,6 ; 44,5]$ & & & \\
\hline Botlle feeding at 5 years old & & & & & $<0,001$ & \# & \\
\hline No & 123 & 66,7 & 33,3 & 1,0 & & & \\
\hline Yes & 236 & 46,8 & 53,2 & $2,2[1,4 ; 3,5]$ & & & \\
\hline
\end{tabular}


Table 6: Multiple logistic regression to anterior open bite. Pelotas, Brazil, 1999.

\begin{tabular}{|c|c|c|c|c|}
\hline Variable & $\mathrm{OR}\left[\mathrm{CI}_{95 \%}(\mathrm{OR})\right]$ & $\mathbf{P}^{c}$ & OR[CI $\left.{ }_{95 \%}(\mathrm{OR})\right]$ & $\mathbf{P}^{\mathbf{c}}$ \\
\hline Maternal schooling (years) & & 0,221 & & 0,221 \\
\hline More than 8 & 1,0 & : & 1,0 & \\
\hline 8 or less & $1,3[0,8 ; 2,1]$ & & $1,3[0,8 ; 2,1]$ & \\
\hline Maternal height $(\mathrm{cm})$ & & 0,012 & & 0,007 \\
\hline 156 or more & 1,0 & & 1,0 & \\
\hline less than 156 & $1,9[1,2 ; 3,1]$ & & $1,9[1,2 ; 3,0]$ & \\
\hline \multicolumn{5}{|l|}{ Maternal age (years) } \\
\hline $14-19$ & 1,0 & & 1,0 & \\
\hline $20-29$ & $1,2[0,7 ; 2,2]$ & 0,656 & $1,2[0,6 ; 2,3]$ & 0,626 \\
\hline $30-39$ & $1,9[1,0 ; 3,8]$ & 0,057 & $2,4[1,1 ; 5,5]$ & 0,023 \\
\hline $40-46$ & $0,9[0,2 ; 3,3]$ & 0,848 & $0,7[0,2 ; 2,9]$ & 0,639 \\
\hline \multicolumn{5}{|l|}{ Breastfeeding (months) } \\
\hline 9 or more & 1,0 & & 1,0 & \\
\hline $4-8,9$ & $2,8[1,5 ; 5,2]$ & 0,001 & $3,0[1,7 ; 5,9]$ & 0,001 \\
\hline $1-3,9$ & $3,0[1,7 ; 5,4]$ & 0,001 & $3,1[1,7 ; 5,6]$ & 0,001 \\
\hline less than 1 & $2,2[1,1 ; 4,5]$ & 0,003 & $2,4[1,1 ; 4,9]$ & 0,022 \\
\hline \multicolumn{5}{|l|}{ Intention to give pacifier at birth } \\
\hline No & 1,0 & & 1,0 & \\
\hline Yes & $2,4[1,1 ; 5,8]$ & 0,035 & $3,0[1,2 ; 7,9]$ & 0,022 \\
\hline \multicolumn{5}{|l|}{ Gender } \\
\hline Male & 1,0 & & 1,0 & 1,0 \\
\hline Female & $1,1[0,7 ; 1,5]$ & 0,943 & $1,1[0,7 ; 1,8]$ & $1,1[0,7 ; 1,8]$ \\
\hline \multicolumn{5}{|l|}{ Pacifier between 12 months and 5 years } \\
\hline Never or partially & 1,0 & & 1,0 & \\
\hline $\begin{array}{l}\text { All time } \\
\text { dmf-t }\end{array}$ & $8,6[5,2 ; 14,2]$ & $<0,001$ & $10,6[5,8 ; 19,1]$ & $<0,001$ \\
\hline Zero & 1,0 & & 1,0 & \\
\hline$\geq 1$ & $1,7[1,1 ; 2,6]$ & 0,022 & $2,0[1,2 ; 3,4]$ & 0,013 \\
\hline \multicolumn{5}{|l|}{ Digital sucking at 6 years old } \\
\hline No & 1,0 & & 1,0 & \\
\hline Yes & $1,7[0,9 ; 3,5]$ & 0,130 & $3,1[1,3 ; 7,2]$ & 0,010 \\
\hline
\end{tabular}




\section{References}

1- Adair SM, Milano M, Lorenzo I, Russel C. Effects of current and former pacifier use on the dentition of 24- to 59- month-old children. Pediatr Dent 1995; 17(7):437-444.

2- Calisti LJP, Cohen MM, Fales MH. Correlation between malocclusion, oral habits, and socio-economic level of preschool children. J Dent Res 1960; 39:450-454.

3- César JÁ. Victora CG, Barros FC, Santos IS, Flores JÁ. Impact of breastfeeding on admission for pneumonia during postneonatal period in Brazil: nested case-control study. $B M J 1999 ; 318(15): 1316-1320$.

4- Corruccini R.S.,.Whitley L.D. Occlusal variation in a rural Kentucky community. American Journal of Orthodontıcs 1981;79:250-62.

5- Davis DW, Bell PA. Infant feeding practices and occlusal outcomes: a longitudinal study. J Canad Dent Ass 1991; 57(7):593-594.

6- Egbuonu L, Starfield B. Child health and social status. Pediatrics 1982; 69:550-557.

7- Farsi NMA, Salama FS. Sucking habits in children: prevalence, contributing factors and effects on the primary dentition. Pediatr Dent 1997; 19(1):28-33.

8- Foster,T.D, Hamilton M.C. Occlusion in the primary dentition. British Dental Journal $1969 ; 21: 76-9$.

9- Frazão P. Epidemiologia da oclusão dentária na infância e os sistemas de saúde. São Paulo 1999. [Tese de doutorado - Faculdade de Saúde Pública da Universidade de São Paulo].

10- Harris E.F., Johnson M.G. Heritability of craniometric and occlusal variables: a longitudinal sib analysis. American Journal of Orthodontics and Dental Facial Orthopedics 1991;99:258-68. 
11- Henderson L, Kitzinger J, Green J. Representig infant feeding: content analysis of British media portrayals of bottle feeding and breast feeding. BMJ 2000; 321(11):1196-1198.

12- Karjalainen S., Ronning O., Lapinleimu H., Simmel O. Association between early weaning, non-nutritive sucking habits and occlusal anomalies in 3-year-old Finnish children. International Journal of Paediatric Dentistry 2000;9:169-73.

14- Kharbanda OP, Sidhu SS, Shukla DK, Sundaram KR. A study of the etiological factors associated with the development of malocclusion. J Clin Ped Dent 1994; 18(2):95-98.

15- Kiliaridis S., Engstrom C., Thilander B. The relationship between masticatory function and craniofacial morphology. I. A cephalometric longitudinal analysis in the growing rat fed a soft diet. European Journal of Orthodontics 1985;7:273-83.

16- Kisling E, Krebs G. Patterns of occlusion in 3-year-old Danish children. Community Dent Oral Epidemiol 1976; 4:152-159.

17- Labbok MH, Hendershot G. Does breastfeeding protect against malocclusion? An analysis of the 1981 Child Health Supplement to the National Health Interview Survey. Am J Prev Med 1987; 3(4):227-232.

18- Meyers A, Hertzberg J. Bottle feeding and malocclusion: Is there an association? Am. J. Dentofac Orthop 1988; 93:149-152.

19- O'Brien H T, Lachapelle D, Gagnon PF, Larocque I, Maheu-Robert LF. Nutritive and nonnutritive sucking habits: a review. ASDC J Dent Child 1996; 63(5):321-327.

20- Paunio P, Rautava P, Sillanpää M. The finnish family competence study: the effects of living conditions on sucking habits in 3-year-old Finnish children and the 
association between these habits and dental occlusion. Acta Odontol Scand 1993; 51:23-29.

21- Silva CHT, Araújo TM. Prevalências das más oclusões em escolares na llha do Governador, Rio de Janeiro. Parte I: Classes I, II e III (Angle) e mordida cruzada. Ortodontia $1983 ; 16(3): 10-16$.

22- Stecksen-Blicks C, Holm AK. Dental caries, tooth trauma, malocclusion, fluoride usage, toothbrushing and dietary habits in 4-year-old Swedish children: changes between 1967 and 1992. Int J Paediatr Dent 1995; 5(3):143-148.

23- Tomita NE. Relação entre determinantes sócio-econômicos e hábitos bucais: influência na oclusão de pré-escolares de Bauru-SP, Brasil. Bauru, 1996. [Tese de doutoradoFaculdade de Odontologia de Bauru, Universidade de São Paulo].

24- Valente A., Mussolino ZM. Freqüência de sobressaliência, sobremordida e mordida aberta na dentição decídua. Rev. Odont. USP 1989; 3(3):402-407.

25- Victora CG, Barros FC, Tomasi E, Menezes AM, Horta BL, Weiderpass E, et al. Tendências e diferenciais materno-infantil: delineamento e metodologia das coortes de 1982 e 1993 de mães e crianças de Pelotas, Rio Grande do Sul. Cad Saúde Pública 1996; 12 (supl 1):7-14.

26- Weiland F.J., Jonke E., Bantleon H.P. Secular trends in malocclusion in Austrian men. European Journal of Orthodontics 2000;19:355-9. 